\title{
SYSTEMATIC RESEARCH OF PHYSICOCHEMICAL PROPERTIES OF FUNCTIONAL PHOTOPOLYMERS FOR ADDITIVE MANUFACTURING
}

\author{
Author: \\ Ely Dannier V. Niño \\ Supervisors: \\ Professor. Andrés Díaz Lantada \\ Professor. José Luis Endrino Armenteros
}

Departamento de Ingeniería Mecánica

Escuela Técnica Superior de Ingenieros Industriales

Universidad Politécnica de Madrid

Madrid, Spain

2019 


\section{Tribunal Tesis Doctoral}

\section{SYSTEMATIC RESEARCH OF PHYSICOCHEMICAL PROPERTIES OF FUNCTIONAL PHOTOPOLYMERS FOR ADDITIVE MANUFACTURING}

AUTOR: Ely Dannier V. Niño

DIRECTOR/ES: Andrés Díaz Lantada, J osé Luis Endrino Armenteros

Tribunal nombrado por el Excmo. y Magfco. Sr. Rector de la Universidad Politécnica de Madrid el día de de 2019.

\begin{tabular}{l|l}
\hline Presidente & D./ Dạ. \\
\hline Vocal & D./ Dạ. \\
\hline Vocal & D./ Dạ. \\
\hline Vocal & D./ Da. \\
\hline Secretario & D./ Da. \\
\hline Suplente & D./ Dạ. \\
\hline Suplente & D./ Dạ. \\
\hline
\end{tabular}

Realizado el acto de defensa el día de de 2019 en la Escuela Técnica Superior de Ingenieros Industriales de la Universidad Politécnica de Madrid.

Calificación obtenida:

EL PRESIDENTE

SECRETARIO 


\title{
Dedicated especially to
}

\author{
My family, \\ Your family, \\ Our family,
}

The family

"If you can find and interpret the interactions that define peoples' behavior, the gods and nature will grant you absolute greatness"

E DV-Niño

"Si logras encontrar e interpretar las interacciones que definen el comportamiento de las personas, los dioses y la naturaleza te concederán la grandeza absoluta"

E DV-Niño 


\section{Acknowledgements}

My more sincerely gratitude to:

My supervisors, professors Andrés Díaz Lantada y J osé Luis Endrino Armenteros, for his guidance and disposition of transfer your academic-scientific knows, as well as providing me the opportunity and the unconditional confidence during the performance of this research project.

The professors Rafael Cabanzo y Enrique Mejía, for supporting this research project with materials (such as graphene oxide), supplies, characterization testing, and infrastructure. As well as the confidence and excellent disposition to discussions, advice and academic-scientific guidance's.

Hugo Estupiñan professor, for his confidence, for his academic-scientific discussions, and for his support with testing performed of instrumented indentation, scanning electron microscopy, energy dispersive spectroscopy, and Raman spectroscopy.

Gustavo Ramírez professor, and staff of Grupo de Investigación en Polímeros, Centro de Investigación Científica y Tecnológica en Materiales y Nanociencia, Parque Tecnológico Guatiguará, Universidad Industrial de Santander, Piedecuesta, Colombia.

Alfonso Santos J aimes professor, Facultad de Ingeniería Mecánica, Universidad Pontificia Bolivariana, Bucaramanga, Colombia.

The professors and staff of División de Ingeniería de Maquinas, Escuela Técnica Superior de Ingenieros Industriales, Universidad Politécnica de Madrid. Especially to J uan Manuel Muñoz, Enrique Chacón, J avier Echávarri, Emilio Bautista, Silvia Ortega y Socorro Martín.

The School of Aerospace, Transport, and Manufacturing, Cranfield University. Especially to Quentin Lonne, for his support with the synthesis of the nanowires.

The Laboratorio de Biomateriales and to Grupo de Investigación en Biosuperficies, Facultad de Minas, Universidad Nacional de Colombia, Medellín, Colombia.

The Laboratorio Espectroscopía Atómica Molecular, Centro de Investigación Científica y Tecnológica en Materiales y Nanociencia, Parque Tecnológico Guatiguará, Universidad Industrial de Santander, Piedecuesta, Colombia.

The Laboratorio de Instrumental, Escuela de Química, Universidad Industrial de Santander, Bucaramanga, Colombia.

The Laboratorios de Microscopía and Rayos X, Centro de Investigación Científica y Tecnológica en Materiales y Nanociencia, Parque Tecnológico Guatiguará, Universidad Industrial de Santander, Piedecuesta, Colombia.

The Grupo de Investigación de Metalurgia Extractiva/Biohidrometarúrgia, Facultad de Ciencias Químicas, Universidad Complutense de Madrid, Madrid, Spain. 
The entrepreneurial fantastic-duo of Nano4Energy, Ivan and Ambiorm; and to the dynamic trio of the Institute of Nuclear Fusion, Antonio, Raquel, and Ovidio, for each one of the teachings transmitted, for feeding my scientific inspiration and for the help they gave me during my scientific training. They are a differently unique group.

The Morcueros, for each of the excellent social and sporting moments, shared. Thank you very much for integrating me in such a select family. J esus, nobility and simplicity. Raúl and Edge, prudence and respect. Delia, generosity. The little big "Paloma", tenderness, softness and delicacy. Santi, commitment, joy, and sense of humor; you are fantastically great. Miguel, the words expressed here are insignificant to the immense gratitude I have for you, thank you very much for your respect, assertiveness, authenticity, simplicity, and trust. Morcuera Family, I hope to feel you are always happy and united. Thank you, thank you very much.

The Ortiz Vásquez family, especially to Blanca Inés Vásquez for her trust, nobility, simplicity, generosity, and unconditional support.

J osé Barba and family, for his friendship, trust, loyalty, sincerity, honesty, and for his teachings. Thank you very much for opening me the door and becoming me part of your family.

Those who by direct or indirect lessons fraternally maintained my emotional-energy balance and contributed to the transformation, the strengthening and the evolution of my knowledge and critical thinking, as well as understanding the behavior of society. My friends and not friends, compadres and not compadres, those who are, those who stopped being and those who will be again; J aime Dulce, Fernando Duran, Uriel Mora, Alejandro Martínez, Harold Paredes, Arturo Plata, Petr Tsygankov, Eduardo Méndez, Humberto Jiménez, Hernán Garnica, Juan Pablo Soler, Fredy Vera, Fredy Parada, German Quiñonez, Benjamin Zuluaga, Juan Carlos Castrillon, Manuel Andrade, Ventura Muñoz, Mariana Pereyra, Sandra Cadena, Luz Marina Almeida, Linda Gil, Myriam Joya, Sugehis Liscano, Ximena Calderón, and many others; thank you very much for the great little details...

The Doctors Adrián De Blas, Guillermo Fernández, Alejandro Abou-Assali, J osé García, and María del Mar Cogollo, for your time, the shared moments, the discussions and the freedom of expression. I wish you are the best of the best. Also, to the engineers' Guillermo Sanz, Javier Hernández, Adrián Martínez, Adrián López, Rodrigo Zapata, Iñigo Herrero, Juvenal Sastre, Álvaro Guzmán, Guillermo Leboreiro, Cristina Aguanell. Boys, in some place of the planet, one extra-community will be remembering them. Thank so much...

¡You my girl!... yes, to you, "LFOV". Thank you very much for being there, for her support and company unconditional, which has been very important for my motivation and inspiration.

To the gods, to nature and especially to my moons...

"The events that take place in our space-time environment, strengthen our aspirations and desires"

E DV-Niño 


\section{Agradecimientos}

Son muchas las personas que por sus enseñanzas directas o indirectas he de expresarles mi gratitud por los aportes académicos, científicos, culturales, deportivos y sociales, que permitieron generar 0 mantener mi creatividad, inspiración e hiperactividad con compromiso y dedicación durante el desarrollo de esta tesis. Por este motivo, si tuviese que escribir sobre cada una de las interacciones que tuve, tengo y tendré, durante el transcurrir de mi entorno espaciotemporal, con cada uno de ellos, esta tesis se convertiría en un "Best-seller". En consecuencia, como es una tesis, intentaré escribir los nombres con breves descripciones de quienes realizaron aportaciones a este maravilloso proyecto científico. No obstante, pido disculpas si el nombre de alguien que hace parte de este selecto y extenso grupo no está aquí reflejado. De acuerdo con lo anterior, mis más sinceros agradecimientos a:

Mis supervisores, profesores Andrés Díaz Lantada y J osé Luis Endrino Armenteros, por la orientación y disposición de trasmitir sus conocimientos académico-científicos; por la oportunidad y la confianza incondicional durante la ejecución de este proyecto de investigación.

Los profesores Rafael Cabanzo y Enrique Mejía, por apoyar este proyecto de investigación con materiales (como el óxido de grafeno), insumos, equipos e infraestructura. Además, por la confianza y la excelente disposición a discusiones, consejos y orientaciones académico-científicas.

Hugo Estupiñan, por la confianza, las discusiones académico-científicas y por el apoyo durante la realización de los ensayos de indentación instrumentada, microscopía electrónica de barrido, espectroscopia de energía dispersiva de rayos X y espectroscopia Raman.

Al profesor Gustavo Ramírez y profesionales adscritos al grupo de Investigación en Polímeros, Centro de Investigación Científica y Tecnológica en Materiales y Nanociencia, Parque Tecnológico Guatiguará, Universidad Industrial de Santander, Piedecuesta, Colombia.

Al profesor Alfonso Santos Jaimes, Facultad de Ingeniería Mecánica, Universidad Pontificia Bolivariana, Bucaramanga, Colombia.

Los profesores y administrativos de la División de ingeniería de Maquinas, Escuela Técnica Superior de Ingenieros Industriales, Universidad Politécnica de Madrid. Especialmente a Juan Manuel Muñoz, Enrique Chacón, Javier Echávarri, Emilio Bautista, Silvia Ortega y Socorro Martín.

School of Aerospace, Transport, and Manufacturing, Cranfield University. Especialmente a Quentin Lonne, por su ayuda con la síntesis de los nanohilos.

Al Laboratorio de Biomateriales y al Grupo de Investigación en Biosuperficies, Facultad de Minas, Universidad Nacional de Colombia, Medellín, Colombia.

Al Laboratorio Espectroscopía Atómica Molecular, Centro de Investigación Científica y Tecnológica en Materiales y Nanociencia, Parque Tecnológico Guatiguará, de Ia Universidad Industrial de Santander, Piedecuesta, Colombia.

Al Laboratorio de Instrumental, Escuela de Química, Universidad Industrial de Santander, Bucaramanga, Colombia. 
Los Laboratorios de Microscopía y Rayos X. Centro de Investigación Científica y Tecnológica en Materiales y Nanociencia, Parque Tecnológico Guatiguará, de Ia Universidad Industrial de Santander, Piedecuesta, Colombia.

Al Grupo de Investigación de Metalurgia Extractiva/Biohidrometarúrgia, Facultad de Ciencias Químicas, Universidad Complutense de Madrid, Madrid, España.

Al dúo fantástico empresarial de Nano4Energy, Ivan y Ambiorm, y al trio dinámico del Instituto de Fusión Nuclear, Antonio, Raquel y Ovidio, por cada una las enseñanzas trasmitidas, por alimentar mi inspiración científica y por las ayudas que me aportaron durante mi formación científica. Son un grupo diferentemente único.

Los Morcueros, por cada uno de los excelentes momentos sociales y deportivos compartidos. Muchas gracias por integrarme en tan selecta familia. Jesús, nobleza y sencillez. Raúl y Edge, prudencia y respeto. Delia, generosidad. La pequeña grande "Paloma", ternura, suavidad y delicadeza. Santi, compromiso, alegría y sentido del humor; eres fantásticamente genial. Miguel, las palabras aquí expresadas son insignificante a la gratitud inmensa que tengo hacia ti, muchas gracias por su respeto, asertividad, autenticidad, sencillez y confianza. Familia Morcuera, espero sentirla siempre alegre y unida. Gracias, muchas gracias.

La familia Ortiz Vásquez, en especial a Blanca Inés Vásquez por su confianza, nobleza, sencillez, generosidad y apoyo incondicional.

J osé Barba y familia, por la amistad, confianza, lealtad, sinceridad, honestidad, y por las enseñanzas. Muchas gracias por abrirme la puerta y hacerme parte de tu familia.

Quienes por las lecciones directas o indirectas mantuvieron fraternalmente mi equilibrio energéticoemocional y contribuyeron en la transformación, el fortalecimiento y la evolución de mi conocimiento y pensamiento crítico; así como a comprender el comportamiento de la sociedad. Mis amigos y no amigos, compadres y no compadres, los que están, los que dejaron de estar y los que volverán a estar; Jaime Dulce, Fernando Duran, Uriel Mora, Alejandro Martínez, Harold Paredes, Arturo Plata, Humberto J iménez, Petr Tsygankov, Eduardo Méndez, Hernán Garnica, J uan Pablo Soler, Fredy Vera, Fredy Parada, German Quiñonez, Manuel Andrade, Benjamin Zuluaga, J uan Carlos Castrillon, Ventura Muñoz, Sandra Cadena, Luz Marina Almeida, Linda Gil, Mariana Pereyra, Myriam J oya, Sugehis Liscano, Ximena Calderón, y a otros muchos más; muchas gracias por los pequeños grandes detalles...

Los Doctores Adrián De Blas, Guillermo Fernández, Alejandro Abou-Assali, J osé García, y María del Mar Cogollo, por el tiempo, los momentos compartidos, las discusiones y la libertad de expresión. Deseo que seas lo mejor de lo mejor. Asimismo, a los ingenieros Guillermo Sanz, J avier Hernández, Adrián Martínez, Adrián López, Rodrigo Zapata, Iñigo Herrero, Juvenal Sastre, Álvaro Guzmán, Guillermo Leboreiro, Cristina Aguanell. Chicos, en algún lugar del planeta, un extracomunitario los estará recordando. Muchas gracias...

¡A ti mi niña!... sí, a ti, "LFOV". Muchas gracias por estar ahí, por tu apoyo y compañía incondicional, que ha sido muy importante para mí motivación e inspiración.

A los dioses, a la naturaleza, y especialmente a mis lunas...

"Los acontecimientos que transcurren en nuestro entorno espacio-tiempo, fortalecen nuestras aspiraciones y deseos"

E. D. V-Niño 


\section{Content}

Content - 1

List of Figures -- 4

List of Tables - 10

List of Abbreviations - 11

Symbols---12 12

Abstract --1.-- 13

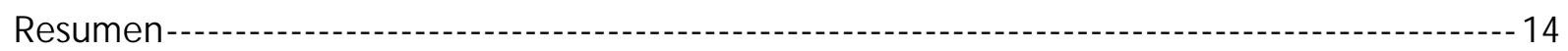

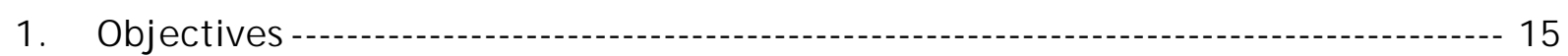

General objective-15

Specific objectives-- 15

2. Introduction --..- 17

2.1. Current State-of-the-Art and Research Trends--.-.-.-17

2.2. Structure and Context of the Doctoral Thesis-a- 20

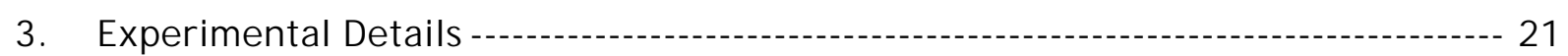

3.1. Materials and Methods - 21

3.2. Designs of Substrates-- 21

3.3. Resins and Nanofillers-- 22

3.4. Mixtures Process --..- 23

3.5. Substrates Manufacturing-- 23

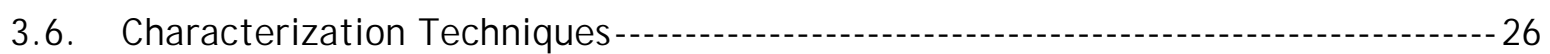

3.6.1. Scanning electron microscopy and energy dispersive spectroscopy.-------- 26

3.6.2. Computed tomography scan.

3.6.3. Tensile testing. - 27

3.6.4. Instrumented indentation. --..- 27

3.6.5. Dynamic mechanical analysis. -- 28

3.6.6. Differential scanning calorimetry and thermogravimetric analysis. --------- 28

3.6.7. Raman spectroscopy. - 29

3.6.8. Fourier-transformed infrared. - 29

3.6.9. X-ray diffraction. - 30 
3.6.10. Microscopy optic. - 30

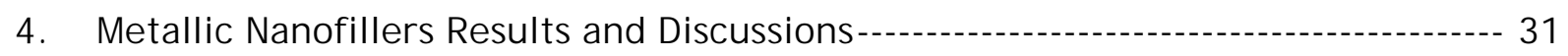

4.1. Cost Considerations-- 31

4.2. Morphological Properties - 32

4.2.1. Scanning electron microscopy and energy-dispersive $x$-ray spectroscopy. -- 32

4.2.2. Computed tomography scan. - 34

4.3. Mechanical Performance--on 37

4.3.1. Tensile testing. - 37

4.3.2. Instrumented indentation. -- 40

4.4. Thermal Performance -- 46

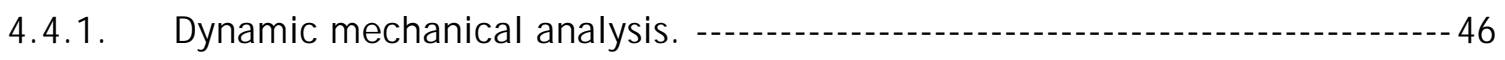

4.4.2. Differential scanning calorimetry. ------- 49

4.4.3. Thermogravimetric analysis. --a-1 51

4.5. Spectroscopic Characterization-- 52

4.5.1. Raman spectroscopy. - 53

4.5.2. Fourier-transformed infrared. -

4.5.3. X-ray diffraction.--- 56

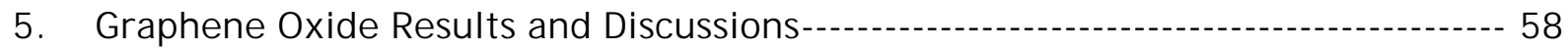

5.1. Cost Considerations-- 58

5.2. Morphological Properties - 59

5.2.1. Scanning electron microscopy and energy-dispersive X-ray spectroscopy. -- 59

5.3. Mechanical Performance-- 60

5.3.1. Tensile testing. - 60

5.3.2. Instrumented indentation. --1.-- 63

5.4. Thermal Performance - 69

5.4.1. Dynamic mechanical analysis. -

5.4.2. Differential scanning calorimetry. --- 73

5.4.3. Thermogravimetric analysis. --.-- 75

5.5. Spectroscopic Characterization-- 77

5.5.1. Raman spectroscopy. --.-- 77

5.5.2. Fourier-transformed infrared. - 80

5.5.3. X-ray diffraction.--- 82

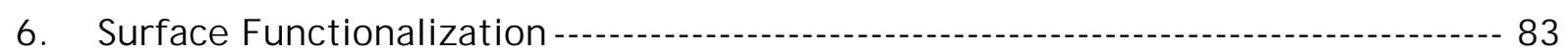

6.1. Experimental Setup--.-1 83

6. 2. Morphological Properties -- 85 
6.2.1. Optical microscopy. - - 85

6.3. Spectroscopic Characterization-- 88

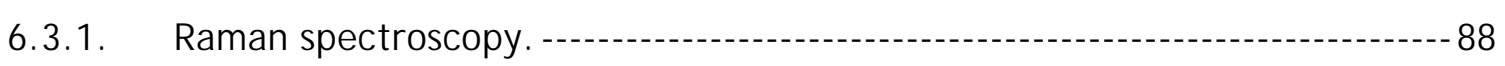

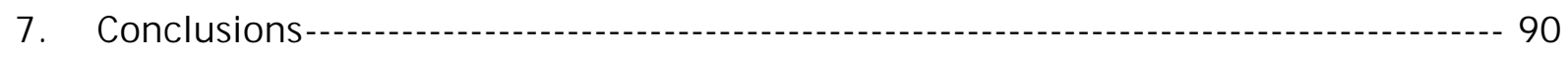

7.1. Scientific and Technological Conclusions - 90

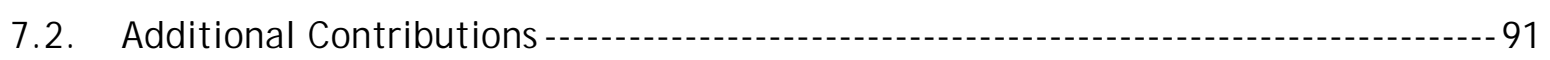

7.3. Future Research Proposals - 92

References --.-- 94

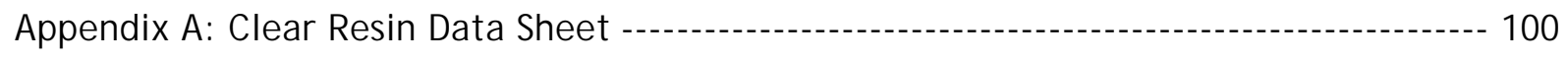

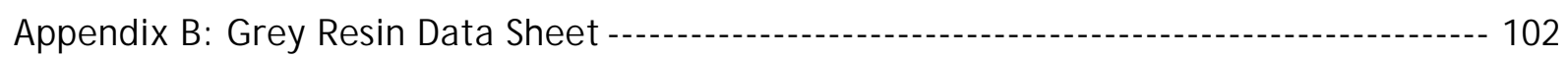




\section{List of Figures}

Figure 1. Overview of the work research develop. - 16

Figure 2. Additive-manufacturing process. ------- 17

Figure 3. Stages of the process for products developments by 3D printing. --------- 21

Figure 4. Substrates designed in FreeCAD, SketchUp Make, SolidWorks and NX. Cylindrical geometries (a) without texture, and with texture of section (b) square, and (c) curvilinear. (d) Specimens for tensile testing [72]. Scaffolds of type (e) sponge and (f) circular tubes. --..- 22

Figure 5. Resin type used in the substrates manufacturing. (a) "Clear FLGPCL 02" pure resin. "Clear FLGPCL 02" resin mixed with (b) Cu NWs at $0.26 \% \mathrm{w} / \mathrm{w}$, (c) Cu NWs+NPs at $0.34 \% \mathrm{w} / \mathrm{w}$, (d) CuNi NWs at $0.42 \% \mathrm{w} / \mathrm{w}$, (e) GO at $0.04 \% \mathrm{w} / \mathrm{w}$, and (f) GO at $0.12 \% \mathrm{w} / \mathrm{w} .-\mathrm{w}-\mathrm{c}$

Figure 6. (a) Form 1+printer. (b) Platform and resin vat of the 3D printer. ---.----- 24

Figure 7. Manufactured substrates. Cylindrical geometries in pure resin (a) without texture, and with a texture of section (b) square, and (c) curvilinear. Cylindrical geometries with (d) Cu NWs at $0.17 \% \mathrm{w} / \mathrm{w}$, (e) Cu NWs+NPs at $0.34 \% \mathrm{w} / \mathrm{w}$, and (f) CuNi NWs at $0.36 \% \mathrm{w} / \mathrm{w}$. Specimens for tensile testing [72], $(\mathrm{g})$ and $(\mathrm{h})$ in pure resin, with (i) CuNi NWs at $0.36 \% \mathrm{w} / \mathrm{w}$ and (j) GO at $0.12 \% \mathrm{w} / \mathrm{w}$. Scaffolds in pure resin of type $(\mathrm{k})$ sponge, $(\mathrm{I})$ circular thick tubes, and $(\mathrm{m})$ circular thin tubes. Scaffolds GO-reinforced at $0.04 \% \mathrm{w} / \mathrm{w}$ of type $(\mathrm{n})$ sponge, (o) circular thick tubes, and (p) circular thin tubes. 25

Figure 8. Scanning electron microscope of thermionic emission Carl Zeiss EVO MA10, located in Facultad de Minas, Universidad Nacional de Colombia, Medellín, Colombia. 26

Figure 9. Computed tomography system XT H 160 CT SCAN, Nikon, located in Museo Nacional de Ciencias Naturales, Madrid, Spain. 26

Figure 10. Universal test system, MTS Criterion model 43, located in Facultad de Ingeniería Mecánica, Universidad Pontificia Bolivariana, Bucaramanga Colombia. --- 27

Figure 11. IBIS-Authority nano-indentation system of Fischer-Cripps Laboratory Pty Ltd., located in Facultad de Minas, Universidad Nacional de Colombia, Medellín, Colombia. 27

Figure 12. Q800 analyzer, TA Instruments Inc., located in Parque Tecnológico, Universidad Industrial de Santander, Piedecuesta, Colombia. 28

Figure 13. STA 449 F5 Jupiter system, located in Escuela de Química, Universidad Industrial de Santander, Bucaramanga, Colombia. 28

Figure 14. Confocal spectrometer LabRam HR Evolution Scientific HORIBA, located in Facultad de Minas, Universidad Nacional de Colombia, Medellín, Colombia.

Figure 15. Nicolet iS50 Spectrometer Thermo Fisher Scientific, located in Parque Tecnológico, Universidad Industrial de Santander, Piedecuesta, Colombia. 29 
Figure 16. Powder diffractometer Bruker model D8 Advance with DaVinci geometry, located in Parque Tecnológico, Universidad Industrial de Santander, Piedecuesta, Colombia. 30

Figure 17. Olympus DSX500 microscope, located in Laboratorio de Desarrollo de Productos, Universidad Politécnica de Madrid, Madrid, Spain. --...- 30

Figure 18. BSE Micrographs on the surface of a substrate with Cu NWs at $0.008 \% \mathrm{w} / \mathrm{w}(\mathrm{a})$, $0.017 \% \mathrm{w} / \mathrm{w}(\mathrm{b}), 0.17 \% \mathrm{w} / \mathrm{w}$ (c), and $0.26 \% \mathrm{w} / \mathrm{w}(\mathrm{d})$; Cu NWs+NPs at $0.34 \% \mathrm{w} / \mathrm{w}(\mathrm{e})$; CuNi NWs at $0.36 \% \mathrm{w} / \mathrm{w}(\mathrm{f})$, and $0.42 \% \mathrm{w} / \mathrm{w}(\mathrm{g})$. 33

Figure 19. 3D rendering of the substrate section that shows the nanofillers distribution of Cu NWs embedded at $0.017 \% \mathrm{w} / \mathrm{w}(\mathrm{a})$ and (b), $0.17 \% \mathrm{w} / \mathrm{w}$ (c) and (d), $0.26 \% \mathrm{w} / \mathrm{w}$ (e) and (f). 35

Figure 20. 3D rendering of the substrate section that shows the nanofillers distribution of Cu NWs+NPs embedded at $0.34 \% \mathrm{w} / \mathrm{w}(\mathrm{a})$, and (b). 36

Figure 21. 3D rendering of the substrate section that shows the nanofillers distribution of CuNi NWs at $0.36 \% \mathrm{w} / \mathrm{w}(\mathrm{a})$ and (b), $0.42 \% \mathrm{w} / \mathrm{w}$ (c) and (d).

Figure 22. Representative tensile testing curves of specimens pure resin and with nanowires. (a) load-displacement curves pure resin (o-a), and $\mathrm{Cu}$ NWs embedded at $0.008 \% \mathrm{w} / \mathrm{w}(\mathrm{a}-\mathrm{b})$, and $0.017 \% \mathrm{w} / \mathrm{w}(\square-c)$; (b) effect of Cu NWs content on $E$ modulus and the TS; (c) stress-strain curves, ( $\circ-\mathrm{a}$ and $\bullet-b)$ pure resin, and Cu NWs embedded at $0.26 \% \mathrm{w} / \mathrm{w}$ ( $\not-c$, and $*$-d); (d) effect of Cu NWs content on $E$ moduli and the $T S$; (e) stress-strain curves, (o-a and $\bullet-b)$ pure resin, and CuNi NWs embedded at $0.42 \% \mathrm{w} / \mathrm{w}$ ( $\square-\mathrm{C}$, and --d); (f) effect of CuNi NWs content on E moduli and the TS.-------- 38

Figure 23. Mathematical relation obtained of experimental data $E$ modulus in function of Cu NWs concentration.

Figure 24. Contour maps of the variation of the mechanical properties $E^{\prime}$ moduli (a), and $H(b)$, obtained on a surface area of $120 \times 150 \mu \mathrm{m}^{2}$, on the substrates manufactured in pure resin. 40

Figure 25. Contour maps of the variation of the mechanical properties $E^{\prime}$ moduli (a) and (c), and $H$ (b) and (d), obtained on a surface area of $120 \times 150 \mu \mathrm{m}^{2}$, on the substrates manufactured with $\mathrm{Cu}$ NWs embedded at $0.017 \% \mathrm{w} / \mathrm{w}(\mathrm{a})$ and (b), and $\mathrm{Cu}$ NWs embedded at $0.17 \% \mathrm{w} / \mathrm{w}$ (c) and (d).

Figure 26. Contour maps of the variation of the mechanical properties $E^{\prime}$ moduli (a), and $H$ (b), obtained on a surface area of $120 \times 150 \mu \mathrm{m}^{2}$, on the substrates manufactured with Cu NWs+NPs embedded at $0.34 \% \mathrm{w} / \mathrm{w}$.

Figure 27. Contour maps of the variation of the mechanical properties $E^{\prime}$ moduli (a), and $H$ (b), obtained on a surface area of $120 \times 150 \mu \mathrm{m}^{2}$, on the substrates manufactured with CuNi NWs embedded at $0.36 \% \mathrm{w} / \mathrm{w}$.

Figure 28. Effect of nanofillers content on mechanical properties variation. $E^{\prime}$ storage modulus (black), and $H$ hardness (red). (a) Cu NWs embedded at $0.017 \% \mathrm{w} / \mathrm{w}$, (b) $\mathrm{Cu}$ NWs embedded at $0.17 \% \mathrm{w} / \mathrm{w}$, (c) Cu NWs+NPs embedded at $0.34 \% \mathrm{w} / \mathrm{w}$, and (d) CuNi NWs embedded at $0.36 \% \mathrm{w} / \mathrm{w}$.

Figure 29. Contour maps of the variation of the mechanical properties $E^{\prime}$ moduli (a) and (b), and $H(c)$ and (d), obtained on a surface area of $120 \times 150 \mu \mathrm{m}^{2}$, on the substrates 
manufactured in pure resin with post-cured during $14 \mathrm{~min}$ and $28 \mathrm{~min}$, respectively. --- 43

Figure 30. Contour maps of the variation of the mechanical properties $E^{\prime}$ moduli (a) and (b), and $H$ (c) and (d), obtained on a surface area of $120 \times 150 \mu \mathrm{m}^{2}$, on the substrates manufactured with $\mathrm{Cu}$ NWs embedded at $0.26 \% \mathrm{w} / \mathrm{w}$ with post-cured during $14 \mathrm{~min}$ and $28 \mathrm{~min}$, respectively. 44

Figure 31. Contour maps of the variation of the mechanical properties $E^{\prime}$ moduli (a) and (b), and $H(c)$ and (d), obtained on a surface area of $120 \times 150 \mu \mathrm{m}^{2}$, on the substrates manufactured with CuNi NWs embedded at $0.42 \% \mathrm{w} / \mathrm{w}$ with post-cured during $14 \mathrm{~min}$ and $28 \mathrm{~min}$, respectively.

Figure 32. Effect of nanowires content and post-cured on mechanical properties variation. $E^{\prime}$ storage modulus (green and black), and $H$ hardness (grey and red). (a) $\mathrm{Cu}$ NWs embedded at $0.26 \% \mathrm{w} / \mathrm{w}$, and (b) CuNi NWs embedded at $0.42 \% \mathrm{w} / \mathrm{w}$.

Figure 33. DMA curves of the substrates manufactured in pure resin and with nanowires. (a) $E^{\prime}(T)$, and (b) $\tan \delta(T)$. Pure resin $(\cdot-a)$, with Cu NWs embedded at $0.008 \% \mathrm{w} / \mathrm{w}(*-$ b), and $0.017 \% \mathrm{w} / \mathrm{w}(-\mathrm{c})$.

Figure 34. DMA curves of the substrates manufactured pure resin and with nanowires. (a) $E^{\prime}(T)$, and (b) $\tan \delta(T)$. Pure resin $(\cdot-a)$, and CuNi NWs embedded at $0.36 \% \mathrm{w} / \mathrm{w}(*-\mathrm{b})$.

Figure 35. DMA curves of the substrates manufactured pure resin and with nanowires. (a) $E^{\prime}(T)$, and (b) $\tan \delta(T)$. Pure resin (o-a and $\left.\bullet-b\right)$, and Cu NWs embedded at $0.26 \% \mathrm{w} / \mathrm{w}$ $(\diamond-c$ and $\diamond-d)$ with post-cured during $14 \mathrm{~min}$ and $28 \mathrm{~min}$, respectively. --...-.-.-. 48

Figure 36. DMA curves of the substrates manufactured pure resin and with nanowires. (a) $E^{\prime}(T)$, and (b) $\tan \delta(T)$. Pure resin (o-a and $\left.\bullet-b\right)$, and CuNi NWs embedded at $0.42 \% \mathrm{w} / \mathrm{w}$ ( $\square-c$ and - -d) with post-cured during $14 \mathrm{~min}$ and $28 \mathrm{~min}$, respectively.

Figure 37. Representative curves DSC thermal analysis. (a) specimens in pure resin (o-a), with Cu NWs embedded at $0.008 \% \mathrm{w} / \mathrm{w}(*-b)$, and $0.017 \% \mathrm{w} / \mathrm{w}(\square-c) ;(b)$ substrates in pure resin (o-a), and CuNi NWs embedded at $0.36 \% \mathrm{w} / \mathrm{w}(\square-b) ;(c)$ specimens in pure resin ( $\circ-a$ and $\bullet-b)$, and Cu NWs embedded at $0.26 \% \mathrm{w} / \mathrm{w}$ ( $\mathrm{x}-\mathrm{c}$ and $*-\mathrm{d}$ ) with post-cured during $14 \mathrm{~min}$ and $28 \mathrm{~min}$, respectively; (d) specimens in pure resin ( $\circ-\mathrm{a}$ and $\bullet-b)$, and CuNi NWs embedded at $0.42 \% \mathrm{w} / \mathrm{w}$ ( $\square-\mathrm{c}$ and $-\mathrm{d}$ ) with post-cured during $14 \mathrm{~min}$ and $28 \mathrm{~min}$, respectively. 50

Figure 38. Representative curves TGA thermal analysis. (a) specimens in pure resin (o-a), with Cu NWs embedded at $0.008 \% \mathrm{w} / \mathrm{w}(*-b)$, and $0.017 \% \mathrm{w} / \mathrm{w}(\square-c)$; (b) substrates in pure resin (o-a), and CuNi NWs embedded at $0.36 \% \mathrm{w} / \mathrm{w}(\square-b) ;(c)$ specimens in pure resin ( $\circ-a$ and $\bullet-b)$, and Cu NWs embedded at $0.26 \% \mathrm{w} / \mathrm{w}$ ( $\mathrm{a}-\mathrm{c}$ and $*$-d) with post-cured during $14 \mathrm{~min}$ and $28 \mathrm{~min}$, respectively; (d) specimens in pure resin ( $\circ-\mathrm{a}$ and $\bullet-b)$, and CuNi NWs embedded at $0.42 \% \mathrm{w} / \mathrm{w}$ ( $\square-\mathrm{c}$ and $-\mathrm{d}$ ) with post-cured during $14 \mathrm{~min}$ and 28 min, respectively.

Figure 39. Raman spectra acquired on substrates manufactured pure resin and with nanowires. (a) pure resin, with $\mathrm{Cu} N W s$ embedded at $0.008 \% \mathrm{w} / \mathrm{w}$, and $0.017 \% \mathrm{w} / \mathrm{w}$; (b) pure resin, and $\mathrm{Cu} N W s$ embedded at $0.17 \% \mathrm{w} / \mathrm{w}$; (c) pure resin, and Cu NWs+NPs embedded at $0.34 \% \mathrm{w} / \mathrm{w}$; (d) pure resin, and CuNi NWs embedded at $0.36 \% \mathrm{w} / \mathrm{w}$. - 53 
Figure 40. Raman spectra acquired on substrates manufactured pure resin and with nanowires. Pure resin ( $\circ-a$ and $\bullet-a)$, and Cu NWs embedded at $0.26 \% \mathrm{w} / \mathrm{w}$ ( $\mathrm{a}-\mathrm{b}$ and $*-$ b) with post-cured during $14 \mathrm{~min}(\mathrm{a})$, and $28 \mathrm{~min}(\mathrm{~b})$. Pure resin ( $-\mathrm{a}$ and $\bullet-\mathrm{a}$ ), and $\mathrm{CuNi}$ NWs embedded at $0.42 \% \mathrm{w} / \mathrm{w}$ ( $\square-\mathrm{b}$ and - $-\mathrm{b}$ ) with post-cured during $14 \mathrm{~min}(\mathrm{c})$, and $28 \min (d)$. 54

Figure 41. FTIR spectra acquired on substrates manufactured pure resin and with nanowires. (a) pure resin, with $\mathrm{Cu} N W s$ at $0.008 \% \mathrm{w} / \mathrm{w}$, and $0.017 \% \mathrm{w} / \mathrm{w}$; (b) pure resin, and Cu NWs embedded at $0.17 \% \mathrm{w} / \mathrm{w}$; (c) pure resin, and Cu NWs+NPs embedded at $0.34 \% \mathrm{w} / \mathrm{w}$; (d) pure resin, and CuNi NWs embedded at $0.36 \% \mathrm{w} / \mathrm{w}$. - - 55

Figure 42. FTIR spectra acquired on substrates manufactured pure resin and with nanowires. Pure resin (o-a and $\bullet-a)$, and Cu NWs embedded at $0.26 \% \mathrm{w} / \mathrm{w}$ ( $\mathrm{a}-\mathrm{b}$ and $*-$ b) with post-cured during $14 \mathrm{~min}(\mathrm{a})$, and $28 \mathrm{~min}(\mathrm{~b})$. Pure resin ( $-\mathrm{a}$ and $\bullet-\mathrm{a})$, and CuNi NWs embedded at $0.42 \% \mathrm{w} / \mathrm{w}$ ( $\square-\mathrm{c}$ and --d) with post-cured during $14 \mathrm{~min}$ (c), and $28 \mathrm{~min}(\mathrm{~d})$.

Figure 43. XRD patterns acquired on the substrates printed pure resin and with nanowires. (a) pure resin $(\cdot-a)$, and Cu NWs embedded at $0.26 \% \mathrm{w} / \mathrm{w}(*-b)$ with postcured during $28 \mathrm{~min}$. (b) pure resin $(\cdot-a)$, and CuNi NWs embedded at $0.42 \% \mathrm{w} / \mathrm{w}(-\mathrm{b})$ with post-cured during $28 \mathrm{~min}$. (c) pure resin (o-a), and CuNi NWs embedded at $0.36 \% \mathrm{w} / \mathrm{w}$ ( $\square-b)$.

Figure 44. SEM Micrographs on the surface of a substrate pure resin (a), with GOreinforced at $0.04 \% \mathrm{w} / \mathrm{w}$ (b), $0.08 \% \mathrm{w} / \mathrm{w}$ (c), and $0.12 \% \mathrm{w} / \mathrm{w}$ (d).

Figure 45. Representative tensile testing curves of specimens' pure resin and with $\mathrm{GO}$. (a) stress-strain curves, (o-a and - -b) pure resin, with GO-reinforced at $0.04 \% \mathrm{w} / \mathrm{w}$ ( $\mathrm{o}$ $c$ and $*-d), 0.08 \% \mathrm{w} / \mathrm{w}(\diamond-e$ and $\bullet-f)$, and $0.12 \% \mathrm{w} / \mathrm{w}(\square-g$ and $-h)$. (b) Effect of GO content on $E$ moduli and the TS.

Figure 46. Representative tensile testing curves of de specimens' pure resin and with GO. (a) stress-strain curves, (o-a) pure resin, with GO-reinforced at $0.02 \% \mathrm{w} / \mathrm{w}(\mathrm{a}-\mathrm{b})$, $0.04 \% \mathrm{w} / \mathrm{w} \quad(*-\mathrm{c}), \quad 0.06 \% \mathrm{w} / \mathrm{w} \quad(\diamond-\mathrm{d}), \quad 0.08 \% \mathrm{w} / \mathrm{w} \quad(\bullet-\mathrm{e}), \quad 0.10 \% \mathrm{w} / \mathrm{w} \quad(\square-\mathrm{f}), \quad$ and $0.12 \% \mathrm{w} / \mathrm{w}(-\mathrm{g})$. (b) Effect of GO content on $E$ modulus and the TS. --- 61

Figure 47. Relation obtained of the experimental data of $E$ modulus as a function of $\mathrm{GO}$ concentration. GO-reinforced specimens with post-cured during $14 \mathrm{~min}$ and $28 \mathrm{~min} .62$

Figure 48. Relation obtained of the experimental data of $E$ modulus as a function of $\mathrm{GO}$ concentration. GO-reinforced specimens to concentrations different. 62

Figure 49. Contour maps of the variation of the mechanical properties $E^{\prime}$ moduli (a) and (b), and $H$ (c) and (d), obtained on a surface area of $120 \times 150 \mu \mathrm{m}^{2}$, on the substrates manufactured in pure resin with post-cured during $14 \mathrm{~min}$ and $28 \mathrm{~min}$, respectively. 63

Figure 50. Contour maps of the variation of the mechanical properties $E^{\prime}$ moduli, obtained on a surface area of $120 \times 150 \mu \mathrm{m}^{2}$, on the substrates manufactured with GOreinforced at $0.04 \% \mathrm{w} / \mathrm{w}(\mathrm{a})$ and $(\mathrm{b}), 0.08 \% \mathrm{w} / \mathrm{w}(\mathrm{c})$ and (d), $0.12 \% \mathrm{w} / \mathrm{w}$ (e) and (f), with post-cured during $14 \mathrm{~min}$ and $28 \mathrm{~min}$, respectively. 64

Figure 51. Contour maps of the variation of the mechanical properties $H$, obtained on a surface area of $120 \times 150 \mu \mathrm{m}^{2}$, on the substrates manufactured with GO-reinforced at 
$0.04 \% \mathrm{w} / \mathrm{w}(\mathrm{a})$ and $(\mathrm{b}), 0.08 \% \mathrm{w} / \mathrm{w}(\mathrm{c})$ and $(\mathrm{d}), 0.12 \% \mathrm{w} / \mathrm{w}(\mathrm{e})$ and $(\mathrm{f})$, with post-cured during $14 \mathrm{~min}$ and $28 \mathrm{~min}$, respectively. --- 65

Figure 52. Effect of GO content and post-cured on mechanical properties variation. $E^{\prime}$ storage modulus (green and black), and $H$ hardness (grey and red). ----------- 66

Figure 53. Contour maps of the variation of the mechanical properties $E^{\prime}$ modulus (a), and $H(b)$, obtained on a surface area of $120 \times 150 \mu \mathrm{m}^{2}$, on the substrates manufactured in pure resin.

66

Figure 54. Contour maps of the variation of the mechanical properties $E^{\prime}$ moduli, obtained on a surface area of $120 \times 150 \mu^{2}$, on the substrates manufactured with GOreinforced at $0.02 \% \mathrm{w} / \mathrm{w}$ (a), $0.04 \% \mathrm{w} / \mathrm{w}$ (b), $0.06 \% \mathrm{w} / \mathrm{w} \quad$ (c), $0.08 \% \mathrm{w} / \mathrm{w}$ (d), $0.10 \% \mathrm{w} / \mathrm{w}(\mathrm{e})$, and $0.12 \% \mathrm{w} / \mathrm{w}(\mathrm{f})$.

Figure 55. Contour maps of the variation of the mechanical properties $H$, obtained on a surface area of $120 \times 150 \mu \mathrm{m}^{2}$, on the substrates manufactured with GO-reinforced at $0.02 \% \mathrm{w} / \mathrm{w}(\mathrm{a}), 0.04 \% \mathrm{w} / \mathrm{w}$ (b), $0.06 \% \mathrm{w} / \mathrm{w}$ (c), $0.08 \% \mathrm{w} / \mathrm{w}(\mathrm{d}), 0.10 \% \mathrm{w} / \mathrm{w}(\mathrm{e})$, and $0.12 \% \mathrm{w} / \mathrm{w}(\mathrm{f})$.

68

Figure 56. Effect of GO content on mechanical properties variation. $E^{\prime}$ storage modulus (black), and $H$ hardness (red). 69

Figure 57. DMA curves of the substrates manufactured pure resin and with GO. (a) Storage modulus, and (b) loss factor as a function of temperature, pure resin (o-a and $\bullet-b)$, with GO-reinforced at $0.04 \% \mathrm{w} / \mathrm{w}(\mathrm{x}-\mathrm{c}$ and $*$-d), $0.08 \% \mathrm{w} / \mathrm{w}(\diamond-\mathrm{e}$ and $\bullet-\mathrm{f})$, and $0.12 \% \mathrm{w} / \mathrm{w}$ ( $\square-\mathrm{g}$ and $-\mathrm{h}$ ), with post-cured during $14 \mathrm{~min}$ and $28 \mathrm{~min}$, respectively. - 70

Figure 58. DMA curves of the substrates manufactured pure resin and with GO. (a) Storage modulus, and (b) loss factor as a function of temperature, pure resin $(*-a)$, with GOreinforced at $0.02 \% \mathrm{w} / \mathrm{w}(\bullet-b), 0.04 \% \mathrm{w} / \mathrm{w}(\diamond-c), 0.06 \% \mathrm{w} / \mathrm{w}(--d), 0.08 \% \mathrm{w} / \mathrm{w}(\square-e)$, $0.10 \% \mathrm{w} / \mathrm{w}(\cdot-\mathrm{f})$, and $0.12 \% \mathrm{w} / \mathrm{w}(\circ-\mathrm{g})$.

Figure 59. Relation obtained of the experimental data of $E^{\prime}$ as a function of $G 0$ concentration. GO-reinforced specimens with post-cured during $14 \mathrm{~min}$ and $28 \mathrm{~min} .73$

Figure 60. Relation obtained of the experimental data of $E^{\prime}$ as a function of $G 0$ concentration. GO-reinforced specimens to concentrations different.

Figure 61. Representative curves of DSC thermal analysis of the specimens in pure resin ( $\circ-\mathrm{a}$ and $\bullet-\mathrm{a}$ ), and GO-reinforced at $0.04 \% \mathrm{w} / \mathrm{w}(\mathrm{x}-\mathrm{b}$ and $*-\mathrm{b}), 0.08 \% \mathrm{w} / \mathrm{w}(\diamond-\mathrm{c}$ and c), and $0.12 \% \mathrm{w} / \mathrm{w}$ ( $\square-\mathrm{d}$ and --d) with post-cured during (a) $14 \mathrm{~min}$, and (b) $28 \mathrm{~min} .74$

Figure 62. Representative curves of DSC thermal analysis on specimens manufactured in pure "Grey PN: F100G" resin $(\bullet-a)$, and GO-reinforced at $0.02 \% \mathrm{w} / \mathrm{w}(\mathrm{x}-\mathrm{b}), 0.04 \% \mathrm{w} / \mathrm{w}$ $(*-c), 0.06 \% \mathrm{w} / \mathrm{w}(\diamond-\mathrm{d}), 0.08 \% \mathrm{w} / \mathrm{w}(\bullet-\mathrm{e}), 0.10 \% \mathrm{w} / \mathrm{w}(\square-\mathrm{f})$, and $0.12 \% \mathrm{w} / \mathrm{w}(-\mathrm{g}) .-75$

Figure 63. Representative curves TGA thermal analysis. (a) specimens in pure resin (o-a), and GO-reinforced at $0.04 \% \mathrm{w} / \mathrm{w}(\mathrm{c}-\mathrm{b}), 0.08 \% \mathrm{w} / \mathrm{w}(\diamond-c)$, and $0.12 \% \mathrm{w} / \mathrm{w}(\square-\mathrm{d})$ during $14 \mathrm{~min}$ of post-cured. (b) specimens in pure resin $(\cdot-a)$, and GO-reinforced at $0.04 \% \mathrm{w} / \mathrm{w}(*-\mathrm{b}), 0.08 \% \mathrm{w} / \mathrm{w}(\bullet-\mathrm{c})$, and $0.12 \% \mathrm{w} / \mathrm{w}(-\mathrm{d})$ during $28 \mathrm{~min}$ of post-cured.

Figure 64. Representative curves of TGA thermal analysis on specimens manufactured in pure "Grey PN: F100G" resin (•-a), and GO-reinforced at $0.02 \% \mathrm{w} / \mathrm{w}(\mathrm{x}-\mathrm{b}), 0.04 \% \mathrm{w} / \mathrm{w}$ $(*-c), 0.06 \% \mathrm{w} / \mathrm{w}(\diamond-\mathrm{d}), 0.08 \% \mathrm{w} / \mathrm{w}(\bullet-e), 0.10 \% \mathrm{w} / \mathrm{w}(\square-\mathrm{f})$, and $0.12 \% \mathrm{w} / \mathrm{w}(-\mathrm{g}) .76$ 
Figure 65. Raman spectra acquired on substrates manufactured pure resin and with GO. (a) specimens in pure resin (o-a), and GO-reinforced at $0.04 \% \mathrm{w} / \mathrm{w}(\mathrm{c}-\mathrm{b}), 0.08 \% \mathrm{w} / \mathrm{w}$ $(\diamond-c)$, and $0.12 \% \mathrm{w} / \mathrm{w}(\square-d)$ during $14 \mathrm{~min}$ of post-cured. (b) specimens in pure resin $(\bullet-\mathrm{a})$, and GO-reinforced at $0.04 \% \mathrm{w} / \mathrm{w}(*-\mathrm{b}), 0.08 \% \mathrm{w} / \mathrm{w}(\bullet-\mathrm{c})$, and $0.12 \% \mathrm{w} / \mathrm{w}(-\mathrm{d})$ during $28 \mathrm{~min}$ of post-cured. 78

Figure 66. Raman spectra acquired on specimens manufactured in pure "Grey PN: F100G" resin (o-a), and GO-reinforced at $0.02 \% \mathrm{w} / \mathrm{w}(\mathrm{p}-\mathrm{b}), 0.04 \% \mathrm{w} / \mathrm{w}(*-c), 0.06 \% \mathrm{w} / \mathrm{w}(\diamond-\mathrm{d})$, $0.08 \% \mathrm{w} / \mathrm{w}(-\mathrm{e}), 0.10 \% \mathrm{w} / \mathrm{w}(\square-\mathrm{f})$, and $0.12 \% \mathrm{w} / \mathrm{w}(-\mathrm{g})$. 79

Figure 67. FTIR spectra acquired on substrates manufactured pure resin and with GO. (a) specimens in pure resin (o-a), and GO-reinforced at $0.04 \% \mathrm{w} / \mathrm{w}(\mathrm{x}-\mathrm{b}), 0.08 \% \mathrm{w} / \mathrm{w}(\diamond-$ c), and $0.12 \% \mathrm{w} / \mathrm{w}(\square-d)$ during $14 \mathrm{~min}$ of post-cured. (b) specimens in pure resin $(\bullet-$ a), and GO-reinforced at $0.04 \% \mathrm{w} / \mathrm{w}(*-\mathrm{b}), 0.08 \% \mathrm{w} / \mathrm{w}(\bullet-\mathrm{c})$, and $0.12 \% \mathrm{w} / \mathrm{w}(-\mathrm{d})$ during $28 \mathrm{~min}$ of post-cured. 80

Figure 68. FTIR spectra acquired on specimens manufactured in pure "Grey PN: F100G" resin $(\cdot-a)$, and GO-reinforced at $0.02 \% \mathrm{w} / \mathrm{w}(\mathrm{x}-\mathrm{b}), 0.04 \% \mathrm{w} / \mathrm{w}(*-\mathrm{c}), 0.06 \% \mathrm{w} / \mathrm{w}(\diamond-$ d), $0.08 \% \mathrm{w} / \mathrm{w}(\bullet-e), 0.10 \% \mathrm{w} / \mathrm{w}(\square-\mathrm{f})$, and $0.12 \% \mathrm{w} / \mathrm{w}(-\mathrm{g})$. 81

Figure 69. XRD patterns acquired on specimens manufactured pure resin and with $\mathrm{GO}$. (a) pure "Clear FLGPCL 02" resin $(\cdot-a)$, and GO-reinforced at $0.04 \% \mathrm{w} / \mathrm{w}(*-b)$, $0.08 \% \mathrm{w} / \mathrm{w}(\bullet-\mathrm{c})$, and $0.12 \% \mathrm{w} / \mathrm{w}(-\mathrm{d})$ with post-cured during $28 \mathrm{~min}$. (b) pure "Grey PN: F100G" resin $(\bullet-a)$, and GO-reinforced at $0.04 \% \mathrm{w} / \mathrm{w}(*-\mathrm{b}), 0.08 \% \mathrm{w} / \mathrm{w}(\bullet-c)$,

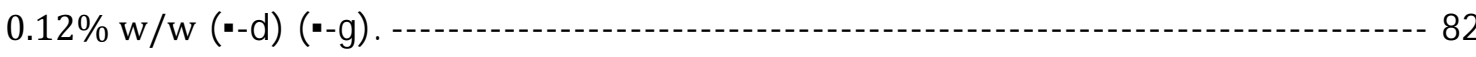

Figure 70. Substrate of curvilinear section modeled in SketchUp.

Figure 71. Specimens with surface textures including a network of $1 \mathrm{~mm}$-diameter crossing ribs. (a) pure resin, (b) Ti-coated and (c) DLC-coated.-------- 84

Figure 72. Acquired images with $10 \mathrm{X}$ objective lenses on the uncoated textured surfaces. (a) crest, (b) valley, and (c) the height between crest and valley. --.---.---.-- 85

Figure 73. Acquired images with $10 \mathrm{X}$ obj ective lenses on the Ti-coated textured surfaces. (a) crest, (b) valley, and (c) the height between crest and valley. ---.-- 86

Figure 74. Acquired images with 10X objective lenses on the Ti-coated textured surfaces. (a) crest, (b) valley, and (c) the height between crest and valley. ----------- 87

Figure 75. Raman spectra acquired on the crests and valleys of the substrate printed in the Form 1+with Clear FLGPCL 02 resin. (a) uncoated surfaces, (b) Ti-coated, (c) DLCcoated, and (d) spectral comparison on the crest. --.-- 89 


\section{List of Tables}

Table 1. Mass measurements of the nanofillers, and mixture features. 23

Table 2. Mass measurements of the graphene oxide, and mixture features. ---.------ 23

Table 3. Approximate cost of some materials. --..-- 31

Table 4. Approximate cost of manufacturing a cylindrical device. -

Table 5. Approximate cost of manufacturing a test specimen. - 32

Table 6. Detected elements in the substrates surface manufactured in pure resin and with Cu NWs, Cu NWs+NPs, and CuNi NWs. -- 34

Table 7. Nanofillers identified in the bulk of the substrates. - 34

Table 8. Values determined from DMA, DSC, and TGA analysis on specimens manufactured in pure resin and with nanofillers. -

Table 9. Approximate cost of some materials. - 58

Table 10. Approximate cost of manufacturing a functional device. - - 58

Table 11. Values determined from DMA, DSC, and TGA analysis on specimens manufactured in pure resin and GO-reinforced. -

Table 12. Values of the length, mass and volume measurements of the cylindrical substrates manufactured in the Form 1+printer. 


\section{List of Abbreviations}

$\begin{array}{ll}\text { 3D: } & \text { Three-dimensional } \\ \text { AM: } & \text { Additive manufacturing } \\ \text { ATR: } & \text { Attenuated total reflection } \\ \text { BSE } & \text { Back-scattered electrons } \\ \text { CAD: } & \text { Computer-aided design } \\ \text { CT: } & \text { Computed tomography } \\ \text { CT-Scan: } & \text { Computed tomography scan } \\ \text { CU: } & \text { Copper } \\ \text { CUNi: } & \text { Copper-nickel } \\ \text { DLP: } & \text { Digital light processing } \\ \text { DMA: } & \text { Dynamic mechanical analysis } \\ \text { DSC: } & \text { Differential scanning calorimetry } \\ \text { DTGA: } & \text { Derivative of thermogravimetric analysis } \\ \text { EDS: } & \text { Energy dispersive spectroscopy } \\ \text { FCC: } & \text { Face centered cubic structure } \\ \text { FTIR: } & \text { Fourier-transformed infrared } \\ \text { G: } & \text { Graphene } \\ \text { GO: } & \text { Graphene oxide } \\ \text { ICDD: } & \text { International Centre for Diffraction Data } \\ \text { IPA: } & \text { Isopropyl alcohol } \\ \text { MAA: } & \text { Methacrylic acid } \\ \text { MEMSs: } & \text { Microelectromechanical systems } \\ \text { MMA: } & \text { Methyl methacrylate } \\ \text { Ni: } & \text { Nickel } \\ \text { NPs: } & \text { Nanoparticles } \\ \text { NWs: } & \text { Nanowires } \\ \text { SEM: } & \text { Scanning electron microscopy } \\ \text { SERS: } & \text { Surface-enhanced Raman spectroscopy } \\ \text { SLA: } & \text { Laser stereolithography } \\ \text { TGA: } & \text { Thermogravimetric analysis } \\ \text { XRD: } & \text { X-ray diffraction } \\ & \end{array}$




\section{Symbols}

\begin{tabular}{llr} 
Symbol & \multicolumn{1}{c}{ Definition } & Units \\
$H$ & Hardness & $\mathrm{GPa}$ \\
$E$ & Young's modulus & $\mathrm{MPa}$ \\
$E^{\prime}$ & Reduced modulus/ Storage modulus & $\mathrm{GPa} / \mathrm{MPa}$ \\
$E^{\prime \prime}$ & Loss modulus & $\mathrm{MPa}$ \\
$T S$ & Tensile strength & $\mathrm{MPa}$ \\
$\tan \delta$ & Relationship between the elastic and inelastic component & \\
$T_{\mathrm{g}}$ & Glass transition temperature & ${ }^{\circ} \mathrm{C}$ \\
$T_{\mathrm{c}}$ & Cold crystallization temperature & ${ }^{\circ} \mathrm{C}$ \\
$T_{\mathrm{m}}$ & Melting temperature & ${ }^{\circ} \mathrm{C}$ \\
$T_{\mathrm{d}}$ & Thermal degradation temperature & ${ }^{\circ} \mathrm{C}$
\end{tabular}




\section{Abstract}

This PhD thesis researches the physicochemical properties of photopolymers employed in laser stereolithography focusing on the effects of mass and surface functionalizations. The mass functionalization is based on the incorporation of copper nanowires, copper nanowires with copper nanoparticles, copper-nickel nanowires, and graphene oxide at different concentrations, and times different post-cured. The nanofillers used lead to innovative photopolymeric resins, whose additive manufacturing is validated for the first time in this research. Once the substrates are manufactured, the modified resins perform similarly to the samples manufactured pure resin, without nanofillers. In addition, the surface functionalization was performed through the deposition of titanium and diamond-like-carbon by the direct current sputtering magnetron technique.

Accordingly, in this research experimental details, the methods, and materials used in the design and manufacture of the selected specimens are described. Likewise, it presents the results and discussions obtained from the analysis of the physicochemical properties of the substrates manufactured by laser stereolithography, using pure photosensitive resin and with dispersed nanofillers as reinforcing agents (copper nanowires, copper nanowires with copper nanoparticles, copper-nickel nanowires, and graphene oxide); as well as the quality of coatings deposited (titanium and diamond-like-carbon). The morphological, mechanical, thermal and chemical characterization was performed by means of scanning electron microscopy, energy dispersive spectroscopy, computed tomography scan, tensile testing, instrumented indentation, dynamic mechanical analysis, differential scanning calorimetry, thermogravimetric analysis, Raman spectroscopy, Fourier-transformed infrared spectroscopy, and X-ray diffraction.

As a result of the characterization studies, this research evidences the effects of dispersion and use of fillers different type, as a reinforcement material in a commercially available photopolymer resin. Likewise, is validate the quality and the aspect of coatings deposited on the surface of the specimens, which presents a homogeneous color and without delamination. The morphological, mechanical, thermal and chemical results of the manufactured specimens, layer by layer approach using a low-cost laser stereolithography system working with a layer thickness of $100 \mu \mathrm{m}$, were examined under well-controlled experimental conditions and technological processes. Consequently, the viability and potentials of mass and surface functionalized photopolymers and devices processable through laser stereolithography is presented and discussed, considering the main current challenges.

Keywords: additive manufacturing; 3D printing; laser stereolithography; photopolymer resin; mass-functionalization; surface-functionalization; nanofiller; physicochemical characterization. 


\section{Resumen}

La presente tesis doctoral investiga las propiedades físicas de fotopolímeros empleados en estereolitografía láser y funcionalidados en masa y superficie. La funcionalización en masa consiste en la incorporación de nanohilos de cobre, nanohilos de cobre con nanopartículas de cobre, nanohilos de cobre-níquel y óxido de grafeno en diferentes concentraciones y tiempos de post-curado. Los nanorellenos empleados llevan a la obtención de resinas innovadoras, cuya posible fabricación aditiva se valida por primera vez en esta investigación. Una vez que se fabrican los sustratos, las resinas modificadas se comportan de manera similar a los substratos fabricados con resina pura, sin nanorellenos. Adicionalmente, la funcionalización de la superficie se realizó a través de la deposición de titanio y carbono amorfo mediante la técnica de magnetrón sputtering de corriente continua.

En consecuencia, en esta investigación se describen los detalles experimentales, los métodos y los materiales utilizados en el diseño y la fabricación de los dispositivos seleccionadas. Asimismo, se presentan los resultados y las discusiones obtenidas del análisis de las propiedades fisicoquímicas de los sustratos fabricados mediante estereolitografía láser, utilizando resina fotosensible pura y con nanorellenos dispersos como agentes de refuerzo (nanohilos de cobre, nanohilos de cobre con nanopartículas de cobre, nanohilos de cobre-níquel y óxido de grafeno); así como la calidad de los recubrimientos depositados (titanio y carbono amorfo). La caracterización morfológica, mecánica, térmica y química se realizó mediante microscopía electrónica de barrido, espectroscopia de energía dispersiva de rayos $X$, tomografía computarizada, ensayos de tracción, indentación instrumentada, análisis mecánico dinámico, calorimetría diferencial de barrido, análisis termogravimétrico, espectroscopia Raman, espectroscopia infrarroja por transformada de Fourier, y difracción de rayos $X$.

En este sentido, esta investigación demuestra con éxito los efectos de la dispersión y el uso de rellenos de diferentes tipos, como material de refuerzo en una resina fotopolimerizable comercialmente disponible. Asimismo, se valida la calidad y el aspecto de los recubrimientos depositados sobre la superficie de las muestras, los cuales presentan un color homogéneo y sin delaminaciones. Los resultados morfológicos, mecánicos, térmicos y químicos de los substratos fabricados, capa por capa utilizando un sistema de estereolitografía láser de bajo costo que funciona con un espesor de capa de $100 \mu \mathrm{m}$, se examinaron bajo condiciones experimentales y procesos tecnológicos bien controlados. Por lo tanto, se muestra la viabilidad y el potencial que estas combinaciones de fotopolímeros y procesos para funcionalización en masa y superficie podrían tener en un futuro próximo, una vez que se resuelvan los principales desafíos.

Palabras clave: fabricación aditiva; impresión 3D; estereolitografía láser; resina fotopolimérica; funcionalización masiva; funcionalización superficial; nano-relleno; caracterización fisicoquímica. 


\section{Objectives}

This thesis is focused on the systematic research of physicochemical properties of functional photopolymers used by stereolithography technique and on the functionalization of objects and devices manufactured using such technique. More specifically, commercial photoreactive resins have been selected and used in this study as the matrix material and different types of nanofillers for bulk functionalization and coatings for surface functionalization have been researched. In this regard, the use of nanofillers is expected to enhance or fine-tune mechanical and thermal properties of the polymeric matrix and the employment of coatings is aimed at modifying contact and aesthetic properties.

Considering that progress in additive manufacturing, especially as regards finding industrial applications for additive photopolymerization technologies, relies on the synthesis of innovative functional resins and on the understanding of their physicochemical properties, as well as on the improvement of final performance by adequate post-processes, this research focuses on the functionalization and characterization of photoreactive resins for the laser stereolithography technique. In this context, the general and specific objectives of this PhD thesis can be formulated as:

\section{General objective}

Developing innovative functional photopolymers for laser stereolithography by employing selected nanofillers, validating their additive manufacturability, improving their performance and systematically characterizing their physicochemical properties, so as to propose potential applications.

In addition:

Through this research, a significant set of characterization techniques is used and their synergies for adequately understanding the behavior, depending on the type of filler and processing conditions are analyzed. This, in turn, leads to a proposal of methodology for characterizing functional photopolymer resins with optimal use of resources and techniques.

\section{Specific objectives}

$\checkmark$ To design substrates and test parts with both simple and complex bulk and surface geometries, so as to evaluate the manufacturability of functional photopolymers using laser stereolithography and to study the physicochemical properties of such functional materials and devices.

$\checkmark$ Research, validate and analyze the potential use of copper and copper-nickel nanowires and of graphene oxide as nanofillers for functionalizing photopolymers for additive manufacturing processes.

$\checkmark$ Research, validate and analyze the potential use of diamond-like carbon and of titanium thin films as surface functionalization options for complex objects created by laser stereolithography. 
Systematically modify the manufacturing parameters, filler contents and postprocessing conditions and study their impact on final properties of test probes and devices.

$\checkmark$ Characterize the bulk and surface properties of the substrates by microscopic, spectroscopic, mechanical and thermal techniques. Identity the nanofiller distribution and the surface functionalization quality and characterize in terms of stiffness, strength, toughness and thermal properties.

$\checkmark$ Propose a methodology with selected combinations of testing techniques for the systematic characterization of functional photopolymers and related devices manufactured by laser stereolithography.

The framework of the proposed research is presented in Figure 1, which shows the main aspects to study and covers different topics connected to the study of physicochemical properties of pure and functionalized photopolymers and devices obtained by laser stereolithography as industrial 3D printing "gold standard".

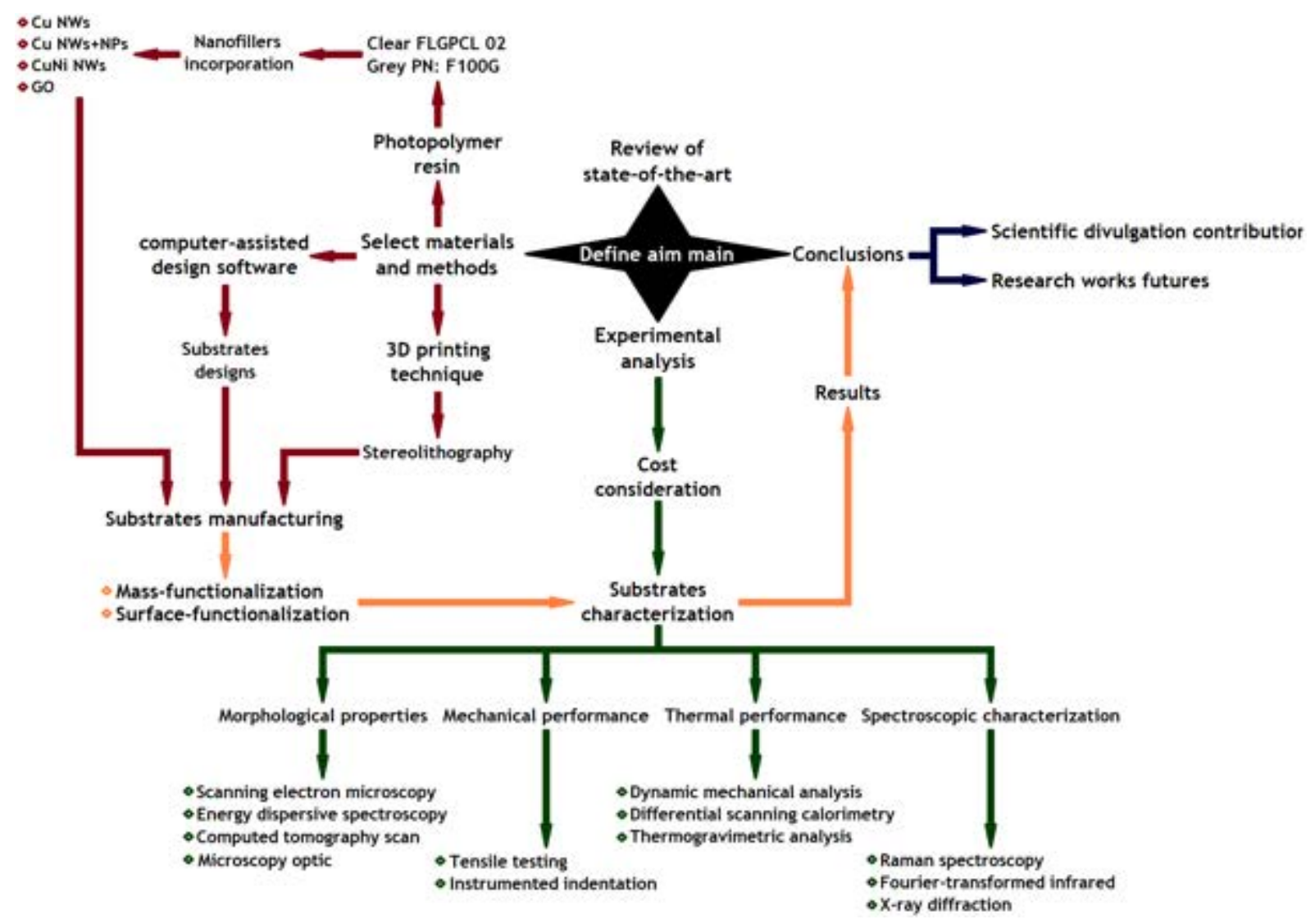

Figure 1. Overview of the work research develop. 


\section{Introduction}

This introduction presents a brief description of the current state-of-the-art and research trends, likewise as the structure and context of the doctoral thesis.

\subsection{Current State-of-the-Art and Research Trends}

Additive manufacturing (AM), more commonly known as three-dimensional (3D) printing [1], has been widely recognized as a disruptive manufacturing technology for a wide variety of applications and consequently hailed as the third industrial revolution [2]. Thus, to difference to the manufacture conventional (the subtractive technologies), AM has the possibility of innovating with complex unique designs and manufacture only with the material required. In consequence, it is achieved through a consecutive and repetitive cycle of steps until getting an optimized product or prototype to final applications (Figure 2).

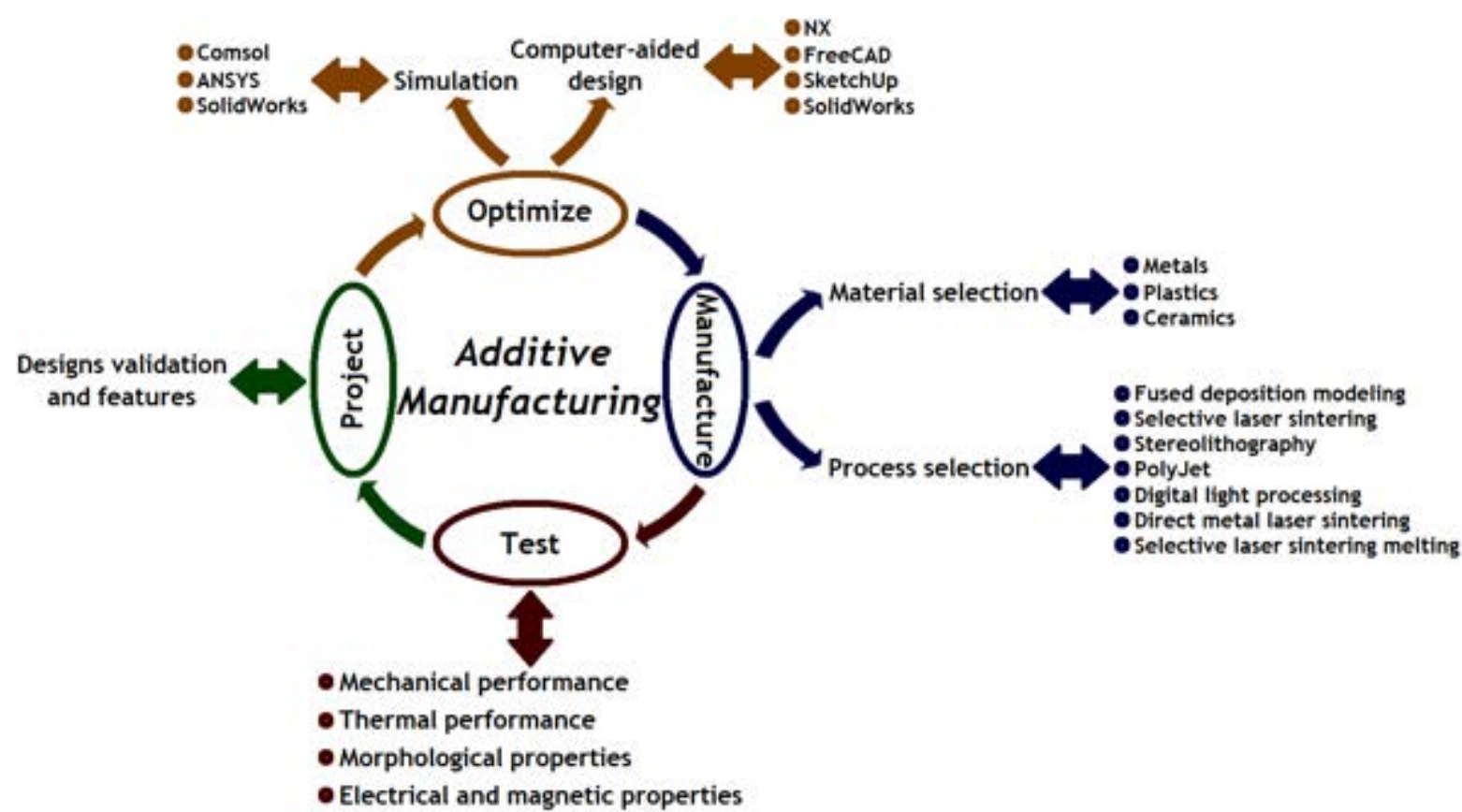

Figure 2. Additive-manufacturing process.

AM technologies, in many cases employed for rapid prototyping (RP), are a set of resources that directly manufacture complex three-dimensional objects using the information of computer-aided design (CAD) files and working in a layer by layer or additive fashion. In this way, polymeric, metallic, ceramic and even composite materials can be processed employing a wide portfolio of technologies, among which vat photopolymerization stands out for the degree of precision and throughput achieved [3-5]. vat photopolymerization technologies, including laser stereolithography (SLA) and digital light processing (DLP), work upon a vat of photopolymerizable resin and use the power of a laser or the light projected through a digital mask to selectively, and in a layer by layer approach, activate the polymerization of the resin in the vat. In the case of laser stereolithography, a 
laser, which usually works in the ultraviolet range, is used for precisely defining the contours and infill of the polymeric layers. Both bottom-up and top-down systems, depending on the movement of the construction platform within the vat, co-exist; the top-down ones standing out for the process stability, the bottom-up ones standing out for their construction simplicity, although sometimes suffering from the detachment of the part under construction from the building platform [3-5].

The weak mechanical property of the polymer and poor surface quality of the metal parts has severely hindered the further progress of AM technology. But by incorporating nanofillers into polymers, the nanocomposites exhibit significantly improved mechanical, thermal, optical or other properties [6].

The dispersion of nanofillers is crucial for the properties of polymer nanocomposites. The mechanism for the interaction in nanofiller/ polymer nanocomposites relies on the polarity, molecular weight, hydrophobicity, reactive groups, etc., $[7,8]$. In this way, nanocomposites' properties will be maximally reinforced by a well-dispersed state [9-11]. Thus, large efforts have been focused on achieving a homogeneous and well-dispersed nanofillers in the polymer matrix [12].

Metallic nanowires (NWs) have been marked as a promising material for the massfunctionalization of manufactured devices by SLA technique, for an applications variety in optoelectronic, photovoltaic [13] and that demand mechanical flexibility $[14,15]$. Thus, copper nanowires and silver nanowires ( $\mathrm{Cu}$ NWs and Ag NWs) have been the metals of choice for some applications, due to their high conductivity, amenability towards solution synthesis and inherent mechanical flexibility. Cu NWs has the added advantage of being relatively abundant and considerably cheaper than silver, making it economically attractive for applications where are required in large quantities [15].

In the current scenario of advances in science, engineering, and technology, metal/ metal oxide nanofiller have a great deal of attention due to their potential applications in the fields of biomedicine, photonics, and surface-enhanced Raman spectroscopy (SERS) [16]. Therefore, the dramatic behavior of metallic nano-entities is attributed to the modification of electronic eigenstates, subject to diverse boundary conditions in the nano-scale, leading to unique electronic, optical, magnetic, and mechanical properties.

However, the endeavor to employ Cu NWs, copper nanowires with copper nanoparticles ( $\mathrm{Cu}$ NWs+NPs) or copper-nickel nanowires (CuNi NWs) in an environmentally and commercially sustainable fashion faces many challenges. These include the need for largescale green synthetic routes, the ability to control the nanowires (NWs) dimensions and their dispersibility in solvents. Clearly, the successful incorporation of nanofillers of $\mathrm{Cu}$ or $\mathrm{Ni}$ with prevailing technologies requires an integrated approach that can meet the requirements in a non-conflicting and cost-effective manner $[15,17]$.

Graphene (G) and graphene oxide (GO) have been applied to improve properties of polymers, including mechanical properties [1,18-25], electrical properties [26-28], thermal properties $[1,29,30]$, optical properties [31,32], electromagnetic interference shielding $[33,34]$ and barrier properties [35-37]. Then, G or GO reinforced polymer composites have been under intensive research $[19,22,38]$. Consequently, the design and behavior of polymer nanocomposites mainly depend on the aspect ratio of nanofillers, percolation threshold and interfacial property of nanofiller and matrix [39]. 
The applications in the printable category keep expanding into many scientific fields of sciences and engineering [40-46]. But graphene, a single-atom-thick $s p^{2}$ carbon crystal, has been used very little as a 3D printing feedstock. To facilitate both, it becomes urgent to push graphene and related materials into the 3D printable category [43].

The graphene composites, as such as graphene sheets have been successfully added into polymers matrix to explore novel applications in mechanical reinforcement, flame retardant or improve the conductive electrical $[47,48]$. In most previous studies, has exposed that graphene fillers must be homogeneously dispersed in the polymers to getting optimal properties [49]. But it is still a great problem confronted by graphene composites because that phase separation between graphene sheets and polymers usually occurs in a synthetic process $[50,51]$. Then, to minimize phase separation and obvious graphene aggregation is used the $\mathrm{GO}$ to substitute the $\mathrm{G}$ as the starting filler material. GO contains oxygenated functional groups on its basal planes, meaning could improve graphene's dispersion in polymer phases [1,52-55]; although these functional groups possibly contribute electrical insulating of the $\mathrm{GO}$ due to the extensive presence of $s p^{3} \mathrm{C}-\mathrm{C}$ bonds $[56,57]$. The electrical conductivity can be retrieved through the restoration of $s p^{2}$ bonds in graphitic domains [43]. Chemical reduction of the $\mathrm{GO}$ is a cost-effective strategy to prepare graphene sheets by utilization of reductant. In addition, hydrazine has been commonly used to high yield production of reduced $\mathrm{GO}$ ( $\mathrm{rGO}$ ) owing to its ability to in situ reduce oxygenated functional groups. It was reported that $\mathrm{rGO}$ restores $80 \% s p^{2}$ in its structure, with the rest of $s p^{3}$ bonds derived from residual oxygen ( $\mathrm{C}: \mathrm{O}$ atom ratio $12.5: 1$ ) after the reduction with hydrazine $[43,57]$. Therefore, in this research work, a series of GO-based photopolymer resin composites were prepared through the controlled mixture to different concentrations and tested in a commercially available 3D printer.

SLA technique, used for the manufacture of devices by photopolymerization is a sort of industrial gold standard in rapid prototyping systems, can manufacture of a wide range of shapes and components with a great control of the dimensions and features of the specimens [4,58-61]. Although this is already a common additive manufacturing technology, also it was introduced for the manufacture of microelectromechanical systems (MEMSs) and microfluidic devices [59,60,62-65]; where the employment of functional elements within the resins to be photopolymerized is an innovative approach towards materials and devices with special properties [66-69]. In consequence, finding methods that improve the mechanical, thermal and electrical properties of materials employed in additive manufacturing is a relevant field of study with industrial and scientific significance. Both surface and bulk functionalization of the essential elements may lead to final devices with enhanced properties and innovative functionalities [61-65, 68-70].

Stereolithography can rapidly, and precisely produce complex 3D structures that cannot be assembled by other means [5,59,64,65,69-71]. In this order of ideas, this research work focuses on designing and for mass/bulk-functionalization manufacturing of specimens reinforced photopolymer (commercial photo-resin for laser stereolithography) by incorporating the advanced nanofillers ( $C u$ NWs, Cu NWs+NPs, CuNi NWs and GO). Moreover, the described experiments, the analysis, and discussion of the results obtained, the which provide useful information regarding the potential benefits, it seeks to validate an approach based on mass-functionalization for solving current challenges of the parts performance manufactured by laser stereolithography. 


\subsection{Structure and Context of the Doctoral Thesis}

The goal of this research is based on a systematic study that allows optimizing to manufacture mass-functionalized devices, through the physicochemical evaluation of the polymer matrix pure resin and reinforced with nanofillers. In the regard, this thesis is structured into seven chapters that clearly lay out the systematic research carried out.

Firstly, in Chapter 1 general and specific objectives of the doctoral thesis are presented. So as the framework of the research proposed.

In chapter 2, the introduction with a brief description of background, needs, and the current approach of additive manufacturing and resin mass-functionalization used by 3D photopolymerization according to research works recently carried out is presented. In chapter 3, experimental details, the methods, and materials used in the design and manufacture of the selected specimens are described.

In chapter 4 and 5, results and discussions obtained from the evaluation of the physicochemical properties (morphological, mechanical, thermal and chemical characterization) of all substrates printed by stereolithography using pure photosensitive resin and with dispersed nanofillers as reinforcing agents are presented. In chapter 6 , results and discussions obtained from surface characterization on the substrates printed by stereolithography using pure photopolymer and coated with titanium and diamond-likecarbon by the direct-current magnetron sputtering technique are presented.

In chapter 7 main scientific and technological conclusions are presented, together with a summary of dissemination activities performed along the PhD thesis and a proposal of continuation research lines, in connection with the future of additive manufacturing and the use of functional materials and devices.

In addition, is very important to highlight that this thesis was carried out with the academic-scientific cooperation between Universidad Politécnica de Madrid (UPM), Cranfield University, Universidad Industrial de Santander (UIS), Universidad Nacional de Colombia (UNAL), and Nano4energy. The Laboratorio de Desarrollo de Productos of the División de Ingeniería de Máquinas, Escuela Técnica Superior de Ingenieros Industriales, UPM, has provided experience in the additive manufacturing process. The Surface Engineering \& Nanotechnology Institute, Cranfield University, and Laboratorio Espectroscopía Atómica Molecular, UIS, has provided experience in nanomaterials. Nano4energy, has provided experience in coatings. Likewise, the Laboratorio de Espectroscopia, Laboratorio de Instrumental, and Grupo de Investigación en Polímeros, UIS, and The Laboratorio de Biomateriales, UNAL, ha supported and allowed the access during seven months to characterization technologies for the analysis of results. 


\section{Experimental Details}

This section presents a description detailed of all materials, methods, and characterization techniques used in the development of the research proposed as a doctoral thesis.

\subsection{Materials and Methods}

Design parameters, manufacturing processes and evaluation methods are detailed below. Figure 3 shows the design and manufacturing process schematically.

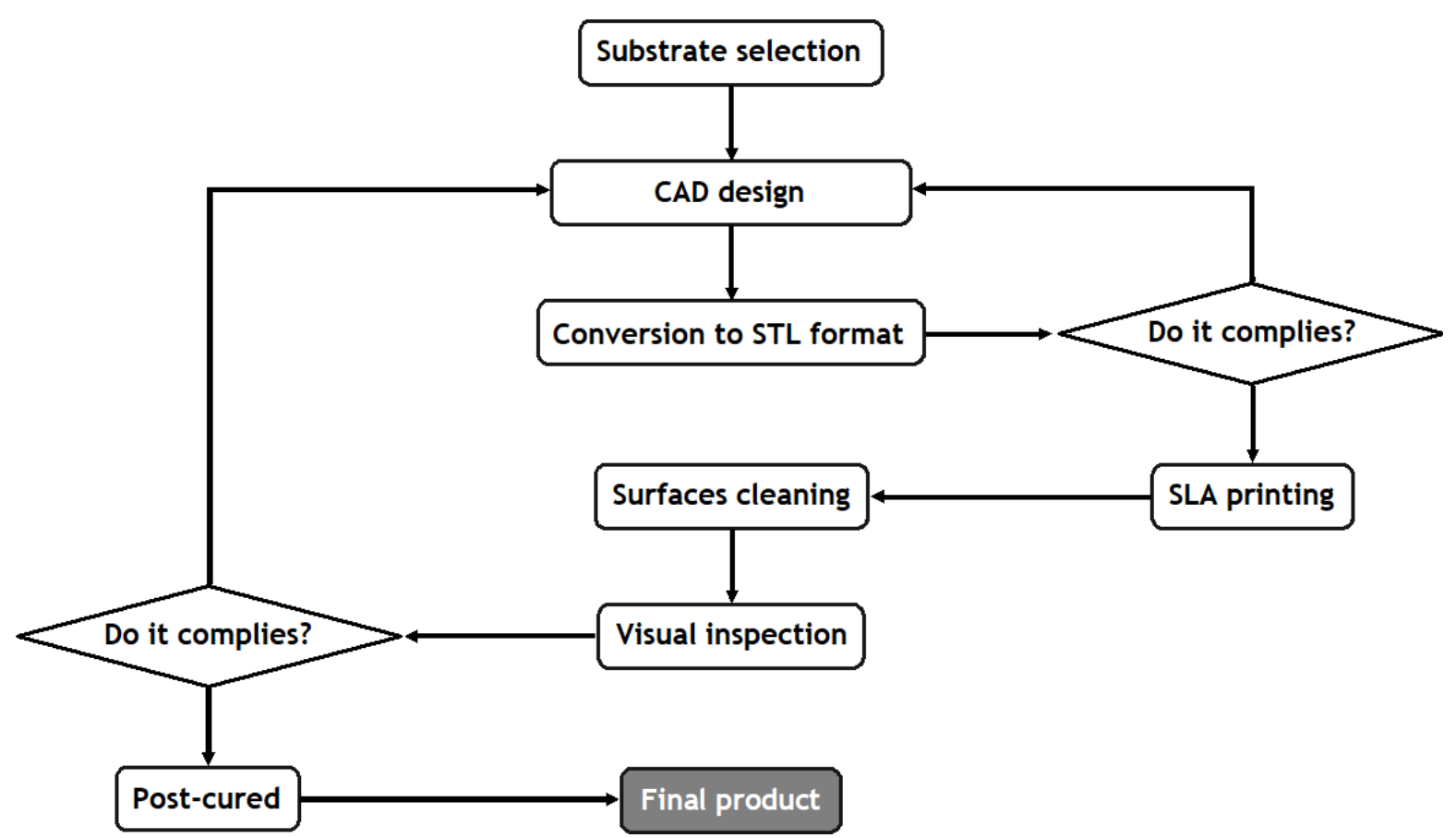

Figure 3. Stages of the process for products developments by 3D printing.

\subsection{Designs of Substrates}

We design cylindrical substrates, $21.3 \mathrm{~mm}$ in diameter and $3 \mathrm{~mm}$ thick, with and without surface texture, substrates for tensile testing according to standard ASTM D638-14 type V [72], and scaffolds (see Figure 4).

Designs are carried out using computer-assisted design software (CAD), the which ease the activities of making, modification, analysis, optimization, and simulations of models validated the characteristic, properties and feasibility of the designs. The software's used were, the FreeCAD v0.16, SketchUp Make 2016 version 16.0.19911 (Trimble Navigation Limited), SolidWorks 2013 version 21.0.0.5024, and NX 2013 version 8. 5. Subsequently, the CAD designs, presented in Figure 4, are exported to standard tessellation language/ stereolithography format (STL), which is a sort of universal file format for additive manufacturing technologies and 3D printers. 


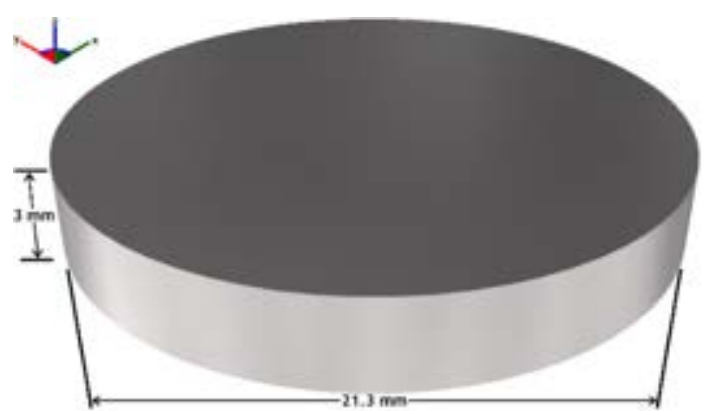

(a)

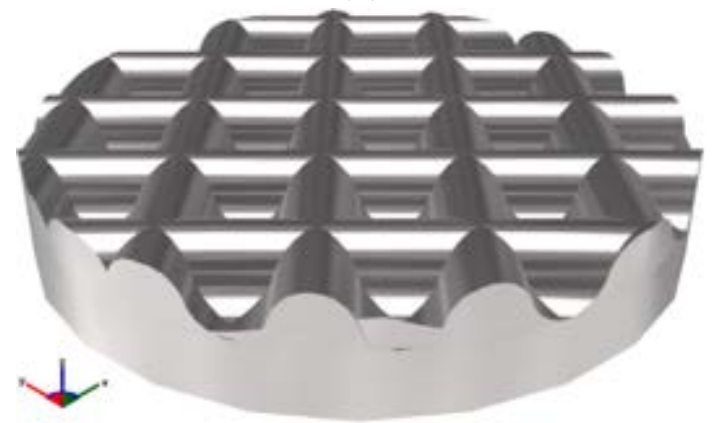

(c)

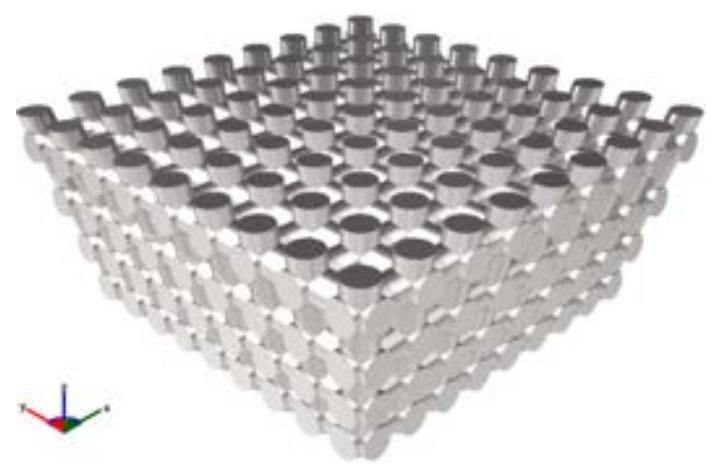

(e)

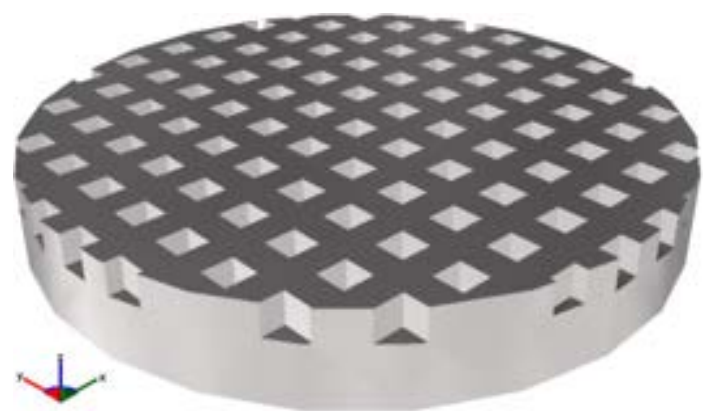

(b)

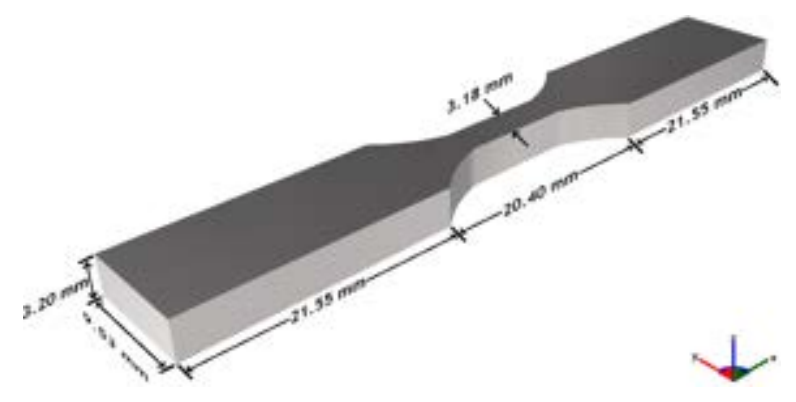

(d)

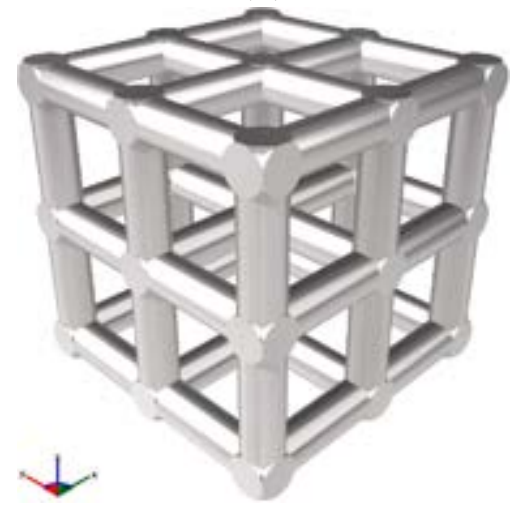

(f)

Figure 4. Substrates designed in FreeCAD, SketchUp Make, SolidWorks and NX. Cylindrical geometries (a) without texture, and with texture of section (b) square, and (c) curvilinear. (d) Specimens for tensile testing [72]. Scaffolds of type (e) sponge and (f) circular tubes.

\subsection{Resins and Nanofillers}

The base material used for the manufacture of the devices was a commercial photoreactive resin of type "Clear FLGPCL 02" and "Grey PN: F100G" (Form 1+, Formlabs) [65, 70], which is a mixture of methacrylic acids esters (methacrylated oligomers and monomers) and photoinitiator (Diphenyl (2,4,6-trimethylbenzoyl)), according to the manufacturer's datasheet (see appendix $A$ and $B$ ).

The Cu NWs, Cu NWs+NPs, CuNi NWs, $[15,70]$ and GO for mass-functionalization were provided by Surface Engineering \& Precision Institute (Cranfield University, UK) and by the Laboratorio de Espectroscopía Atómica y Molecular (Universidad Industrial de Santander, Colombia), respectively, according to data reported in Table 1 and Table 2. The process to synthesize pure Cu NWs was reported previously $[15,70]$. 
Table 1. Mass measurements of the nanofillers, and mixture features.

\begin{tabular}{|c|c|c|c|c|c|c|c|}
\hline \multirow{3}{*}{$\begin{array}{l}\text { Resin type } \\
\text { Type of additive } \\
\text { Mass of the nanofiller solution (g) }\end{array}$} & \multicolumn{7}{|c|}{ Clear FLGPCL 02} \\
\hline & \multicolumn{4}{|c|}{ Cu NWs } & \multirow{2}{*}{$\frac{\mathrm{Cu} \text { NWs+NPs }}{8.821}$} & \multicolumn{2}{|c|}{ CuNi NWs } \\
\hline & \multicolumn{2}{|c|}{6.003} & 6.831 & 5.691 & & 9.376 & 3.849 \\
\hline Nanofiller mass (mg) & \multicolumn{2}{|c|}{9.8} & 66.6 & 97.8 & 163.6 & 159.6 & 162.0 \\
\hline Nanofiller solution percentage $(\% \mathrm{w} / \mathrm{w})^{*}$ & 5.1 & 10.0 & 15.4 & 15.0 & 17.3 & 20.7 & 10.0 \\
\hline Nanofiller percentage $(\% \mathrm{w} / \mathrm{w})^{*}$ & 0.008 & 0.017 & 0.170 & 0.260 & 0.340 & 0.360 & 0.420 \\
\hline Mixture time (min) & \multicolumn{2}{|c|}{30} & 120 & 120 & 120 & \multicolumn{2}{|c|}{120} \\
\hline
\end{tabular}

Table 2. Mass measurements of the graphene oxide, and mixture features.

\begin{tabular}{ccccc}
\hline \multirow{2}{*}{ Resin type } & $\begin{array}{c}\text { GO-solution mass } \\
\mathbf{( g )}\end{array}$ & $\begin{array}{c}\text { GO-solution percentage } \\
(\% \mathbf{w} / \mathbf{w})^{*}\end{array}$ & $\begin{array}{c}\text { GO-percentage } \\
(\% \mathbf{w} / \mathbf{w})^{*}\end{array}$ & $\begin{array}{c}\text { Mixture time } \\
(\mathbf{m i n})\end{array}$ \\
\hline \multirow{2}{*}{ Clear FLGPCL 02 } & 5.030 & 10 & 0.04 & 120 \\
& 10.590 & 20 & 0.08 & 0.12 \\
Grey PN: F100G & 14.866 & 30 & 0.02 & 65 \\
& 2.054 & 5 & 0.04 & \\
& 4.036 & 10 & 0.06 & \\
\hline
\end{tabular}

\subsection{Mixtures Process}

The mixture of "Clear FLGPCL 02" and "Grey PN: F100G" resins with the Cu NWs, Cu NWs+NPs and CuNi NWs stored in isopropyl alcohol (IPA), and GO was performed in three processes:

1. In the MPC 004ST vacuum casting machine, with a $30^{\circ}$ of inclination approximately, during 30 min to high speed.

2. In the stirring hot plates model SPA 1020B of Thermolyne with magnetic stirrer bar by $60 \mathrm{~min}$ to $1000 \mathrm{rpm}$.

3. in the vortex mixer model TopMix FB15024 of Fisher Scientific to a frequency of $20 \mathrm{~Hz}$ during $5 \mathrm{~min}$ and $30 \mathrm{~min}$ according to the case. The photoreactive resins mixed with nanofillers are show in Figure 5 . The features of the mixtures are reported in Tables 1 and Table 2.

\subsection{Substrates Manufacturing}

Substrates manufactured in pure resin, and with Cu NWs, Cu NWs+NPs, CuNi NWs and and GO (see Table 1 and Table 2) was carried out using a low-cost laser stereolithography system, more specifically with the Formlabs Form 1+printer (see Figure 6) $[65,70]$, which is capable of reading information of part geometries from the original CAD files exported to STL format. Accordingly, the specimens were manufactured in a layer-by-layer approach, with a layer thickness of $100 \mu \mathrm{m}$. Laser stereolithography is a process based on a liquid resin, whose polymerization is selectively activated by an ultraviolet laser. This later gradually draws layers on the surface of the liquid resin, following a pattern defined in the STL file $[5,69,70]$. 
Substrates using pure resin and resin functionalized with and with Cu NWs, Cu NWs+NPs, CuNi NWs and GO are printed in groups of three ( 3 specimens in the same process) at a resolution of $100 \mu \mathrm{m}$ per layer (see Figure 7). The time period of manufacturer was $15 \mathrm{~min}$ for cylindrical substrates and $22 \mathrm{~min}$ for the tensile testing specimens [70].

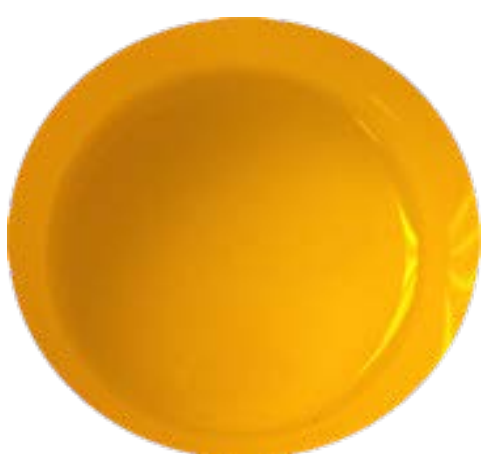

(a)

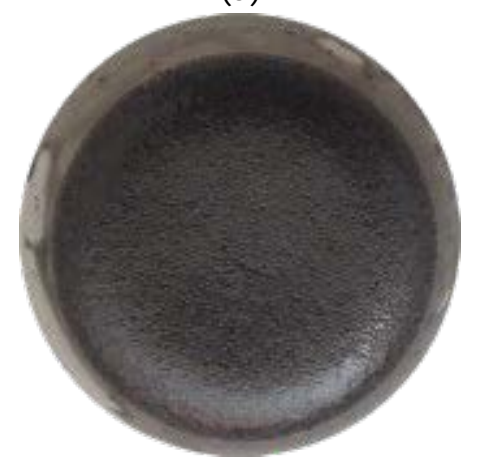

(d)

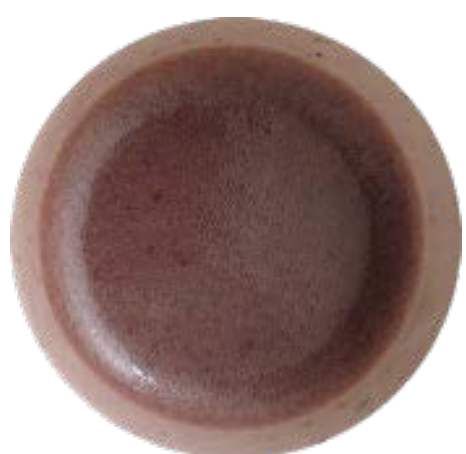

(b)

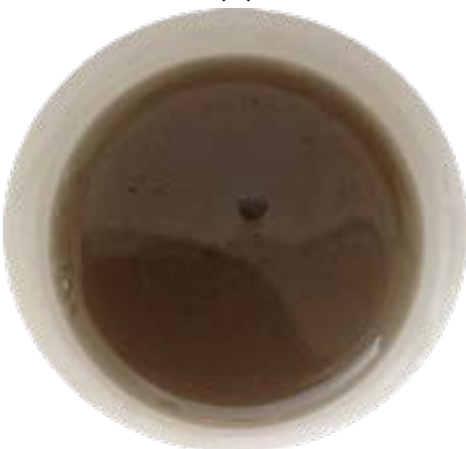

(e)

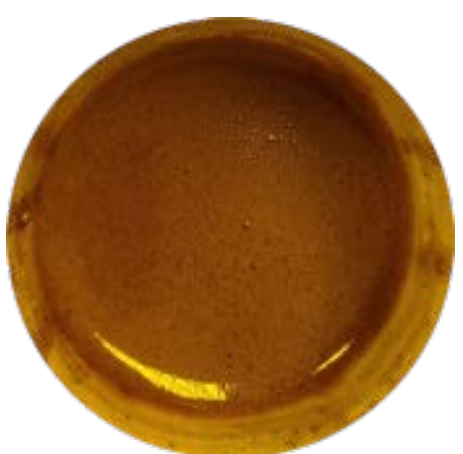

(c)

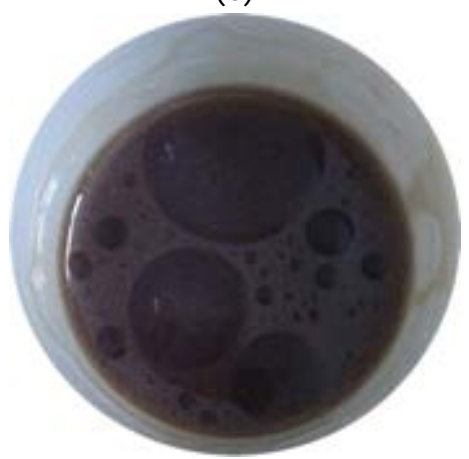

(f)

Figure 5. Resin type used in the substrates manufacturing. (a) "Clear FLGPCL 02" pure resin. "Clear FLGPCL 02" resin mixed with (b) Cu NWs at $0.26 \% \mathrm{w} / \mathrm{w}$, (c) Cu NWs+NPs at $0.34 \% \mathrm{w} / \mathrm{w}$, (d) CuNi NWs at $0.42 \% \mathrm{w} / \mathrm{w}$, (e) GO at $0.04 \% \mathrm{w} / \mathrm{w}$, and (f) GO at $0.12 \% \mathrm{w} / \mathrm{w}$.

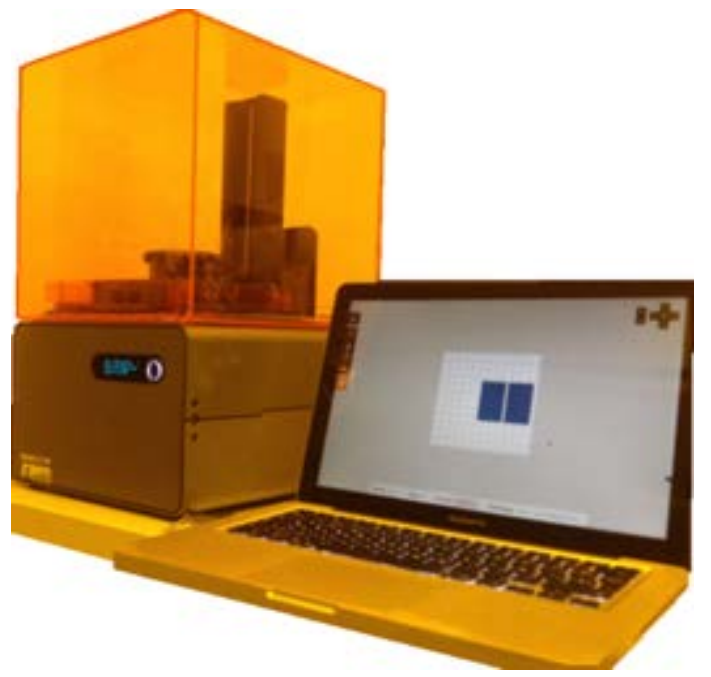

(a)

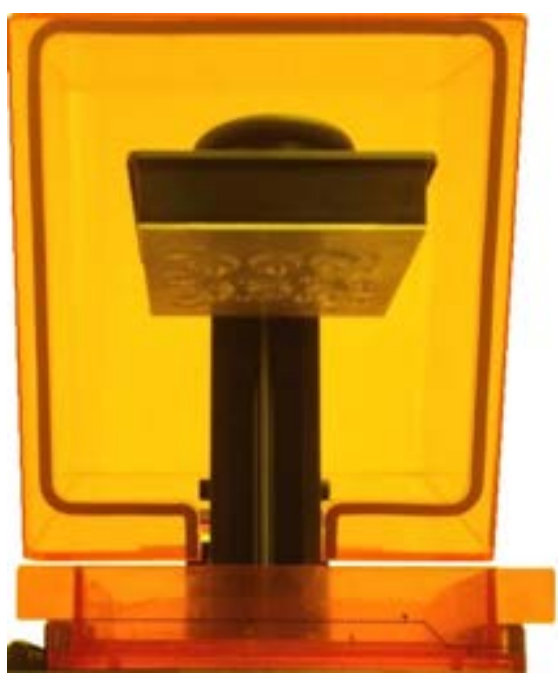

(b)

Figure 6. (a) Form 1+printer. (b) Platform and resin vat of the 3D printer. 


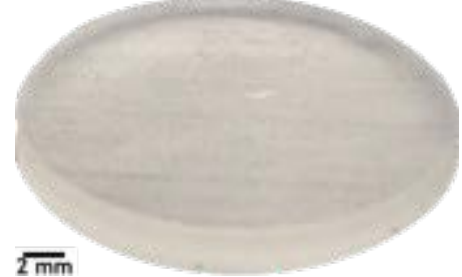

(a)

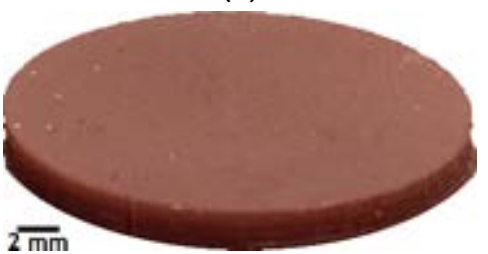

(d)

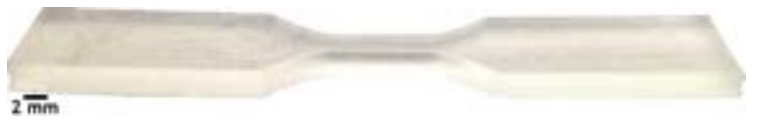

(g)

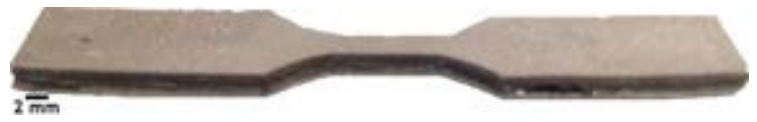

(i)

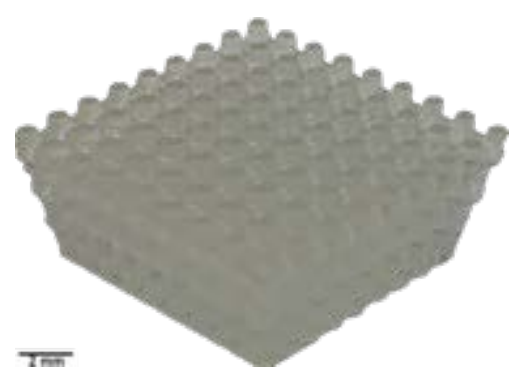

(k)

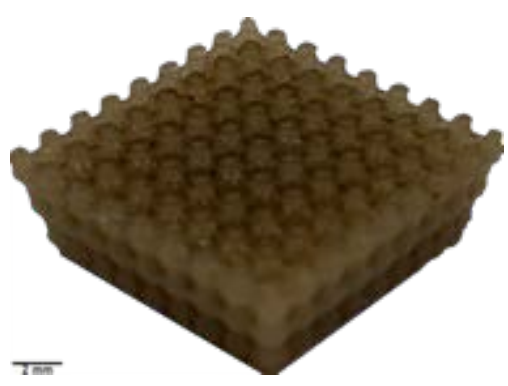

(n)

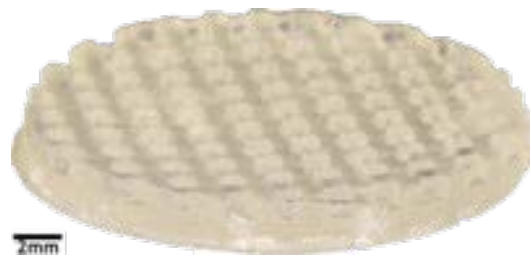

(b)

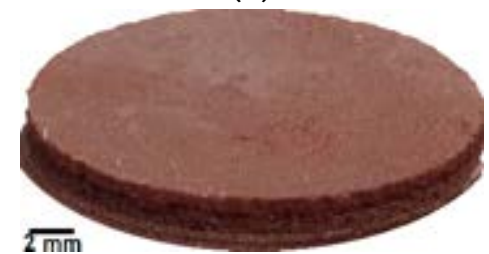

(e)

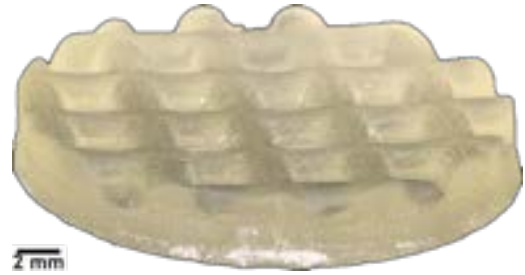

(c)

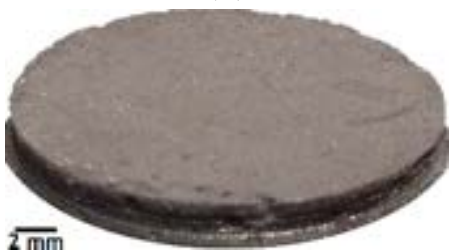

(f)

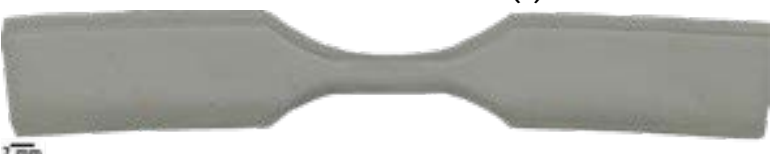

(h)

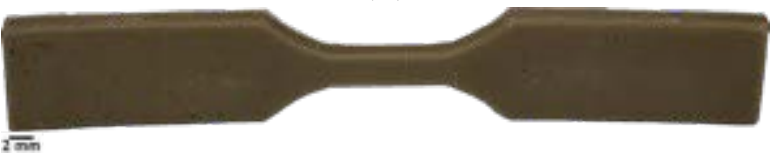

(j)

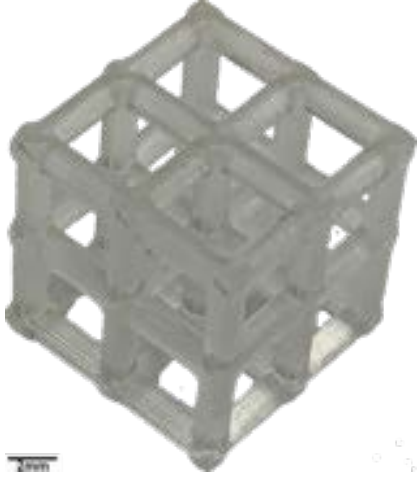

(I)

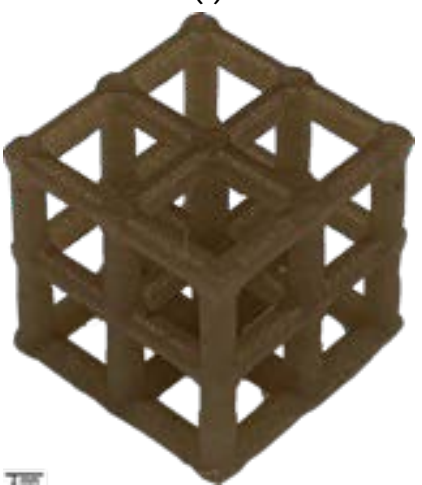

(0)

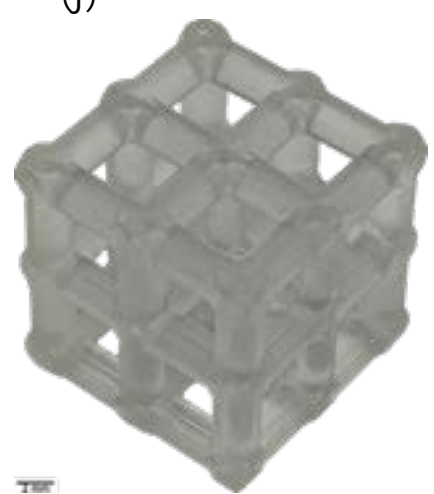

TE

(m)

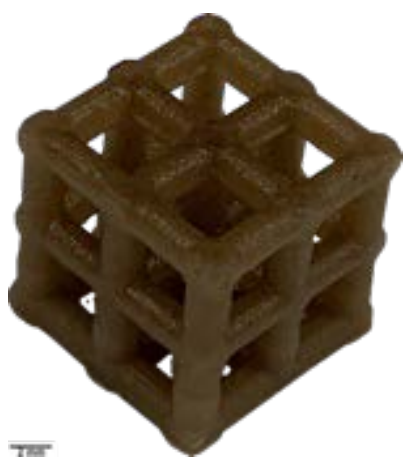

(p)

Figure 7. Manufactured substrates. Cylindrical geometries in pure resin (a) without texture, and with a texture of section (b) square, and (c) curvilinear. Cylindrical geometries with (d) Cu NWs at $0.17 \% \mathrm{w} / \mathrm{w}$, (e) Cu NWs+NPs at $0.34 \% \mathrm{w} / \mathrm{w}$, and (f) CuNi NWs at $0.36 \% \mathrm{w} / \mathrm{w}$. Specimens for tensile testing [72], (g) and (h) in pure resin, with (i) CuNi NWs at $0.36 \% \mathrm{w} / \mathrm{w}$ and (j) GO at $0.12 \% \mathrm{w} / \mathrm{w}$. Scaffolds in pure resin of type (k) sponge, (I) circular thick tubes, and (m) circular thin tubes. Scaffolds GO-reinforced at $0.04 \% \mathrm{w} / \mathrm{w}$ of type (n) sponge, (o) circular thick tubes, and (p) circular thin tubes. 


\subsection{Characterization Techniques}

The analysis of physicochemical properties of the substrates manufactured by 3D photopolymerization, pure resin and with nanofillers (Cu NWs, Cu NWs+NPs, CuNi NWs and GO) were performed by scanning electron microscopy (SEM) and energy dispersive spectroscopy (EDS), computed tomography scan (Industrial X-ray and CT systems), tensile testing, instrumented indentation, dynamic mechanical analysis (DMA), differential scanning calorimetry (DSC) and thermogravimetric analysis (TGA), Raman spectroscopy, Fouriertransformed infrared (FTIR), and X-ray diffraction (XRD). Following is presented a brief description of each characterization technique used.

3.6.1. Scanning electron microscopy and energy dispersive spectroscopy. The morphological characterization was performed in the SEM of thermionic emission Carl Zeiss EVO MA10 (Figure 8), through the acquisition imagen by secondary electrons and retroprojected electrons [73]. The elements identification and your distribution on the image were performed by EDS with a detector Oxford X-act coupled to MEB. In the analysis is established a work distance was od $8.5 \mathrm{~mm}$ and an acceleration voltage of $20 \mathrm{kV}$.

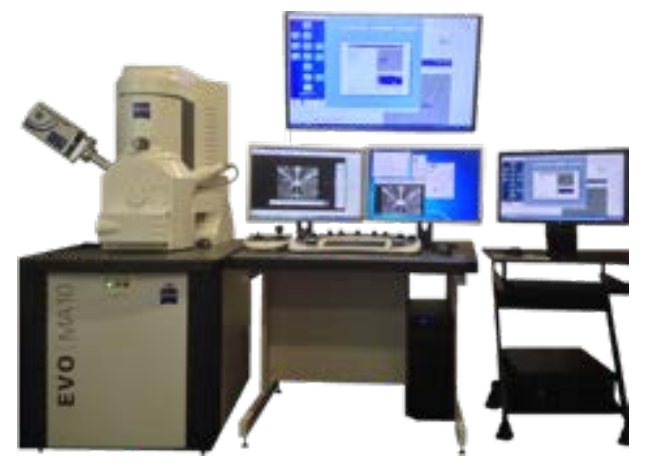

Figure 8. Scanning electron microscope of thermionic emission Carl Zeiss EVO MA10, located in Facultad de Minas, Universidad Nacional de Colombia, Medellín, Colombia.

3.6.2. Computed tomography scan. The $3 D$ rendering distribution of $\mathrm{Cu} N W s$, Cu NWs+NPs, and CuNi NWs after manufacture, was performed by using a computed tomography system XT H 160 CT SCAN, Nikon (Figure 9). The beam energy used was $150 \mathrm{kV}$ and $50 \mu \mathrm{A}$, and the distance between the specimen and the detector was set to provide a degree of phase contrast to facilitate the visualization of nanowires. The exposure time was $500 \mathrm{~ms}$, where four frames (each one of 540 projections) were collected by radiography. Moreover, we fixed the voxel size at $10 \mu \mathrm{m}$, which was adequate to image the notch region.

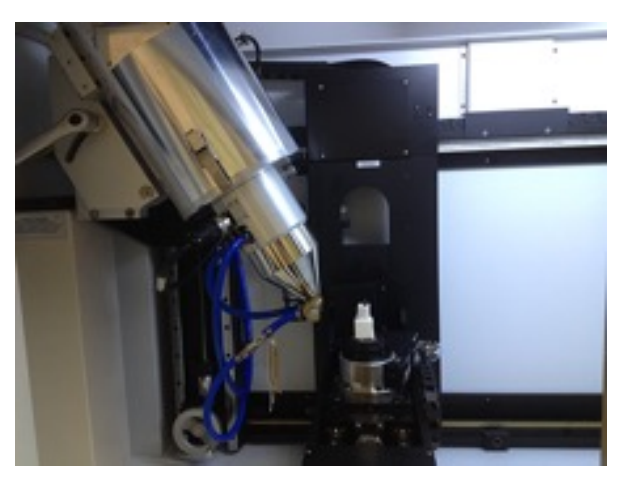

Figure 9. Computed tomography system XT H 160 CT SCAN, Nikon, located in Museo Nacional de Ciencias Naturales, Madrid, Spain. 
3.6.3. Tensile testing. The mechanical properties (elasticity, yield strength, ultimate tensile strength, and ductility) are obtained through tensile tests according to ASTM D63814 standard [72], with type $V$ specimens and a deformation speed of $1 \mathrm{~mm} / \mathrm{min}$ in the universal test system, MTS Criterion model 43 (Figure 10).

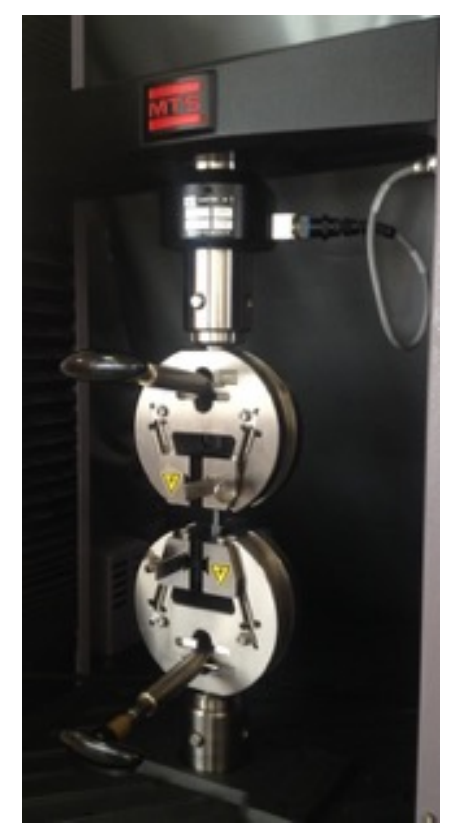

Figure 10. Universal test system, MTS Criterion model 43, located in Facultad de Ingeniería Mecánica, Universidad Pontificia Bolivariana, Bucaramanga Colombia.

3.6.4. Instrumented indentation. The mechanical properties, the reduced modulus $\left(E^{\prime}\right)$ and hardness $(H)$, are carried out using instrumented indentation testing in the IBIS-Authority nano-indentation system of Fischer-Cripps Laboratory Pty Ltd. (Figure 11). A Berkovich diamond probe was used for all experiments. During the loading cycle, a force of $10 \mathrm{mN}$ and a $10 \mathrm{~s}$ creep was selected. In turn, the storage modulus and hardness, to assume elasticviscoelastic correspondence, were obtained from 30 indentations separated from each other $30 \mu \mathrm{m}$ on a rectangular section area $[74,75]$.

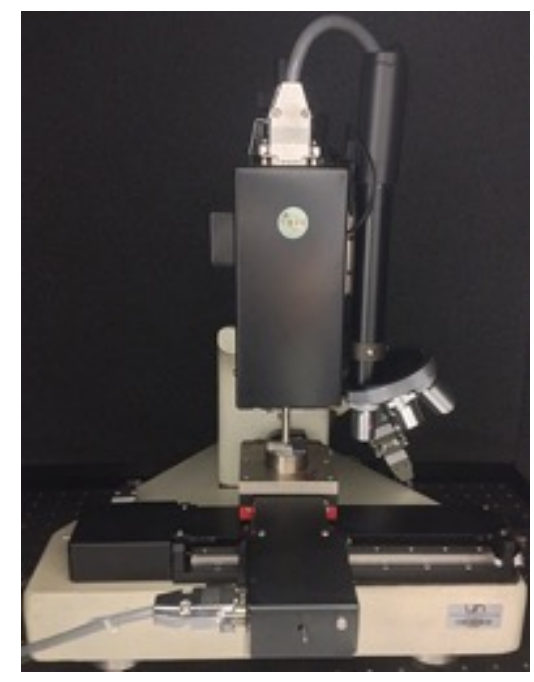

Figure 11. IBIS-Authority nano-indentation system of FischerCripps Laboratory Pty Ltd., located in Facultad de Minas, Universidad Nacional de Colombia, Medellín, Colombia. 
3.6.5. Dynamic mechanical analysis. DMA was carried out using a $Q 800$ analyzer, TA Instruments Inc. (Figure 12) to determine the viscoelastic behavior of the substrates. The instrument was completely calibrated in accordance with the procedures of TA Instruments. During the sweep tests, the substrate was clamped at both ends, where a force of $1 \mathrm{~N}$, a frequency of $1 \mathrm{~Hz}$, a ramp rate of $5{ }^{\circ} \mathrm{C} / \mathrm{min}$, in a temperature range of $30{ }^{\circ} \mathrm{C}-130{ }^{\circ} \mathrm{C}$ was selected. In these tests, $E^{\prime}$ is the storage modulus, the elastic component that measures the energy stored during one oscillation cycle and which is related to the sample stiffness; $E^{\prime \prime}$ is the loss modulus, the viscous component that measures the mechanical energy dissipated through molecular motion in an oscillation cycle; and $\tan \delta$ is the relationship between the elastic and inelastic components (phase lag referred to as loss tangent) that arises from any of the several molecular-level lossy processes such as entanglement, slip or friction between the monomers. Consequently, $\tan \delta$ has higher values for amorphous polymers and lower values for greater ordering polymers $[70,76]$.

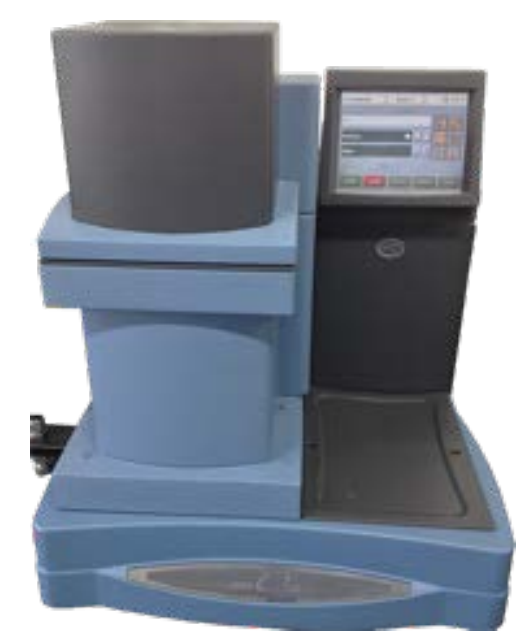

Figure 12. Q800 analyzer, TA Instruments Inc., located in Parque Tecnológico, Universidad Industrial de Santander, Piedecuesta, Colombia.

3.6.6. Differential scanning calorimetry and thermogravimetric analysis. The analysis of the thermal behavior using DSC and TGA was carried out employing an STA 449 F5 J upiter system operated under a nitrogen atmosphere (Figure 13). Samples were analyzed between $32{ }^{\circ} \mathrm{C}$ and $100{ }^{\circ} \mathrm{C}$ with a heating rate of $10^{\circ} \mathrm{C} / \mathrm{min}$, to determine their glass transition temperatures and crystallographic properties.

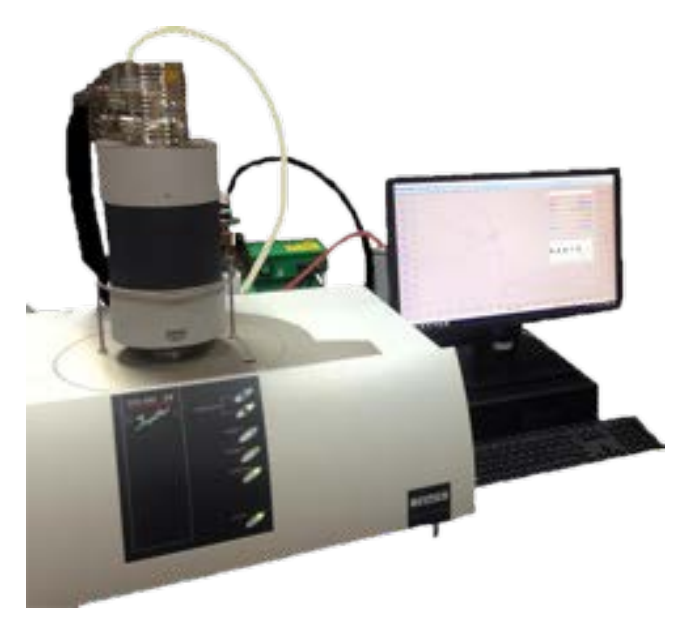

Figure 13. STA 449 F5 J upiter system, located in Escuela de Química, Universidad Industrial de Santander, Bucaramanga, Colombia. 
3.6.7. Raman spectroscopy. The characterization by Raman spectroscopy was performed to determine the vibrations and bands of the species present on the surface of the substrates. The Raman spectra were acquired using the confocal spectrometer LabRam HR Evolution Scientific HORIBA, which is equipped with a $532 \mathrm{~nm}$ laser (Figure 14). All Raman spectra we obtained with a grating of $600 \mathrm{~g} / \mathrm{mm}$ (slit aperture), 50X and 100X microscope objectives, $20 \mathrm{~mW}$ and $15 \mathrm{~mW}$ laser power, $6 \mathrm{~s}$ and $8 \mathrm{~s}$ acquisition times, according to substrate type. Accordingly, each sample was scanned in the range of $25 \mathrm{~cm}^{-1}-4000 \mathrm{~cm}^{-1}$. LabSpec 6 software Horiba Scientific was used for Raman spectra acquisition and analysis. Additionally, in order to better identify Raman spectra peaks, every spectrum was submitted to pretreatment of smoothed with the purpose of removing noise while preserving the resolution of the signal.

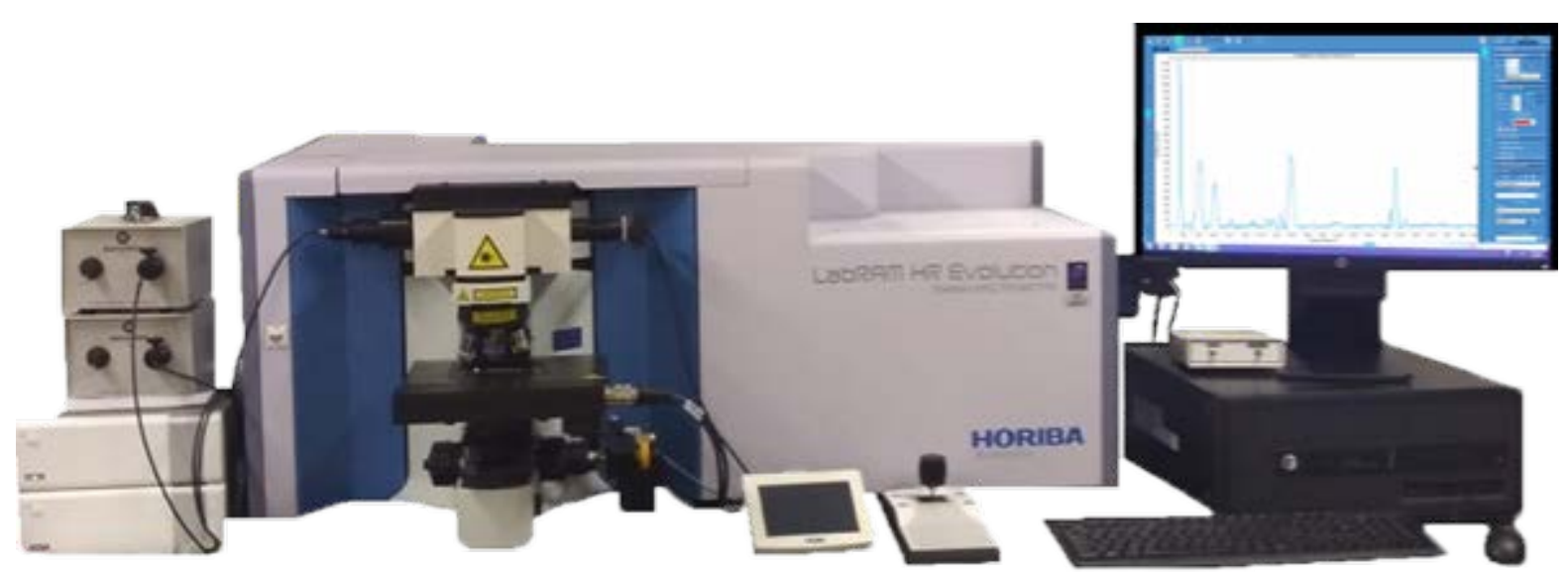

Figure 14. Confocal spectrometer LabRam HR Evolution Scientific HORIBA, located in Facultad de Minas, Universidad Nacional de Colombia, Medellín, Colombia.

3.6.8. Fourier-transformed infrared. The FTIR spectra were obtained by the attenuated total reflection (ATR) technique in the Nicolet iS50 Spectrometer Thermo Fisher Scientific (Figure 15). The spectra were analyzed in terms of transmittance in a wavenumber range of $400 \mathrm{~cm}^{-1}-4000 \mathrm{~cm}^{-1}$ using a resolution of $4 \mathrm{~cm}^{-1}$ and an optical velocity of $0.1581 \mathrm{~cm} / \mathrm{s}$. This analysis was used to determine the absorption bands of the organic functional groups on the surface of the substrates.

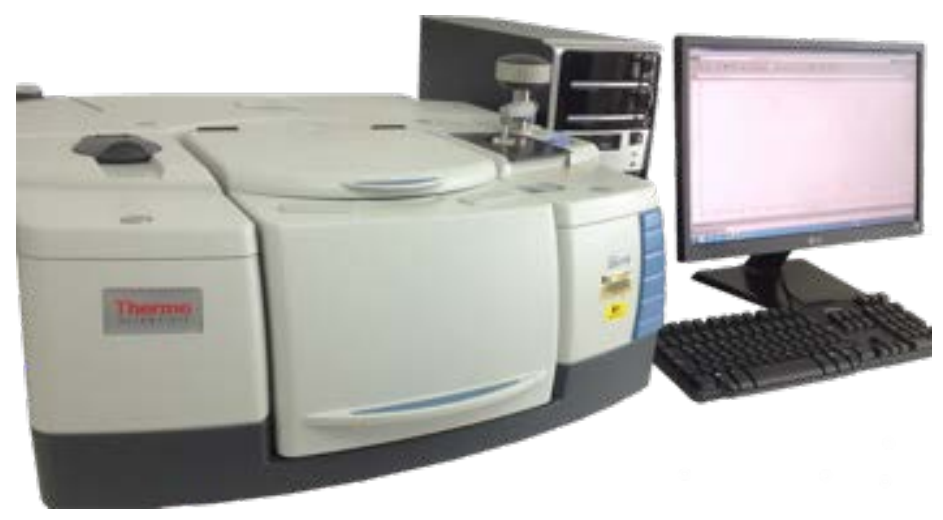

Figure 15. Nicolet iS50 Spectrometer Thermo Fisher Scientific, located in Parque Tecnológico, Universidad Industrial de Santander, Piedecuesta, Colombia. 
3.6.9. X-ray diffraction. XRD patterns were acquired in the powder diffractometer Bruker model D8 Advance with DaVinci geometry under the following conditions: a LynxEye linear detector, $40 \mathrm{kV}$ voltage, $0.6 \mathrm{~mm}$ divergence gap, $0.02035^{\circ}$ step, $0.6 \mathrm{~s}$ per step, and a range of $3.5^{\circ}-70^{\circ}$ (Figure 16). The qualitative analysis of the phases was performed through the comparison of the experimental XRD patterns with the database PDF-2 (2014) of the international centre for diffraction data (ICDD).

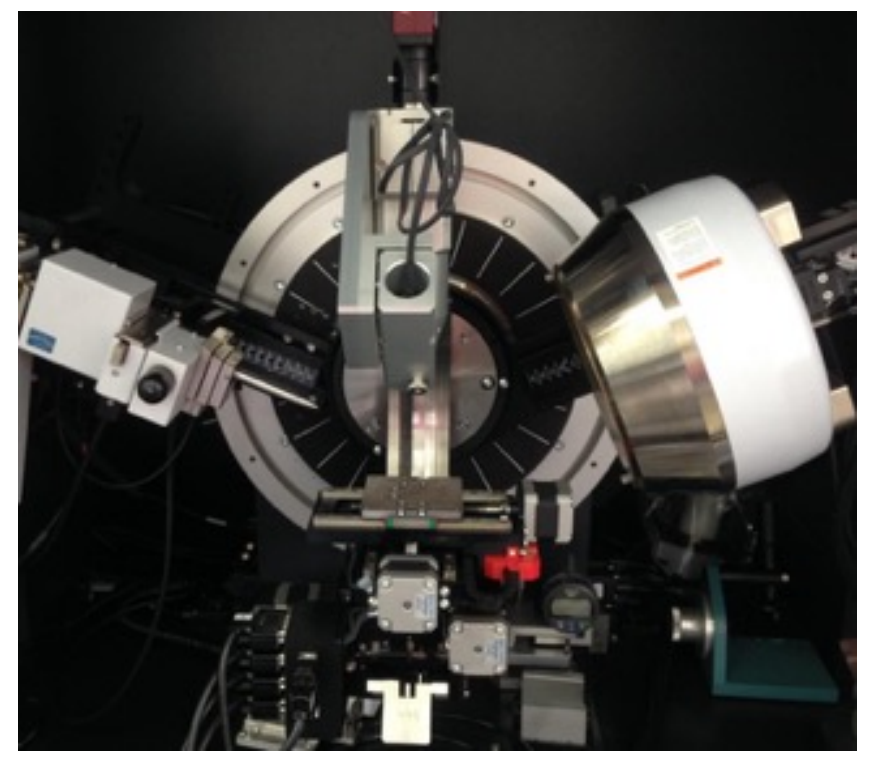

Figure 16. Powder diffractometer Bruker model D8 Advance with DaVinci geometry, located in Parque Tecnológico, Universidad Industrial de Santander, Piedecuesta, Colombia.

3.6.10. Microscopy optic. Images of the textured surfaces were acquired by optical microscopy with a 10X lens on the Olympus DSX500 microscope. DSX-BSW 2.1.4 software (Olympus Corporation) was used in the optics microscopy for image acquisition and analysis. The measure of the surfaces, coated and uncoated, reconstructed digitally were obtained with the motorized focus to a resolution of $0.01 \mu \mathrm{m}$ and accuracy $\mathrm{X}-\mathrm{Y}= \pm 3 \%$ (Figure 17). This method helps us to quantify, validate and guarantee the quality of the external surfaces of any object manufactured by SLA technique.

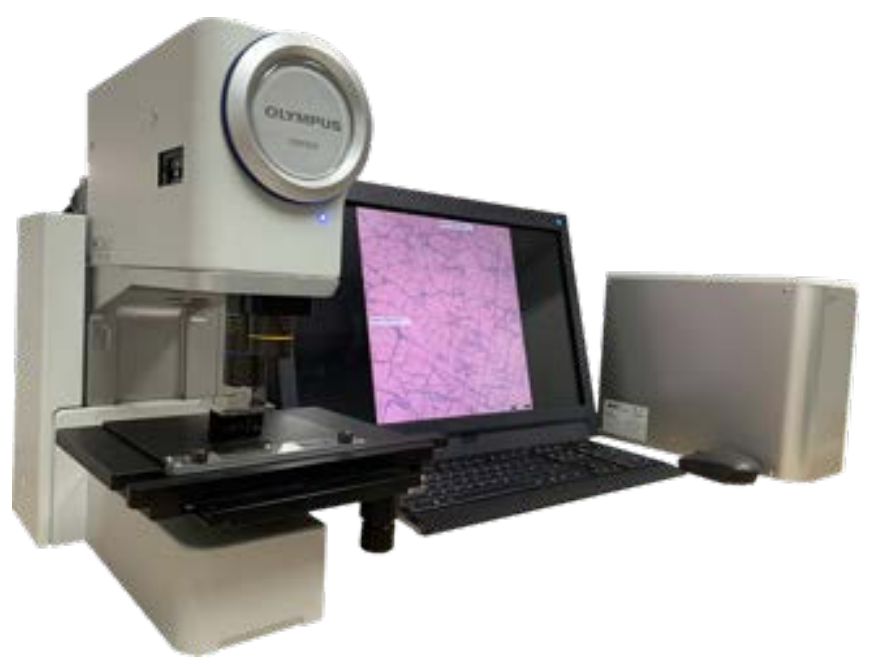

Figure 17. Olympus DSX500 microscope, located in Laboratorio de Desarrollo de Productos, Universidad Politécnica de Madrid, Madrid, Spain. 


\section{Metallic Nanofillers Results and Discussions}

This section presents main surface and bulk characterization results of substrates and probes mass-functionalized or reinforced with copper nanowires (Cu NWs), copper nanowires and nanoparticles (CU NWs+NPs) and copper nickel nanowires ( $\mathrm{Cu} \mathrm{Ni} \mathrm{NWs),} \mathrm{as} \mathrm{compared} \mathrm{with} \mathrm{the}$ pure resin specimens. A versatile set of analytical techniques is used to promote a systematic research and provide characterization results of morphological, mechanical, thermal, viscoelastic and structural properties of the substrates and samples manufactured by laser stereolithography.

\subsection{Cost Considerations}

The manufacturing time of 3 cylindrical specimens or 3 substrates for tensile testing, pure resin or with nanofillers, is approximately $17 \mathrm{~min}$ and $22 \mathrm{~min}$, respectively. Then, each layer, with a surface area of $3.6 \mathrm{~cm}^{2}$ by substrate cylindrical or $5.1 \mathrm{~cm}^{2}$ by specimen for tensile testing, is fabricated in approximately 11 seconds and 14 seconds, respectively. Table 3 reports the cost approximate of materials used for each cylindrical substrate or tensile testing manufactured.

Table 3. Approximate cost of some materials.

\begin{tabular}{lc}
\hline \multicolumn{1}{c}{ Materials } & Cost \\
\hline Liquid resin & $0.14(€ / \mathrm{ml})$ \\
Cu NWs/ Cu NNWs+Nps/ Cu Ni NWs & $0.45(€ / \mathrm{mg})^{*}$ \\
\hline * This cost only considers the chemicals used for synthesis and \\
washing of the nanofillers.
\end{tabular}

Manufacturing cost a functional device with nanofillers depends on the percentage and nanofiller type added, these costs are presented in Table 4 and Table 5. This cost calculation only considered the chemicals used for the synthesis and washing of the $\mathrm{Cu} N W s, \mathrm{Cu}$ NNWs+Nps, and Cu Ni NWs, and not the energy, inert gas, and other supplies used during the manufacturing.

Table 4. Approximate cost of manufacturing a cylindrical device.

\begin{tabular}{lccc}
\hline Nanofiller type & $\begin{array}{c}\text { Nanofiller solution percentage } \\
(\% \mathbf{w} / \mathbf{w})\end{array}$ & $\begin{array}{c}\text { Nanofiller percentage } \\
(\% \mathbf{w} / \mathbf{w})\end{array}$ & $\begin{array}{c}\text { Cost } \\
(€)\end{array}$ \\
\hline Pure resin & 0.0 & 0.000 & 0.14 \\
\hline \multirow{3}{*}{ Cu NWs } & 5.1 & 0.008 & 0.17 \\
& 10.0 & 0.017 & 0.21 \\
& 15.4 & 0.170 & 0.91 \\
Cu NWs+NPs & 15.0 & 0.260 & 1.38 \\
\hline \multirow{2}{*}{ CuNi NWs } & 17.3 & 0.340 & 1.77 \\
& 20.7 & 0.360 & 1.88 \\
& 10.0 & 0.420 & 2.20 \\
\hline
\end{tabular}


Table 5. Approximate cost of manufacturing a test specimen.

\begin{tabular}{lccc}
\hline Nanofiller type & $\begin{array}{c}\text { Nanofiller solution percentage } \\
(\% \mathbf{w} / \mathbf{w})\end{array}$ & $\begin{array}{c}\text { Nanofiller percentage } \\
(\% \mathbf{w} / \mathbf{w})\end{array}$ & $\begin{array}{c}\text { Cost } \\
(€)\end{array}$ \\
\hline Pure resin & 0.0 & 0.000 & 0.21 \\
\hline \multirow{3}{*}{ Cu NWs } & 5.1 & 0.008 & 0.27 \\
& 10.0 & 0.017 & 0.32 \\
& 15.4 & 0.170 & 0.91 \\
Cu NWs+NPs & 15.0 & 0.260 & 1.38 \\
\hline \multirow{2}{*}{ CuNi NWs } & 17.3 & 0.340 & 2.68 \\
\hline
\end{tabular}

\subsection{Morphological Properties}

Morphological properties of specimens manufactured in pure resin and with nanofillers of $\mathrm{Cu}$ NWS and CUNi NWs embedded in the polymeric-matrix were analyzed through SEM, EDS, and computed tomography scan (CT-Scan) techniques, presented to following. Partial results of the current section have been already presented in [70] and have been submitted for evaluation to Polymers (peer-reviewed open access journal).

4.2.1. Scanning electron microscopy and energy-dispersive $x$-ray spectroscopy. The back-scattered electrons (BSE) micrographs in Figure 18 demonstrate the flat image that differentiates the composition of the Cu NWs (Figure 18(a) to Figure 18(d)), Cu NWs+NPs (Figure 18(e)), and CuNi NWs (Figure 18(f) to Figure 18(h)) embedded in the photopolymerized resin due of the difference of emission of the electrons of the respective species according to their atomic number (the heavier are brighter, and the light are darker). Then, is observed the content of the nanofillers nanowires is well below the percolation threshold. Thus, the NWs nanofillers are expected to influence the thermo-mechanical properties $[70,77,78]$ of the polymer matrix but not its electrical properties $[70,79]$. In addition, according to the laser direction that polymerizes the resin during SLA printing, the surface roughness can vary significantly. Adding the nanowires and a homogenous filler distribution should be pursued to achieve adequate dispersion for adequate manufacturability and functionalization (i.e., change of the mechanical and electromagnetic properties) [70]. EDS analysis gives the elemental chemical compositions and the atomic concentrations of the surfaces pure resin (Figure 18, spectrum 5) and with NWs (Figure 18, spectra 1 to 4 ).

The EDS data are summarized in Table 6 . No Cu or Ni was detected in the polymer matrix (spectrum 5), which means that the NWs were not degraded during the mixing and the SLA process. Moreover, there are differences in the contents of $\mathrm{Cu}$ and $\mathrm{Ni}$. Consequently, thorough mixing of the NWs in the resin is required to average these differences and obtain homogeneous properties of the final composite. 


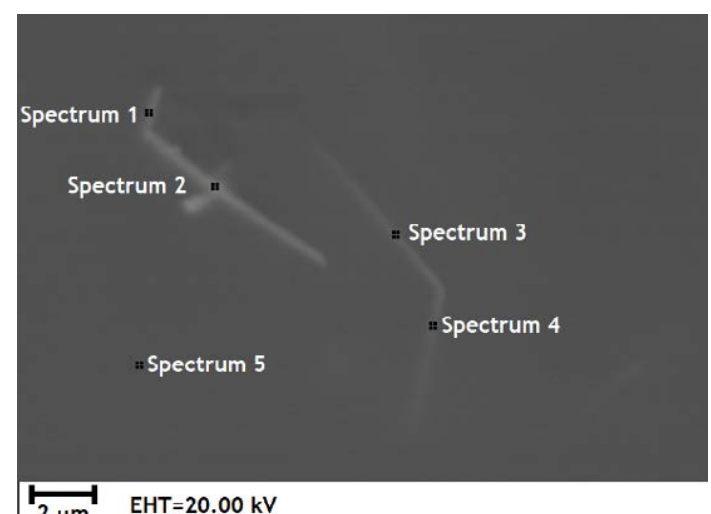

(a)

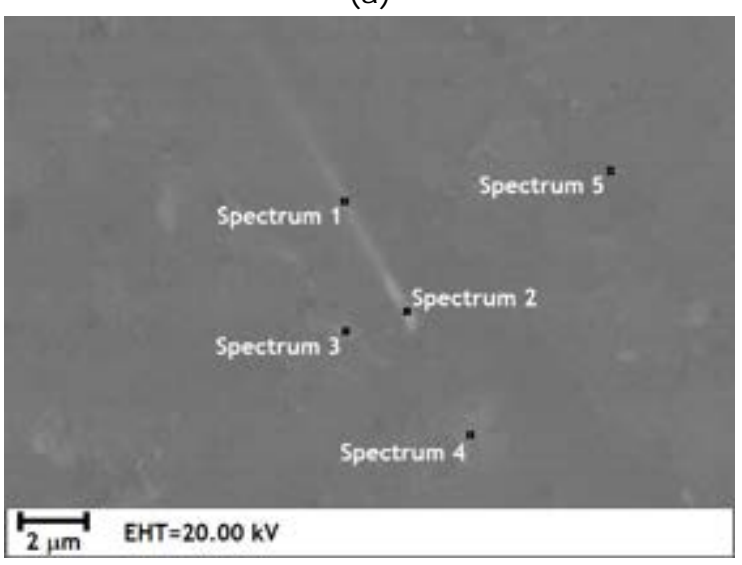

(c)

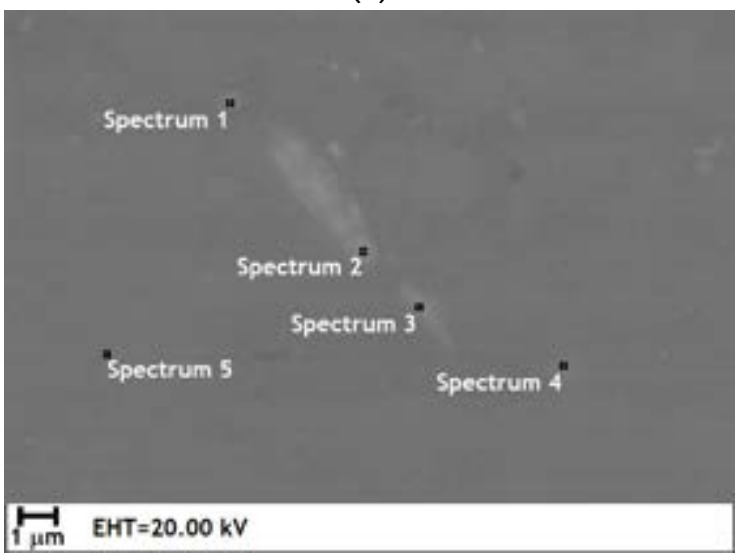

(e)

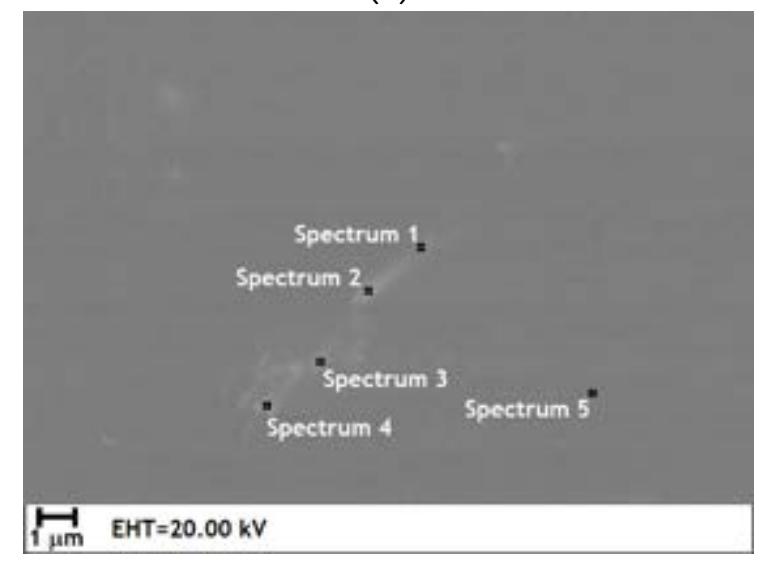

(g)

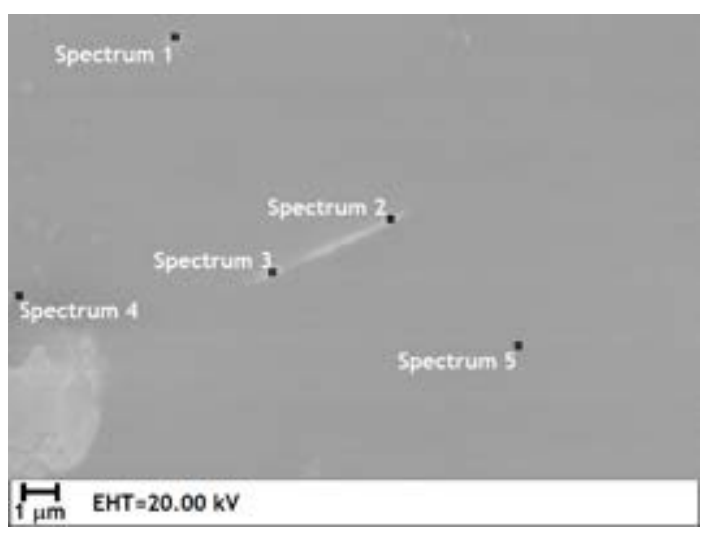

(b)

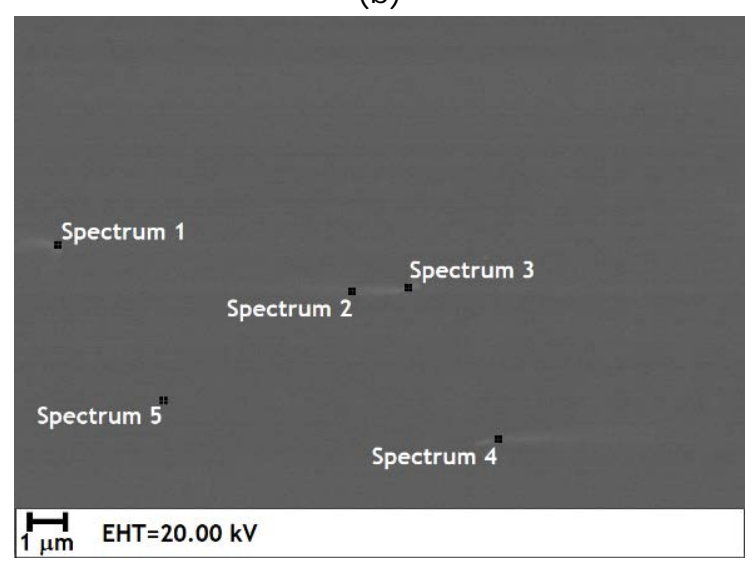

(d)

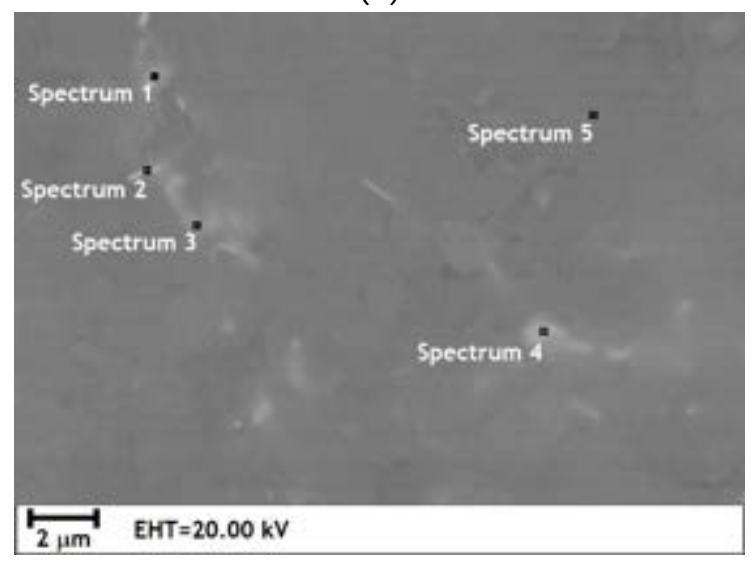

(f)

Figure 18. BSE Micrographs on the surface of a substrate with $\mathrm{Cu} N W s$ at $0.008 \% \mathrm{w} / \mathrm{w}$ (a), $0.017 \% \mathrm{w} / \mathrm{w}$ (b), $0.17 \% \mathrm{w} / \mathrm{w}$ (c), and $0.26 \% \mathrm{w} / \mathrm{w}$ (d); Cu NWs+NPs at $0.34 \% \mathrm{w} / \mathrm{w}$ (e); CuNi NWs at $0.36 \% \mathrm{w} / \mathrm{w}$ (f), and $0.42 \% \mathrm{w} / \mathrm{w}$ (g). 
Table 6. Detected elements in the substrates surface manufactured in pure resin and with Cu NWs, Cu NWs+NPs, and CuNi NWs.

\begin{tabular}{|c|c|c|c|c|c|c|c|c|c|c|}
\hline \multicolumn{2}{|c|}{ BSE Micrographs } & \multicolumn{3}{|c|}{ Element (At\%) } & \multicolumn{2}{|c|}{ BSE Micrographs } & \multicolumn{4}{|c|}{ Element (At $\%)$} \\
\hline Figure 18 & Spectrum & C k & $0 \mathrm{k}$ & Cu k & Figure 18 & Spectrum & C k & $0 \mathrm{k}$ & Cu k & Ni k \\
\hline \multirow{5}{*}{ (a) } & 1 & 80.9 & 17.5 & 1.5 & \multirow{5}{*}{ (e) } & 1 & 83.6 & 16.2 & 0.2 & - \\
\hline & 2 & 80.6 & 18.4 & 1.2 & & 2 & 86.1 & 13.7 & 0.2 & - \\
\hline & 3 & 77.3 & 21.8 & 0.9 & & 3 & 86.8 & 13.0 & 0.2 & - \\
\hline & 4 & 81.0 & 18.6 & 0.4 & & 4 & 87.6 & 12.1 & 0.3 & - \\
\hline & 5 & 82.3 & 17.7 & - & & 5 & 86.3 & 13.7 & - & - \\
\hline \multirow{5}{*}{ (b) } & 1 & 78.5 & 20.7 & 0.8 & \multirow{5}{*}{ (f) } & 1 & 84.5 & 13.4 & 0.8 & 1.3 \\
\hline & 2 & 80.9 & 16.4 & 2.7 & & 2 & 85.0 & 12.1 & 2.0 & 0.9 \\
\hline & 3 & 82.2 & 16.0 & 1.8 & & 3 & 87.1 & 11.1 & 1.1 & 0.7 \\
\hline & 4 & 76.6 & 23.3 & 0.2 & & 4 & 84.5 & 12.8 & 1.7 & 1.0 \\
\hline & 5 & 83.8 & 16.2 & - & & 5 & 87.3 & 12.7 & - & - \\
\hline \multirow{5}{*}{ (c) } & 1 & 88.3 & 10.0 & 1.7 & \multirow{5}{*}{ (g) } & 1 & 86.0 & 11.3 & 1.9 & 0.8 \\
\hline & 2 & 85.8 & 12.4 & 1.8 & & 2 & 84.8 & 12.7 & 2.0 & 0.5 \\
\hline & 3 & 82.9 & 15.9 & 1.2 & & 3 & 85.5 & 10.5 & 3.2 & 0.9 \\
\hline & 4 & 89.9 & 8.9 & 1.2 & & 4 & 86.5 & 9.7 & 2.9 & 0.9 \\
\hline & 5 & 84.4 & 15.6 & - & & 5 & 83.5 & 16.5 & - & - \\
\hline \multirow{5}{*}{ (d) } & 1 & 83.6 & 15.8 & 0.6 & & & & & & \\
\hline & 2 & 91.0 & 7.9 & 1.1 & & & & & & \\
\hline & 3 & 83.5 & 16.0 & 0.5 & & & & & & \\
\hline & 4 & 90.0 & 9.7 & 0.3 & & & & & & \\
\hline & 5 & 89.5 & 10.5 & - & & & & & & \\
\hline
\end{tabular}

4.2.2. Computed tomography scan. X-ray computed tomography $(C T)$ is used to capture the 3D distribution of the nanofillers in the bulk of substrates manufactured in photoreactive resin by 3D photopolymerization, as shown in Figure 19 to Figure 21. The brightness of X-ray CT images depends on the amount of X-ray penetration, which allows the identification of several nanofillers randomly distributed into the bulk because, as the density of the specimens increases, the amount of X-ray penetration decreases, resulting in a brighter image [70,80-82]. In the substrate section analyzed, the bulk distribution approximate of nanofillers are identified and are reported in Table 7. From Figure 19(b), Figure 19(d), Figure 19(f), Figure 20(b), Figure 21(b) and Figure 21(d), fillers form dispersed aggregates well, which can explain the absence of percolation of the nanofillers. The aggregation phenomenon could be due to the resin viscosity or to the presence of polar groups on the polymeric chains [70,80-82].

Table 7. Nanofillers identified in the bulk of the substrates.

\begin{tabular}{lccc}
\hline Nanofiller type & $\begin{array}{c}\text { Nanofiller percentage } \\
(\mathbf{\%} \mathbf{~} / \mathbf{w})\end{array}$ & $\begin{array}{c}\text { Volume analyzed } \\
\left(\mathbf{m m}^{\mathbf{3}} \mathbf{)}\right.\end{array}$ & $\begin{array}{c}\text { Nanofillers identified } \\
\mathbf{( \% )}\end{array}$ \\
\hline \multirow{2}{*}{ Cu NWs } & 0.017 & 55.0 & 0.004 \\
& 0.170 & 56.8 & 0.022 \\
\hline Cu NWs+NPs & 0.260 & 75.6 & 0.100 \\
\hline \multirow{2}{*}{ CuNi NWs } & 0.340 & 75.9 & 0.980 \\
\hline
\end{tabular}




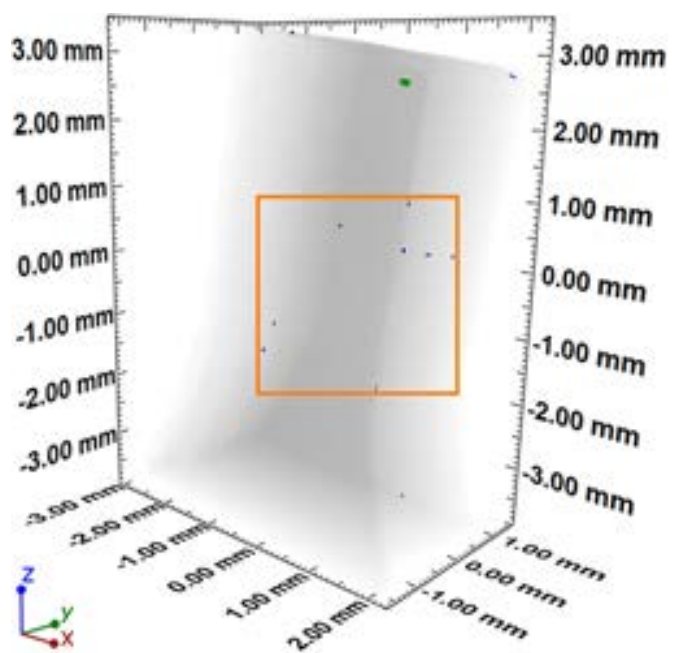

(a)

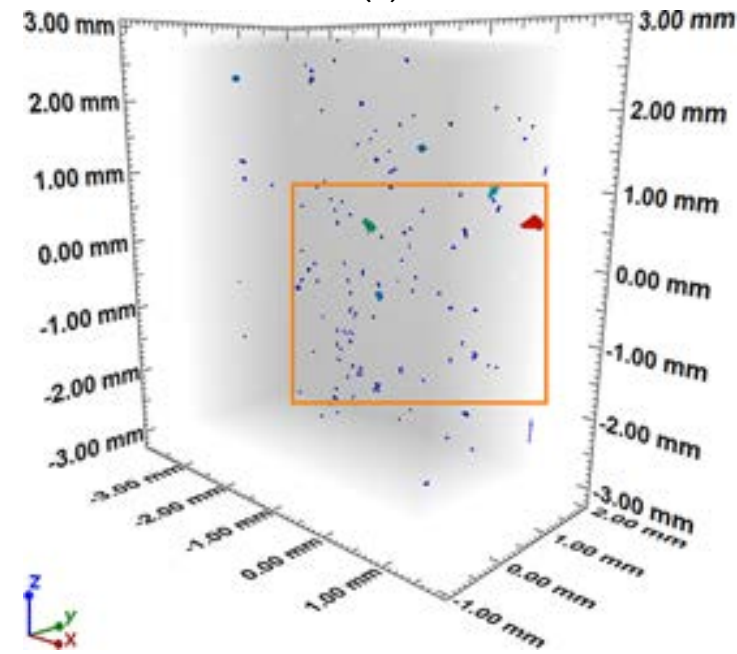

(c)

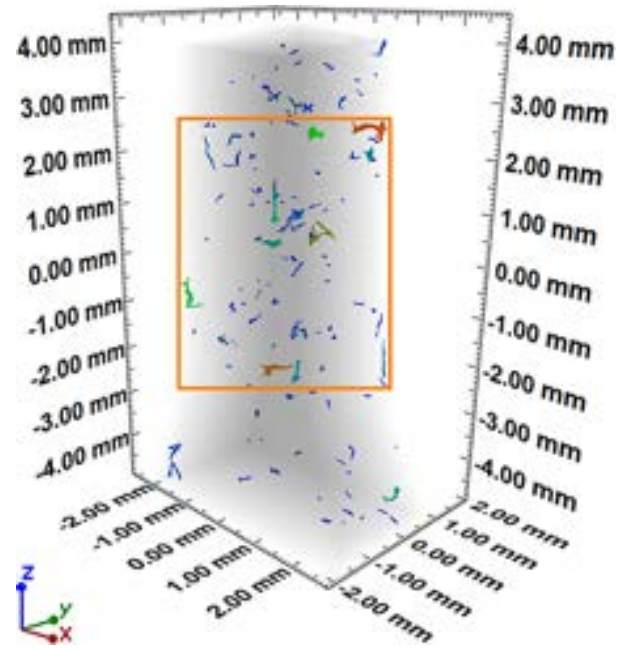

(e)

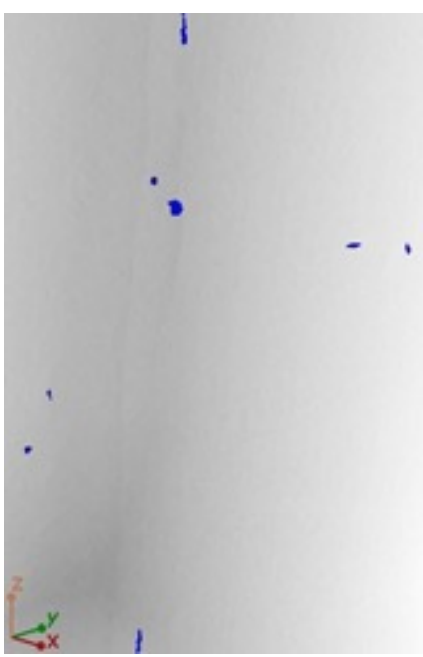

(b)

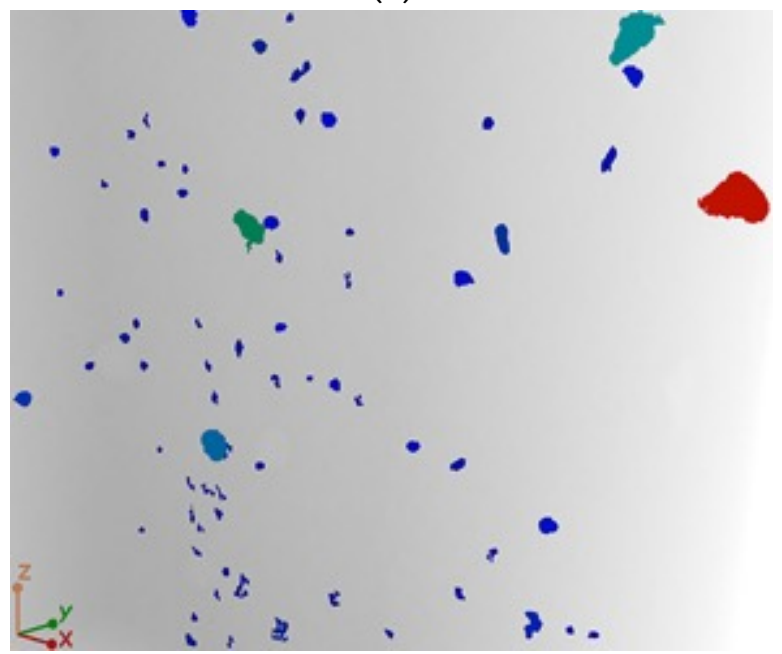

(d)

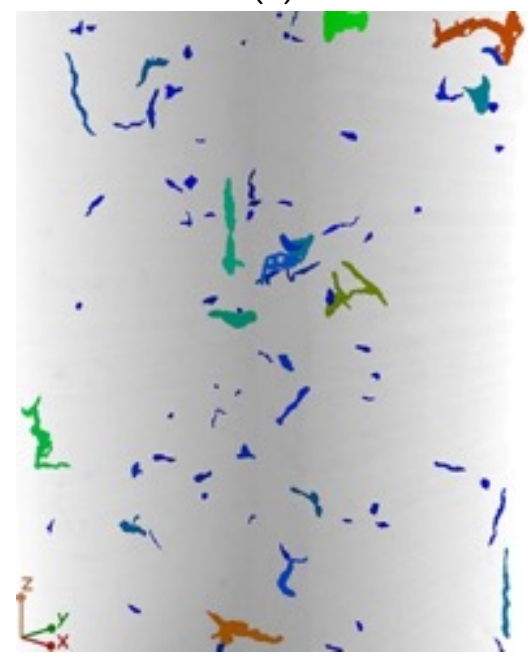

(f)

Figure 19. 3D rendering of the substrate section that shows the nanofillers distribution of $\mathrm{Cu}$ NWs embedded at $0.017 \% \mathrm{w} / \mathrm{w}$ (a) and (b), $0.17 \% \mathrm{w} / \mathrm{w}$ (c) and (d), $0.26 \% \mathrm{w} / \mathrm{w}$ (e) and (f). 


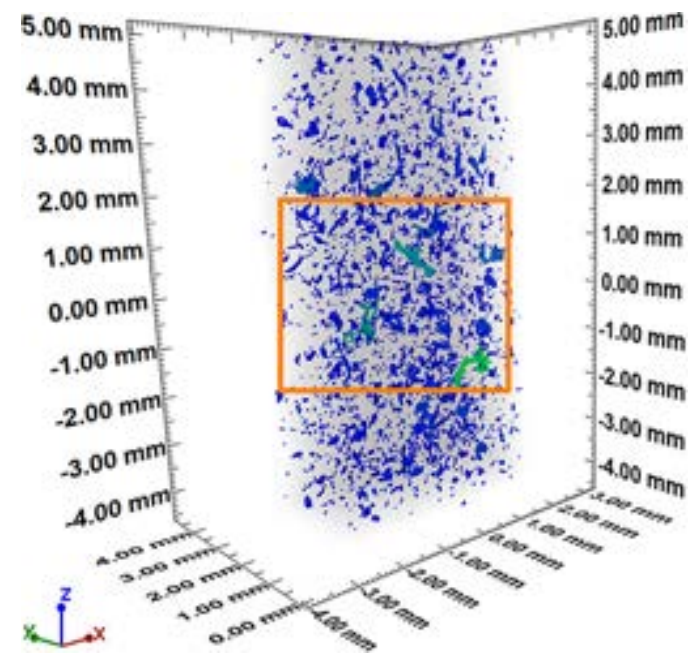

(a)

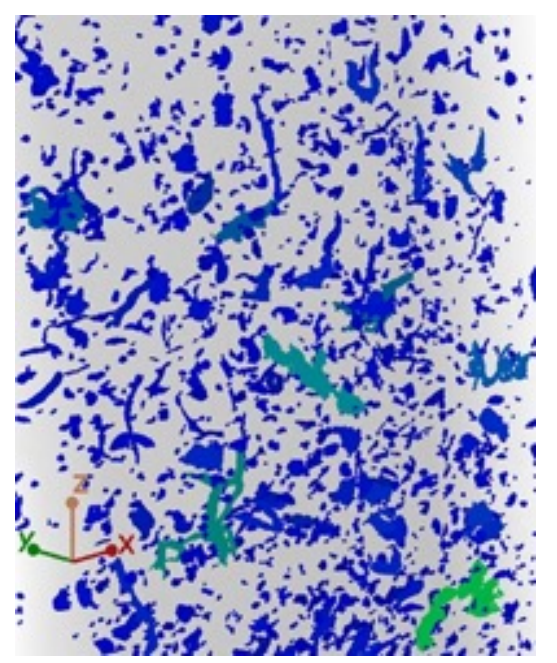

(b)

Figure 20. $3 \mathrm{D}$ rendering of the substrate section that shows the nanofillers distribution of $\mathrm{Cu}$ NWs+NPs embedded at $0.34 \% \mathrm{w} / \mathrm{w}$ (a), and (b).

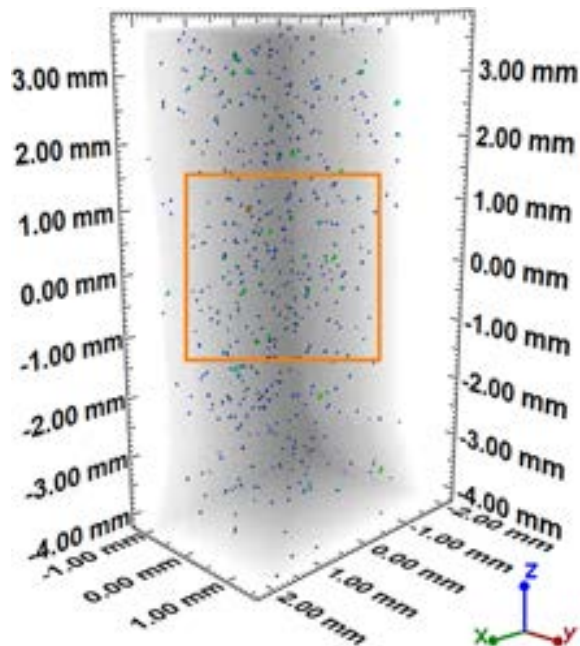

(a)

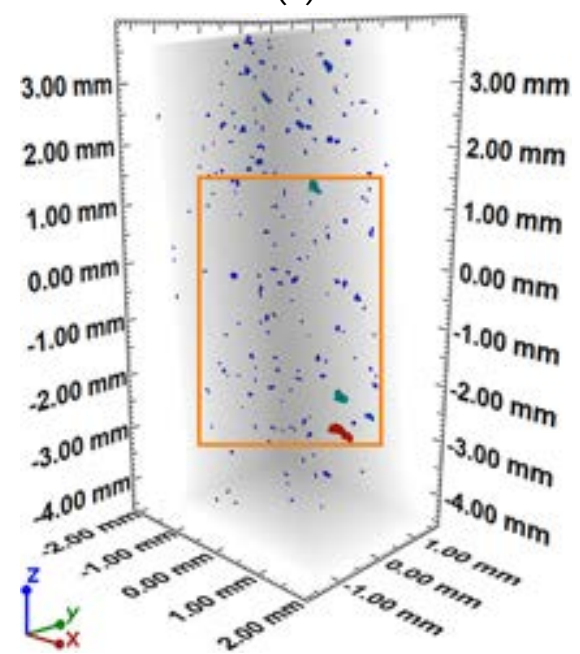

(c)

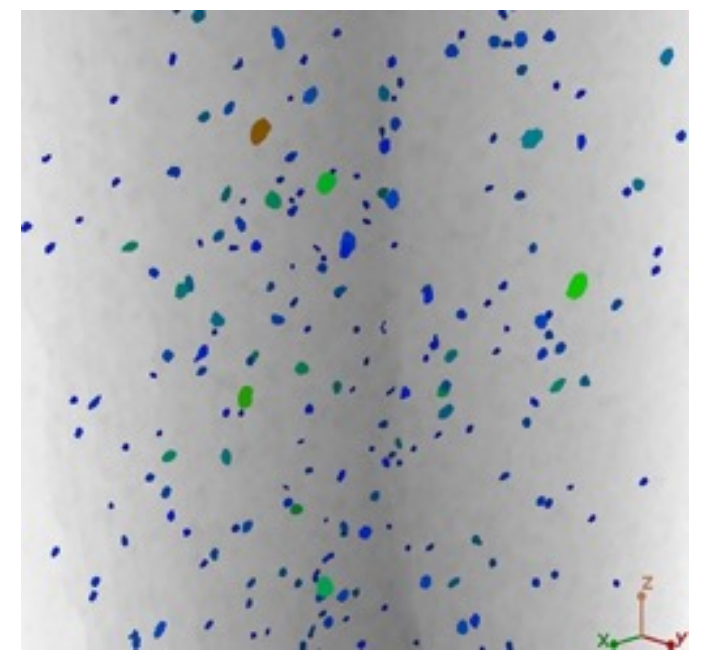

(b)

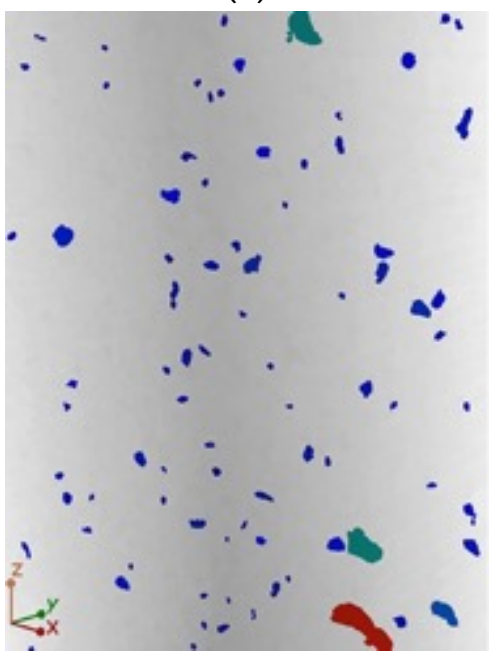

(d)

Figure 21. 3D rendering of the substrate section that shows the nanofillers distribution of CuNi NWs at $0.36 \% \mathrm{w} / \mathrm{w}$ (a) and (b), $0.42 \% \mathrm{w} / \mathrm{w}$ (c) and (d). 


\subsection{Mechanical Performance}

Mechanical performance of specimens manufactured in pure resin and with $\mathrm{Cu}$ NWS and CuNi NWs embedded in the polymeric-matrix were analyzed through tensile testing and Instrumented indentation techniques, as shows to following. Partial results of the current section have been already presented in [70] and have been submitted for evaluation to Polymers (peer-reviewed open access journal).

4.3.1. Tensile testing. Representative load-displacement curves for the substrates manufactured using the photoreactive commercial resin, both pure resin and with nanofillers used for mass-functionalization, are provided in Figure 22.

Figure 22(a) it can be observed that the curves pure resin and with $\mathrm{Cu} N W \mathrm{~s}$ at $0.008 \% \mathrm{w} / \mathrm{w}$ leads to a brittle behavior, while the curve of the specimen at $0.017 \% \mathrm{w} / \mathrm{w}$ have ductile behavior. Figures 22(a) and Figure 22(b) show that the tensile strength (TS) significantly increases in the specimen with Cu NWs at $0.008 \% \mathrm{w} / \mathrm{w}$.

TS values are $21.5 \mathrm{MPa}, 20.3 \mathrm{MPa}$ and $19.8 \mathrm{MPa}$ for the specimen with Cu NWs contents of $0.008 \% \mathrm{w} / \mathrm{w}, 0.017 \% \mathrm{w} / \mathrm{w}$ and pure resin, respectively. For these samples, corresponding Young's moduli $(E)$ are $260.9 \mathrm{MPa}, 300.4 \mathrm{MPa}$ and $238.9 \mathrm{MPa}$ as shown in Figure 22(b), respectively. The decrease in tensile strength above a Cu NWs content of $0.008 \% \mathrm{w} / \mathrm{w}$ may be related to the decrease in volume and mass when the content of $\mathrm{Cu}$ NWs increases, due to the IPA evaporation during the cured and post-cured process. It could also be attributed to a decrease in the interfacial interactions between the polymeric matrix and fillers, due to solubility parameter that determined the substances affinity among the dissolvent and polymer, which do not differ in more than one or two units [83,84].

In addition, the presence of Cu NWs may also affect the polymerization degree of the final device producing a plastification effect for the higher nanowires contents, then, should always be considered in photopolymerization-based additive manufacturing techniques. Furthermore, during the specimens' strain, it is determined that the molecular structure of the substrates pure resin was the one capable of absorbing more energy, while the substrate containing $\mathrm{Cu} N W \mathrm{~s}$ at $0.008 \% \mathrm{w} / \mathrm{w}$ proved the worst in terms of energy absorbance. Further, the specimens with $\mathrm{Cu} N W \mathrm{~N}$ at $0.008 \% \mathrm{w} / \mathrm{w}$ and $0.017 \% \mathrm{w} / \mathrm{w}$ showed a more brittle fracture, when compared to the reference substrate.

Figure 22(c) shows that the material in pure resin (regardless of post-curing time) has a brittle behavior, while the material functionalized with $\mathrm{Cu}$ NWs at $0.26 \% \mathrm{w} / \mathrm{w}$ and postcured during $14 \mathrm{~min}$ and $28 \mathrm{~min}$ presents a ductile performance. Figures 22(c) and Figure 22(d) show that the tensile strength significantly increases with the post-cured in the specimens' pure resin but have a slight decrease of tensile strength is demonstrated in the specimens with nanowires.

TS values are 45.4 MPa, 42.6 $\mathrm{MPa}, 16.5 \mathrm{MPa}$ and $15.2 \mathrm{MPa}$ for the specimens' pure resin post-cured during $28 \mathrm{~min}$, and $14 \mathrm{~min}$; with $\mathrm{Cu}$ NWs at $0.26 \% \mathrm{w} / \mathrm{w}$ post-cured during $14 \mathrm{~min}$ and $28 \mathrm{~min}$, respectively. For these substrates, corresponding $E$ moduli are $667.0 \mathrm{MPa}$, 653.1 MPa, 227. MPa, and 186.5 MPa as shown in Figure 22(d), respectively. The decrease in tensile strength with $\mathrm{Cu}$ NWs content at $0.26 \% \mathrm{w} / \mathrm{w}$ may be attributed to a decrease in the interfacial interactions between the polymeric matrix and fillers, due to solubility parameter 
that determined the substances affinity among the dissolvent and polymer, which do not differ in more than one or two units [83,84].

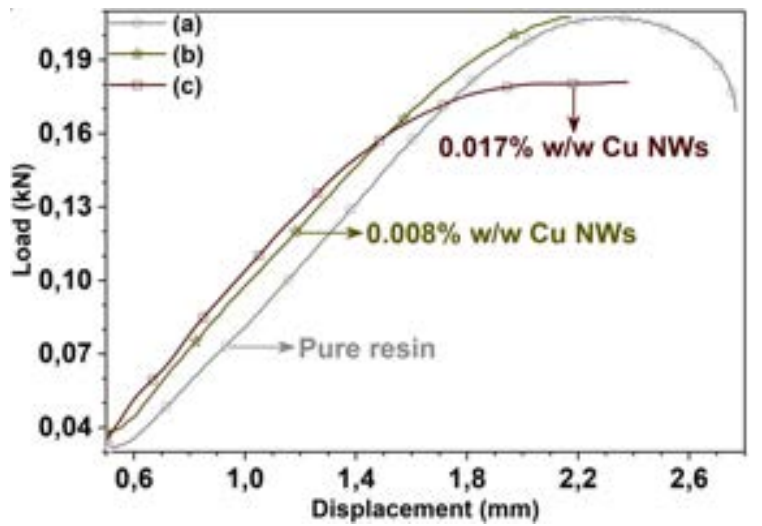

(a)

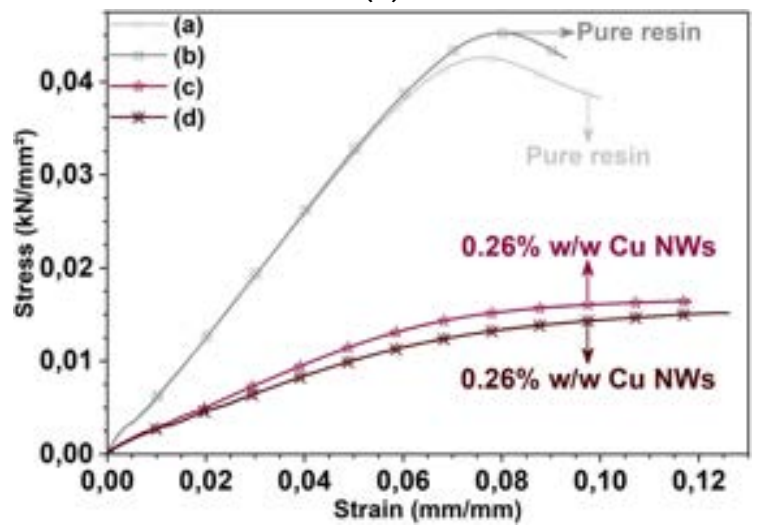

(c)

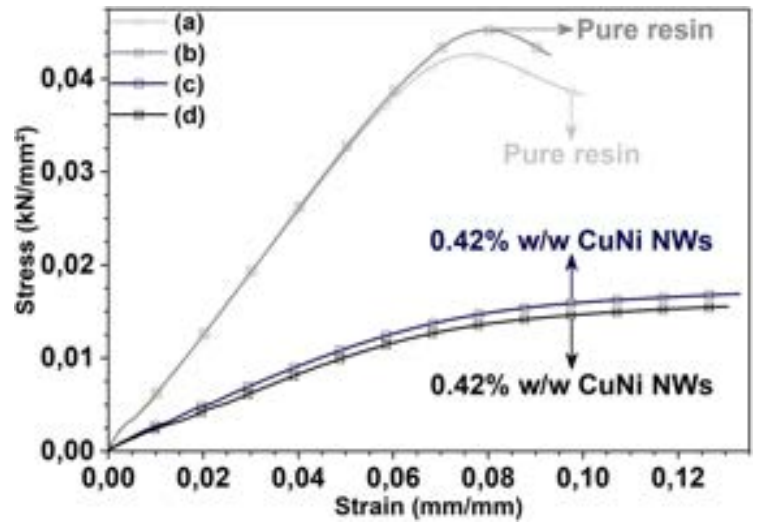

(e)

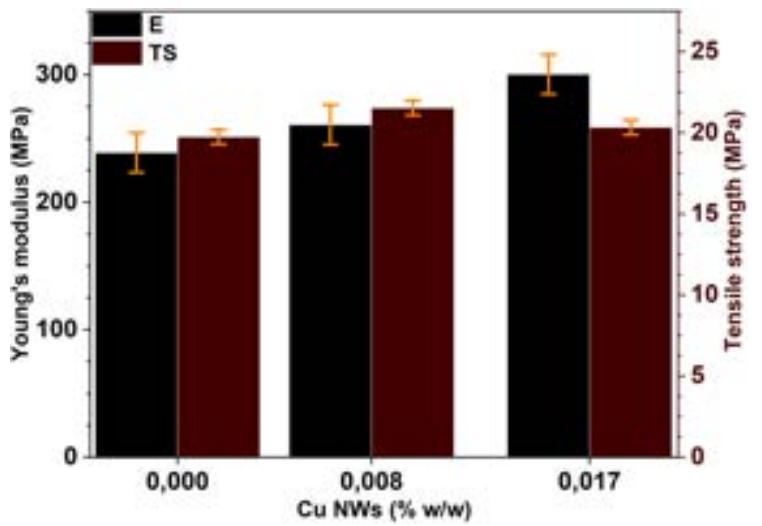

(b)

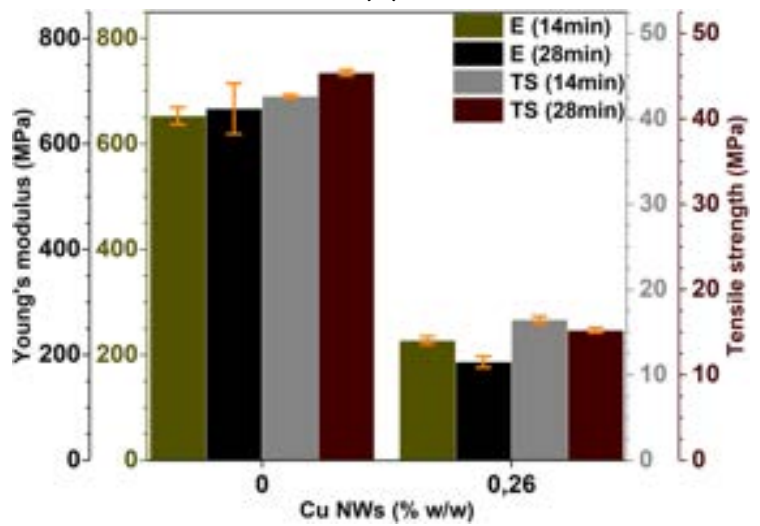

(d)

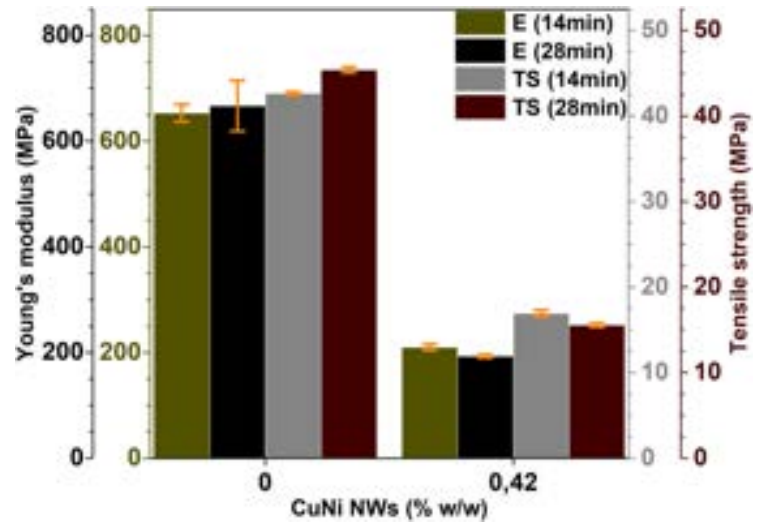

(f)

Figure 22. Representative tensile testing curves of specimens' pure resin and with nanowires. (a) load-displacement curves pure resin (o-a), and $\mathrm{Cu}$ NWs embedded at $0.008 \% \mathrm{w} / \mathrm{w}(\mathrm{a}-\mathrm{b})$, and $0.017 \% \mathrm{w} / \mathrm{w}$ ( $\square-\mathrm{C})$; (b) effect of Cu NWs content on $E$ modulus and the TS; (c) stress-strain curves, ( $\circ-a$ and - -b) pure resin, and Cu NWs embedded at $0.26 \% \mathrm{w} / \mathrm{w}$ ( $\mathrm{c}-\mathrm{c}$, and $*-\mathrm{d}$ ); (d) effect of Cu NWs content on $E$ moduli and the TS; (e) stress-strain curves, (o-a and $--b)$ pure resin, and CuNi NWs embedded at $0.42 \% \mathrm{w} / \mathrm{w}$ ( $\square-\mathrm{C}$, and --d); (f) effect of CuNi NWs content on $E$ moduli and the TS.

In consequence, the presence of $\mathrm{Cu}$ NWs may also affect the polymerization degree of the final devices producing a plastification effect when increasing of the nanowires content, which is a parameter, should always be taken into account in photopolymerization-based additive manufacturing techniques. Moreover, during the specimens' strain, is determined 
that the molecular structure of the substrates in pure resin is that absorbs more energy, while the substrates with $\mathrm{Cu}$ NWs at $0.26 \% \mathrm{w} / \mathrm{w}$ proves the worst in terms of energy absorbance. Furthermore, the specimens with $\mathrm{Cu}$ NWs show a more ductile fracture, when compared to the reference specimens which present a brittle fracture.

Figure 22(e) it can be observed that the curves pure resin lead to a brittle behavior, while that curve of the specimen functionalized with CuNi NWs at $0.42 \% \mathrm{w} / \mathrm{w}$ have ductile behavior. Figures 22(e) and Figure 22(f) show that the tensile strength significantly decreases in the specimens with CuNi NWs at $0.42 \% \mathrm{w} / \mathrm{w}$.

$E$ moduli values are 667.0 MPa, 653.1 MPa, 209.9 MPa, and 192.9 MPa for the specimens' pure resin post-cured during $28 \mathrm{~min}$, and $14 \mathrm{~min}$; with CuNi NWs at $0.42 \% \mathrm{w} / \mathrm{w}$ post-cured during $14 \mathrm{~min}$ and $28 \mathrm{~min}$, respectively. For these specimens, corresponding TS is $45.4 \mathrm{MPa}$, 42.6 $\mathrm{MPa}$, 16.9 $\mathrm{MPa}$, and $15.6 \mathrm{MPa}$ as shown in Figure 22(f), respectively. The decrease in tensile strength of the substrates with CuNi NWs content at $0.42 \% \mathrm{w} / \mathrm{w}$, may be attributed to the presence of CuNi NWs that affect the polymerization degree of the final devices, producing a plastification effect when increasing of the nanowires content. So, this parameter should always be considered in photopolymerization-based additive manufacturing techniques. Further, during the specimens' strain, it is determined that the molecular structure of the substrates pure resin was that absorbing more energy in regarding the specimens with CuNi NWs content at $0.42 \% \mathrm{w} / \mathrm{w}$, that proved the worst in energy absorbance terms.

Figure 22(c) and Figure 22(e) show a significant increase in materials ductility due to the addition of NWs. The overall behavior is less brittle. The increase in mechanical performance is attributed to the successful load transfer from the matrix to the nanofillers. Accordingly, is demonstrated that the printed specimens with Cu NWs or CuNi NWs by the SLA technique have good ductility, moreover than the elongation increase by $86.7 \%$, so that leads to a devices' reliability manufactured with these nanowires type.

Figure 23 presents the $E$ modulus as a function of nanofillers concentration and show the mathematical relation obtained of the experimental data. Besides, additions of $\mathrm{Cu} N W s$ to low concentrations have a linear influence on Young's modulus, while higher concentrations lead to a second-order polynomial fit, although, additional tests would be advisable for finetune the proposed fit.

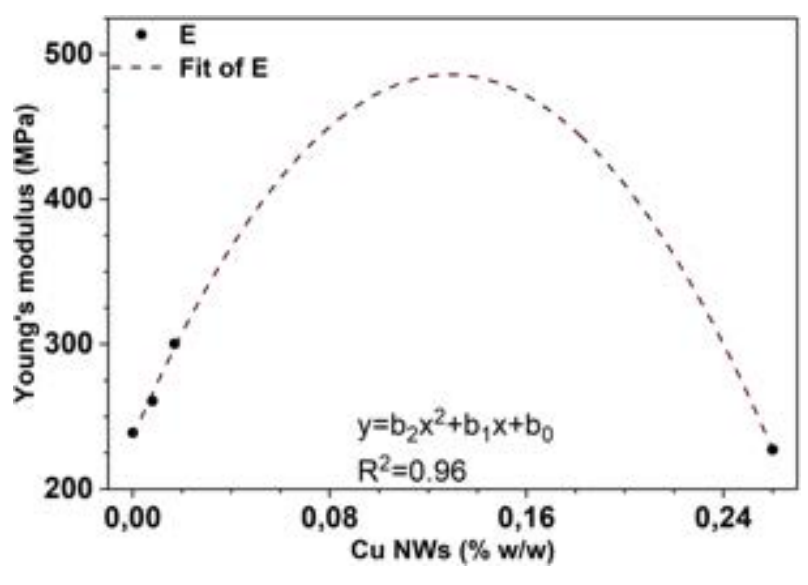

Figure 23. Mathematical relation obtained of experimental data $E$ modulus in function of Cu NWs concentration. 
4.3.2. Instrumented indentation. Figure 24 to Figure 28 highlight the significant increase of $E^{\prime}$ and modulus $H$ when loading the polymeric matrix with Cu NWs (Figure 25, Figure 28(a) and Figure 28(b)), Cu NWs+NPs (Figure 26 and Figure 28(c)), and CuNi NWs (Figure 27 and Figure $28(\mathrm{~d})$ ). The measurement of $E^{\prime}$ modulus and $H$ is represented in Figure 24 to Figure 27 , where variations in the values of the deformation resistance were found.

Figure 28 presents the average values of $E^{\prime}$ modulus and $H$ for the pure resin and for the one loaded with the $0.017 \% \mathrm{w} / \mathrm{w}$ Cu NWs (Figure 28(a)), 0.17\% w/w Cu NWs (Figure 28(b)), $0.34 \% \mathrm{w} / \mathrm{w}, \mathrm{Cu}$ NWs+NPs (Figure 28(c)), and $0.36 \% \mathrm{w} / \mathrm{w}$ CuNi NWs (Figure 28(d)). The increase of $E^{\prime}$ in $133.1 \%, 149.2 \%, 57.3 \%$; and the increase of $H$ in $179.3 \%, 287.7 \%$, and 28.5\% when loading the resin with Cu NWs, Cu NWs+NPs, and CuNi NWs can be attributed to the load transfer. However, for the specimen with Cu NWs at $0.017 \% \mathrm{w} / \mathrm{w}$, the $E^{\prime}$ modulus increased by $106.5 \%$ but $H$ decreased by $18.7 \%$.

In the case of $E^{\prime}$ moduli, the values average acquired in all substrates with the different nanofillers (Figure 25(a), Figure 25(c), Figure 26(a), and Figure 27(a)) is greater than the value average obtained for the specimen manufactured in pure resin (Figure 24(a)). While measures of $H$, have not to differences significative for both the specimens' manufactured with nanofillers (Figure 25(b), Figure 25(d), Figure 26(b), and Figure $27(b)$ ) as the manufactured in pure resin (Figure 24(b)).

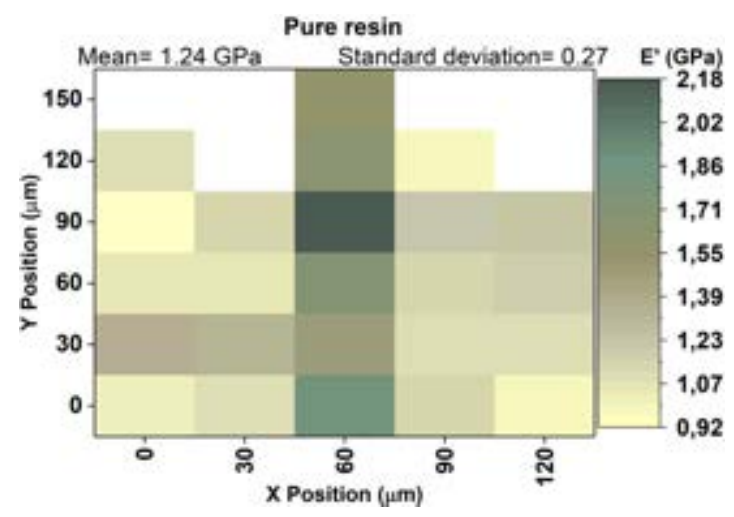

(a)

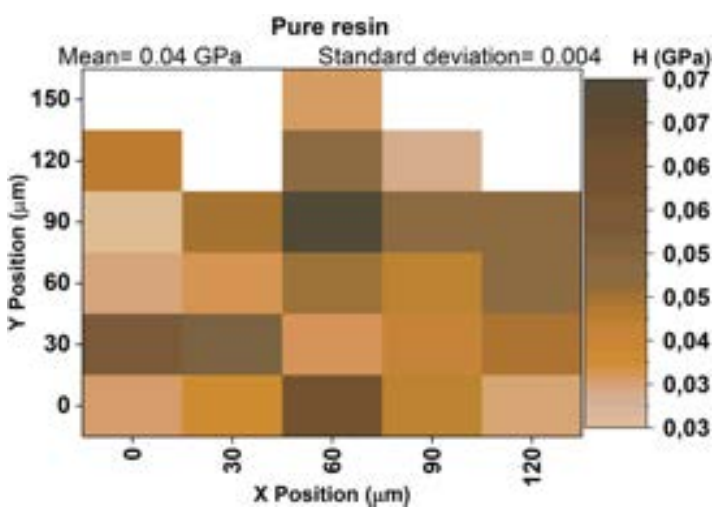

(b)

Figure 24. Contour maps of the variation of the mechanical properties $E^{\prime}$ moduli (a), and $H$ (b), obtained on a surface area of $120 \times 150 \mu^{2}$, on the substrates manufactured in pure resin.

In Figure 24 to Figure 27, the darkening corresponds to higher concentrations of the nanowires embedded in the matrix of the photopolymer resin. This behavior is similar for both $E^{\prime}$ moduli (Figure 24(a), Figure 25(a), Figure 25(c), Figure 26(a), and Figure 27(a)) and $H$ (Figure 24(b), Figure 25(b), Figure 25(d), Figure 26(b), and Figure 27(b)). This indicates an efficient adhesion of the $\mathrm{Cu}$ NWs, Cu NWs+NPs, and CuNi NWs to the resin; also, the Cu NWs, Cu NWs+NPs, and CuNi NWs function as hardeners of the corresponding matrix (see Figure 28). Thus, the efforts are transferred perfectly from the nanowires to the matrix, then to the having good adhesion it has good rigidity. Removal of such entangled agglomerates is a major focus of the many methods used to disperse any filler in polymer matrices. In fact, as the aggregates are only weakly infiltrated by the polymer, they degrade the relative properties of the polymer. On the contrary, a suitable dispersion of the nanofillers would result in optimized matrix/ filler bonding and enhanced properties $[70,85$ 89]. 


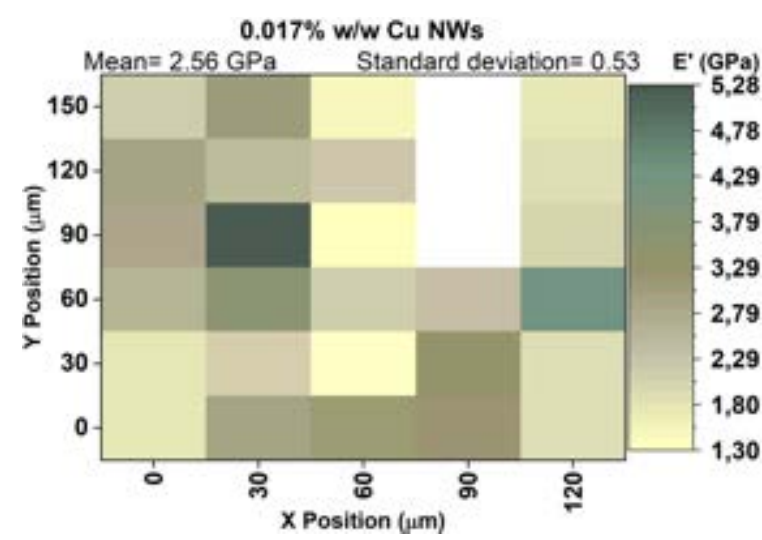

(a)

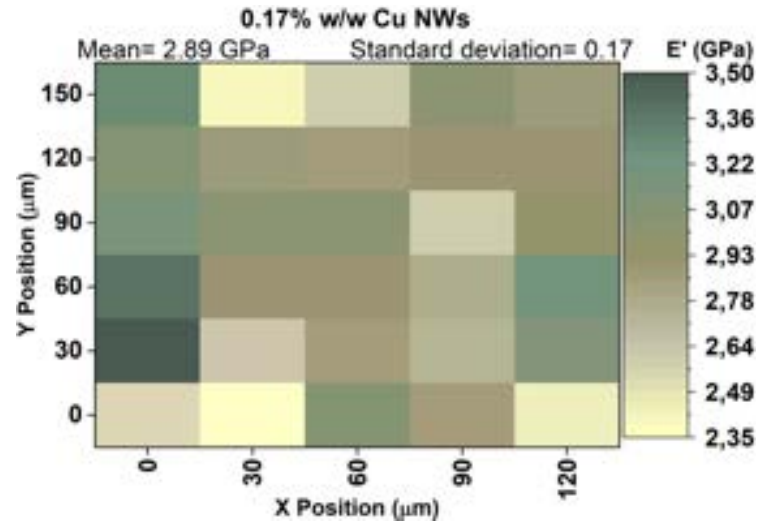

(c)

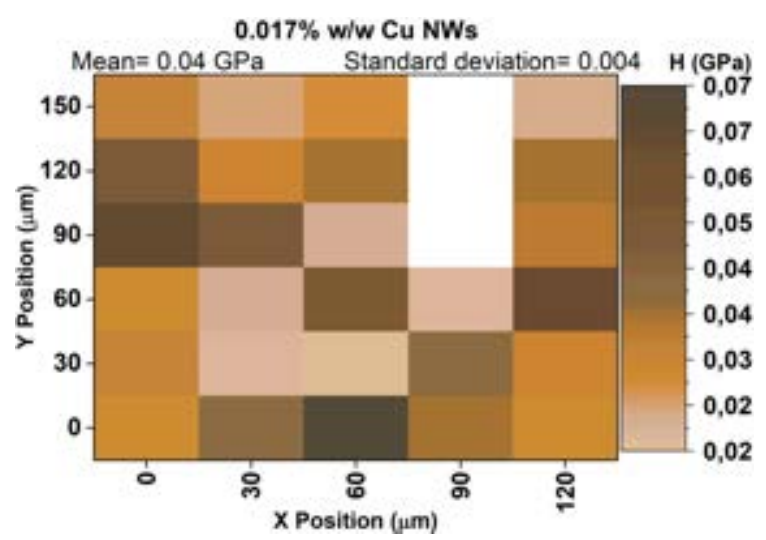

(b)

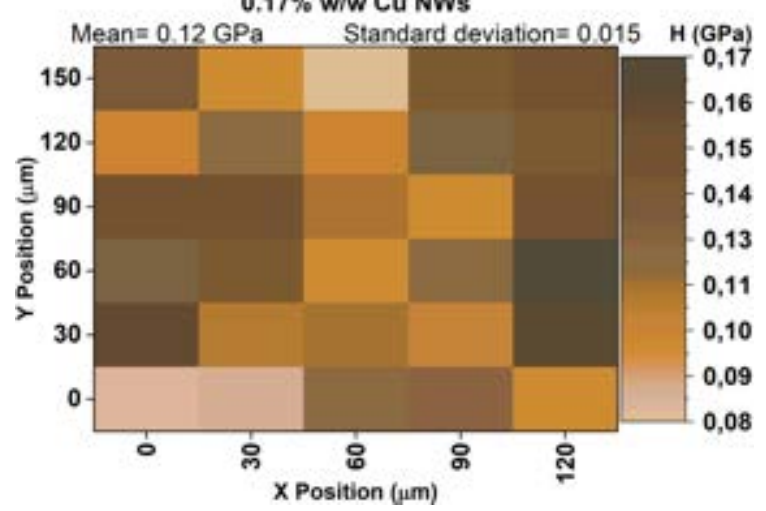

(d)

Figure 25. Contour maps of the variation of the mechanical properties $E^{\prime}$ moduli (a) and (c), and $H$ (b) and (d), obtained on a surface area of $120 \times 150 \mu \mathrm{m}^{2}$, on the substrates manufactured with Cu NWs embedded at $0.017 \% \mathrm{w} / \mathrm{w}$ (a) and (b), and Cu NWs embedded at $0.17 \% \mathrm{w} / \mathrm{w}$ (c) and (d).

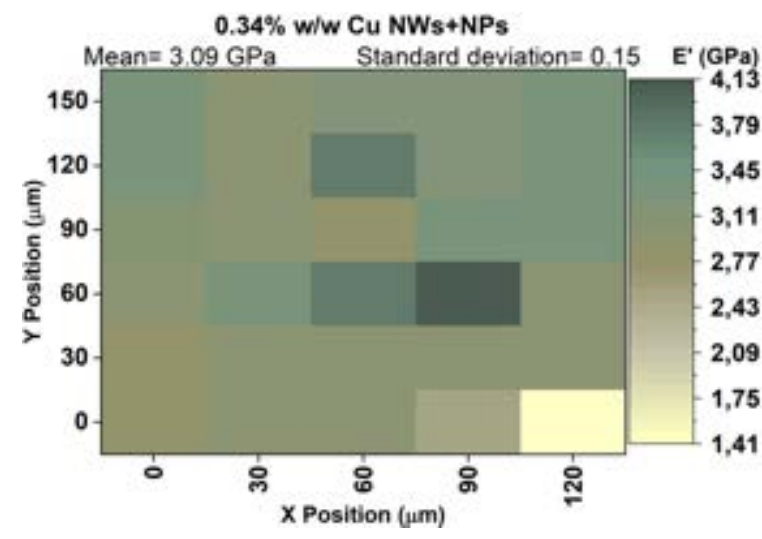

(a)

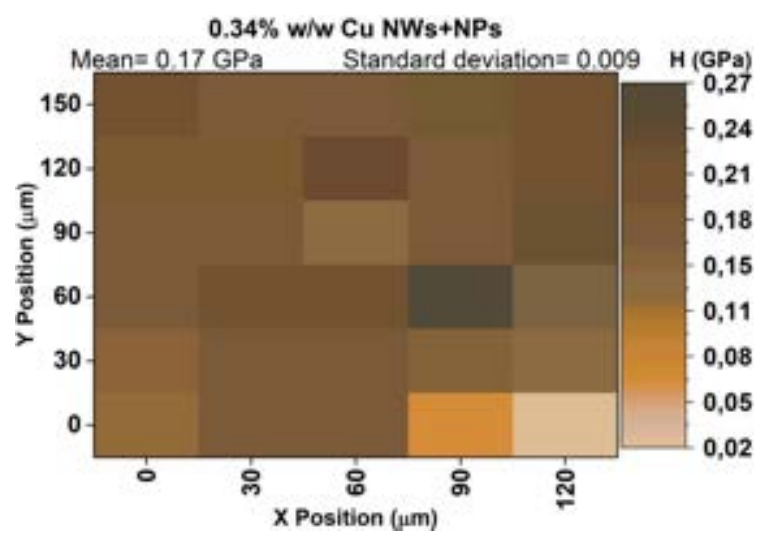

(b)

Figure 26. Contour maps of the variation of the mechanical properties $E^{\prime}$ moduli (a), and $H$ (b), obtained on a surface area of $120 \times 150 \mu \mathrm{m}^{2}$, on the substrates manufactured with Cu NWs+NPs embedded at $0.34 \% \mathrm{w} / \mathrm{w}$.

In Figure 24 to Figure 27, the local "soft or clear" spots, which are due to the small differences in the dispersion, correspond to regions with degraded mechanical properties, probably due to $\mathrm{Cu}$ or $\mathrm{CuNi}$ aggregates poorly infiltrated by the polymeric matrix. On the other hand, the local "hard or dark" spots correspond to areas with enhanced mechanical properties, likely reflecting an adequate polymer infiltration of the Cu NWs, Cu NWs+Nps, or CuNi NWs aggregates. 
The advantage of maps such as Figure 24 to Figure 27, allows assessed directly and visually that there are no local variations in the mechanical properties. Moreover, the average values extracted from these maps can be representative of the entire composites if the studied areas are large enough (Figure 28$)[70,88,89]$.

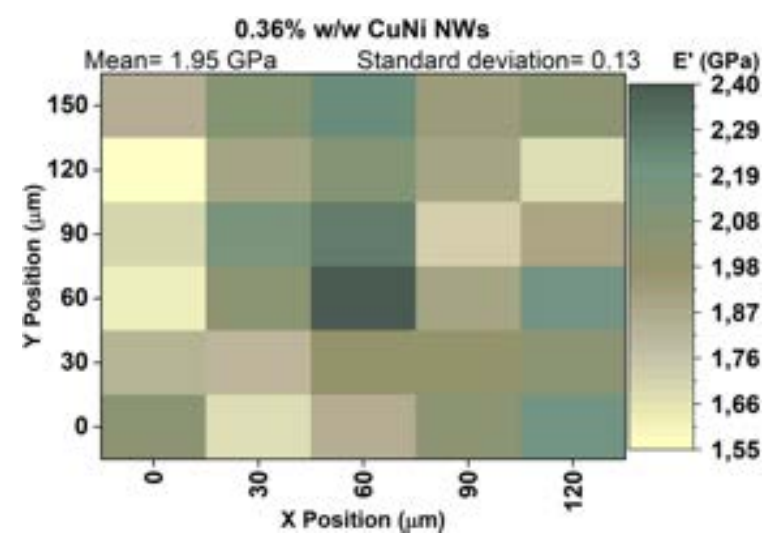

(a)

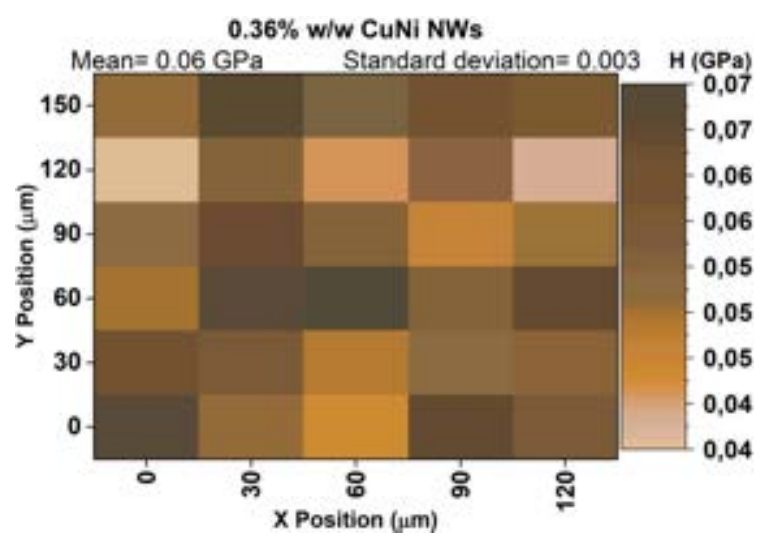

(b)

Figure 27. Contour maps of the variation of the mechanical properties $E^{\prime}$ moduli (a), and $H$ (b), obtained on a surface area of $120 \times 150 \mu \mathrm{m}^{2}$, on the substrates manufactured with CuNi NWs embedded at $0.36 \% \mathrm{w} / \mathrm{w}$.

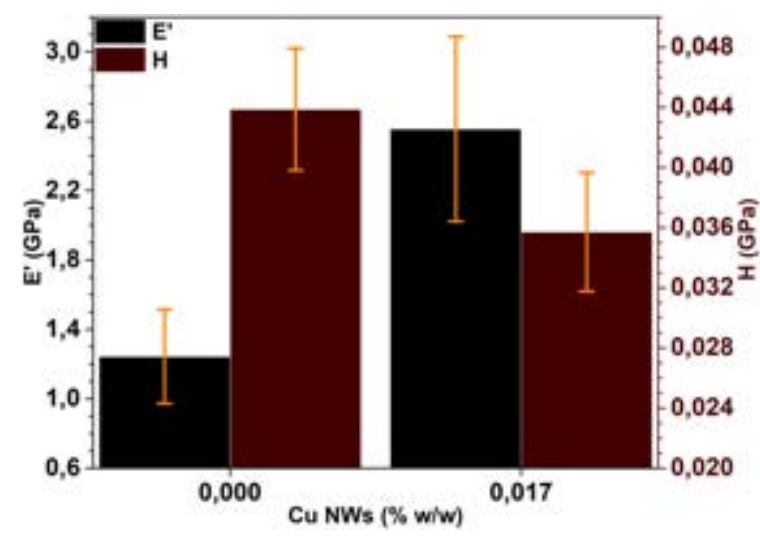

(a)

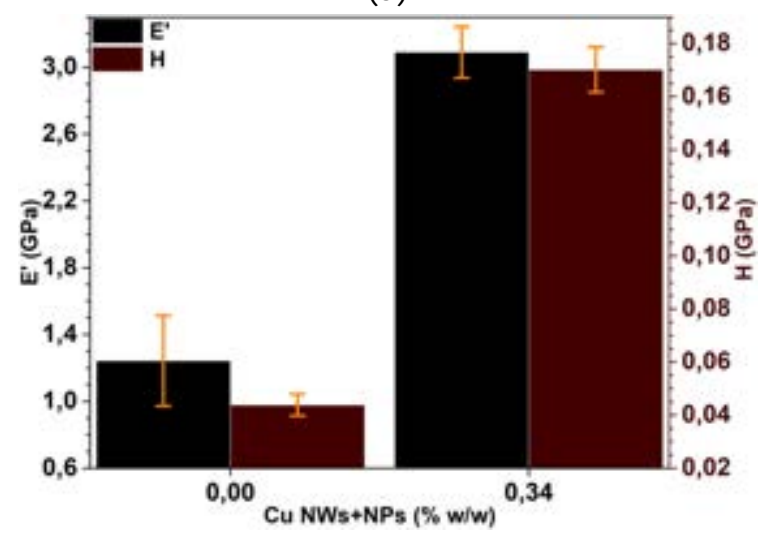

(c)

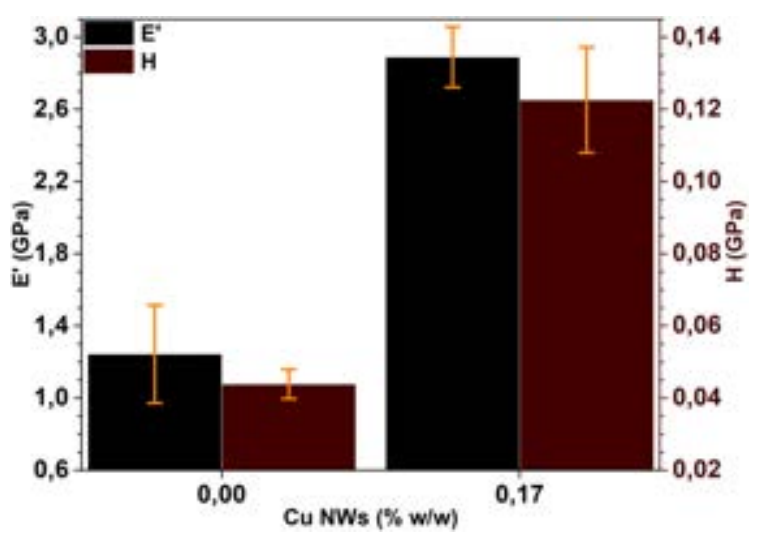

(b)

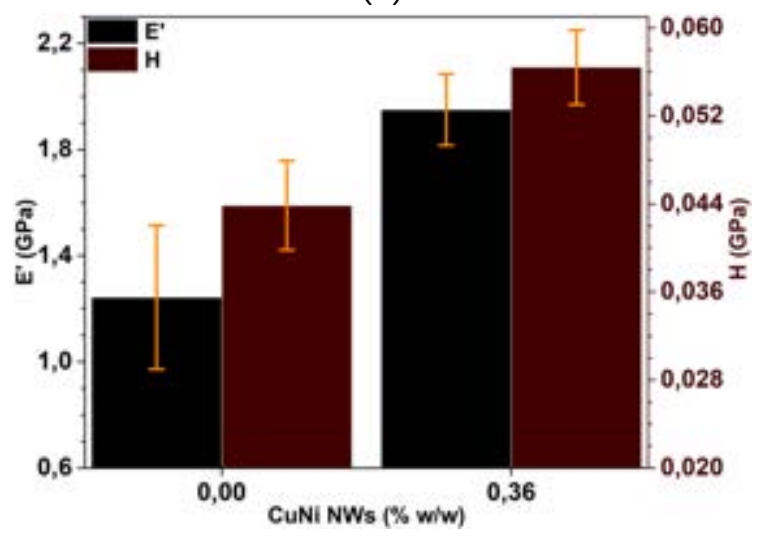

(d)

Figure 28. Effect of nanofillers content on mechanical properties variation. $E^{\prime}$ storage modulus (black), and $H$ hardness (red). (a) Cu NWs embedded at $0.017 \% \mathrm{w} / \mathrm{w}$, (b) Cu NWs embedded at $0.17 \% \mathrm{w} / \mathrm{w}$, (c) Cu NWs+NPs embedded at $0.34 \% \mathrm{w} / \mathrm{w}$, and (d) CuNi NWs embedded at $0.36 \% \mathrm{w} / \mathrm{w}$. 
Figure 29 to Figure 32 highlight the significant decrease of $E^{\prime}$ modulus and $H$ when loading the polymeric matrix with Cu NWs (Figure 30 and Figure 32(a)), and CuNi NWs (Figure 31 and Figure 32(b)), to different post-cured time. The measurement of $E^{\prime}$ modulus and $H$ is represented in Figure 29 to Figure 31, where minimum variations in the values of the deformation resistance were found. Figure 32 presents the average values of $E^{\prime}$ modulus and $H$ for the specimens manufactured with type "Clear FLGPCL 02" pure resin and for the specimens reinforced with $\mathrm{Cu} N W s$ at $0.26 \% \mathrm{w} / \mathrm{w}$ (Figure 32(a)), and CuNi at $0.42 \% \mathrm{w} / \mathrm{w}$ (Figure 32(b)). The decrease of $E^{\prime}$ modulus in $15.0 \%, 17.4 \%, 16.9 \%, 29.6 \%$ for specimens reinforced $\mathrm{Cu}$ NWs and CuNi NWs and post-cured during $14 \mathrm{~min}$ and $28 \mathrm{~min}$ respectively; and the decrease of $H$ in $9.0 \%, 17.4 \%, 20.3 \%, 25.2 \%$ for specimens reinforced Cu NWs and CuNi NWs and post-cured during $14 \mathrm{~min}$ and $28 \mathrm{~min}$ respectively, can be attributed to the soften of polymeric chains.

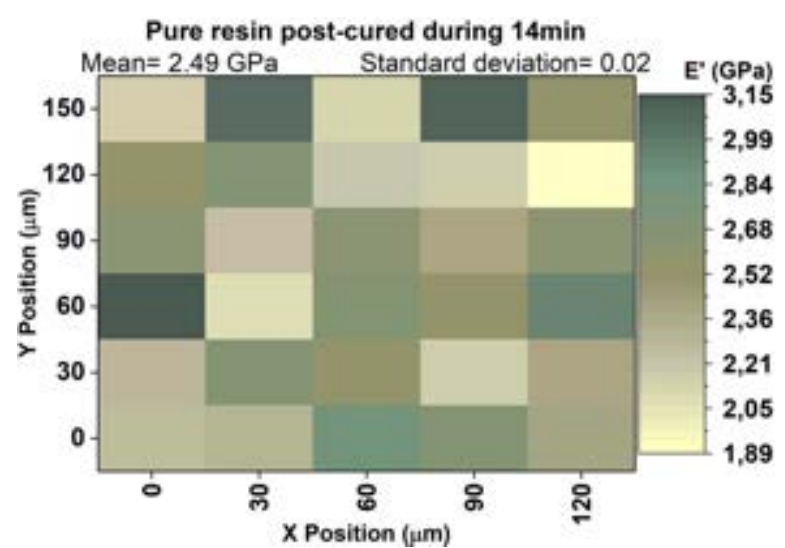

(a)

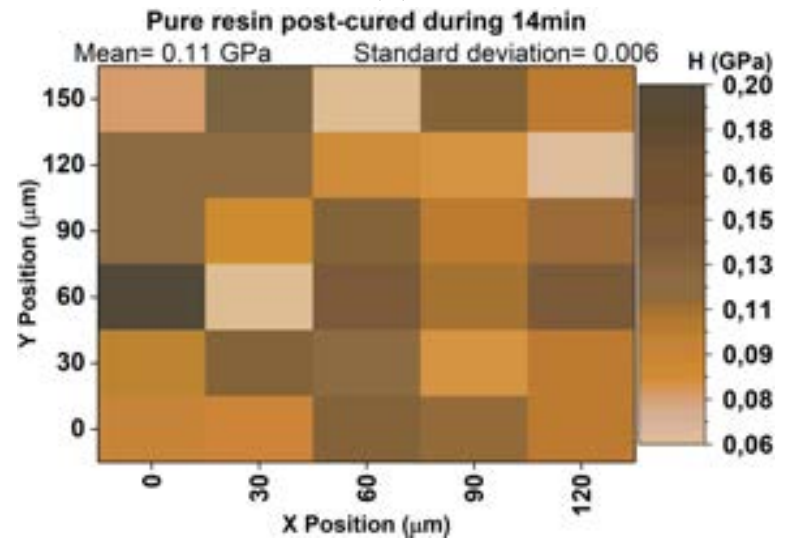

(c)

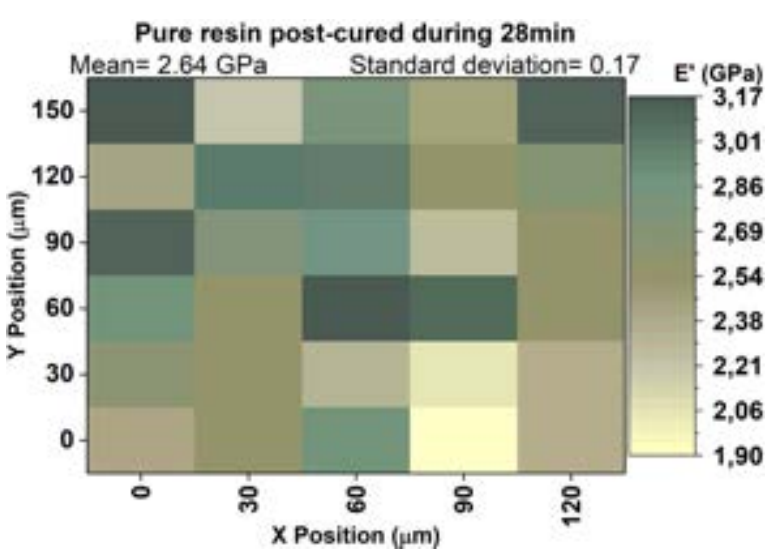

(b)

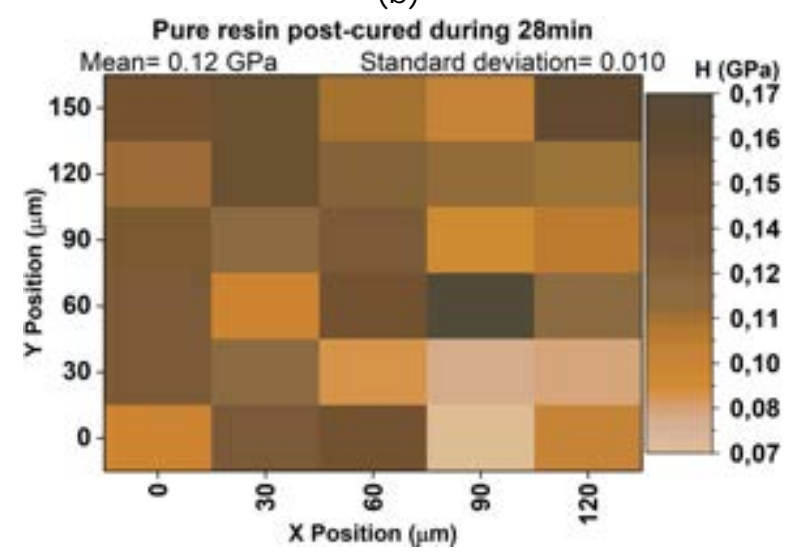

(d)

Figure 29. Contour maps of the variation of the mechanical properties $E^{\prime}$ moduli (a) and (b), and $H$ (c) and (d), obtained on a surface area of $120 \times 150 \mu \mathrm{m}^{2}$, on the substrates manufactured in pure resin with post-cured during $14 \mathrm{~min}$ and $28 \mathrm{~min}$, respectively.

In Figure 29 to Figure 31, the local "soft or clear" spots, which are due to the small differences in the dispersion, correspond to regions with degraded mechanical properties, probably due to $\mathrm{Cu}$ or CuNi nanowires infiltrated by the polymeric matrix. On the other hand, the local "hard or dark" spots correspond to areas with enhanced mechanical properties, likely reflecting an adequate polymer infiltration. Consequently, the advantage of maps such as Figure 29 to Figure 31 allows assessed directly and visually that there are no local 
variations in the mechanical properties. Moreover, the average values extracted from these maps (Figure 32) can be representative of the entire composites if the studied areas are large enough [19,85-89].

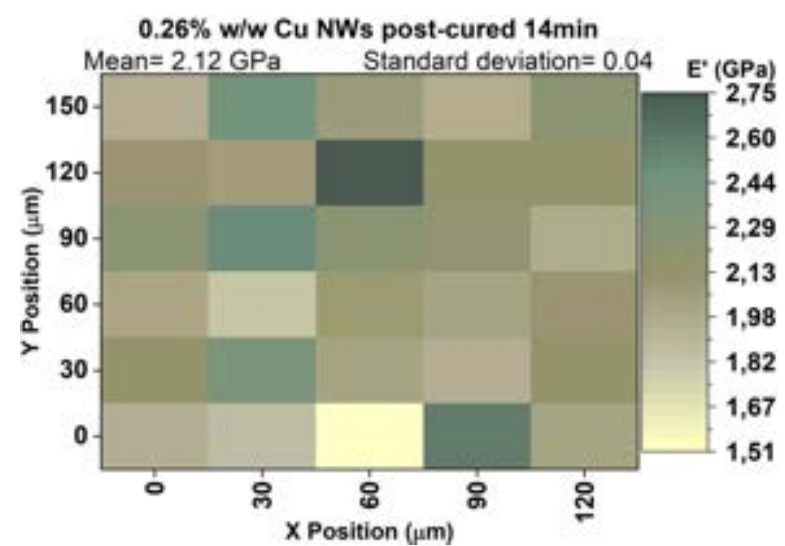

(a)

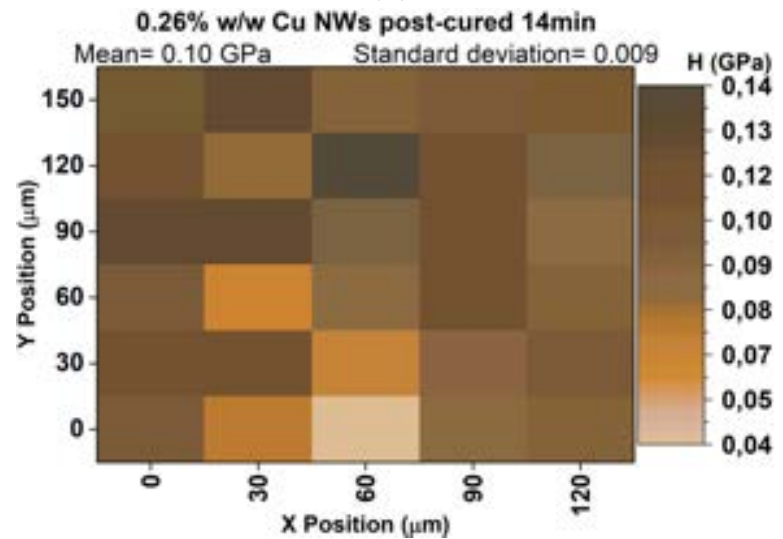

(c)

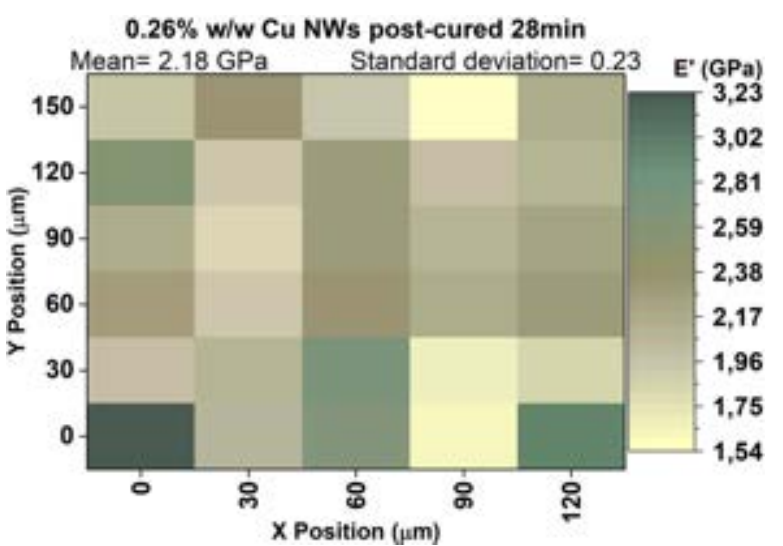

(b)

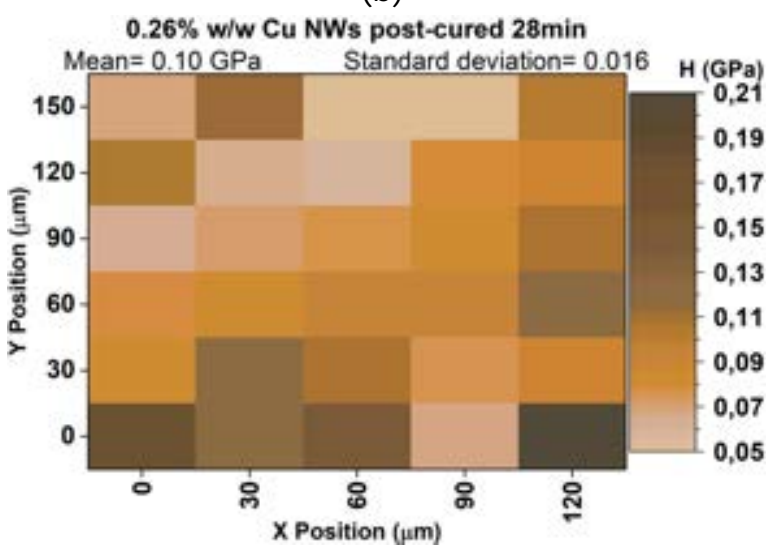

(d)

Figure 30. Contour maps of the variation of the mechanical properties $E^{\prime}$ moduli (a) and (b), and $H$ (c) and (d), obtained on a surface area of $120 \times 150 \mu \mathrm{m}^{2}$, on the substrates manufactured with Cu NWs embedded at $0.26 \% \mathrm{w} / \mathrm{w}$ with post-cured during $14 \mathrm{~min}$ and $28 \mathrm{~min}$, respectively.

In Figure 29 to Figure 31, the darkening corresponds to higher concentrations of the nanowires embedded in the matrix of the photopolymer resin. This behavior is similar for both $E^{\prime}$ moduli (Figure 29(a), Figure 29(b), Figure 30(a), Figure 30(b), Figure 31(a) and Figure $31(b)$ ), and $H$ (Figure 29(c), Figure 29(d), Figure 30(c), Figure 30(d), Figure 31(c) and Figure 31(d)). This indicates a successful load transfer from the polymeric matrix to the Cu NWs and CuNi NWs, where the Cu NWs and CuNi NWs function as disentangled of the polymeric chains (see Figure 32). Moreover, as the aggregates are only weakly infiltrated by the polymer, they may degrade the relative properties of the polymer. Then, a suitable dispersion of the wires would result in optimized matrix/ nanowires bonding with enhanced properties according to the application. Thus, a major focus could be to find a good method for the dispersion of any nanowires in polymer matrices. 


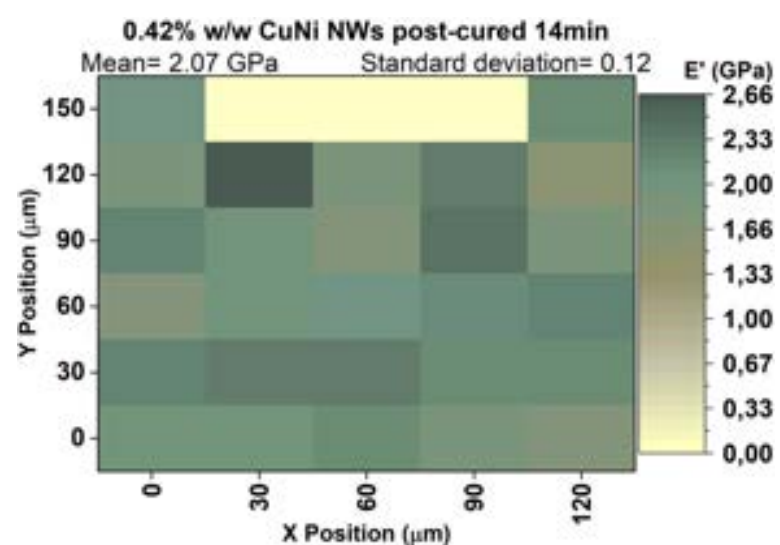

(a)

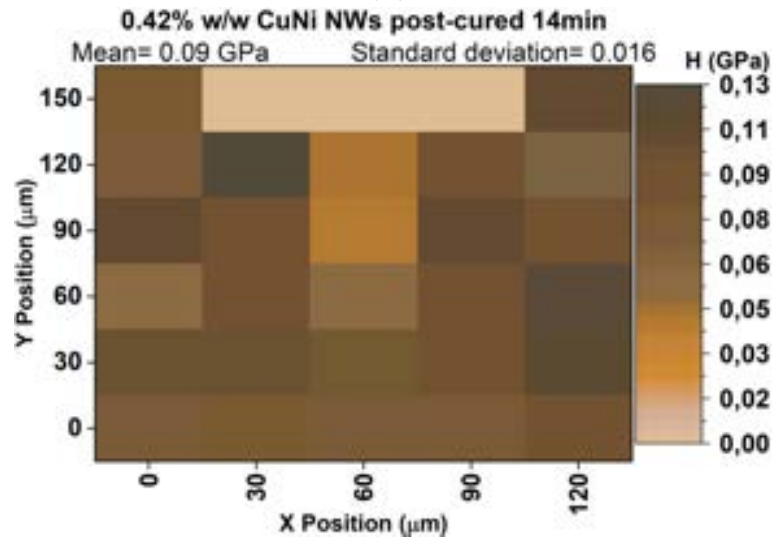

(c)

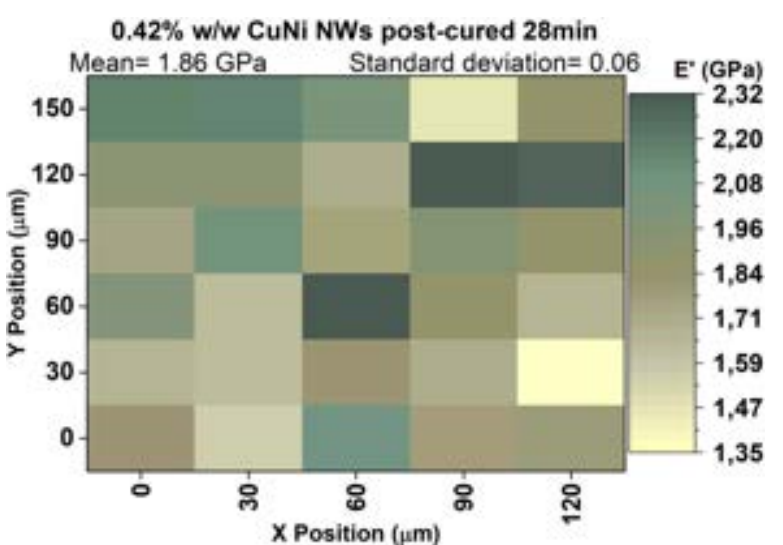

(b)

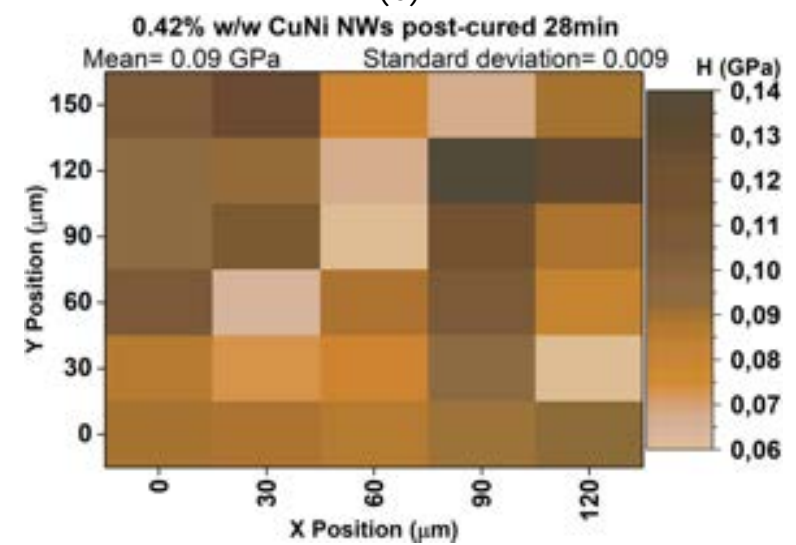

(d)

Figure 31. Contour maps of the variation of the mechanical properties $E^{\prime}$ moduli (a) and (b), and $H$ (c) and (d), obtained on a surface area of $120 \times 150 \mu \mathrm{m}^{2}$, on the substrates manufactured with CuNi NWs embedded at $0.42 \% \mathrm{w} / \mathrm{w}$ with post-cured during $14 \mathrm{~min}$ and $28 \mathrm{~min}$, respectively.

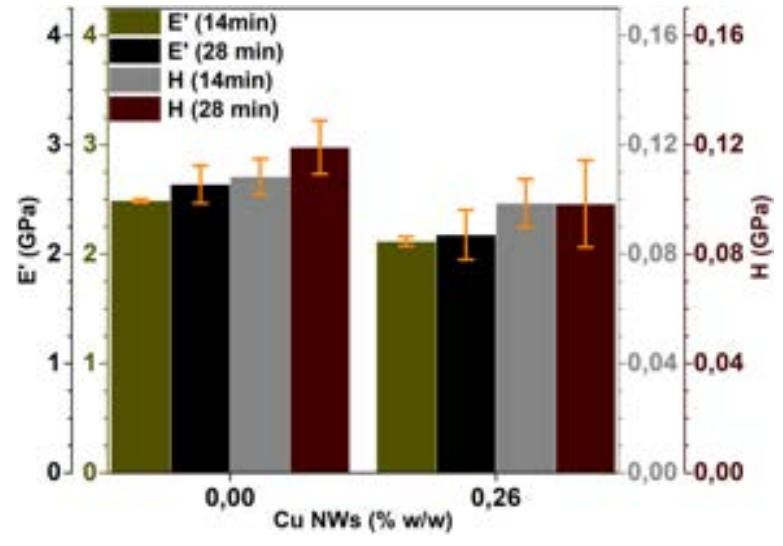

(a)

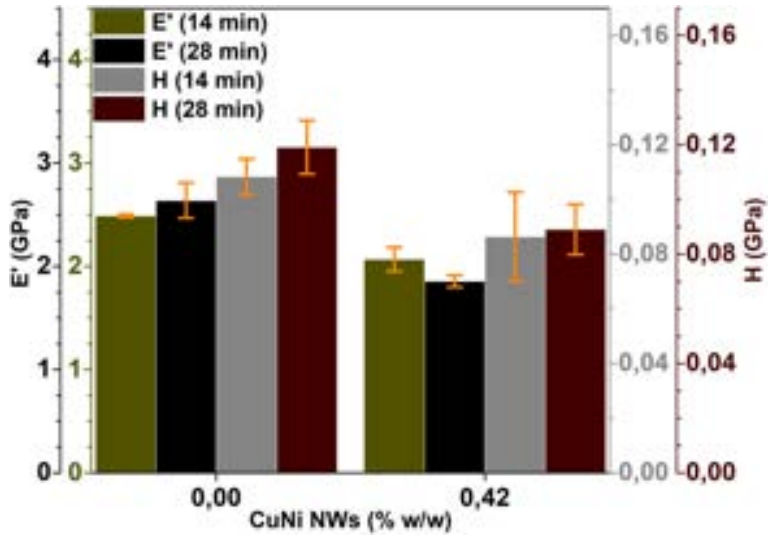

(b)

Figure 32. Effect of nanowires content and post-cured on mechanical properties variation. $E^{\prime}$ storage modulus (green and black), and $H$ hardness (grey and red). (a) Cu NWs embedded at $0.26 \% \mathrm{w} / \mathrm{w}$, and (b) CuNi NWs embedded at $0.42 \% \mathrm{w} / \mathrm{w}$. 


\subsection{Thermal Performance}

The thermal properties of specimens manufactured in "Clear FLGPCL 02" and "Grey PN: F100G" resins and reinforced with nanofillers were carefully assessed with standard techniques, such as DMA, DSC, and TGA. Partial results of the current section have been already presented in [70] and have been submitted for evaluation to Polymers (peerreviewed open access journal).

4.4.1. Dynamic mechanical analysis. Figure 33 to Figure 36 illustrates the influence of the temperature on $E^{\prime}$ and $\tan \delta$ for substrates manufactured with the pure "Clear FLGPCL 02" resin and with a load of Cu NWs and CuNi NWs. Figure 33(a), Figure 34(a), Figure 35(a) and Figure 36(a) demonstrate that $E^{\prime}$ has the highest value for the pure resin and decreases with the addition of nanowires, regardless cure time, highlighting the glass transition region. Furthermore, factors such as the reaction degree and the crosslinking density mainly influence the value of $E^{\prime}$. The glass transition process is thereby confirmed, suggesting that the behavior of the material in pure resin and with nanowires of $\mathrm{Cu}$ and CuNi can be evaluated through rheological properties.

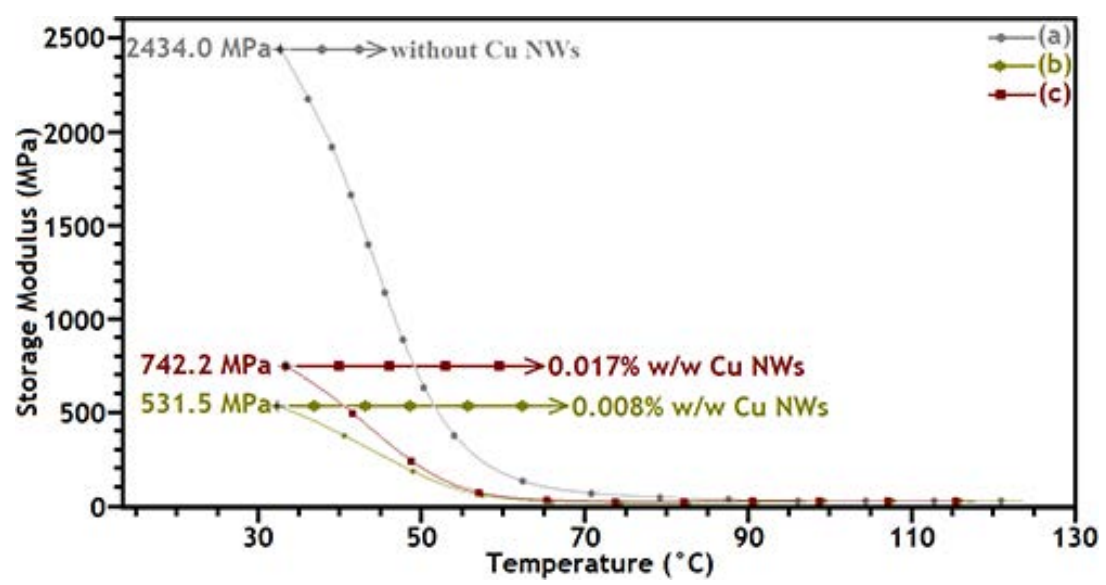

(a)

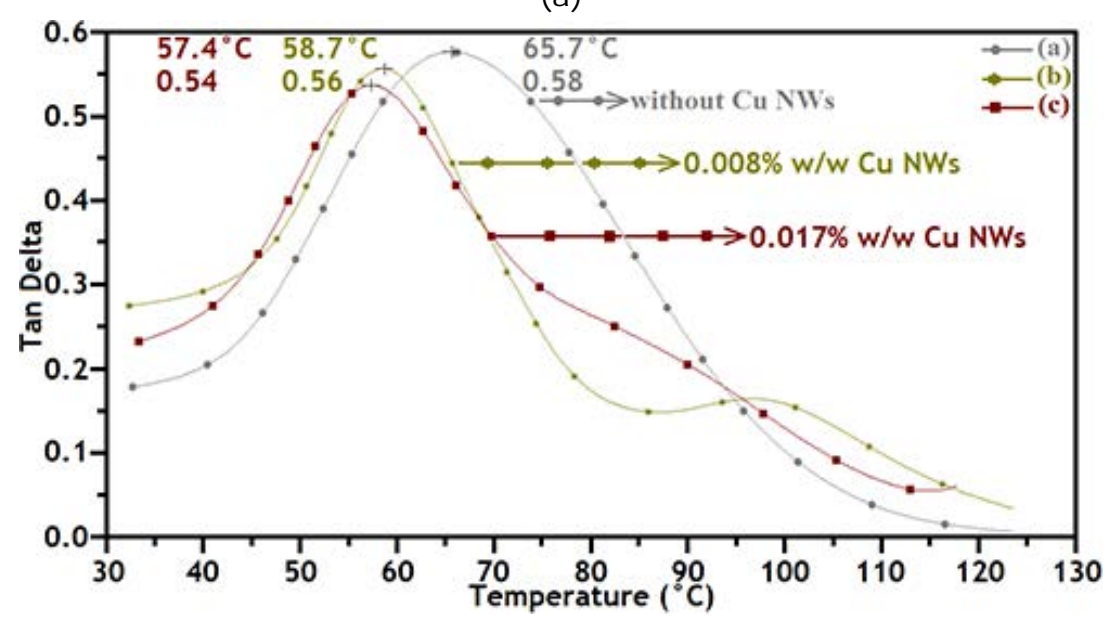

(b)

Figure 33. DMA curves of the substrates manufactured in pure resin and with nanowires. (a) $E^{\prime}(T)$, and (b) $\tan \delta(T)$. Pure resin $(\cdot-a)$, with Cu NWs embedded at $0.008 \% \mathrm{w} / \mathrm{w}(*-\mathrm{b})$, and $0.017 \% \mathrm{w} / \mathrm{w}(--\mathrm{c})$. 
Figure 33(b), Figure 34(b), Figure 35(b) and Figure 36(b) highlight the change of tan $\delta$ of the specimens' pure resin and with $\mathrm{Cu}$ NWs and CuNi NWs. The maximum value of $\tan \delta$ is mainly influenced by the glass transition temperature $\left(T_{\mathrm{g}}\right)$. Consequently, loading the polymeric matrix with $\mathrm{Cu}$ NWs and CuNi NWs lowers $\tan \delta$ because it decreases the crosslinking density and leads to the higher mobility of polymer chains during glass transition. The sharper peak of $\tan \delta$ indicates that a more regular structure is formed without the load of Cu NWs and CuNi NWs.

It was expected that polymer's viscoelasticity would change after the incorporation of the Cu NWs and the CuNi NWs. The $\tan \delta$, the ratio of $E^{\prime \prime}$ and $E^{\prime}$, is usually a characteristic indicator of how much energy dissipates in the polymer matrix [90]. The peak maximum occurs at the glassy transition regime of polymer's [90,91] (Figure 33(b), Figure 34(b), Figure $35(\mathrm{~b})$ and Figure 36(b)). It is known that large $\tan \delta$ value reflects a viscous behavior whereas small $\tan \delta$ indicates an elastic behavior [90].

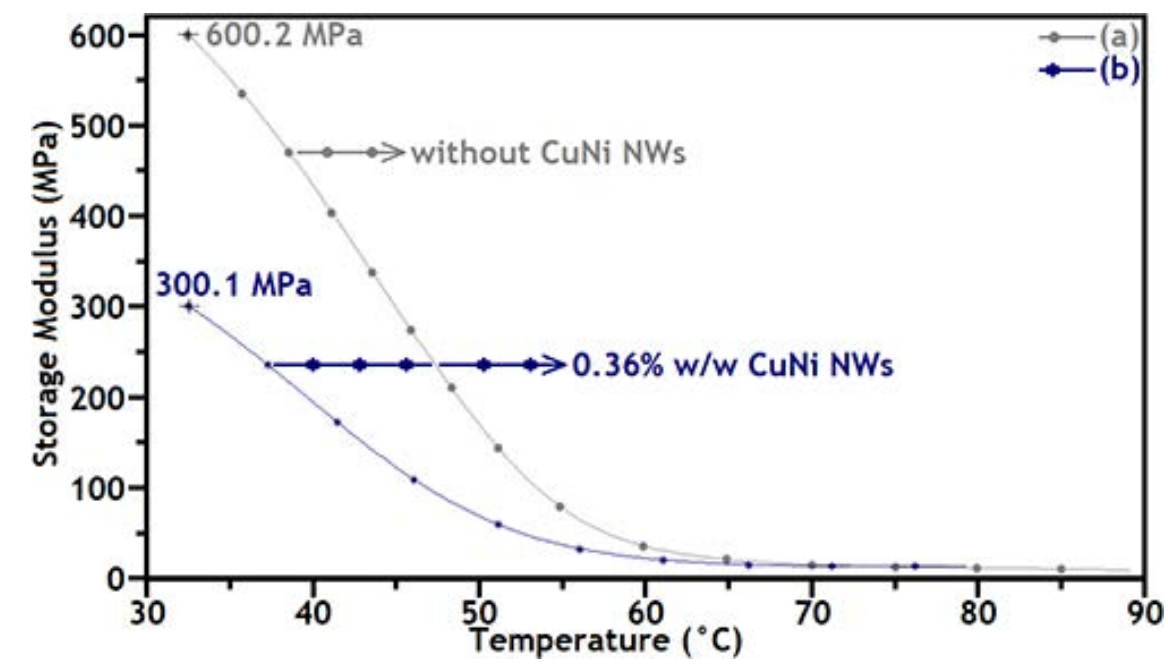

(a)

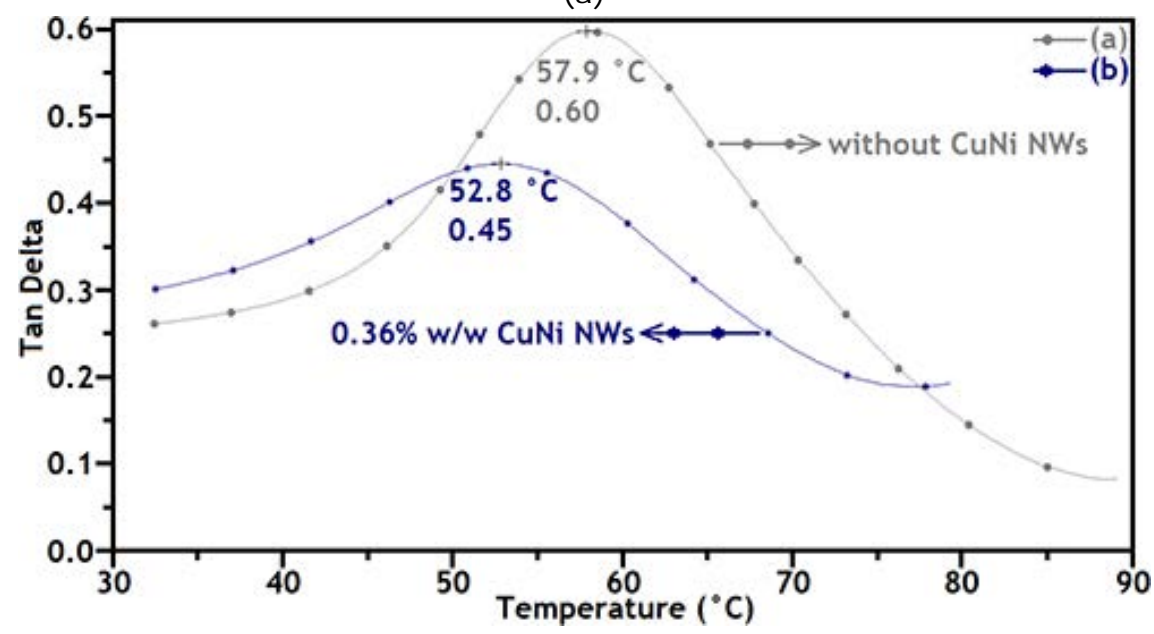

(b)

Figure 34. DMA curves of the substrates manufactured pure resin and with nanowires. (a) $E^{\prime}(T)$, and (b) $\tan \delta(T)$. Pure resin $(\bullet-a)$, and CuNi NWs embedded at $0.36 \% \mathrm{w} / \mathrm{w}(*-\mathrm{b})$. 
The presence of $\mathrm{Cu}$ and $\mathrm{CUNi}$ nanowires in the "Clear FLGPCL 02" resin lowered the maximum $\tan \delta$ value, from $\sim 0.58$ for the specimen manufactured in pure resin to $\sim 0.56$ and $\sim 0.54$ for the substrates manufactured with $\mathrm{Cu} N W \mathrm{~N}$ at $0.008 \% \mathrm{w} / \mathrm{w}$ and $0.017 \% \mathrm{w} / \mathrm{w}$; moreover, for the specimens manufactured with CuNi NWs at $0.36 \% \mathrm{w} / \mathrm{w}$ the maximum $\tan \delta$ value is lowered from $\sim 0.60$ (obtained of the pure resin) to $\sim 0.45$. For the case the substrates with $14 \mathrm{~min}$ and $28 \mathrm{~min}$ of post-cured, the maximum $\tan \delta$ value was lowered from $\sim 0.53$ for the specimen manufactured in pure resin to $\sim 0.39$ for the substrates manufactured with $\mathrm{Cu}$ NWs at $0.26 \% \mathrm{w} / \mathrm{w}$, in both post-cured times; while for the substrates manufactured with CuNi at $0.42 \% \mathrm{w} / \mathrm{w}$ with $14 \mathrm{~min}$ and $28 \mathrm{~min}$ of post-cured, the maximum $\tan \delta$ value is lowered to $\sim 0.40$ and $\sim 0.39$ respectively. The $\mathrm{Cu}$ NWs and CuNi NWs highly influenced the molecular dynamics in the polymeric-matrix, giving rise to a reduction of the $T_{\mathrm{g}}$ and thermal stability of the substrates as compared to the polymeric specimen's pure resin [90]. The storage modulus results showed that the specimens manufactured with $\mathrm{Cu}$ NWs and CuNi, are lower than the specimen in photopolymer pure resin in the glass transition regime between $56^{\circ} \mathrm{C}$ and $70^{\circ} \mathrm{C}$. The DMA results of the specimens manufactured with nanowires embedded in the polymeric-matrix demonstrated a more elastic behavior as compared with the substrates manufactured in pure resin, suggesting an enhanced stiffness of the material.

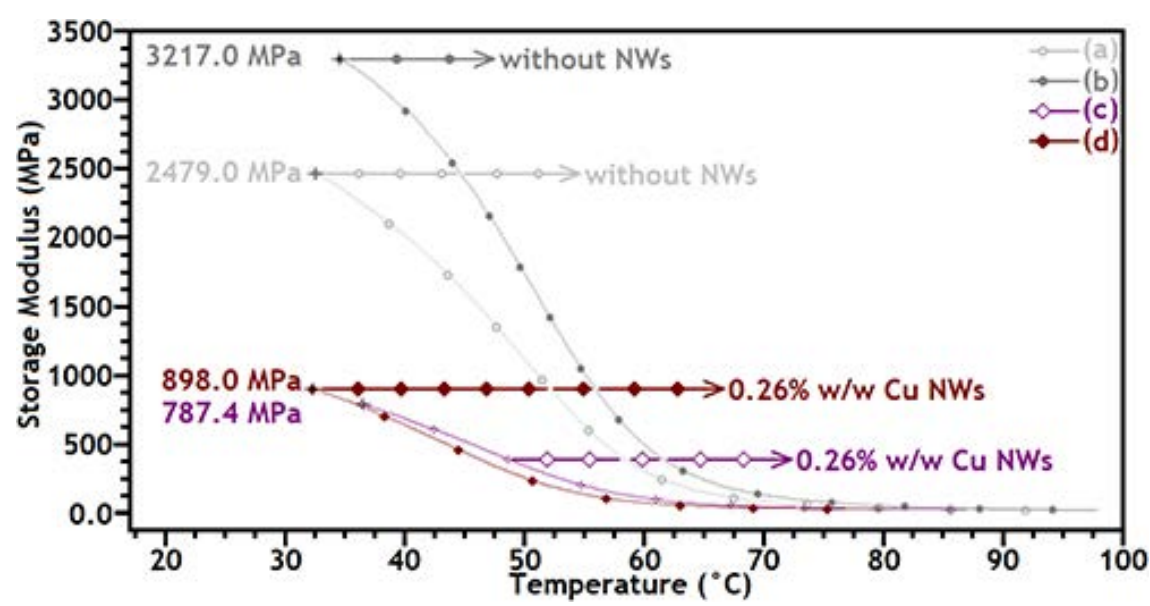

(a)

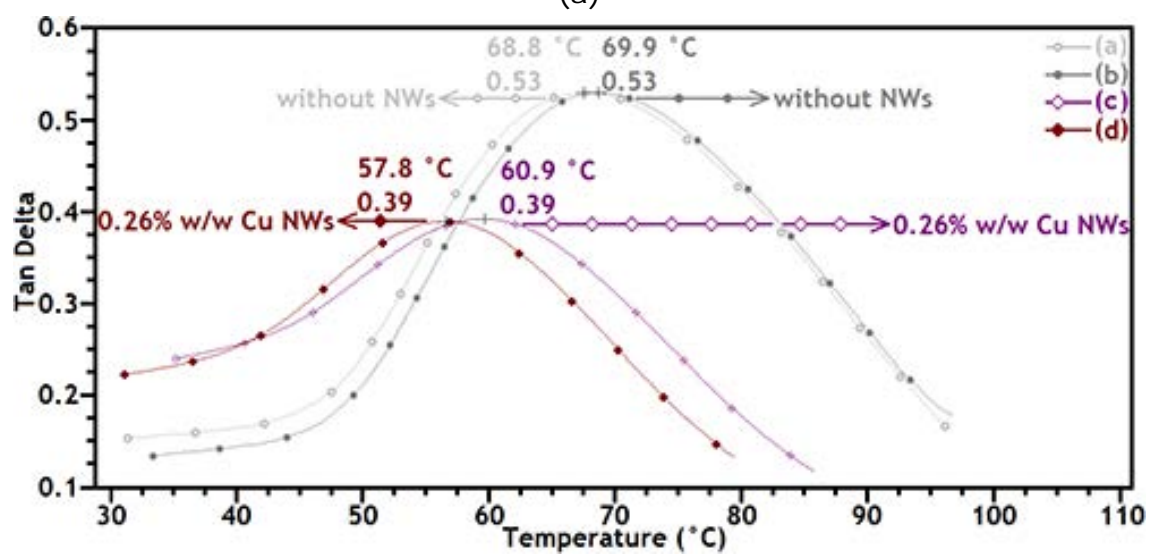

(b)

Figure 35. DMA curves of the substrates manufactured pure resin and with nanowires. (a) $E^{\prime}(T)$, and (b) $\tan \delta(T)$. Pure resin (o-a and $\left.\bullet-b\right)$, and $\mathrm{Cu}$ NWs embedded at $0.26 \% \mathrm{w} / \mathrm{w}(\diamond-\mathrm{c}$ and $\bullet-\mathrm{d})$ with post-cured during $14 \mathrm{~min}$ and $28 \mathrm{~min}$, respectively. 


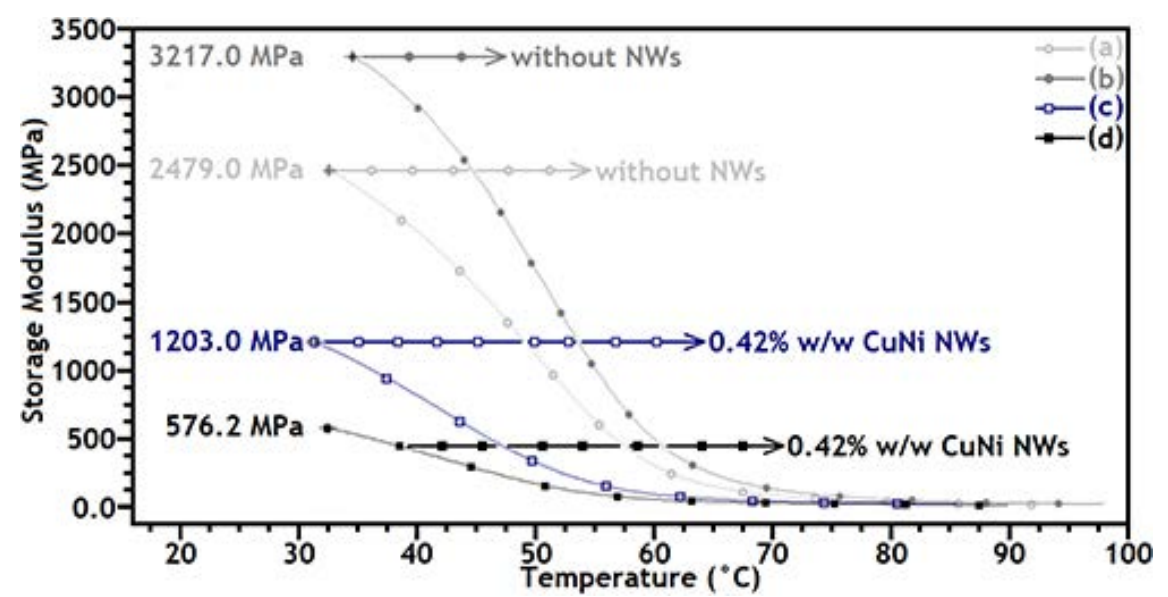

(a)

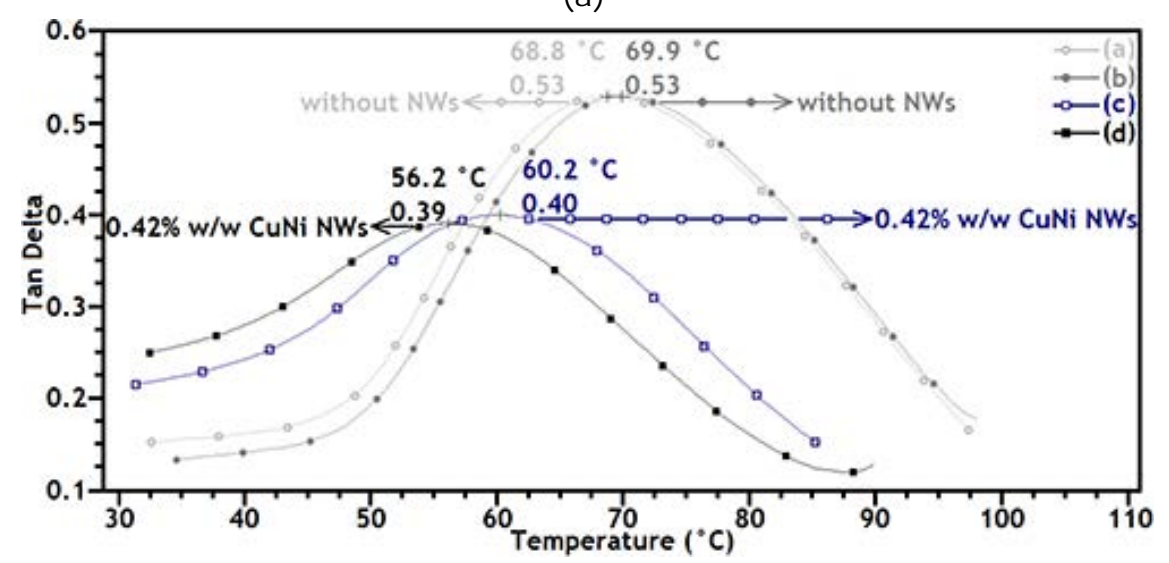

(b)

Figure 36. DMA curves of the substrates manufactured pure resin and with nanowires. (a) $E^{\prime}(T)$, and (b) $\tan \delta(T)$. Pure resin (o-a and $\left.\bullet-b\right)$, and CuNi NWs embedded at $0.42 \% \mathrm{w} / \mathrm{w}(\square-\mathrm{c}$ and $\cdot-\mathrm{d}$ ) with post-cured during $14 \mathrm{~min}$ and $28 \mathrm{~min}$, respectively.

The specimen manufactured in pure "Clear FLGPCL 02" resin has a $T_{\mathrm{g}}$ value close to $\sim 65.7{ }^{\circ} \mathrm{C}$. This value slightly shifted to $\sim 54.7^{\circ} \mathrm{C}$ with the increase of $\mathrm{Cu}$ NWs (Figure $33(\mathrm{~b}$ ) and Table 8 ). In another case, on the substrate in pure resin is obtained a $T_{\mathrm{g}}$ value close to $\sim 57.9^{\circ} \mathrm{C}$ and slightly shifted to $\sim 52.8^{\circ} \mathrm{C}$ for the specimen with CuNi NWs at $0.36 \% \mathrm{w} / \mathrm{w}$ (Figure 34(b) and Table 8). In the other hand, the substrates manufactured in pure resin with $14 \mathrm{~min}$ and $28 \mathrm{~min}$ of post-cured have $T_{g}$ values close to $\sim 68.8^{\circ} \mathrm{C}$ and $\sim 69.9{ }^{\circ} \mathrm{C}$ respectively and slightly shifted to $\sim 60.9{ }^{\circ} \mathrm{C}$ and $\sim 57.8^{\circ} \mathrm{C}$ for specimens manufactured with Cu NWs at $0.26 \% \mathrm{w} / \mathrm{w}$ with $14 \mathrm{~min}$ and $28 \mathrm{~min}$ of post-cured respectively (Figure 35(b) and Table 8), and to $\sim 60.2{ }^{\circ} \mathrm{C}$ and $\sim 52.2^{\circ} \mathrm{C}$ for specimens manufactured with CuNi NWs at $0.42 \% \mathrm{w} / \mathrm{w}$ with $14 \mathrm{~min}$ and $28 \mathrm{~min}$ of post-cured respectively (Figure 36(b) and Table 8).

4.4.2. Differential scanning calorimetry. DSC curves of pure resin specimens and manufactured with Cu NWs and CuNi NWs are provided in Figure 37. The results of the DSC tests demonstrate a broadly distributed glass transition region and the presence of an exothermal signal for the first scan. The distributions of the glass transition region cover a region between $32{ }^{\circ} \mathrm{C}$ and $135^{\circ} \mathrm{C}$ for the substrate in pure resin of type "Clear FLGPCL 02", between $32{ }^{\circ} \mathrm{C}$ and $80{ }^{\circ} \mathrm{C}$ for the specimens with $\mathrm{Cu}$ NWs at $0.008 \% \mathrm{w} / \mathrm{w}$, between $57^{\circ} \mathrm{C}$ and 
$115^{\circ} \mathrm{C}$ for the substrates with Cu NWs at $0.017 \% \mathrm{w} / \mathrm{w}$ (Figure $37(\mathrm{a})$ ); and between $31^{\circ} \mathrm{C}$ and $97^{\circ} \mathrm{C}$ for the specimens with CuNi NWs at $0.36 \% \mathrm{w} / \mathrm{w}$ (Figure $37(\mathrm{~b})$ ). Thus, the $T_{\mathrm{g}}$ value slightly decreased when polymer-matrix is loading with $\mathrm{Cu}$ NWs and CuNi NWs. Glass transition temperature $\left(T_{\mathrm{g}}\right)$, cold crystallization $\left(T_{\mathrm{c}}\right)$, melting temperature $\left(T_{\mathrm{m}}\right)$, and thermal degradation temperature $\left(T_{\mathrm{d}}\right)$, were measured and are reported in Table 8 . These transition temperatures present minimal variations upon the addition of $\mathrm{Cu}$ NWs and CuNi NWs as indicated in Figure 37; where the Cu NWs and CuNi NWs acting as extra nucleation sites for heterogeneous nucleation, a phenomenon that is quite typical for nanosized filler additions $[70,93,94]$.

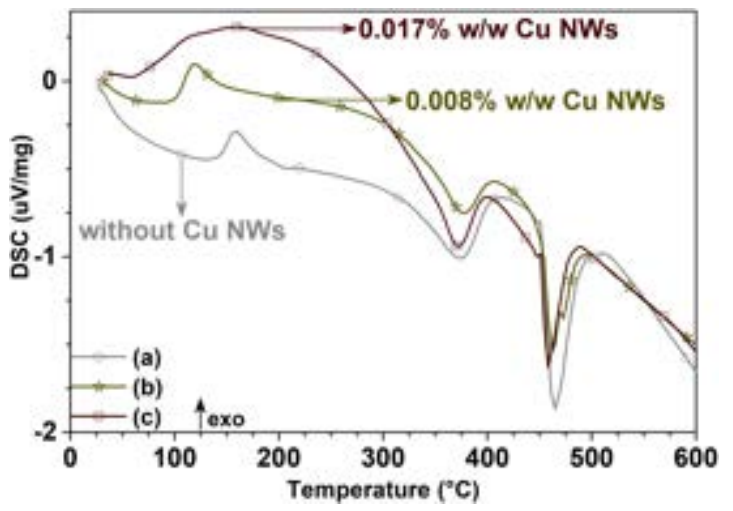

(a)

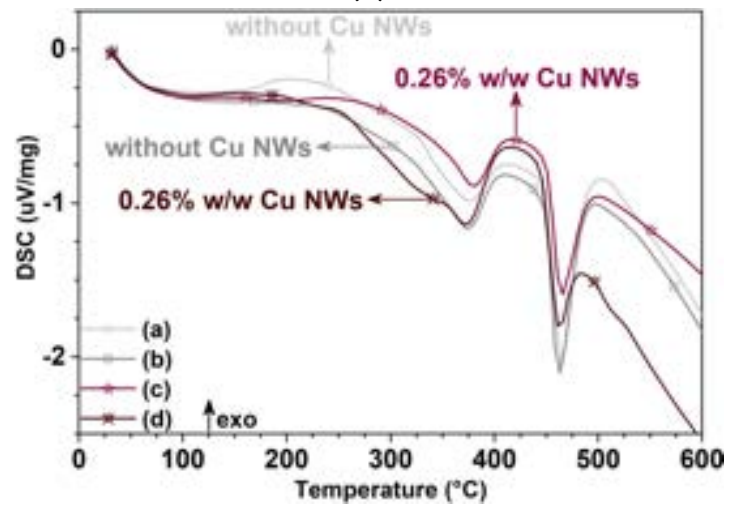

(c)

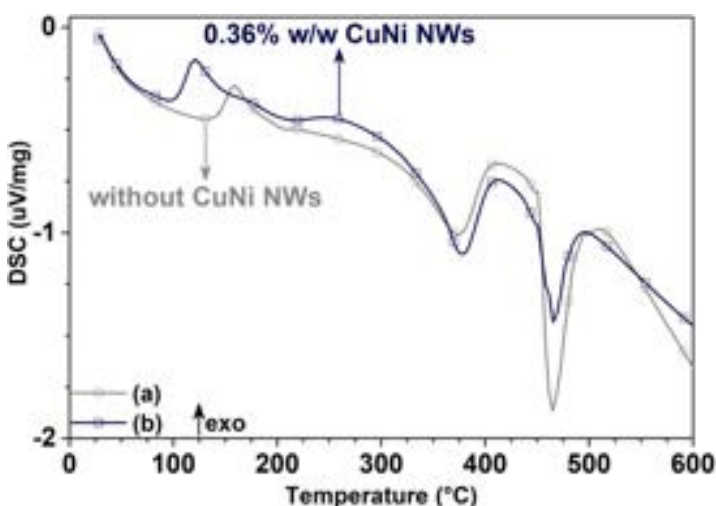

(b)

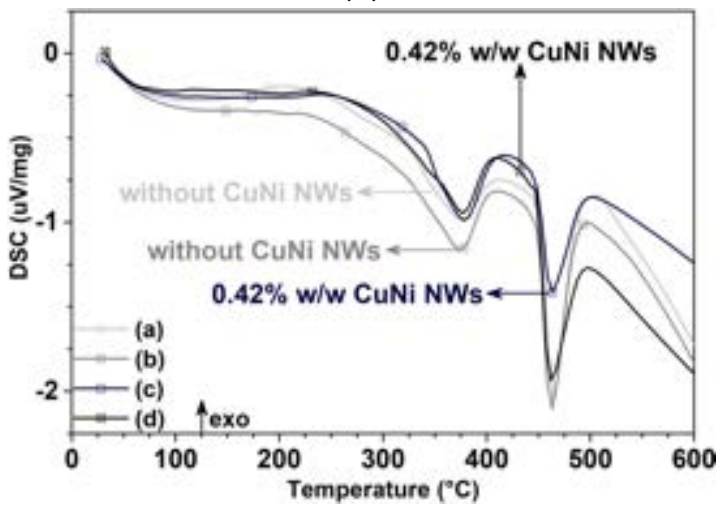

(d)

Figure 37. Representative curves DSC thermal analysis. (a) specimens in pure resin (o-a), with Cu NWs embedded at $0.008 \% \mathrm{w} / \mathrm{w}(*-b)$, and $0.017 \% \mathrm{w} / \mathrm{w}(\square-c) ;(b)$ substrates in pure resin $(0-a)$, and CuNi NWs embedded at $0.36 \% \mathrm{w} / \mathrm{w}(\square-b)$; (c) specimens in pure resin $(0-a$ and $\bullet-b)$, and Cu NWs embedded at $0.26 \% \mathrm{w} / \mathrm{w}$ ( $\mathrm{x}-\mathrm{c}$ and $*$-d) with post-cured during $14 \mathrm{~min}$ and $28 \mathrm{~min}$, respectively; (d) specimens in pure resin ( $(0-a$ and $\bullet-b)$, and CuNi NWs embedded at $0.42 \% \mathrm{w} / \mathrm{w}$ ( $\square-\mathrm{C}$ and $-\mathrm{d}$ ) with post-cured during $14 \mathrm{~min}$ and $28 \mathrm{~min}$, respectively.

DSC curves of pure resin specimens and of specimens using resin functionalized with $\mathrm{Cu}$ NWs and CuNi NWs, employing post-curing times of $14 \mathrm{~min}$ and $28 \mathrm{~min}$, are presented in Figure 37(c) and Figure 37(d) respectively. The results of the DSC tests demonstrate a broadly distributed glass transition region and the presence of an exothermal signal. The distributions of the glass transition region cover a region between $51{ }^{\circ} \mathrm{C}$ to $72{ }^{\circ} \mathrm{C}$ for the substrates in pure "Clear FLGPCL 02" resin with post-cured of $14 \mathrm{~min}$ and $28 \mathrm{~min}$, between $32{ }^{\circ} \mathrm{C}$ and $98^{\circ} \mathrm{C}$ for the specimens manufactured with $\mathrm{Cu}$ NWs at $0.26 \% \mathrm{w} / \mathrm{w}$ and post-cured during $14 \mathrm{~min}$ and $28 \mathrm{~min}$ (Figure $37(\mathrm{C})$ ), $31^{\circ} \mathrm{C}$ to $112^{\circ} \mathrm{C}$ for the substrates manufactured 
with CuNi NWs at $0.42 \% \mathrm{w} / \mathrm{w}$ and post-cured during $14 \mathrm{~min}$ and $28 \mathrm{~min}$ (Figure 37(d)). Therefore, the $T_{\mathrm{g}}$ value slightly decreased when polymer-matrix is loading with Cu NWs and CuNi NWs. The $T_{\mathrm{g}}, T_{\mathrm{c}}, T_{\mathrm{m}}$, and $T_{\mathrm{d}}$, were measured and are reported in Table 8 . These transition temperatures present minimal variations with the content of $\mathrm{Cu} N W s$ and $\mathrm{CuNi}$ NWs as indicated in Figure 37; where the Cu NWs and CuNi NWs acting as extra nucleation sites for heterogeneous nucleation, a phenomenon that is quite typical for nanosized filler additions $[70,93,94]$.

4.4.3. Thermogravimetric analysis. The thermal stability of the samples was investigated by TGA to ensure the $\mathrm{Cu}$ and $\mathrm{CuNi}$ nanowires into the bulk of the specimens were stable. Under pyrolytic conditions in the $\mathrm{N}_{2}$ atmosphere, the degradation of the samples occurred with a sharp weight loss around $300{ }^{\circ} \mathrm{C}-500{ }^{\circ} \mathrm{C}$, accompanied with possible organic fragments (e.g. methacrylic acid and ester) [70,98]. Thermogravimetric analysis results between $320^{\circ} \mathrm{C}$ and $600{ }^{\circ} \mathrm{C}$, are provided in Figure 38. Slight mass loss from TGA curves around $80{ }^{\circ} \mathrm{C}$ was attributed to the loss of organics dissolvent absorbed by resin as such as IPA, where most of the IPA was to be evaporated during the UV post-curing, and after $100^{\circ} \mathrm{C}$.

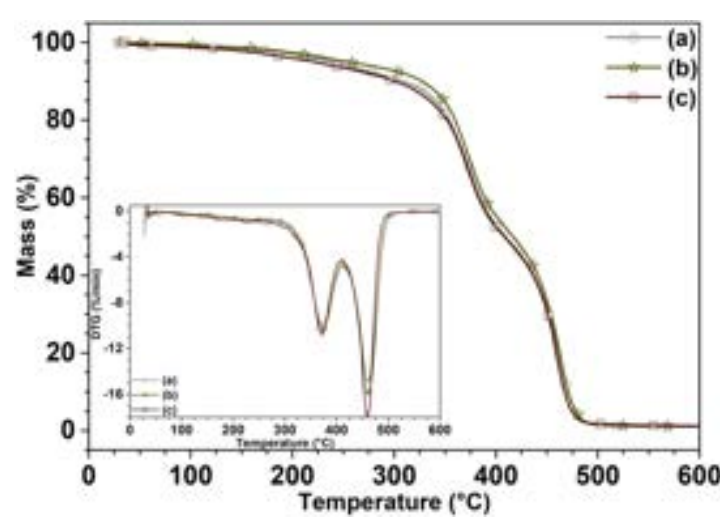

(a)

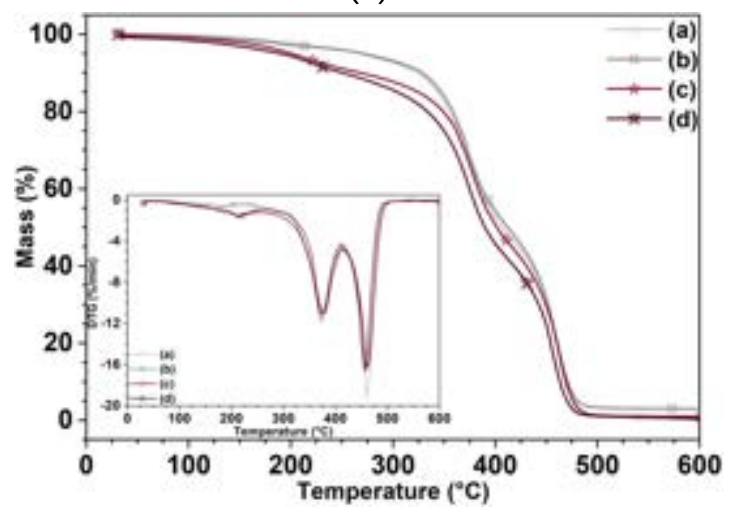

(c)

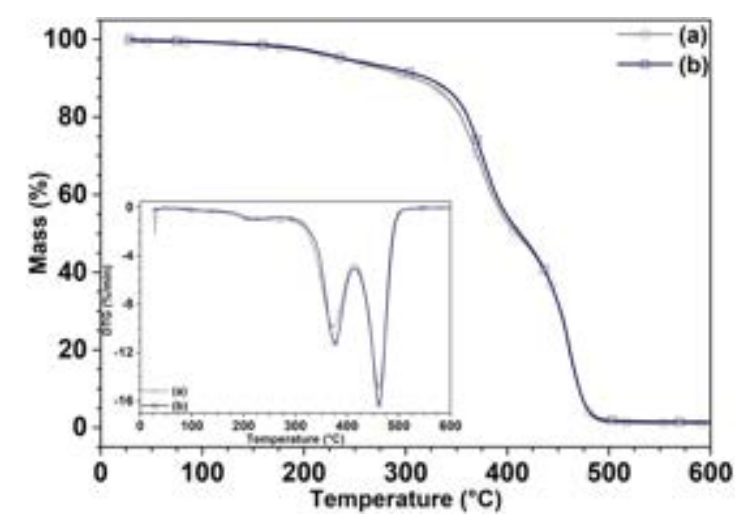

(b)

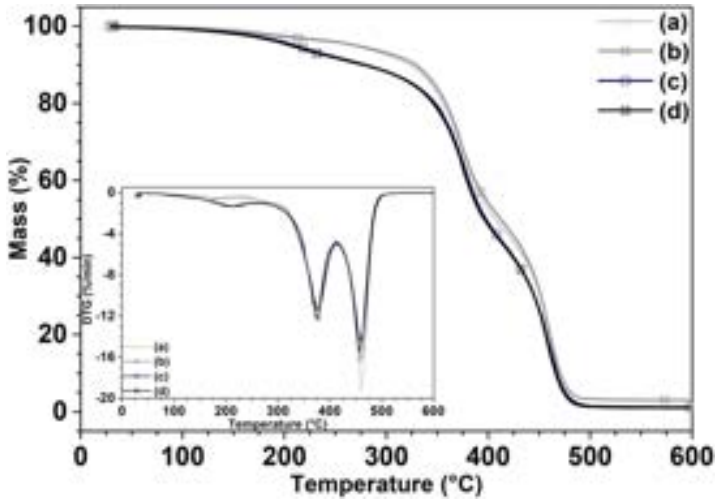

(d)

Figure 38. Representative curves TGA thermal analysis. (a) specimens in pure resin (o-a), with Cu NWs embedded at $0.008 \% \mathrm{w} / \mathrm{w}(*-b)$, and $0.017 \% \mathrm{w} / \mathrm{w}(\square-c)$; (b) substrates in pure resin (o-a), and CuNi NWs embedded at $0.36 \% \mathrm{w} / \mathrm{w}(\square-b)$; (c) specimens in pure resin (o-a and $\bullet-b)$, and Cu NWs embedded at $0.26 \% \mathrm{w} / \mathrm{w}$ ( $\mathrm{x}-\mathrm{c}$ and $*$-d) with post-cured during $14 \mathrm{~min}$ and $28 \mathrm{~min}$, respectively; (d) specimens in pure resin ( $\circ-\mathrm{a}$ and $\bullet-b)$, and CuNi NWs embedded at $0.42 \% \mathrm{w} / \mathrm{w}$ ( $\square-c$ and - d) with post-cured during $14 \mathrm{~min}$ and $28 \mathrm{~min}$, respectively. 
The effects of the thermal melting and thermal degradation behavior of the specimens in pure resin and with nanowires are apparent in the first derivative of thermogravimetric analysis (DTGA) curves provided in Figure 38. The $T_{m}$ and $T_{\mathrm{d}}$ are tabulated and provided in Table 8. These temperatures are almost unchanged with the addition of $\mathrm{Cu}$ NWs at $0.008 \% \mathrm{w} / \mathrm{w}$ and $0.017 \% \mathrm{w} / \mathrm{w}$ (Figure 38(a)) and CuNi NWs at $0.36 \% \mathrm{w} / \mathrm{w}$ (Figure 38(b)) nor with the addition of $\mathrm{Cu}$ NWs at $0.26 \% \mathrm{w} / \mathrm{w}$ (Figure $38(\mathrm{c})$ ) or CuNi NWs at $0.42 \% \mathrm{w} / \mathrm{w}$ (Figure 38(d)) during $14 \mathrm{~min}$ and $28 \mathrm{~min}$ of post-cured. One of the reasons for this behavior is the lack of chemical interaction between "Clear FLGPCL 02" resin and Cu NWs (Figure 38(a) and Figure 38(c)) and CuNi NWs (Figure 38(b) and Figure 38(d)). Before resin starts to melt and degrade, surface interactions between the resin with $\mathrm{Cu}$ NWs or with CuNi NWs might get lost. The stability of the Cu NWs or CuNi NWs was attributed to the protective nature of the polymer-matrix at high temperatures $\left(600^{\circ} \mathrm{C}\right.$ in this case) for a limited amount of time.

Table 8 shows a discrepancy between the $T_{\mathrm{g}}$ values obtained from DSC measurements and DMA analysis. The difference is attributed to the fact that DMA is highly dependent on the frequency of strain oscillation, whereas DSC measures a heat quantity in a temperature change between the target sample and the reference sample, where variations are inevitable. Although $T_{\mathrm{g}}$ results obtained from these two means are not identical in the specimens in pure resin and the specimens nanofillers-reinforced, both show a tendency that the $T_{\mathrm{g}}$ varies slightly as the nanofiller loading varies in the polymeric matrix. Accordingly, $T_{\mathrm{g}}$ obtained on the substrates with $\mathrm{Cu}$ NWs and CuNi NWs decrease in relation to $T_{\mathrm{g}}$ measured on the pure resin specimen.

Table 8. Values determined from DMA, DSC, and TGA analysis on specimens manufactured in pure resin and with nanofillers.

\begin{tabular}{lcccccc}
\hline \multicolumn{1}{c}{ Material type used } & $\begin{array}{c}\text { Nanofiller } \\
\text { percentage } \\
\text { (\% } \mathbf{~ w / w )}\end{array}$ & \multicolumn{2}{c}{ Transition and degradation temperatures } & $\begin{array}{c}\text { Residue } \\
\left({ }^{\circ} \mathbf{C}\right)\end{array}$ \\
& Pure resin & 65.7 & 60.8 & 374.5 & 459.3 & 0.5 \\
\hline Clear FLGPCL 02 resin & 0.008 & 58.7 & 55.3 & 374.2 & 462.6 & 0.9 \\
Cu NWs & 0.017 & 57.4 & 57.5 & 371.7 & 460.3 & 0.1 \\
CuNi NWs & 0.360 & 52.8 & 51.6 & 375.7 & 461.7 & 1.1 \\
\hline Clear FLGPCL 02 resin & Pure resin & 68.8 & 61.8 & 376.1 & 460.8 & 0.8 \\
Cu NWs w (14 min post-cured) & 0.260 & 60.9 & 60.5 & 377.5 & 462.0 & 0.7 \\
CuNi NWs (14 min post-cured) & 0.420 & 60.2 & 60.6 & 376.4 & 459.2 & 1.0 \\
\hline Clear FLGPCL 02 resin & Pure resin & 69.9 & 61.0 & 373.6 & 459.8 & 2.7 \\
Cu NWs (28 min post-cured) & 0.260 & 57.8 & 57.4 & 374.3 & 457.5 & 0.8 \\
CuNi NWs (28 min post-cured) & 0.420 & 56.2 & 55.8 & 375.5 & 457.4 & 0.7 \\
\hline
\end{tabular}

\subsection{Spectroscopic Characterization}

The chemical and structural properties of specimens manufactured in "clear FLGPCL 02 resin and reinforced with nanofillers of $\mathrm{Cu} N W s$ and CuNi NWs, were carefully assessed with standard techniques, such as Raman, FTIR, and DRX. Partial results of the current section have been already presented in [70] and have been submitted for evaluation to Polymers (peer-reviewed open access journal). 
4.5.1. Raman spectroscopy. The Raman spectra obtained on the substrates manufactured in the pure "Clear FLGPCL 02" resin and with Cu NWs, Cu NWs+NPs, and CuNi NWs embedded in the polymer matrix are presented in Figure 39 and Figure 40.

Figure 39 and Figure 40 show $\mathrm{Cu}$ and $\mathrm{Ni}$ vibrational modes at very low frequencies (phonon frequencies, $\sim 10 \mathrm{~cm}^{-1}$. The spectra of Figure 39 and Figure 40 acquired on the surface of the pure resin specimen, reveals three intense Raman peaks at $\sim 1441 \mathrm{~cm}^{-1}$ (strong), $2928 \mathrm{~cm}^{-1}$ and $\sim 2948 \mathrm{~cm}^{-1}$ (very intense) that correspond to the $\mathrm{C}-\mathrm{H}$ bond vibrations. Consequently, the medium and weak peaks at $\sim 1560 \mathrm{~cm}^{-1}$ and $\sim 1590 \mathrm{~cm}^{-1}$ are attributed to the $\mathrm{C}-\mathrm{N}-\mathrm{H}$ and $\mathrm{C}-\mathrm{NO}_{2}$ bond vibrations, respectively. The peaks at $\sim 595 \mathrm{~cm}^{-1}$ (medium) and $\sim 1608 \mathrm{~cm}^{-1}$ (weak) correspond to the $\mathrm{C}-\mathrm{C}$ and $\mathrm{C}=\mathrm{C}$ bond vibrations, respectively. The medium peaks at $\sim 1632 \mathrm{~cm}^{-1}$ and $\sim 1712 \mathrm{~cm}^{-1}$ refer to the $\mathrm{C}=0$ symmetric and antisymmetric bond vibrations, and the one at $\sim 1396 \mathrm{~cm}^{-1}$ to the $\mathrm{CH}_{3}$ asymmetric bond stretching vibration. The band between $\sim 785 \mathrm{~cm}^{-1}$ and $\sim 980 \mathrm{~cm}^{-1}$ corresponds to the $\mathrm{C}-\mathrm{O}-\mathrm{C}$ bond vibrations, the one between $\sim 1000 \mathrm{~cm}^{-1}$ and $\sim$ $1160 \mathrm{~cm}^{-1}$, to the $\mathrm{C}-\mathrm{O}-\mathrm{C}$ bond asymmetric stretching vibrations, and the one between $~$ $1300 \mathrm{~cm}^{-1}$ and $\sim 1380 \mathrm{~cm}^{-1}$, to the $\mathrm{C}-\mathrm{CH}_{3}$ bond vibrations. Additionally, the weak peaks between $\sim 2650 \mathrm{~cm}^{-1}$ and $\sim 2810 \mathrm{~cm}^{-1}$, and between $\sim 3050 \mathrm{~cm}^{-1}$ and $\sim 3500 \mathrm{~cm}^{-1}$ are attributed to the $\mathrm{O}-\mathrm{C}-\mathrm{H}$ and $\mathrm{O}-\mathrm{H}$ bond vibrations, respectively $[99,100]$.

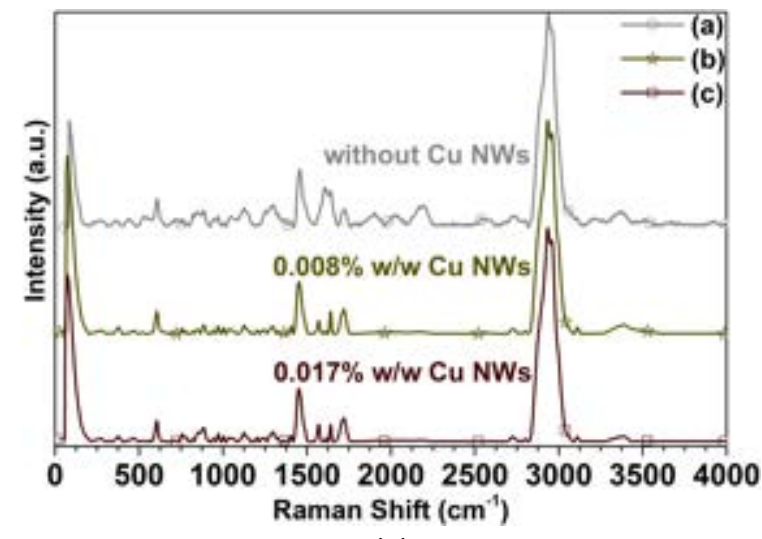

(a)

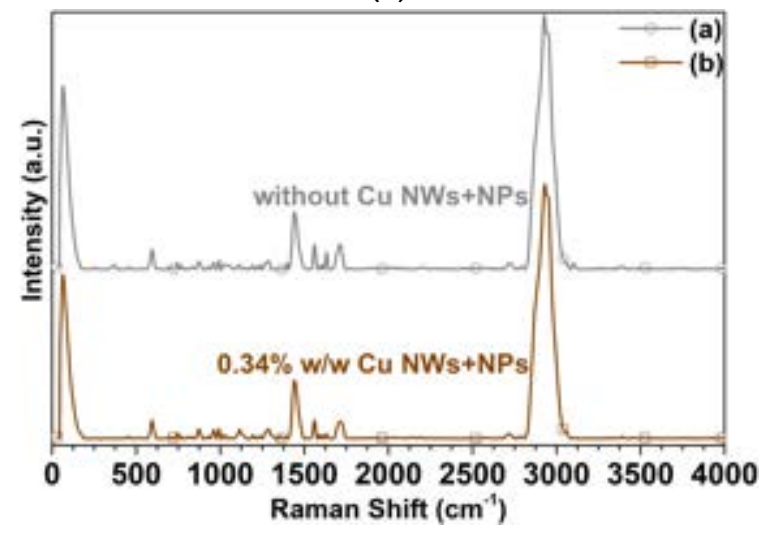

(c)

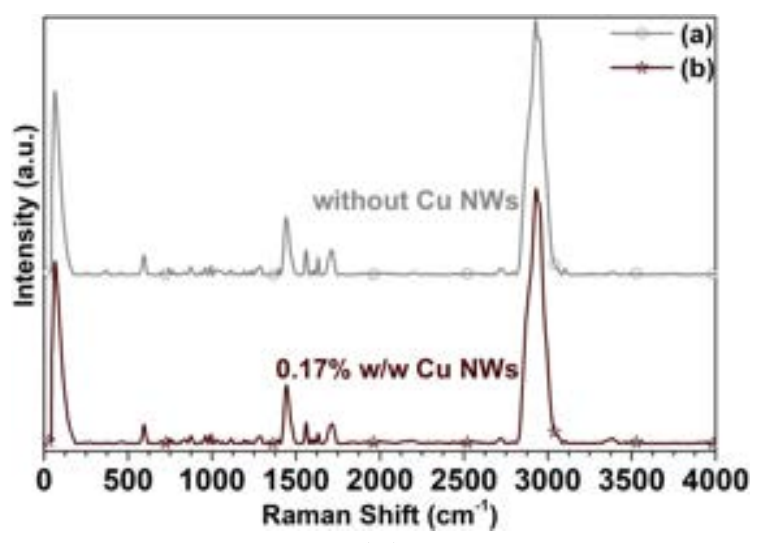

(b)

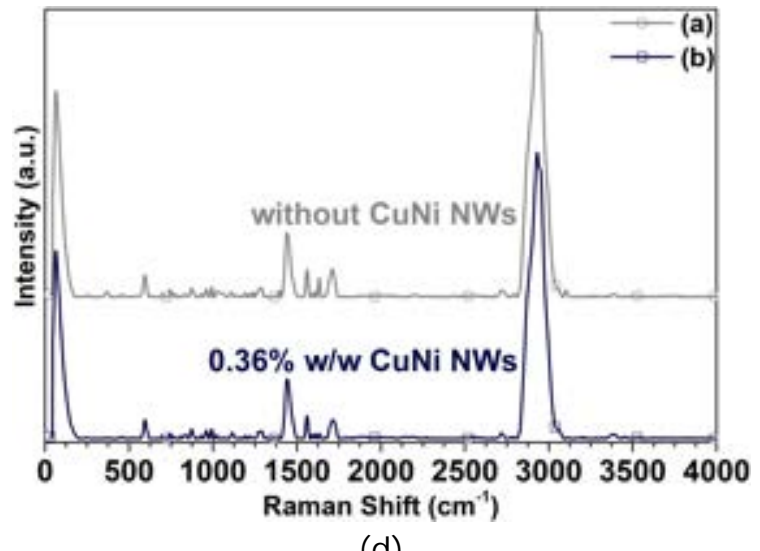

(d)

Figure 39. Raman spectra acquired on substrates manufactured pure resin and with nanowires. (a) pure resin, with Cu NWs embedded at $0.008 \% \mathrm{w} / \mathrm{w}$, and $0.017 \% \mathrm{w} / \mathrm{w}$; (b) pure resin, and Cu NWs embedded at $0.17 \% \mathrm{w} / \mathrm{w}$; (c) pure resin, and Cu NWs+NPs embedded at $0.34 \% \mathrm{w} / \mathrm{w}$; (d) pure resin, and CuNi NWs embedded at $0.36 \% \mathrm{w} / \mathrm{w}$. 
Raman spectroscopy reveals the surface interaction between organic materials and metallic nanostructures, through surface-enhanced Raman scattering. Figure 39 and Figure 40 present a similar Raman spectra profile both in the pure resin specimen as for specimens reinforced with metallic nanofillers of $\mathrm{Cu}$ and CuNi. For this reason, it is possible to observe intensification in vibrational signals corresponding to $\mathrm{C}-\mathrm{H}\left(2928 \mathrm{~cm}^{-1}-2948 \mathrm{~cm}^{-1}\right)$ and $\mathrm{O}-\mathrm{H}\left(3050 \mathrm{~cm}^{-1}-3500 \mathrm{~cm}^{-1}\right)$ vibrational modes [70,101-103]. This is evidence of the surface interaction between the polymeric resin and CuNi NWs through $\mathrm{C}-\mathrm{H}$ and $\mathrm{O}-\mathrm{H}$ functional groups. Furthermore, metallic structures such as $\mathrm{Cu}$ and $\mathrm{Ni}$ do not present vibrational frequencies (phonon frequencies) in the range of wavenumbers observed in this study. Thus, this surface interaction can be responsible for the difference of $T_{\mathrm{g}}$ before and after doping. Additionally, these studies allow us to identify differences in the degree of crystallinity due to the influence of the doping agents.

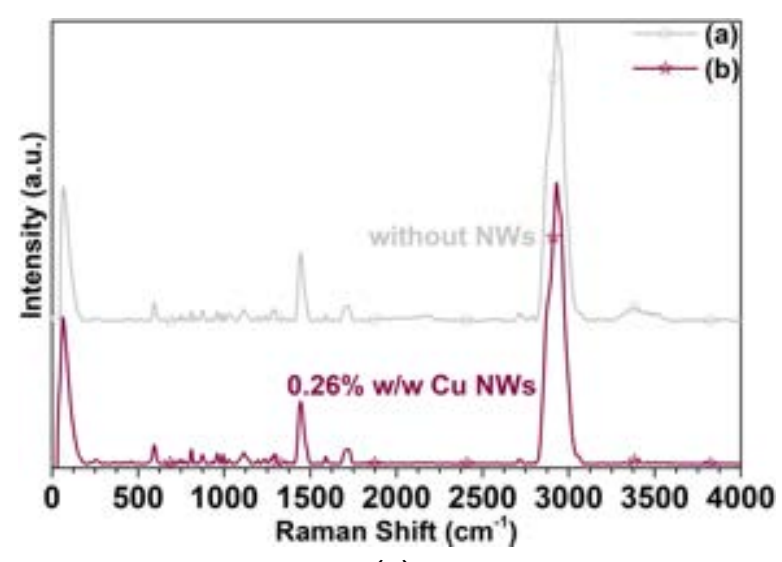

(a)

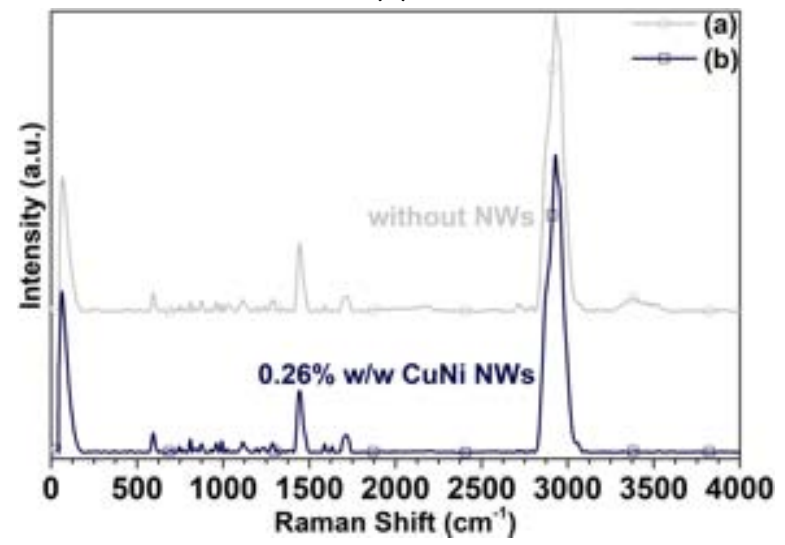

(c)

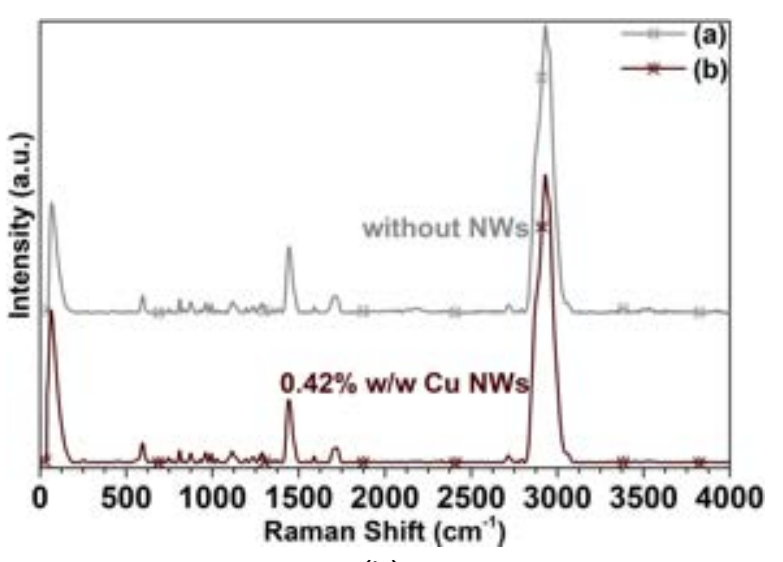

(b)

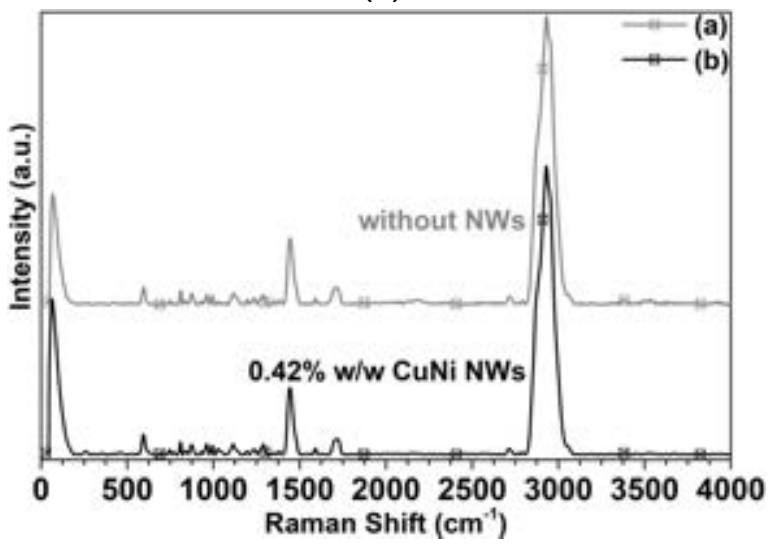

(d)

Figure 40. Raman spectra acquired on substrates manufactured pure resin and with nanowires. Pure resin ( $\circ-\mathrm{a}$ and $\bullet-a)$, and Cu NWs embedded at $0.26 \% \mathrm{w} / \mathrm{w}$ ( $\mathrm{a}-\mathrm{b}$ and $*-\mathrm{b}$ ) with post-cured during $14 \mathrm{~min}$ (a), and $28 \mathrm{~min}$ (b). Pure resin ( $\circ-\mathrm{a}$ and $\bullet-a$ ), and CuNi NWs embedded at $0.42 \% \mathrm{w} / \mathrm{w}$ ( $\square-\mathrm{b}$ and - b) with post-cured during $14 \mathrm{~min}(\mathrm{c})$, and $28 \mathrm{~min}(\mathrm{~d})$.

4.5.2. Fourier-transformed infrared. Figure 41 and Figure 42 present the FT-IR spectra of the substrates manufactured in pure "Clear FLGPCL 02" resin and with Cu NWs, Cu NWs+NPs, and CuNi NWs embedded in the polymer matrix, where there are distinct absorption bands from $1150 \mathrm{~cm}^{-1}$ to $1250 \mathrm{~cm}^{-1}$, which can be attributed to the $\mathrm{C}-\mathrm{O}-\mathrm{C}$ stretching vibrations. The two bands at $1386 \mathrm{~cm}^{-1}$ and $748 \mathrm{~cm}^{-1}$ can be attributed to the $\alpha$-methyl 
group vibrations. Moreover, the bands at $865 \mathrm{~cm}^{-1}, 1297 \mathrm{~cm}^{-1}, 1367 \mathrm{~cm}^{-1}$, and $1405 \mathrm{~cm}^{-1}$ can be attributed to the $\mathrm{C}-\mathrm{C}, \mathrm{O}-\mathrm{CH}_{2}, \mathrm{C}-\mathrm{H}$, and $\mathrm{C}-\mathrm{OH}$ stretching vibration, respectively. The band at $1700 \mathrm{~cm}^{-1}$ indicates the presence of the ester group $\mathrm{C}=0$ stretching vibrations. The band at $1451 \mathrm{~cm}^{-1}$ can be attributed to the bending vibrations of the $\mathrm{C}-\mathrm{H}$ bonds of the $-\mathrm{CH}_{3}$ groups. The three bands at $2952 \mathrm{~cm}^{-1}, 2932 \mathrm{~cm}^{-1}$, and $2862 \mathrm{~cm}^{-1}$ can be assigned to the $\mathrm{C}-\mathrm{H}$ bond stretching vibrations. Furthermore, there are two weak absorption bands at $\sim 3375 \mathrm{~cm}^{-1}$ and $\sim 1637 \mathrm{~cm}^{-1}$, which can be attributed to the $-\mathrm{OH}$ group stretching and bending vibrations, respectively. Notwithstanding, there are no appreciable differences between the FTIR spectra of the pure resin and with CuNi NWs because the resin does not form any covalent bond with this type of nanofillers; additionally, the nanofillers do not add new functional groups that can be observed with infrared (see Figure 41 and Figure 42).

Regarding the above discussions, it can be concluded that the photoreactive polymer resin is a type of macromolecular methacrylic acid (MAA) and methyl methacrylate (MMA) mixture [70,94, 107-109].

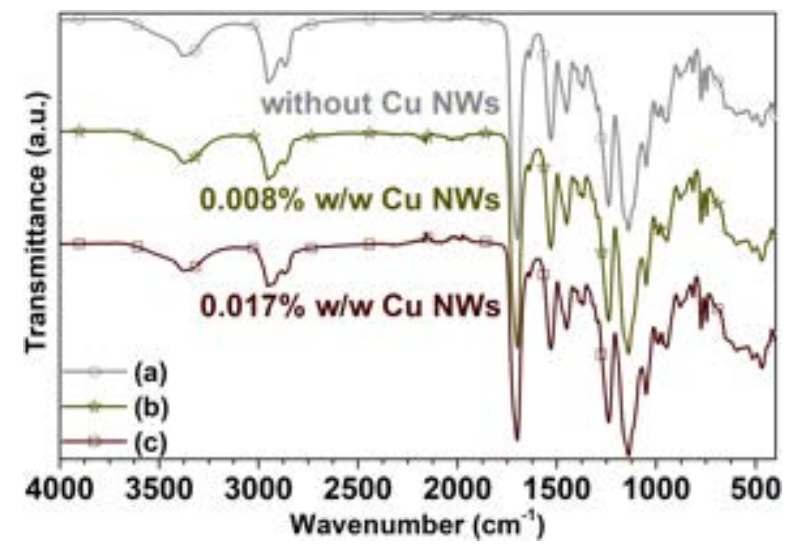

(a)

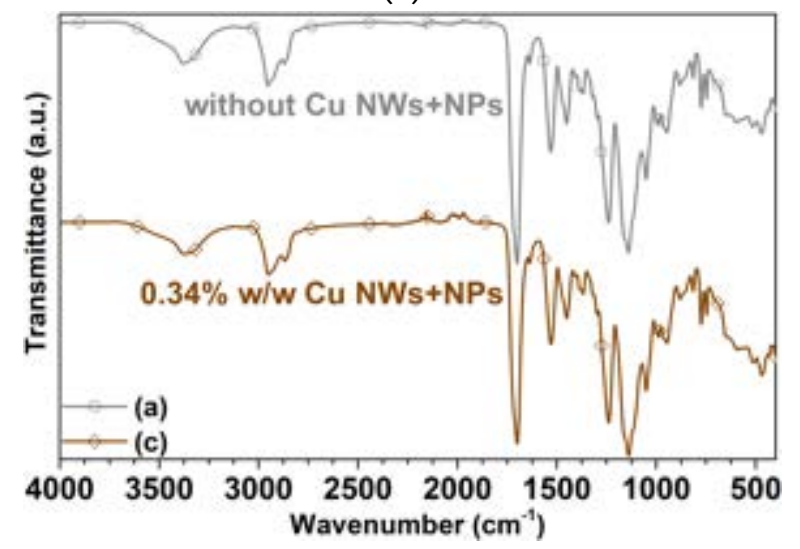

(c)

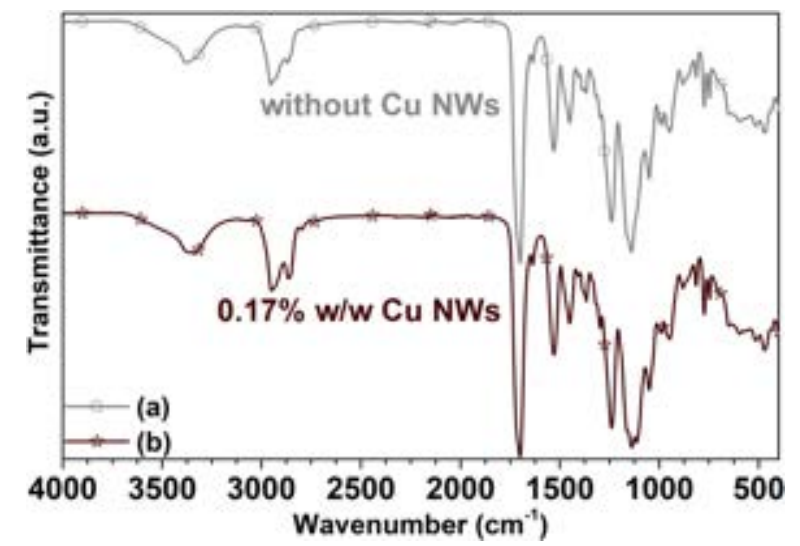

(b)

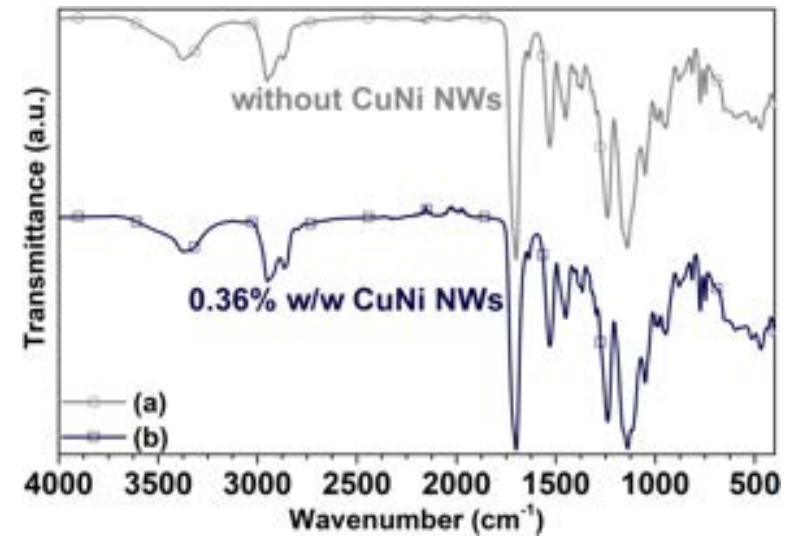

(d)

Figure 41. FTIR spectra acquired on substrates manufactured pure resin and with nanowires. (a) pure resin, with Cu NWs at $0.008 \% \mathrm{w} / \mathrm{w}$, and $0.017 \% \mathrm{w} / \mathrm{w}$; (b) pure resin, and Cu NWs embedded at $0.17 \% \mathrm{w} / \mathrm{w}$; (c) pure resin, and Cu NWs+NPs embedded at $0.34 \% \mathrm{w} / \mathrm{w}$; (d) pure resin, and CuNi NWs embedded at $0.36 \% \mathrm{w} / \mathrm{w}$. 


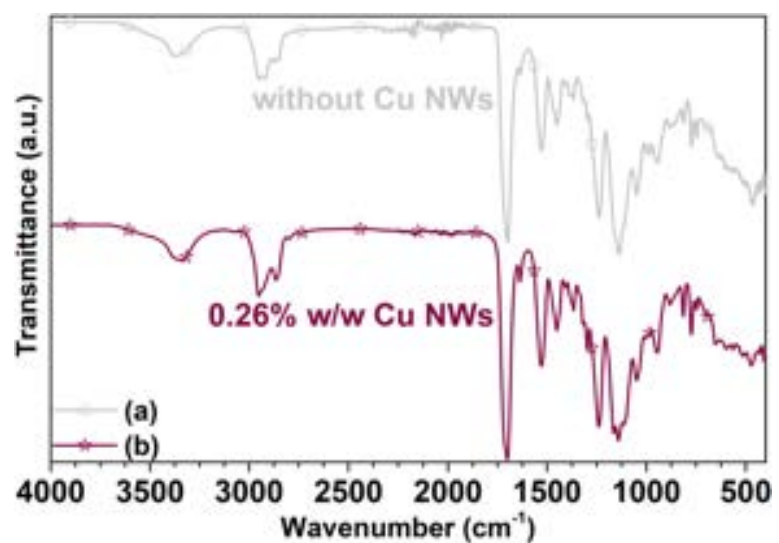

(a)

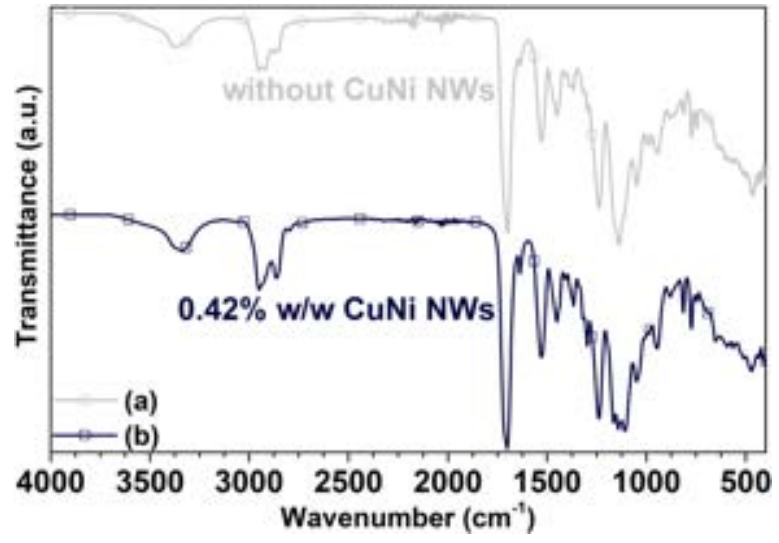

(c)

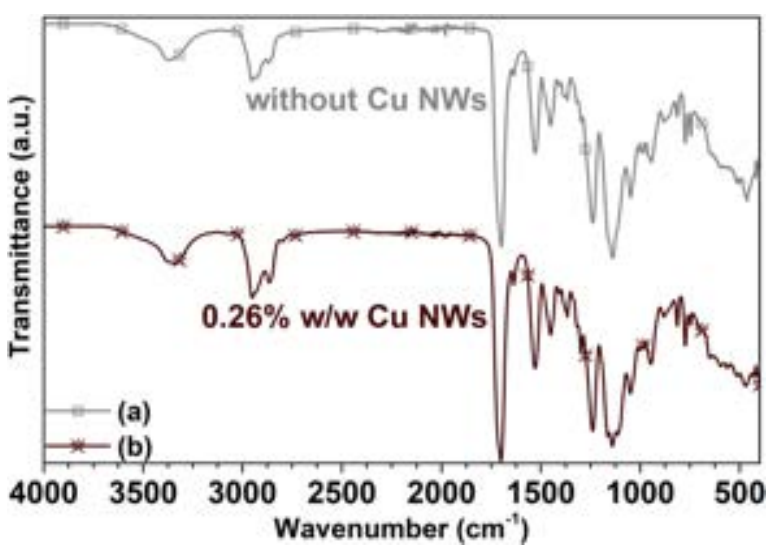

(b)

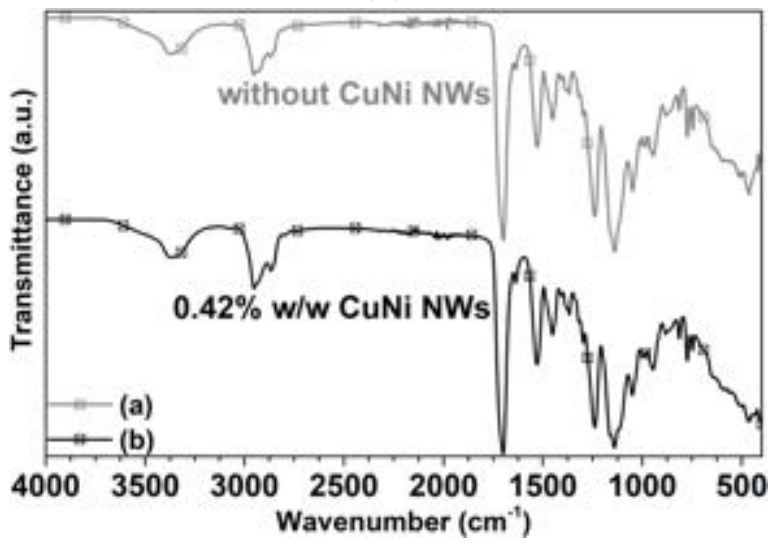

(d)

Figure 42. FTIR spectra acquired on substrates manufactured pure resin and with nanowires. Pure resin ( $0-\mathrm{a}$ and $\cdot-\mathrm{a})$, and $\mathrm{Cu}$ NWs embedded at $0.26 \% \mathrm{w} / \mathrm{w}$ ( $\mathrm{a}-\mathrm{b}$ and $*-\mathrm{b})$ with post-cured during $14 \mathrm{~min}$ (a), and $28 \mathrm{~min}$ (b). Pure resin ( $\circ-\mathrm{a}$ and $\bullet-a$ ), and CuNi NWs embedded at $0.42 \% \mathrm{w} / \mathrm{w}$ ( $\square-\mathrm{C}$ and - -d) with post-cured during $14 \mathrm{~min}$ (c), and $28 \mathrm{~min}$ (d).

4.5.3. X-ray diffraction. The XRD patterns of Figure 43 prove that the Cu NWs and CuNi NWs embedded in the polymer matrix of the substrates manufactured by 3D printing have a facecentered cubic structure (in agreement with the database PDF-02 of the ICDD).

The characteristic diffraction peaks of copper at $\sim 43.3^{\circ}$ and $\sim 50.5^{\circ}$ were observed, which correspond to the (1 111$)$ and (2 000$)$ planes of the face centered cubic structure (FCC) respectively (Figure $43(\mathrm{a})$ ). The high peak intensity indicates that the Cu NWs are of high crystallinity. On the other hand, in Figure 43(b) and Figure 43(c), moreover to Cu peaks, two characteristic peaks of nickel are identified at $\sim 44.0^{\circ}$ and $\sim 51.5^{\circ}$, which correspond to the diffraction planes (1 111$)$ and (2 000$)$ respectively.

XRD patterns presented in Figure 43, corresponding to the substrates manufactured with nanofillers, no peaks from other phases or impurity peaks were detected. Then, this result confirms that in the bulk of the specimens only the Cu NWs and CuNi NWs are embedded. On the other hand, no diffraction peaks were observed in the XRD patterns of the specimens manufactured in pure "Clear FLGPCL 02" resin, because are amorphous.

Semi-quantitative analysis of the phases found in the specimens manufactured with nanowires of $\mathrm{Cu}$ and $\mathrm{CuNi}$ was performed using the Rietveld method. The percentages determined to correspond to the polycrystalline phases without considering the percentage 
of amorphous material. Therefore, copper contents are between $\sim 51 \%$ to $\sim 60 \%$, and the nickel between $\sim 40 \%$ to $\sim 49 \%$, which were evaluated from the semi-quantitative analysis.

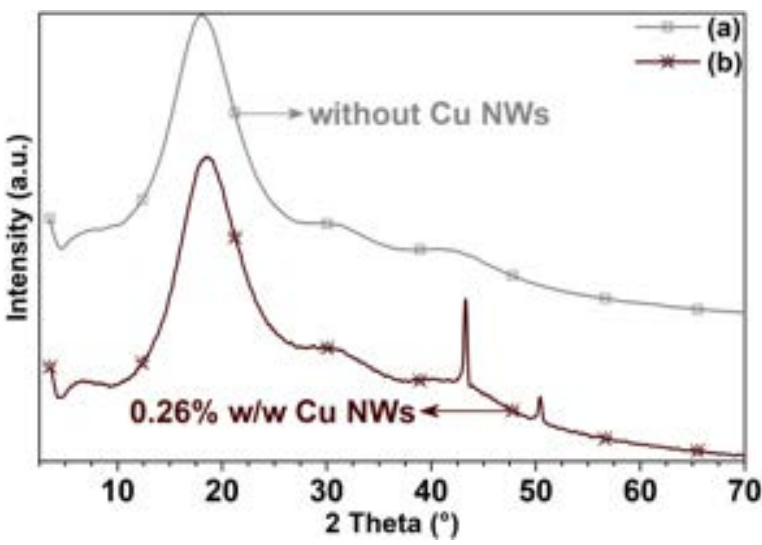

(a)

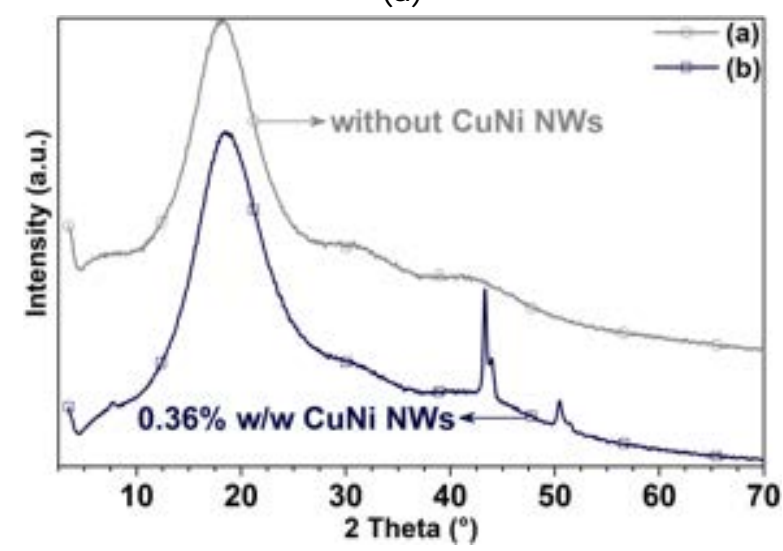

(c)

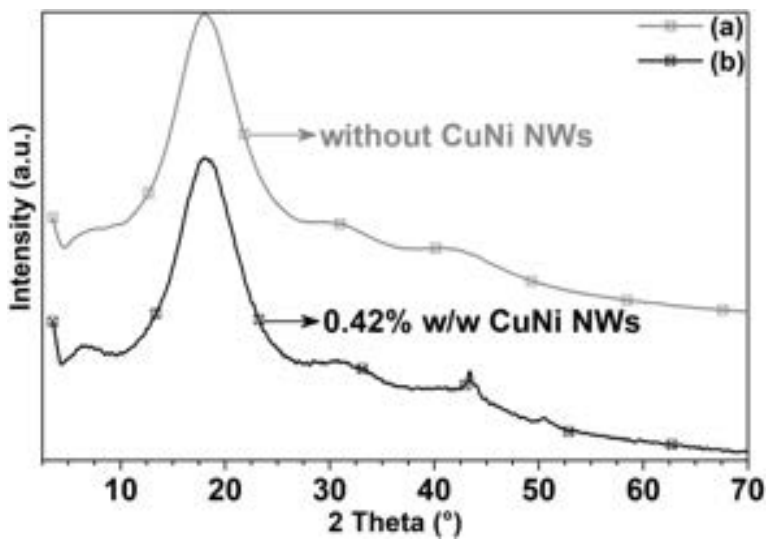

(b)

Figure 43. XRD patterns acquired on the substrates printed pure resin and with nanowires. (a) pure resin $(\cdot-a)$, and $\mathrm{Cu}$ NWs embedded at $0.26 \% \mathrm{w} / \mathrm{w}(*-\mathrm{b})$ with post-cured during $28 \mathrm{~min}$. (b) pure resin $(\cdot-a)$, and CuNi NWs embedded at $0.42 \% \mathrm{w} / \mathrm{w}(--b)$ with post-cured during $28 \mathrm{~min}$. (c) pure resin (o-a), and CuNi NWs embedded at $0.36 \% \mathrm{w} / \mathrm{w}(\square-b)$. 


\section{Graphene Oxide Results and Discussions}

This section presents main surface and bulk characterization results of substrates and probes mass-functionalized or reinforced with graphene oxide (GO), as compared with the pure resin specimens. A versatile set of analytical techniques is used to promote a systematic research and provide characterization results of morphological, mechanical, thermal, viscoelastic and structural properties of the substrates and samples manufactured by laser stereolithography.

\subsection{Cost Considerations}

The manufacturing time of 3 cylindrical specimens or 3 substrates for tensile testing, with nanofillers or pure resin, is approximately $17 \mathrm{~min}$ and $22 \mathrm{~min}$, respectively. Then, each layer, with a surface area of $3.6 \mathrm{~cm}^{2}$ by substrate cylindrical or $5.1 \mathrm{~cm}^{2}$ by specimen for tensile testing, is fabricated in approximately 11 seconds and 14 seconds, respectively. Table 9, the approximate cost of materials used for manufacturing each cylindrical substrate or for tensile testing manufactured is reported. The cost of manufacturing of a functional device with GO depends on the percentage added, these costs are presented in Table 10. This cost calculation only considered the chemicals used for the synthesis of the GO, and not the energy, inert gas, and other supplies used during the manufacturing.

Table 9. Approximate cost of some materials.

\begin{tabular}{lc}
\hline \multicolumn{1}{c}{ Materials } & Cost \\
\hline Liquid resin & $0.14(€ / \mathrm{ml})$ \\
Graphene oxide & $0.01(€ / \mathrm{mg})^{*}$ \\
\hline *This cost only considers the chemicals used for synthesis of the GO. \\
\hline
\end{tabular}

Table 10. Approximate cost of manufacturing a functional device.

\begin{tabular}{|c|c|c|c|c|}
\hline Substrate type & $\begin{array}{l}\text { Nanofiller } \\
\text { type }\end{array}$ & $\begin{array}{c}\text { Nanofiller solution percentage } \\
\qquad(\% \mathrm{w} / \mathrm{w})\end{array}$ & $\begin{array}{c}\text { Nanofiller percentage } \\
(\% \mathbf{w} / \mathbf{w})\end{array}$ & $\begin{array}{l}\text { Cost } \\
(€)\end{array}$ \\
\hline \multirow{7}{*}{ Cylindrical } & Pure resin & 0.0 & 0.000 & 0.14 \\
\hline & \multirow{6}{*}{ GO } & 5.0 & 0.020 & 0.13 \\
\hline & & 10.0 & 0.040 & 0.13 \\
\hline & & 15.0 & 0.060 & 0.12 \\
\hline & & 20.0 & 0.080 & 0.12 \\
\hline & & 25.0 & 0.100 & 0.11 \\
\hline & & 30.0 & 0.120 & 0.11 \\
\hline \multirow{7}{*}{ Test specimens } & Pure resin & 0.0 & 0.000 & 0.21 \\
\hline & \multirow{6}{*}{ GO } & 5.0 & 0.020 & 0.20 \\
\hline & & 10.0 & 0.040 & 0.20 \\
\hline & & 15.0 & 0.060 & 0.19 \\
\hline & & 20.0 & 0.080 & 0.18 \\
\hline & & 25.0 & 0.100 & 0.17 \\
\hline & & 30.0 & 0.120 & 0.17 \\
\hline
\end{tabular}




\subsection{Morphological Properties}

Morphological properties of specimens manufactured in pure resin and GO-reinforced were analyzed through SEM and EDS.

5.2.1. Scanning electron microscopy and energy-dispersive $X$-ray spectroscopy. The micrographs in Figure 44 demonstrate the flat morphological images of the surfaces of specimens manufactured with GO embedded, at concentrations different, in the photopolymerized resin. Consequently, is observed the content of the $\mathrm{GO}$ is well dispersed, where the GO distribution does not present patterns of agglutinants, clusters or localized agglomerations that predict the anisotropy of the bulk. Hence, this behavior is expected to influence the mechanical properties of the polymer matrix [70,77-79]. The EDS-determined only the presence of such as $\mathrm{C}$ and $\mathrm{O}$ element, which are the same predominant elements of the photopolymer resin and of atmosphere where were measurement the specimens, therefore the EDS is no suitable technique to detect and quantify the GO.

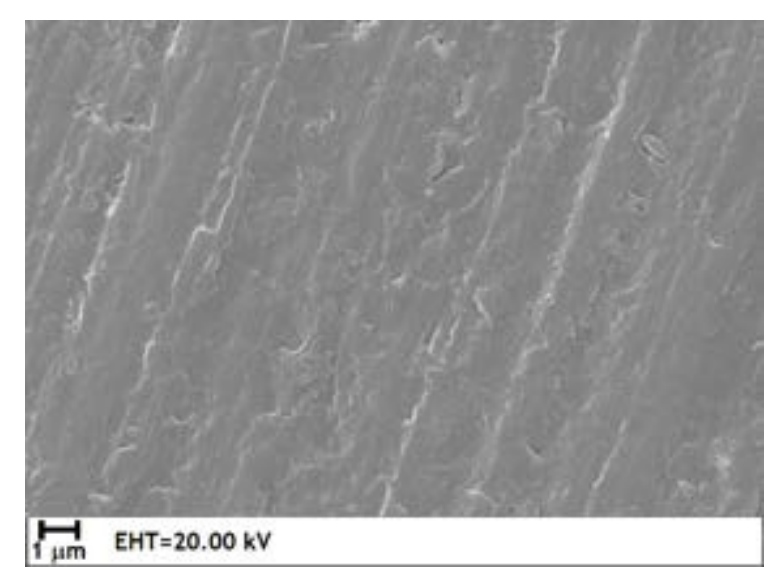

(a)

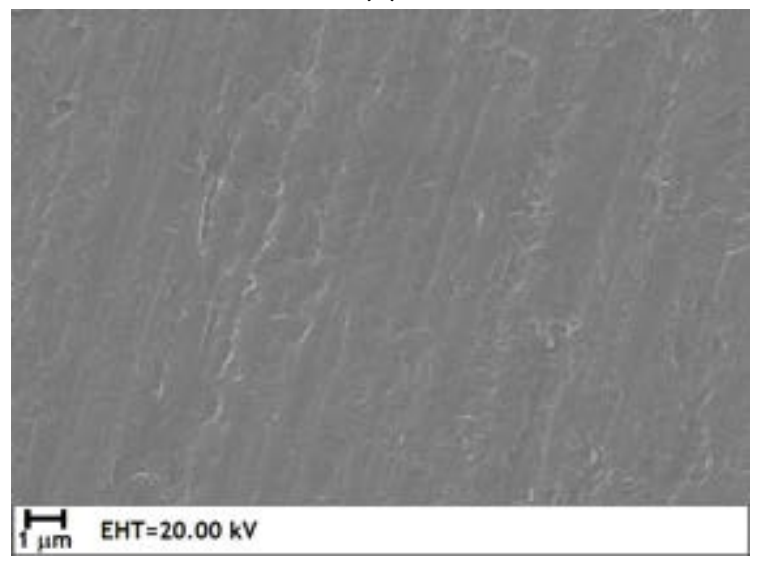

(c)

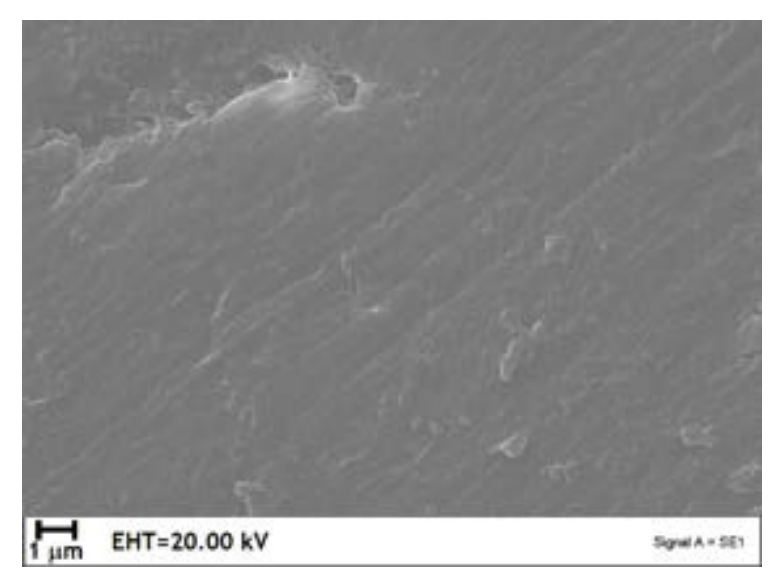

(b)

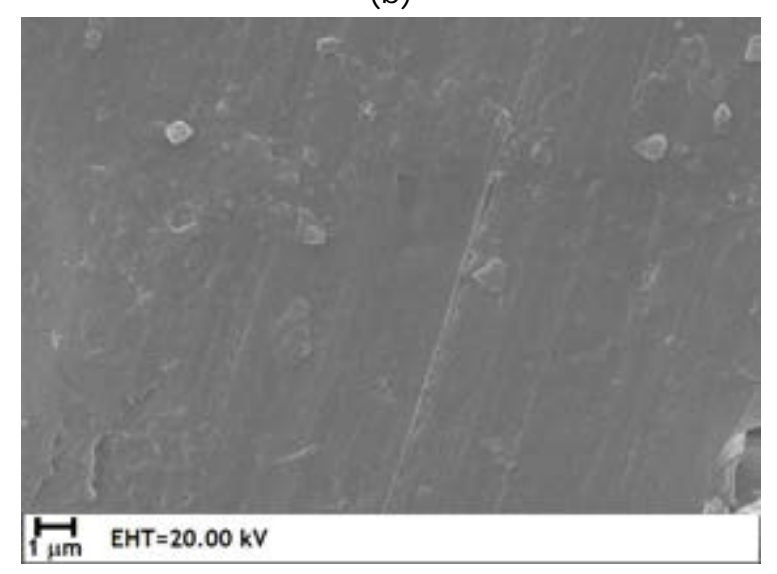

(d)

Figure 44. SEM Micrographs on the surface of a substrate pure resin (a), with GO-reinforced at $0.04 \% \mathrm{w} / \mathrm{w}$ (b), $0.08 \% \mathrm{w} / \mathrm{w}$ (c), and $0.12 \% \mathrm{w} / \mathrm{w}$ (d).

The micrographs in Figure 44 demonstrate the flat morphological images of the surfaces of specimens manufactured with GO-reinforced, at concentrations different, in the photopolymerized resin. Consequently, is observed the content of the GO is well dispersed, where the GO distribution does not present patterns of agglutinants, clusters or localized 
agglomerations that predict the anisotropy of the bulk. Hence, this behavior is expected to influence the mechanical properties of the polymer matrix [70,77-79]. The EDS-determined only the presence of such as $\mathrm{C}$ and $\mathrm{O}$ element, which are the same predominant elements of the photopolymer resin and of atmosphere where were measurement the specimens, therefore the EDS is no suitable technique to detect and quantify the GO.

\subsection{Mechanical Performance}

Mechanical performance of specimens manufactured in pure resin and GO-reinforced was analyzed through tensile testing and Instrumented indentation techniques, as shown below.

5.3.1. Tensile testing. Representative load-displacement curves for the substrates manufactured using the photopolymer commercial resin, both with and GO-reinforced used for mass-functionalization, are provided in Figure 45 and Figure 46.

In Figure 45(a) observes that the curve of the specimens manufactured with "Clear FLGPCL 02 " pure resin and with $\mathrm{GO}$ at $0.04 \% \mathrm{w} / \mathrm{w}$ lead to ductile behavior, while that curves of the substrates with concentrations of $\mathrm{GO}$ at $0.08 \% \mathrm{w} / \mathrm{w}$ and $0.12 \% \mathrm{w} / \mathrm{w}$, have brittle behaviors. Figures 45(a) and Figures 45(b) show that the TS significantly decreases in the specimens when increasing the GO concentration to $0.12 \% \mathrm{w} / \mathrm{w}$, that was the lower value of $T S$ obtained.

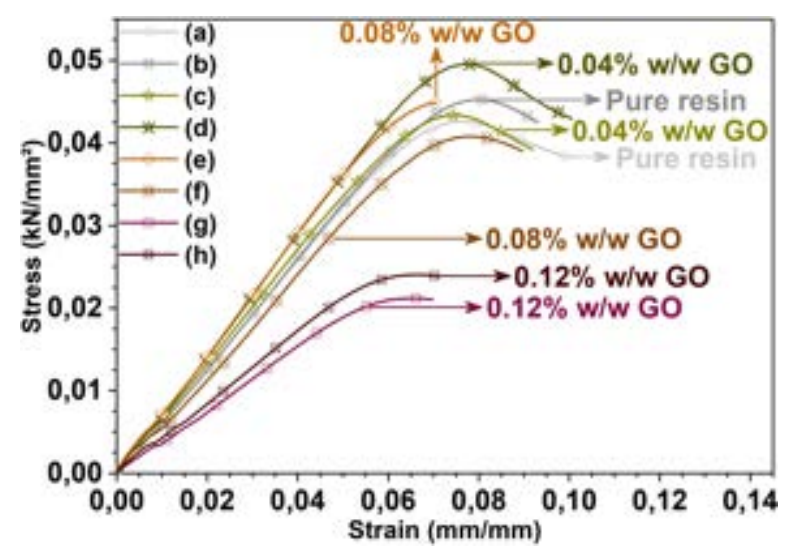

(a)

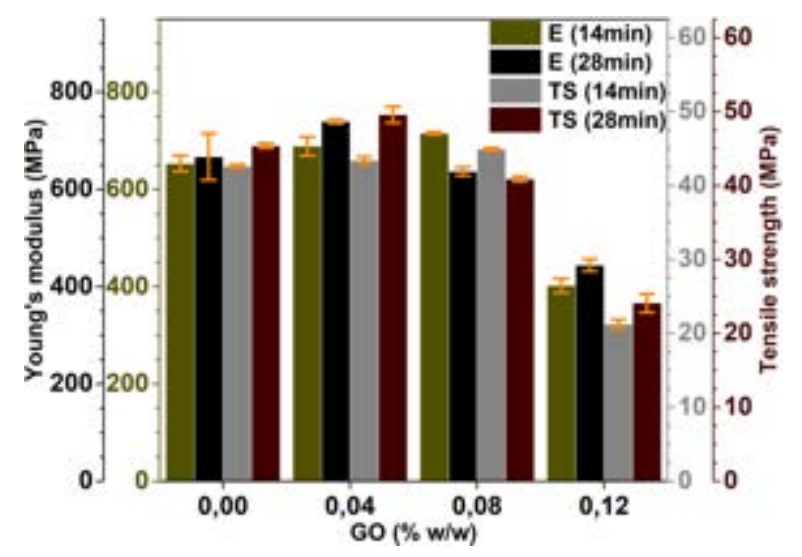

(b)

Figure 45. Representative tensile testing curves of specimens' pure resin and with GO. (a) stressstrain curves, (o-a and $\bullet-b)$ pure resin, with GO-reinforced at $0.04 \% \mathrm{w} / \mathrm{w}$ ( $\mathrm{x}-\mathrm{c}$ and $*-\mathrm{d}$ ), $0.08 \% \mathrm{w} / \mathrm{w}$ $(\diamond-e$ and $\bullet-f)$, and $0.12 \% \mathrm{w} / \mathrm{w}(\square-g$ and - h). (b) Effect of GO content on $E$ moduli and the TS.

TS values are 42.6 MPa, 45.4 MPa, 43.4 MPa, 49.6 MPa, 44.9 MPa, 40.9 MPa, 21.2 MPa, and 24.1 MPa for the specimens' pure resin post-cured during $14 \mathrm{~min}$, and $28 \mathrm{~min}$; and substrates GO-reinforced at $0.04 \% \mathrm{w} / \mathrm{w}, 0.08 \% \mathrm{w} / \mathrm{w}$, and $0.12 \% \mathrm{w} / \mathrm{w}$ post-cured during $28 \mathrm{~min}$ and $14 \mathrm{~min}$, respectively. For these specimens, corresponding $E$ moduli values are $653.1 \mathrm{MPa}$, 667.0 MPa, 688.8 MPa, 739.5 MPa, 715.5 MPa, 637.1 MPa, 402.3 MPa, and 444.2 MPa as shown in Figure $45(\mathrm{~b})$, respectively. The decrease of the $T S$ of the substrates for $\mathrm{GO}$ concentration of $0.12 \% \mathrm{w} / \mathrm{w}$, may be attributed to the saturation in the dispersion of the GO that affects the polymerization degree of the final specimens, producing a reduction toughness effect 
when increasing the GO content. So, this parameter should always be considered in photopolymerization-based additive manufacturing techniques. Moreover, during the specimens' strain, it is determined that the molecular structure of the GO-reinforced substrates at $0.04 \% \mathrm{w} / \mathrm{w}$ was that absorbed more energy in regarding the specimens with GO content at $0.12 \% \mathrm{w} / \mathrm{w}$, that proved the lower in absorbance energy terms.

Accordingly, is demonstrated that the specimens manufactured by $3 D$ photopolymerization in type "Clear FLGPCL 02" resin with GO to low-concentrations and postcured during $14 \mathrm{~min}$ and $28 \mathrm{~min}$ achieve a good combination of strength and ductility. Regarding above, TS increased by $1.9 \%$ and $9.3 \%$, and the elongation decreased by $1.3 \%$ and $2.6 \%$ for the GO-reinforced substrate at $0.04 \% \mathrm{w} / \mathrm{w}$ and post-cured during $14 \mathrm{~min}$ and 28 min, respectively.

In Figure 46(a) observes that the curve of the specimens manufactured with type "Grey PN: F100G" pure resin lead to a ductile behavior, while that curves of the functionalizedsubstrates with concentrations different of $\mathrm{GO}$ at $0.12 \% \mathrm{w} / \mathrm{w}, 0.10 \% \mathrm{w} / \mathrm{w}, 0.08 \% \mathrm{w} / \mathrm{w}$, $0.06 \% \mathrm{w} / \mathrm{w}, 0.04 \% \mathrm{w} / \mathrm{w}$, and $0.02 \% \mathrm{w} / \mathrm{w}$ have brittle behaviors. Figure $46(\mathrm{a})$ and Figure 46(b) show that the TS significantly decreases in the specimens when increasing the GO concentration after $0.04 \% \mathrm{w} / \mathrm{w}$; however, the lower value of TS was obtained for the substrate pure resin.

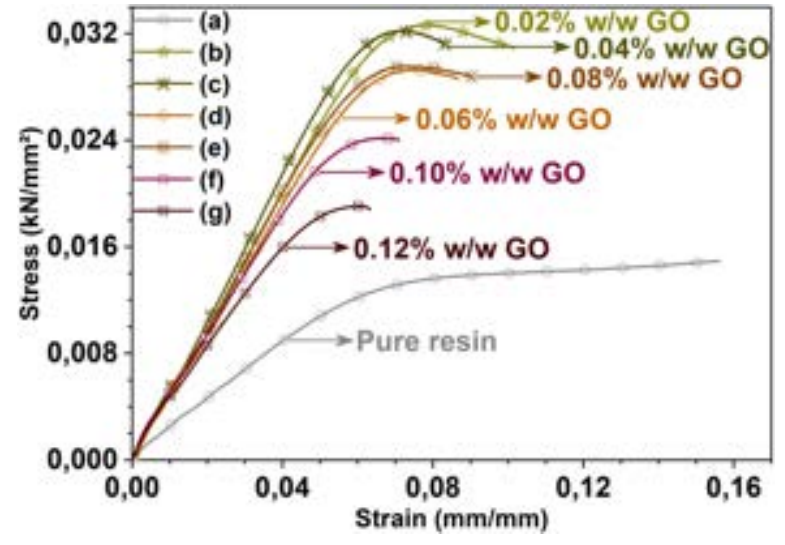

(a)

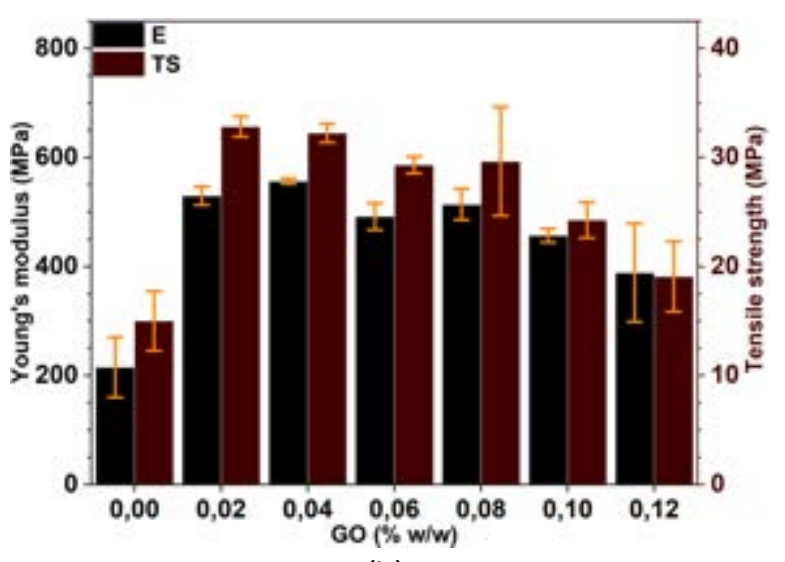

(b)

Figure 46. Representative tensile testing curves of de specimens' pure resin and with GO. (a) stress-strain curves, (o-a) pure resin, with GO-reinforced at $0.02 \% \mathrm{w} / \mathrm{w}(\mathrm{x}-\mathrm{b}), 0.04 \% \mathrm{w} / \mathrm{w}(*-c)$, $0.06 \% \mathrm{w} / \mathrm{w}(\diamond-\mathrm{d}), 0.08 \% \mathrm{w} / \mathrm{w}(\bullet-\mathrm{e}), 0.10 \% \mathrm{w} / \mathrm{w}(\square-\mathrm{f})$, and $0.12 \% \mathrm{w} / \mathrm{w}(-\mathrm{g})$. (b) Effect of $\mathrm{GO}$ content on $E$ modulus and the TS.

$E$ moduli values are 215.2 MPa, 529.7 $\mathrm{MPa}, 556.6 \mathrm{MPa}$, 491.9 $\mathrm{MPa}, 514.0 \mathrm{MPa}, 456.9 \mathrm{MPa}$, and $388.7 \mathrm{MPa}$ for the specimens' pure resin; and substrates GO-reinforced at $0.02 \% \mathrm{w} / \mathrm{w}$, $0.04 \% \mathrm{w} / \mathrm{w}, 0.06 \% \mathrm{w} / \mathrm{w}, 0.08 \% \mathrm{w} / \mathrm{w}, 0.10 \% \mathrm{w} / \mathrm{w}$, and $0.12 \% \mathrm{w} / \mathrm{w}$, respectively. For these specimens, corresponding TS is $15.0 \mathrm{MPa}, 32.8 \mathrm{MPa}, 32.2 \mathrm{MPa}, 29.3 \mathrm{MPa}, 29.6 \mathrm{MPa}, 24.3 \mathrm{MPa}$, and $19.1 \mathrm{MPa}$ as shown in Figure 46(b), respectively. The decrease of the TS of the substrates for $\mathrm{GO}$ concentration after $0.04 \% \mathrm{w} / \mathrm{w}$, may be attributed to the saturation in the dispersion of the GO that affects the polymerization degree of the final specimens, producing a reduction toughness effect when increasing the GO content. So, this parameter should always be considered in photopolymerization-based additive manufacturing techniques. Furthermore, during the specimens' strain, it is determined that the molecular structure of 
the substrates with $\mathrm{GO}$ at $0.02 \% \mathrm{w} / \mathrm{w}$ was that absorbing more energy, in regarding the specimens with $\mathrm{GO}$ content at $0.12 \% \mathrm{w} / \mathrm{w}$, that proved the lower in absorbance energy terms.

Accordingly, is demonstrate that the specimens manufactured by 3D photopolymerization in type "Grey PN: F100G" resin with graphene oxide to low concentrations achieve a good combination of strength and ductility. Then, with only $0.02 \% \mathrm{w} / \mathrm{w} \mathrm{GO}$, the tensile strength is increased by $118.7 \%$, but the elongation decreases by $53.1 \%$.

Figure 47 and Figure 48 the behavior of the $E$ modulus in function of $\mathrm{GO}$ concentration was demonstrated and is presented. Figure 47 shows the mathematical relation obtained of experimental data for GO-reinforced specimens and with post-cured during $14 \mathrm{~min}$ and $28 \mathrm{~min}$. This behavior tends a second-order polynomial, likewise to the presented in Figure 23. The $E$ moduli behavior for substrates manufactured in "Grey PN: F100G" resin and GOreinforced are presented in Figure 48. In this case, again highlights a mathematical relation second-order polynomic that it is obtained analyzing two sections (due to results dispersion); for concentrations between $0.00 \% \mathrm{w} / \mathrm{w}$ to $0.04 \% \mathrm{w} / \mathrm{w}$, and concentrations between $0.04 \% \mathrm{w} / \mathrm{w}$ to $0.12 \% \mathrm{w} / \mathrm{w}$ (see Figure $48(\mathrm{~b})$ ).

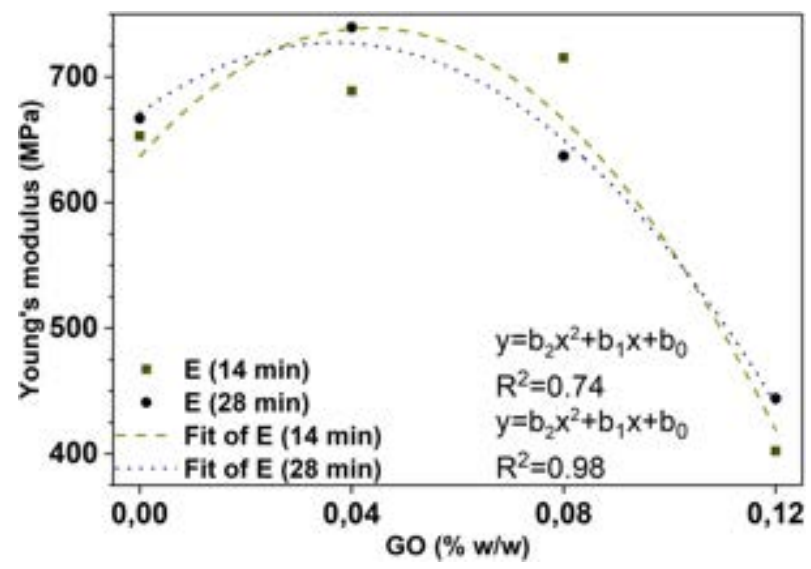

Figure 47. Relation obtained of the experimental data of $E$ modulus as a function of GO concentration. GO-reinforced specimens with post-cured during $14 \mathrm{~min}$ and $28 \mathrm{~min}$.

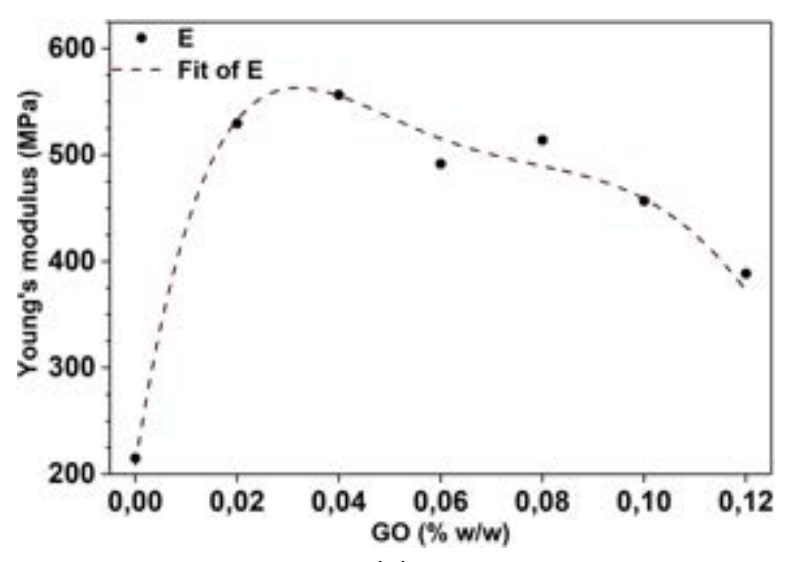

(a)

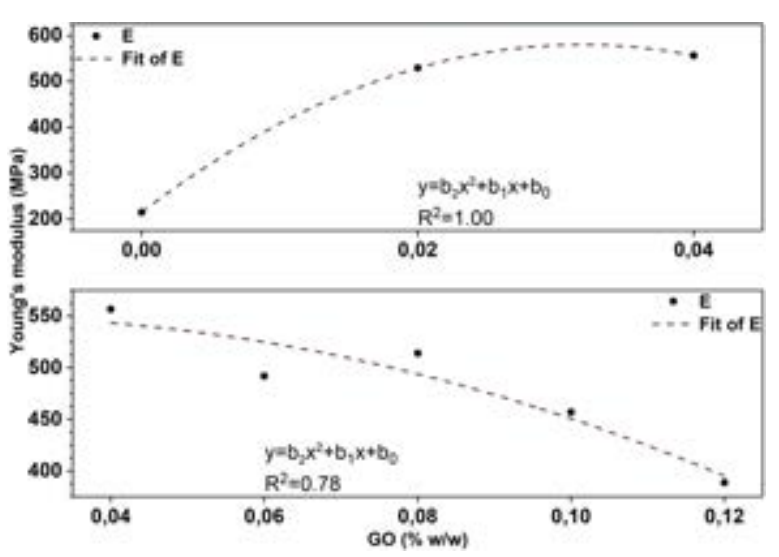

(b)

Figure 48. Relation obtained of the experimental data of $E$ modulus as a function of $\mathrm{GO}$ concentration. GO-reinforced specimens to concentrations different. 
5.3.2. Instrumented indentation. Figure 49 to Figure 52 highlight significant variations of $E^{\prime}$ modulus (Figure 49(a), Figure 49(b), and Figure 50) and $H$ (Figure 49(c), Figure 49(d), and Figure 51 ) when $\mathrm{GO}$ is aggregated to the polymeric matrix. The measurement of $E^{\prime}$ modulus and $H$ is represented in Figure 49 to Figure 51, where minimum variations in the values of the deformation resistance were found. Figure 52 present the average values of $E^{\prime}$ moduli and $H$ for the specimens manufactured with type "Clear FLGPCL 02" pure resin and specimens GO-reinforced at $0.04 \% \mathrm{w} / \mathrm{w}, 0.08 \% \mathrm{w} / \mathrm{w}$, and $0.12 \% \mathrm{w} / \mathrm{w}$; and post-cured during $14 \mathrm{~min}$ and $28 \mathrm{~min}$, respectively.

Accordingly, $E^{\prime}$ modulus increase in $20.2 \%, 4.1 \%$ and $6.4 \%$, for specimens GO-reinforced at $0.08 \% \mathrm{w} / \mathrm{w}$ with post-cured during $14 \mathrm{~min}$ and $28 \mathrm{~min}$, and GO-reinforced at $0.12 \% \mathrm{w} / \mathrm{w}$ with post-cured during $14 \mathrm{~min}$, respectively; while $H$ increase in $4.2 \%, 24.1 \%, 15.1 \%$ and $25.9 \%$ for specimens GO-reinforced at $0.04 \% \mathrm{w} / \mathrm{w}$ with post-cured during $28 \mathrm{~min}, \mathrm{GO}$ reinforced at $0.08 \% \mathrm{w} / \mathrm{w}$ with post-cured during $14 \mathrm{~min}$ and $28 \mathrm{~min}$, and GO-reinforced at $0.12 \% \mathrm{w} / \mathrm{w}$ with post-cured during $14 \mathrm{~min}$, respectively. Although, for specimens GOreinforced at $0.04 \% \mathrm{w} / \mathrm{w}$ with post-cured during $14 \mathrm{~min}$ and $28 \mathrm{~min}$, and G0-reinforced at $0.12 \% \mathrm{w} / \mathrm{w}$ with post-cured to $28 \mathrm{~min}$, the $E^{\prime}$ modulus decrease by $16.0 \%, 2.1 \%$ and $12.7 \%$, respectively; likewise, $H$ decreased by $13.0 \%$ and $8.4 \%$ for specimens GO-reinforced at $0.04 \% \mathrm{w} / \mathrm{w}$ with post-cured during $14 \mathrm{~min}$, and GO-reinforced at $0.12 \% \mathrm{w} / \mathrm{w}$ with post-cured during $28 \mathrm{~min}$, respectively.

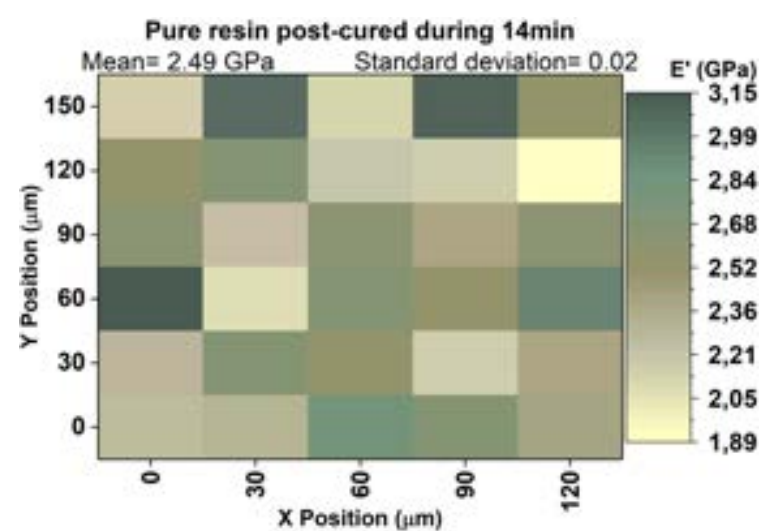

(a)

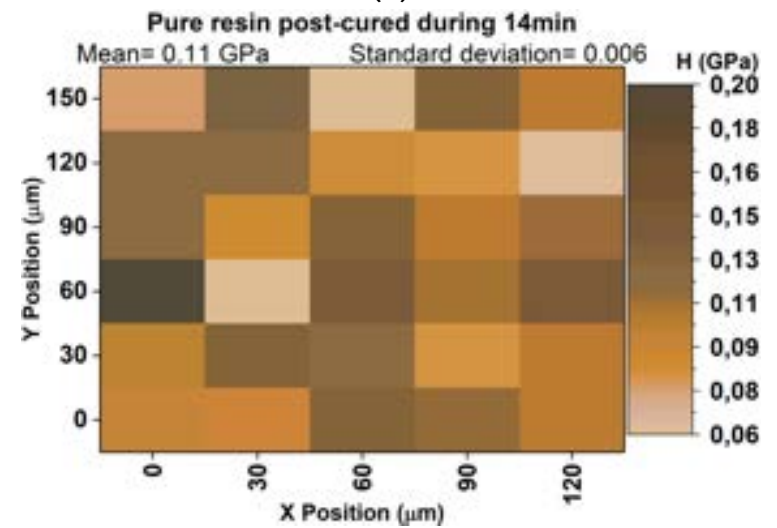

(c)

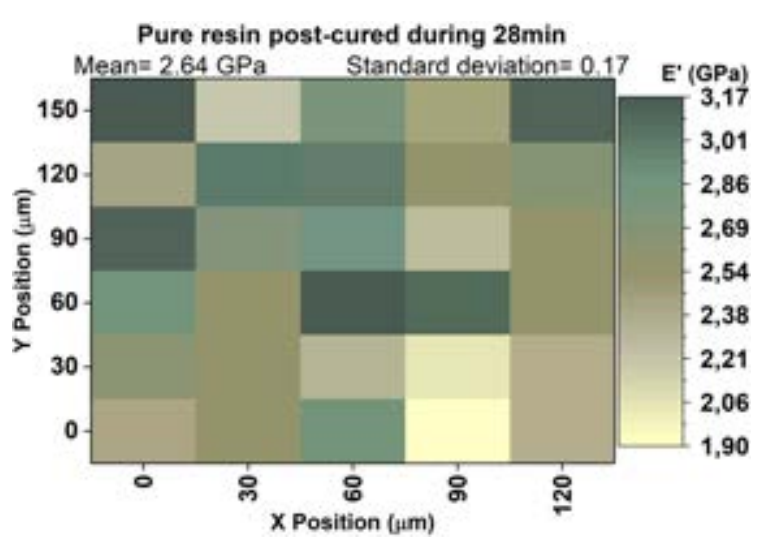

(b)

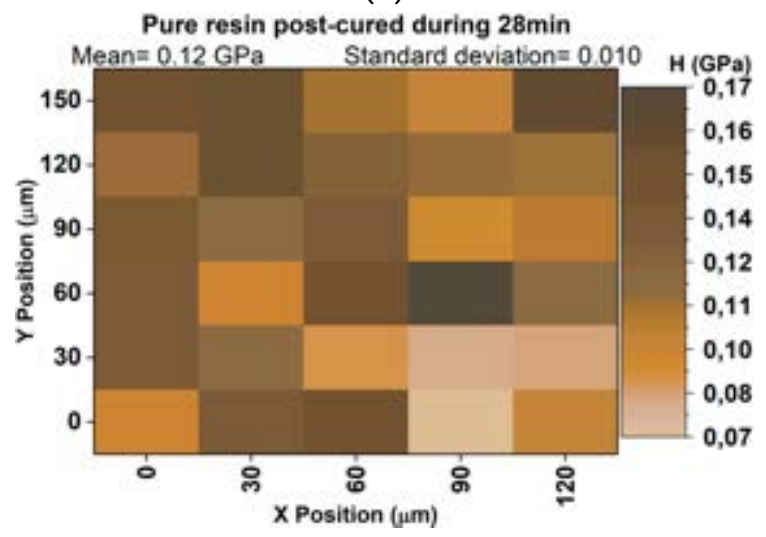

(d)

Figure 49. Contour maps of the variation of the mechanical properties $E^{\prime}$ moduli (a) and (b), and $H$ (c) and (d), obtained on a surface area of $120 \times 150 \mu \mathrm{m}^{2}$, on the substrates manufactured in pure resin with post-cured during $14 \mathrm{~min}$ and $28 \mathrm{~min}$, respectively. 


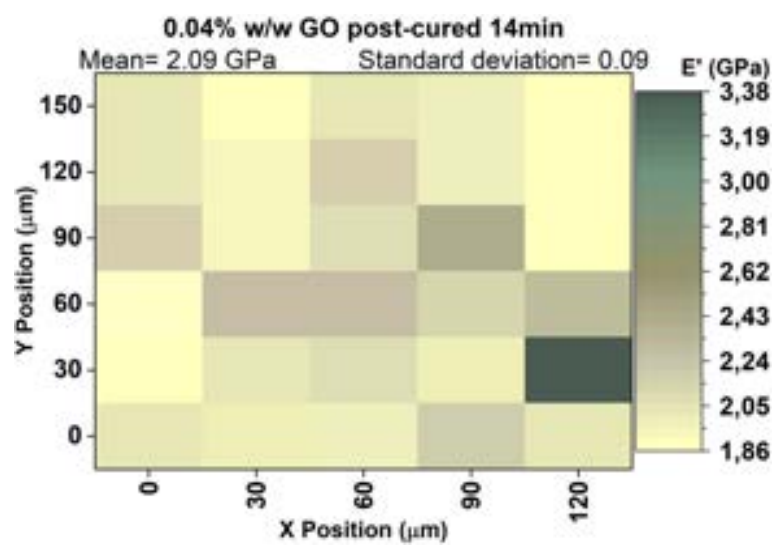

(a)

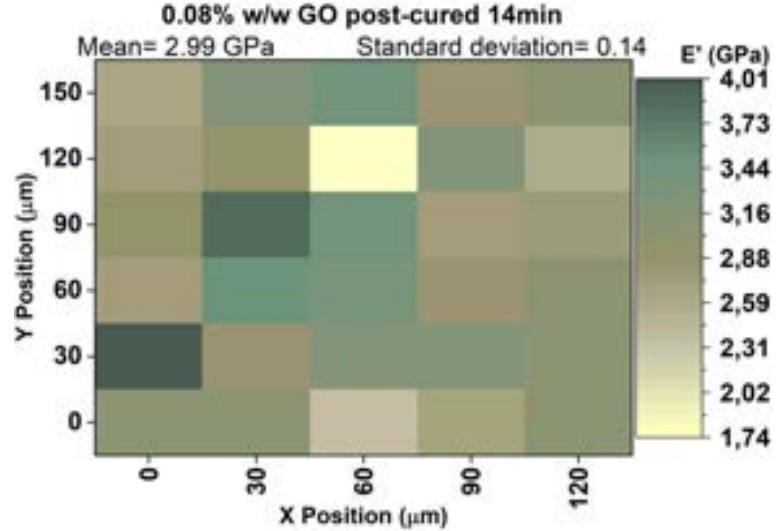

(c)

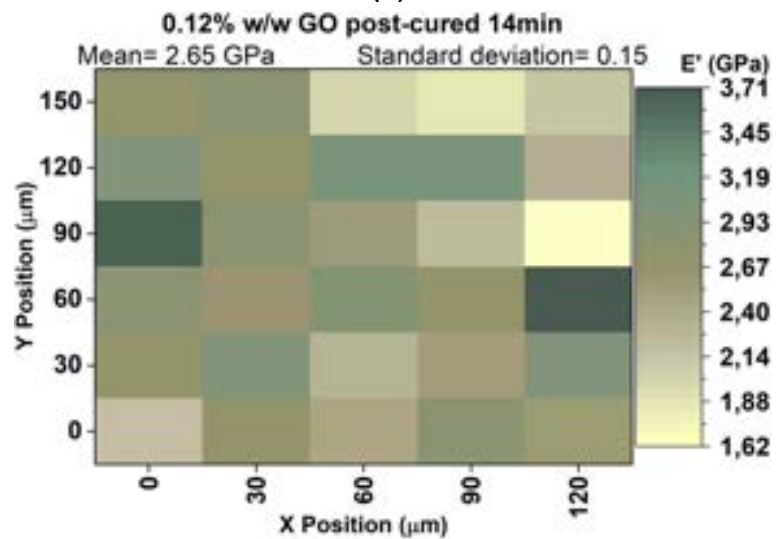

(e)

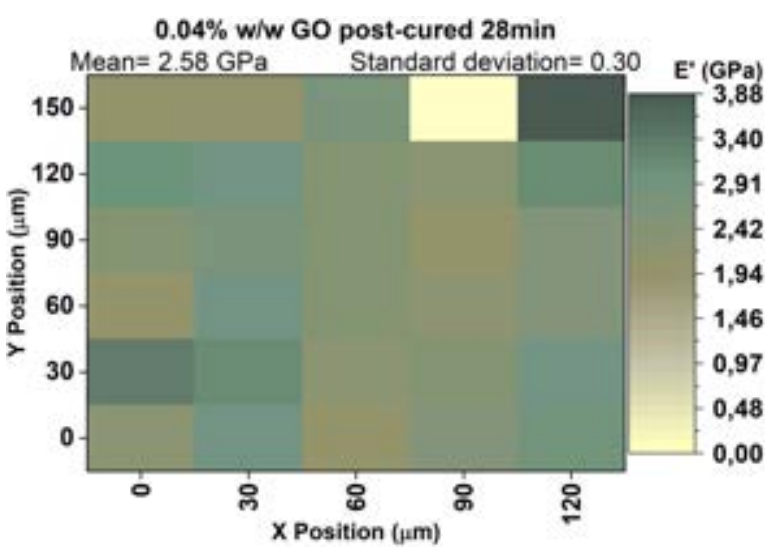

(b)

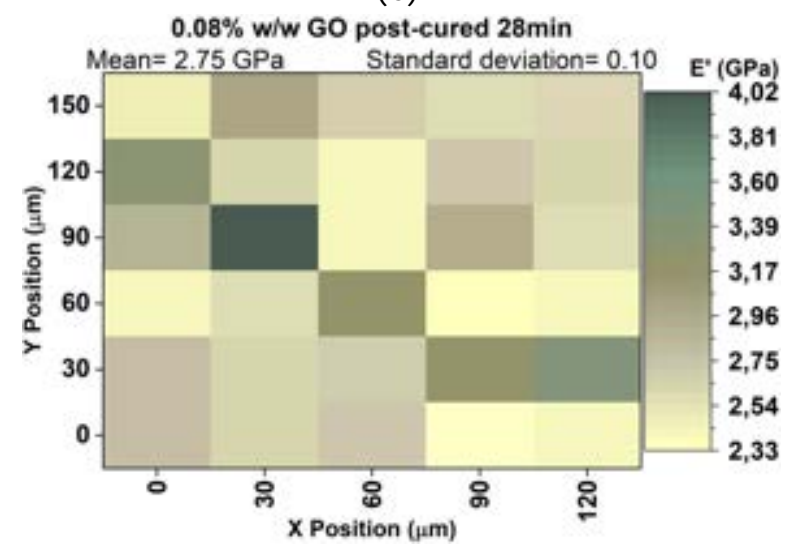

(d)

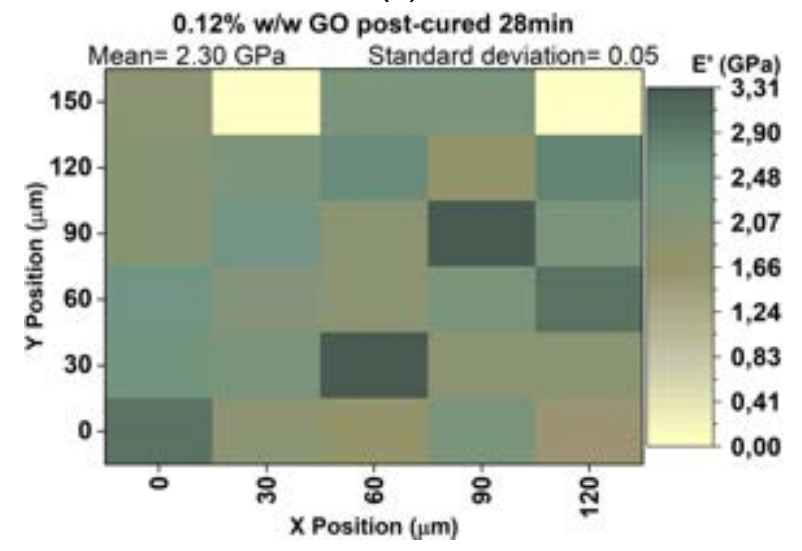

(f)

Figure 50. Contour maps of the variation of the mechanical properties $E^{\prime}$ moduli, obtained on a surface area of $120 \times 150 \mu \mathrm{m}^{2}$, on the substrates manufactured with GO-reinforced at $0.04 \% \mathrm{w} / \mathrm{w}$ (a) and (b), $0.08 \% \mathrm{w} / \mathrm{w}$ (c) and (d), $0.12 \% \mathrm{w} / \mathrm{w}$ (e) and (f), with post-cured during $14 \mathrm{~min}$ and $28 \mathrm{~min}$, respectively.

Figure 49 to Figure 51 the darkening corresponds to higher concentrations of GO embedded in the matrix of the photopolymer resin. This behavior is similar for both $E^{\prime}$ moduli (Figure 49(a), Figure 49(b), and Figure 50), and $H$ (Figure 49(c), Figure 49(d), and Figure 51). This indicates an efficient adhesion of the GO with the resin; and for some concentrations, $\mathrm{GO}$ behave as hardeners of the corresponding matrix (see Figure 52). Therefore, the efforts are transferred perfectly from GO to the matrix; then, to the have good adhesion it has good rigidity. In fact, as the aggregates are only weakly infiltrated by the polymer, they degrade the relative properties of the polymer. On the contrary, a suitable dispersion of the 
nanofillers would result in optimized matrix/filler bonding and enhanced properties. Furthermore, removal of entangled agglomerates is the major focus of the many methods used to disperse any filler in polymer matrices [70,85-89].

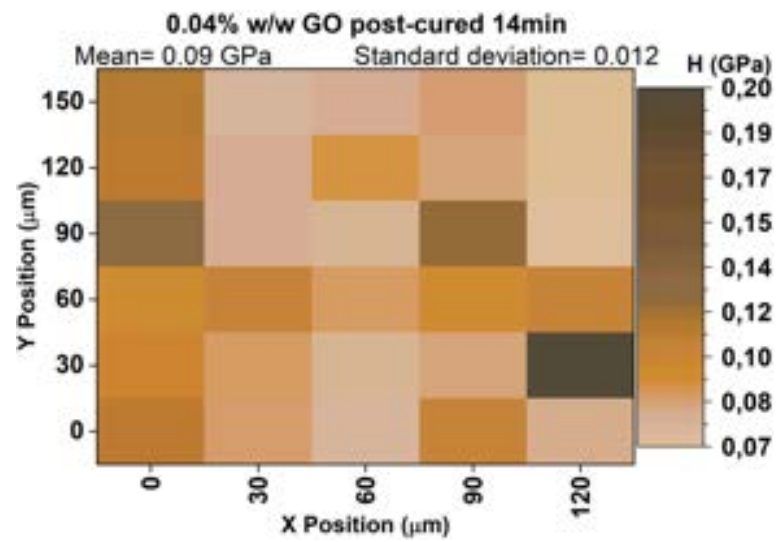

(a)

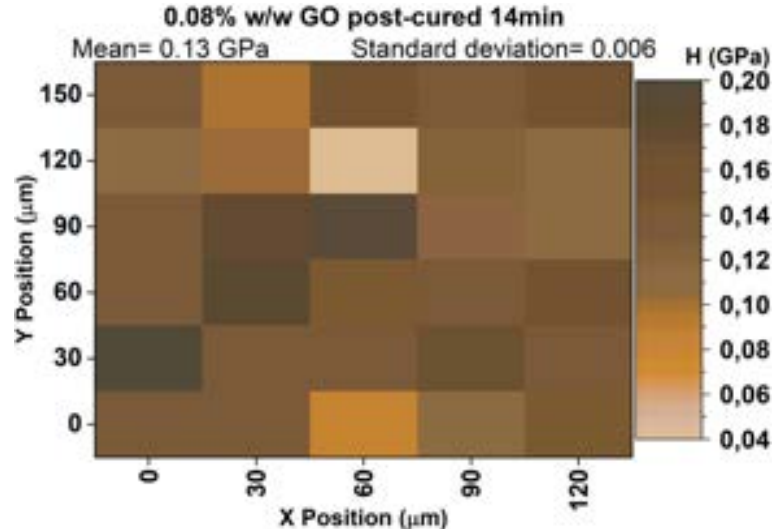

(c)

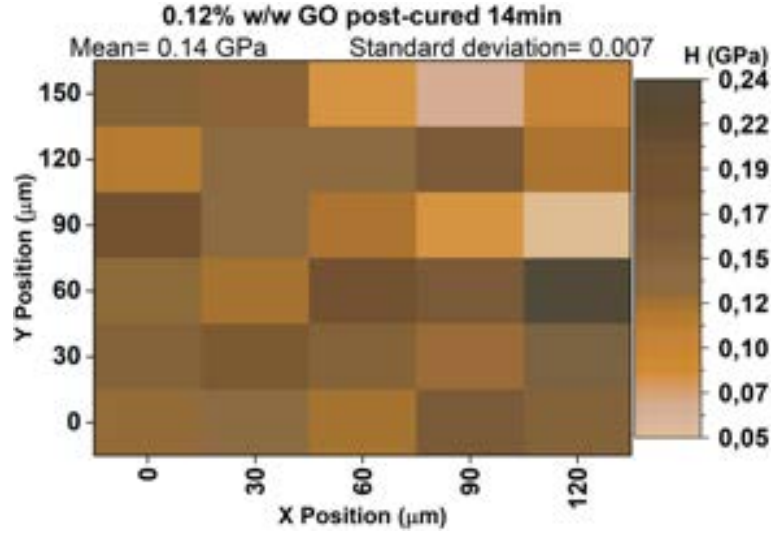

(e)

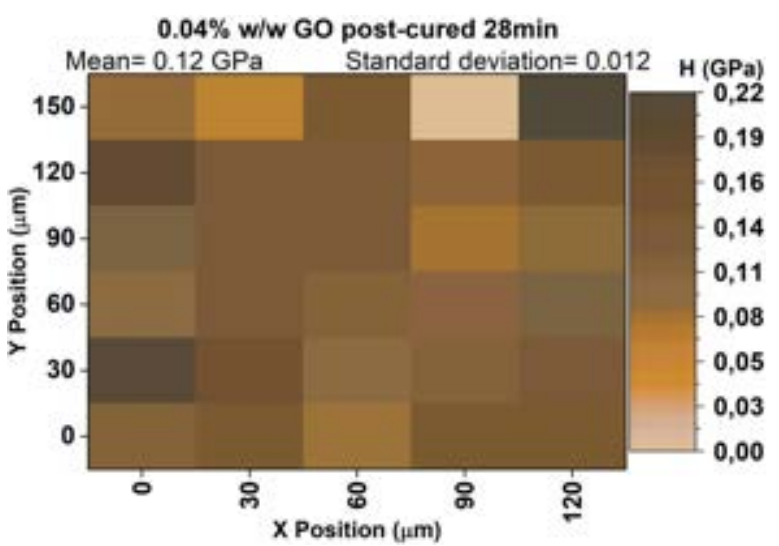

(a)

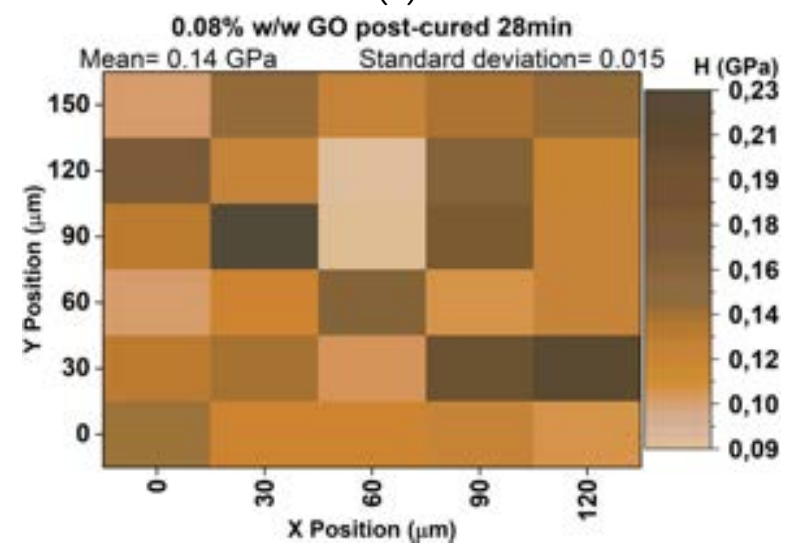

(d)

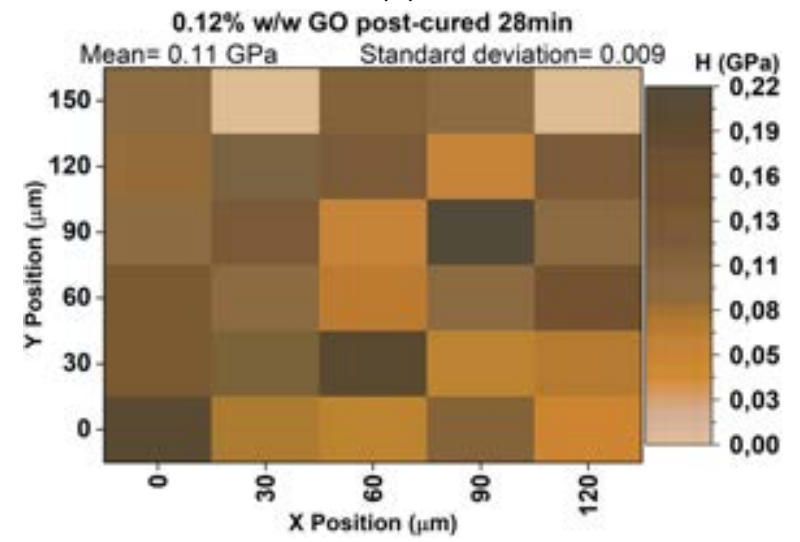

(f)

Figure 51. Contour maps of the variation of the mechanical properties $H$, obtained on a surface area of $120 \times 150 \mathrm{~mm}^{2}$, on the substrates manufactured with GO-reinforced at $0.04 \% \mathrm{w} / \mathrm{w}$ (a) and (b), $0.08 \% \mathrm{w} / \mathrm{w}$ (c) and (d), $0.12 \% \mathrm{w} / \mathrm{w}$ (e) and (f), with post-cured during $14 \mathrm{~min}$ and $28 \mathrm{~min}$, respectively. 


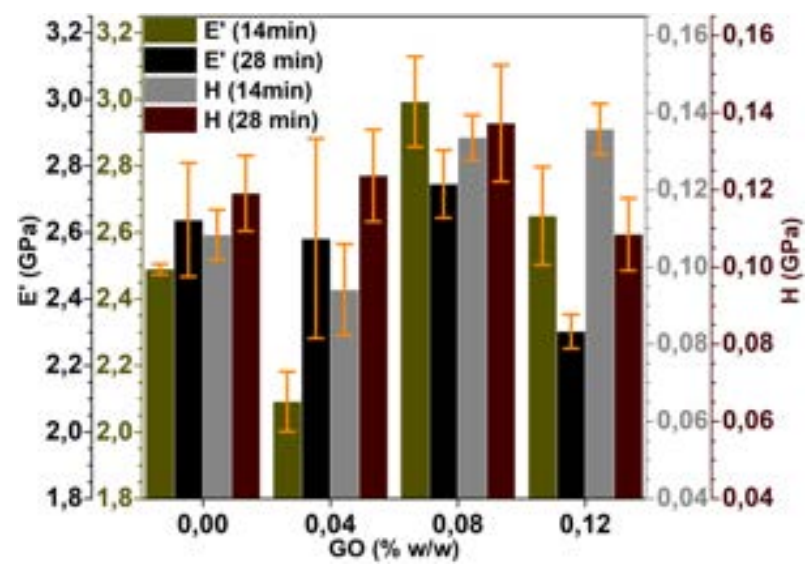

Figure 52. Effect of GO content and postcured on mechanical properties variation. $E^{\prime}$ storage modulus (green and black), and $H$ hardness (grey and red).

Figure 53 to Figure 55 highlight the significant variations of $E^{\prime}$ modulus and $H$, when GO is aggregated to the polymeric matrix with GO, to different post-cured time. The measurement of $E^{\prime}$ modulus and $H$ is represented in Figure 53 to Figure 55, where minimum variations in the values of the deformation resistance were found. Figure 56 presents the average values of $E^{\prime}$ modulus and $H$ for the specimens manufactured with type "Grey PN: F100G" pure resin and with GO. The decrease of $E^{\prime}$ modulus in $39.6 \%, 1.6 \%, 32.7 \%, 16.2 \%$, $24.7 \%$ for specimens GO-reinforced at $0.02 \% \mathrm{w} / \mathrm{w}, 0.04 \% \mathrm{w} / \mathrm{w}, 0.06 \% \mathrm{w} / \mathrm{w}, 0.08 \% \mathrm{w} / \mathrm{w}$, $0.12 \% \mathrm{w} / \mathrm{w}$, respectively; and the decrease of $H$ in $72.2 \%, 48.5 \%, 14.4 \%, 6.2 \%$ for specimens GO-reinforced at $0.02 \% \mathrm{w} / \mathrm{w}, 0.06 \% \mathrm{w} / \mathrm{w}, 0.08 \% \mathrm{w} / \mathrm{w}, 0.12 \% \mathrm{w} / \mathrm{w}$, respectively, can be attributed to the soften of polymeric chains. However, for the specimen GO-reinforced at $0.10 \% \mathrm{w} / \mathrm{w}$, the $E^{\prime}$ modulus increased by $6.0 \%$, and $H$ increased by $4.1 \%$; also, for specimen GO-reinforced at $0.02 \% \mathrm{w} / \mathrm{w}$, the $H$ increased by $2.1 \%$.

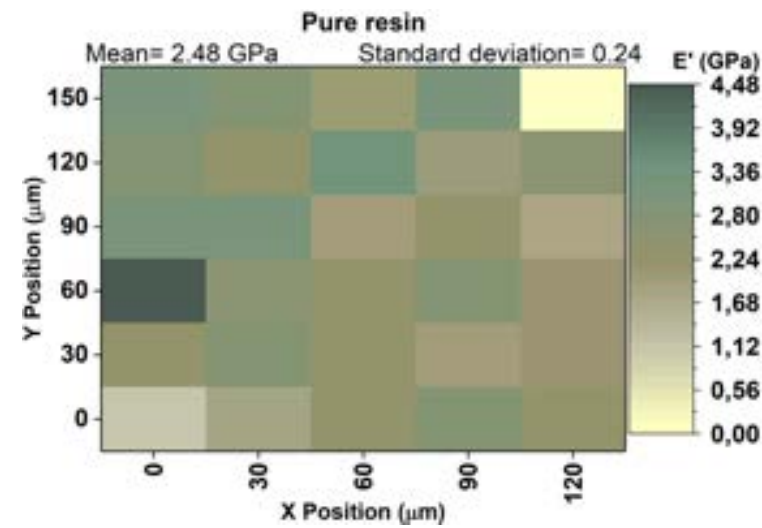

(a)

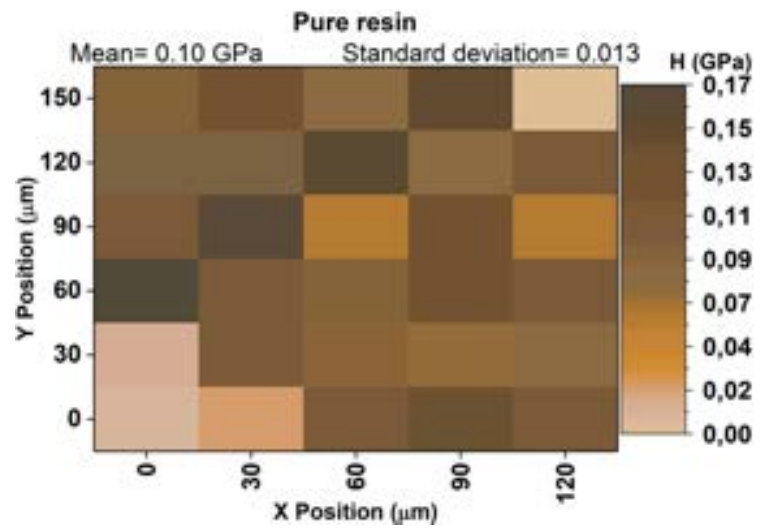

(b)

Figure 53. Contour maps of the variation of the mechanical properties $E^{\prime}$ modulus (a), and $H$ (b), obtained on a surface area of $120 \times 150 \mu \mathrm{m}^{2}$, on the substrates manufactured in pure resin.

Figure 53 to Figure 55 the darkening corresponds to higher concentrations of GO embedded in the matrix of the photopolymer resin. This behavior is similar for $E^{\prime}$ moduli (Figure 53(a) and Figure 54), and for $H$ (Figure 53(b) and Figure 55). This indicates an efficient adhesion of the $\mathrm{GO}$ with the resin; and for some concentrations, the GO behave as hardeners of the corresponding matrix (see Figure 56). Which means that the efforts are transferred perfectly from GO to the matrix; then, to the have good adhesion it has good rigidity. 


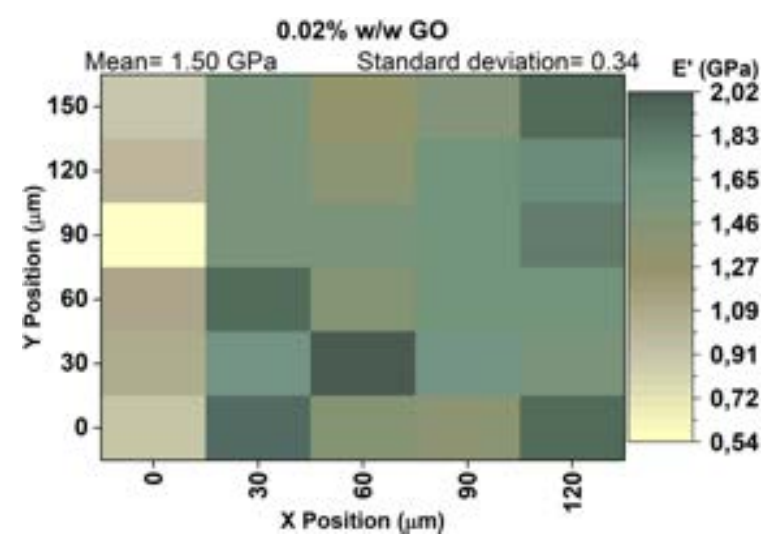

(a)

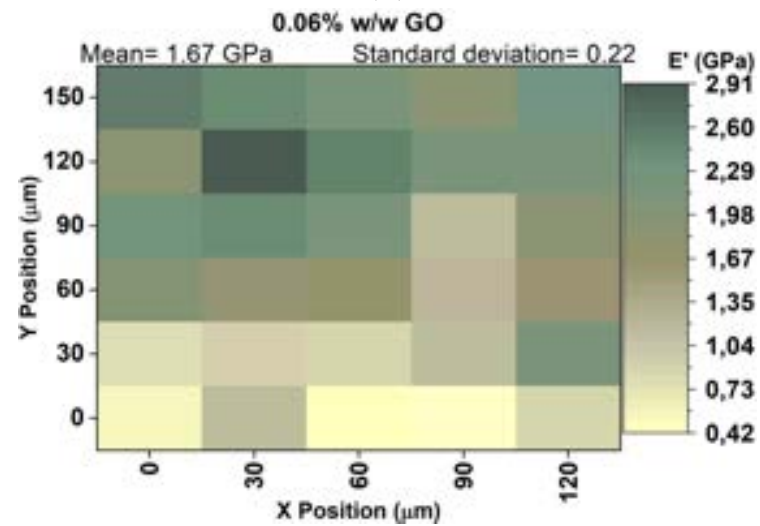

(c)

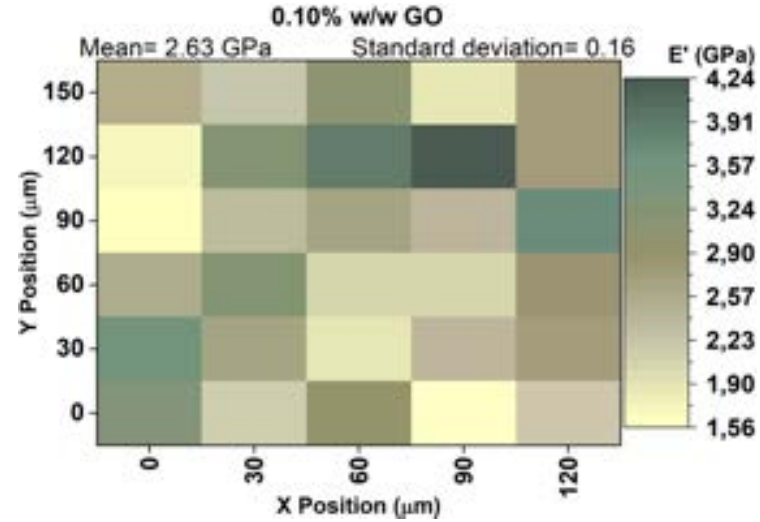

(e)

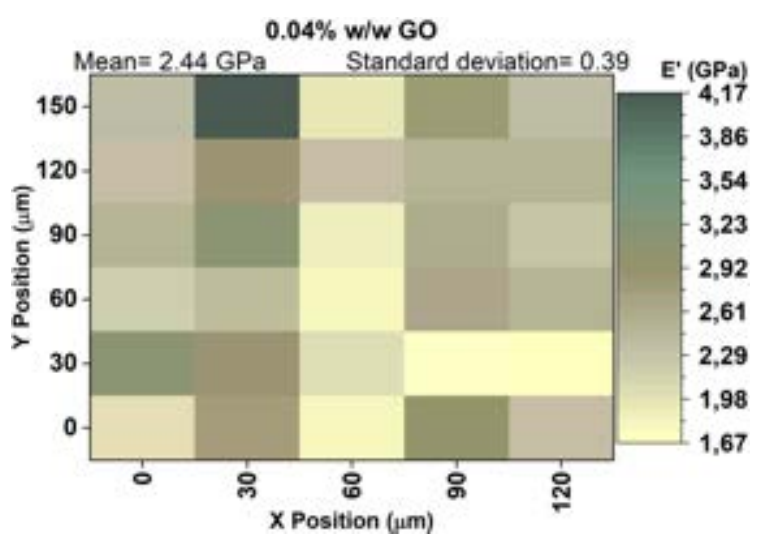

(b)

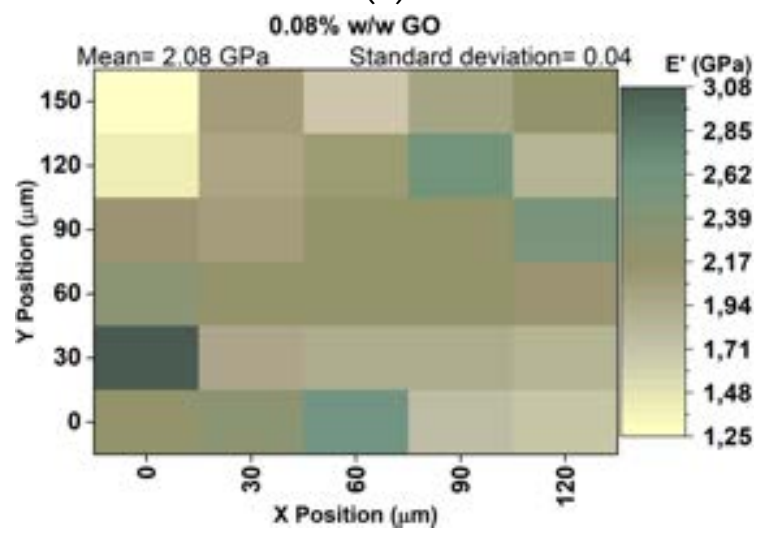

(d)

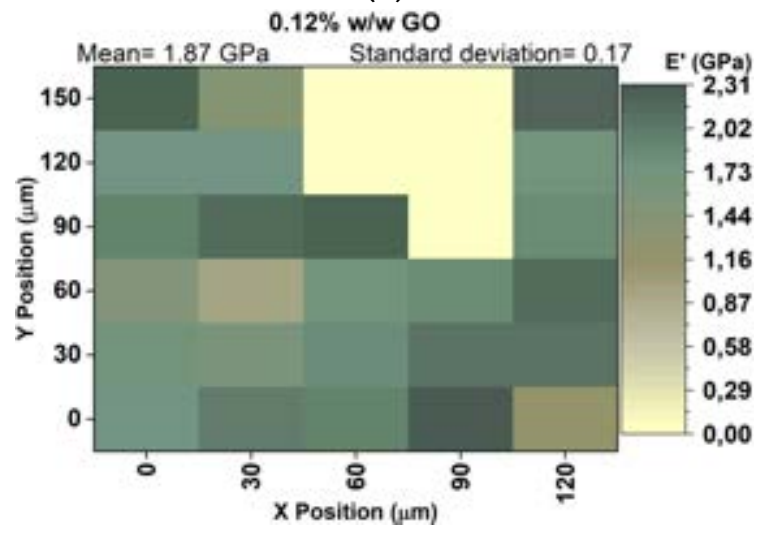

(f)

Figure 54. Contour maps of the variation of the mechanical properties $E^{\prime}$ moduli, obtained on a surface area of $120 \times 150 \mathrm{~mm}^{2}$, on the substrates manufactured with GO-reinforced at $0.02 \% \mathrm{w} / \mathrm{w}$ (a), $0.04 \% \mathrm{w} / \mathrm{w}$ (b), $0.06 \% \mathrm{w} / \mathrm{w}$ (c), $0.08 \% \mathrm{w} / \mathrm{w}$ (d), $0.10 \% \mathrm{w} / \mathrm{w}$ (e), and $0.12 \% \mathrm{w} / \mathrm{w}$ (f).

Figure 49 to Figure 51 and Figure 53 to Figure 55 the local "soft or clear" spots, which are due to the small differences in the dispersion, correspond to regions with degraded mechanical properties, probably due to the GO aggregates poorly infiltrated by the polymeric matrix. On the other hand, the local "hard or dark" spots correspond to areas with enhanced mechanical properties, likely reflecting an adequate polymer infiltration. In fact, as the aggregates are only weakly infiltrated by the polymer, they degrade the relative properties of the polymer. On the contrary, a suitable dispersion of the nanofillers would result in optimized matrix/ filler bonding and enhanced properties. Furthermore, removal of entangled agglomerates is the major focus of the many methods used to disperse any filler in polymer matrices [70,85-89]. 


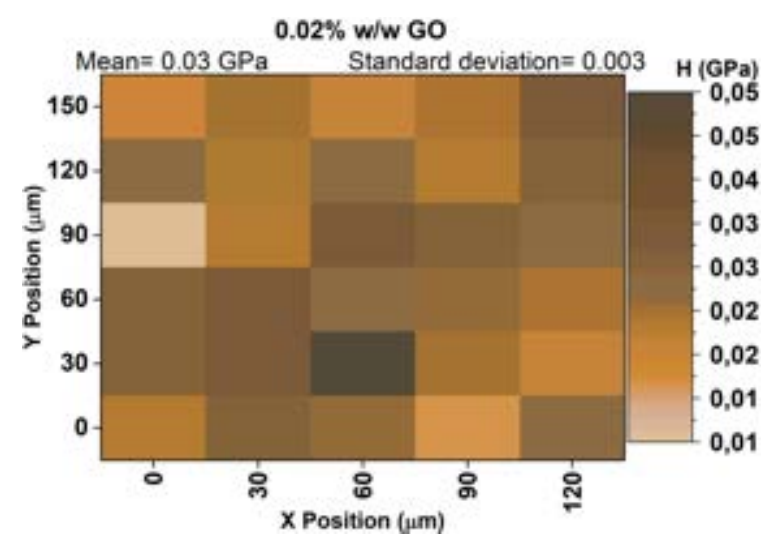

(a)

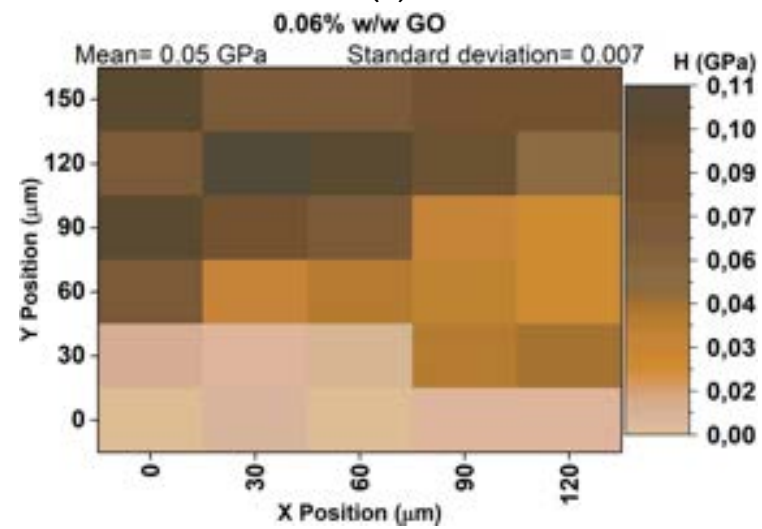

(c)

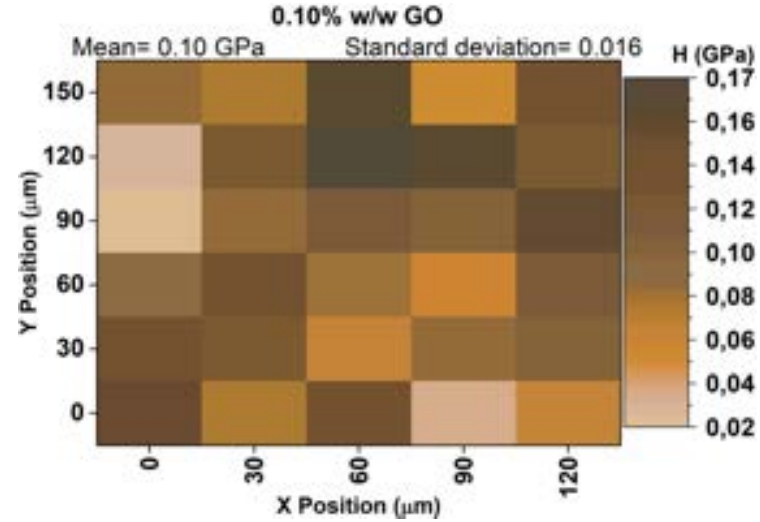

(e)

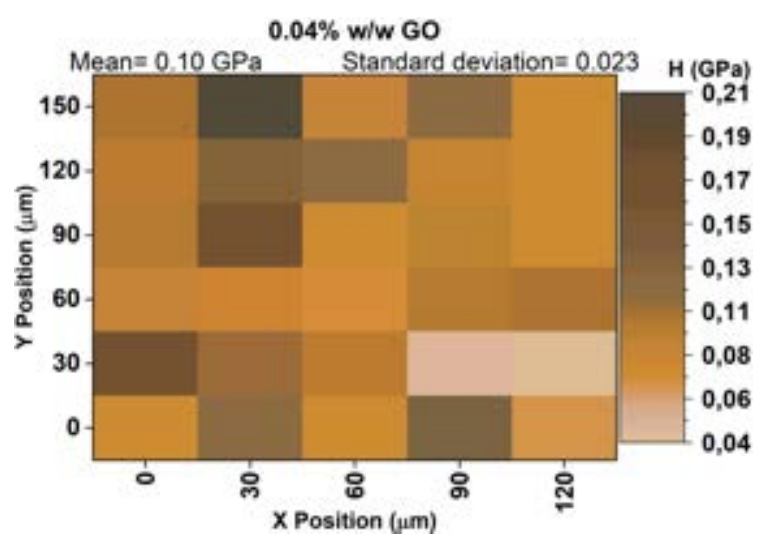

(b)

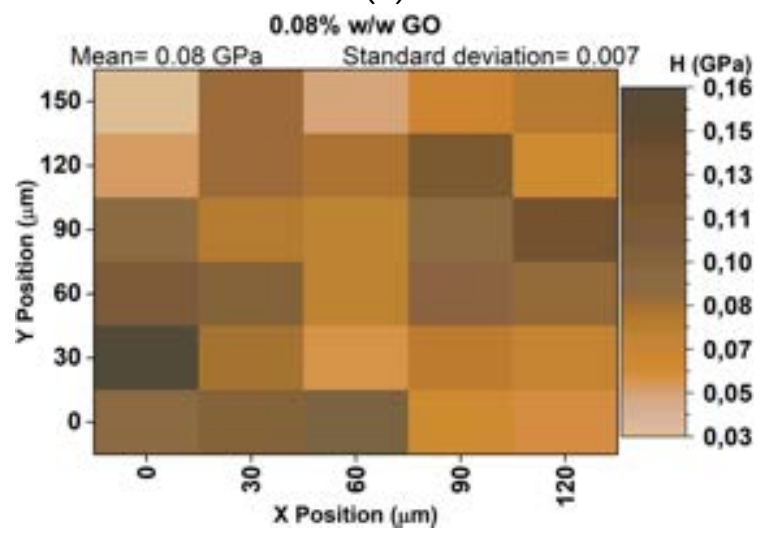

(d)

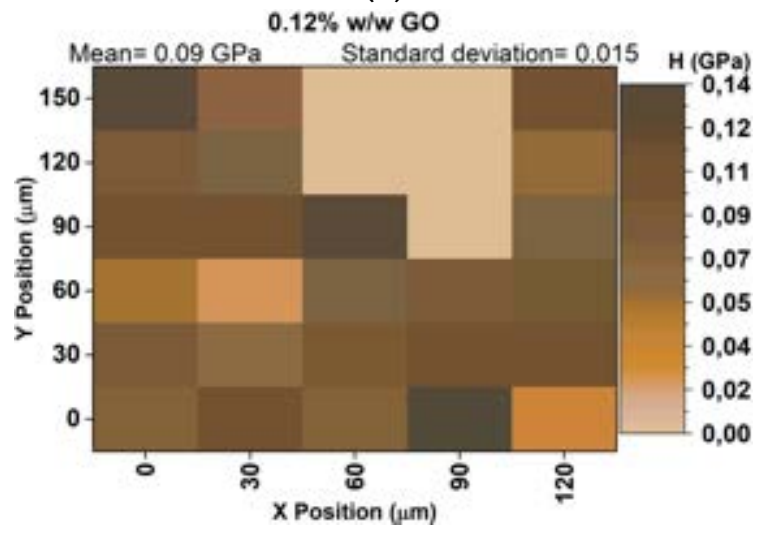

(f)

Figure 55. Contour maps of the variation of the mechanical properties $H$, obtained on a surface area of $120 \times 150 \mu \mathrm{m}^{2}$, on the substrates manufactured with GO-reinforced at $0.02 \% \mathrm{w} / \mathrm{w}$ (a), $0.04 \% \mathrm{w} / \mathrm{w}$ (b), $0.06 \% \mathrm{w} / \mathrm{w}$ (c), $0.08 \% \mathrm{w} / \mathrm{w}$ (d), $0.10 \% \mathrm{w} / \mathrm{w}$ (e), and $0.12 \% \mathrm{w} / \mathrm{w}$ (f).

On the other hand, Figure 49 to Figure 51 and Figure 53 to Figure 55 highlights, however, that the variations of $E^{\prime}$ modulus and $H$ are not uniform: some areas exhibit less than average deformation resistance, and some areas exhibit greater than average deformation resistance, with strong correlation between $E^{\prime}$ modulus and $H$. These areas probably reflect localized increased concentrations of $\mathrm{GO}$ and are comparable in size to the hundreds of micrometers to millimeter-scale agglomerates.

The above observations enable interpretation of the maps scans of Figure 49 to Figure 51 and Figure 53 to Figure 55 in terms of the GO-reinforced microstructures, where variations minimum of $E^{\prime}$ modulus and the $H$ of the polymeric matrix due to the $\mathrm{GO}$ that it is entirely 
associated with the resin and probably in molecular scale. Moreover, the implication here is that the incorporated GO in the polymeric-resin, in some cases, is slowing the deformation process and possibly is making it more difficult, probably over length scales comparable to the indentation size.

The advantage of maps showed Figure 49 to Figure 51 and Figure 53 to Figure 55 , is that allow assessed directly and visually that there are no local variations in the mechanical properties. Likewise, the average values (Figure 52 and Figure 56) extracted from these maps (Figure 49 to Figure 51 and Figure 53 to Figure 55) can be representative of the entire composites if the studied areas are large enough $[70,85,89]$.

Accordingly, if globally averaged properties are required for a polymeric or composite matrix to predict the overall response of a device, then knowing the result of many indentations over a large enough area is necessary. Given practical considerations, the indentation-based mapping of the mechanical properties of polymeric systems (soft materials) will always need more considerable indentation spacing than that employed for harder materials. Therefore, matching the indentation spacing and size to the length scale of the microstructure is essential [70,85-89].

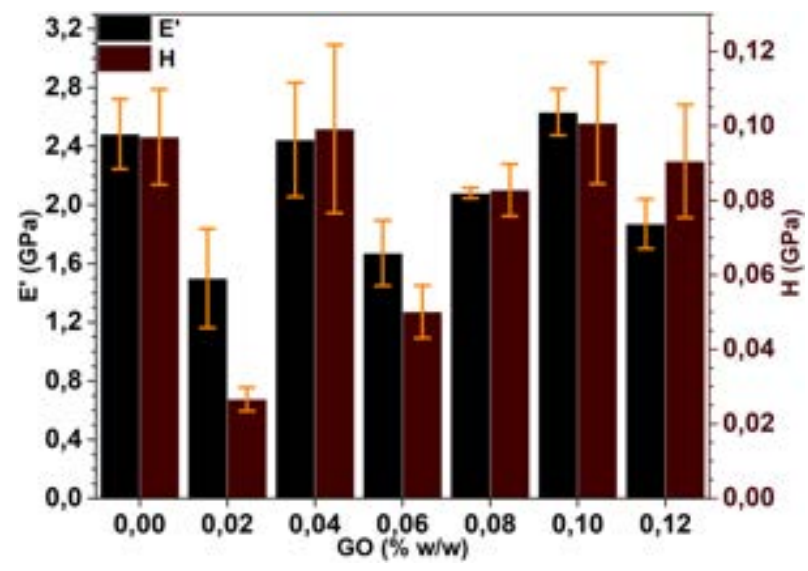

Figure 56. Effect of GO content on mechanical properties variation. $E^{\prime}$ storage modulus (black), and $H$ hardness (red).

\subsection{Thermal Performance}

The thermal properties of specimens manufactured in "Clear FLGPCL 02" and "Grey PN: F100G" resins and reinforced with nanofillers were carefully assessed with standard techniques, such as DMA, DSC, and TGA.

5.4.1. Dynamic mechanical analysis. Figure 57 illustrates the influence of the temperature on $E^{\prime}$ and $\tan \delta$ for substrates manufactured with the pure "Clear FLGPCL 02" resin, and with a load of GO. Figure $57(\mathrm{a})$ demonstrate that $E^{\prime}$ has the highest value for the substrates with GO-reinforced at $0.04 \% \mathrm{w} / \mathrm{w}$ with post-cured during $28 \mathrm{~min}\left(E^{\prime}=3970 \mathrm{MPa}\right)$, and $0.08 \% \mathrm{w} / \mathrm{w}$ with post-cured during $28 \mathrm{~min}$ and $14 \mathrm{~min}\left(E^{\prime}=3601 \mathrm{MPa}\right.$ and $\left.E^{\prime}=3556 \mathrm{MPa}\right)$, respectively; and decreases to high concentrations of GO (at $0.12 \% \mathrm{w} / \mathrm{w}$, is obtained $E^{\prime}=2063 \mathrm{MPa}$ and $E^{\prime}=1970 \mathrm{MPa}$, with post-cure during $28 \mathrm{~min}$ and $14 \mathrm{~min}$, respectively). This means that the post-cured time, as well as the GO concentrations, is affecting the mechanical properties of the polymeric matrix. Furthermore, factors such as the reaction degree and the crosslinking density mainly influence the value of $E^{\prime}$. Then, the glass transition process is thereby 
confirmed, suggesting that the behavior of the material in pure resin and with $\mathrm{GO}$ can be evaluated through rheological properties.

Figure 57 (b) highlights the change of $\tan \delta$ of the specimens' pure resin and with GO. The maximum value of $\tan \delta$ is mainly influenced by the $T_{\mathrm{g}}$. Consequently, loading the polymeric matrix GO-reinforced lowers $\tan \delta$ to greater GO concentrations, while that to low GO concentration the $\tan \delta$ is approximately equal to the value obtained in the specimen pure resin. The lower values of $\tan \delta$ may attribute it decreases the crosslinking density and leads to the higher mobility of polymer chains during glass transition, which indicates an elastic behavior (see Figure 57 (b) for specimens G0-reinforced at $0.12 \% \mathrm{w} / \mathrm{w}$ with post-cured during $28 \mathrm{~min}$ and $14 \mathrm{~min}$, respectively). In the maximum peak occurs the polymer's glassy transition regime $[90,91]$, and when the peak is sharp the $\tan \delta$ indicates that a regular structure is formed (see Figure 57 (b) for specimen GO-reinforced at $0.04 \% \mathrm{w} / \mathrm{w}$ with postcured during $28 \mathrm{~min}$ and $14 \mathrm{~min}$, respectively).

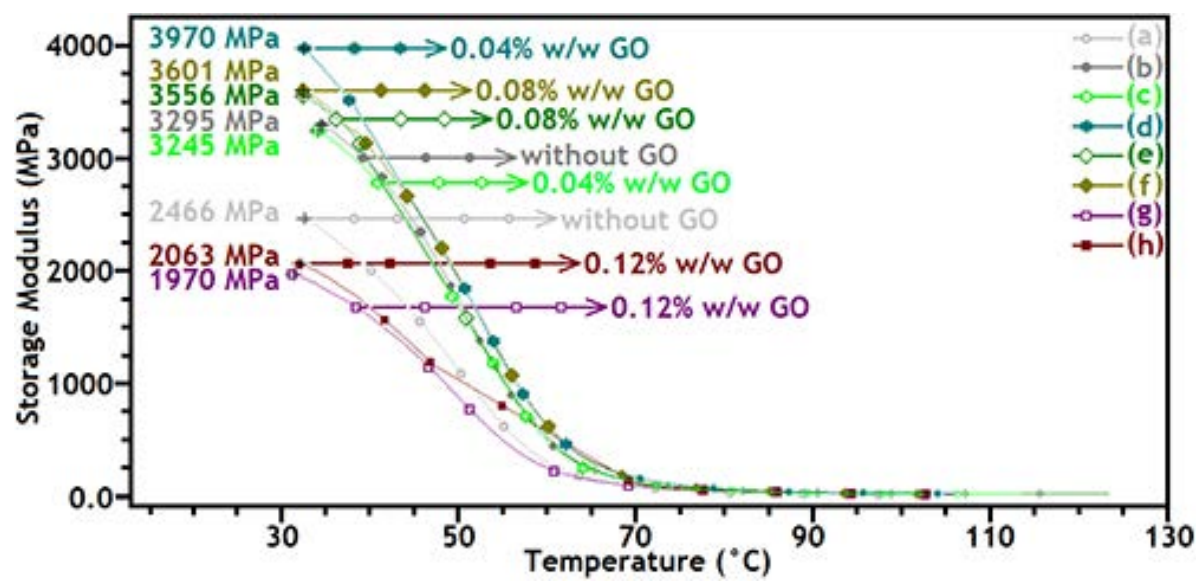

(a)

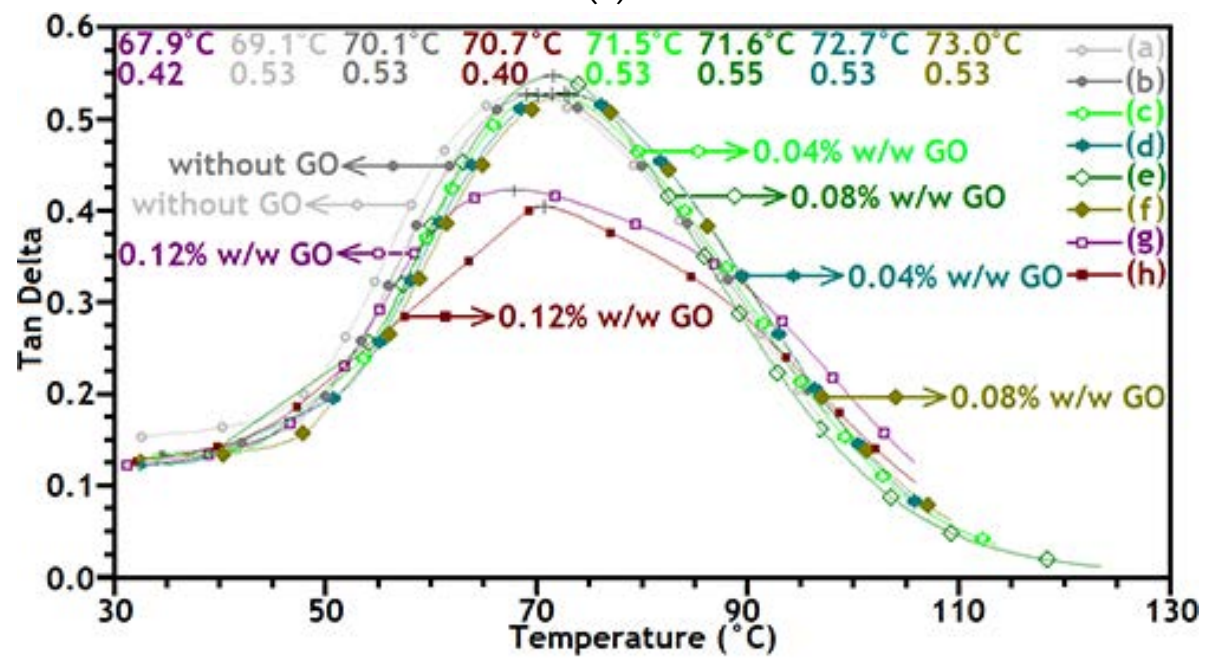

(b)

Figure 57. DMA curves of the substrates manufactured pure resin and with GO. (a) Storage modulus, and (b) loss factor as a function of temperature, pure resin (o-a and $\bullet-b)$, with GO-reinforced at $0.04 \% \mathrm{w} / \mathrm{w}$ ( $\mathrm{x}-\mathrm{c}$ and $*-\mathrm{d})$, $0.08 \% \mathrm{w} / \mathrm{w}(\diamond-\mathrm{e}$ and $-\mathrm{f})$, and $0.12 \% \mathrm{w} / \mathrm{w}(\square-\mathrm{g}$ and $-\mathrm{h})$, with post-cured during $14 \mathrm{~min}$ and $28 \mathrm{~min}$, respectively. 
The presence of GO in polymeric-matrix clearly lowered the maximum $\tan \delta$ value, from $\sim 0.55$ for specimens GO-reinforced at $0.08 \% \mathrm{w} / \mathrm{w}$ and $0.04 \% \mathrm{w} / \mathrm{w}$ to less than $\sim 0.40$ for specimens GO-reinforced at $0.12 \% \mathrm{w} / \mathrm{w}$ (Figure $57(\mathrm{~b})$ ). The $\mathrm{GO}$ highly influenced the molecular dynamics in the polymeric-matrix, giving rise to increasing the $T_{\mathrm{g}}$ and thermal stability of the specimens GO-reinforced as compared to the specimen in pure resin [90]. The $E^{\prime}$ results showed that specimens GO-reinforced and post-cured during $28 \mathrm{~min}$ are higher than the specimen in pure resin in the glass transition regime between $67^{\circ} \mathrm{C}$, and $73{ }^{\circ} \mathrm{C}$. The DMA results of specimens GO-reinforced demonstrated a more elastic behavior for higher $\mathrm{GO}$ concentrations as compared with the substrate in pure resin, suggesting an enhanced stiffness of the material $[1,43,90,92]$.

Pure "Clear FLGPCL 02" resin has a $T_{\mathrm{g}}$ value between $69.1^{\circ} \mathrm{C}$ and $70.1^{\circ} \mathrm{C}$. This value range slightly shifted depending on the concentrations GO loadings and the post-cure time (Table 11). The polymer-matrix reinforced with GO might lead to enhancement of $T_{\mathrm{g}}$. Moreover, $\mathrm{GO}$ restricts the segmental mobility of the photopolymer resin chain, which increases the melting temperature of the amorphous materials $[1,43,90,92]$.

Figure 58 illustrates the influence of the temperature on $E^{\prime}$ and $\tan \delta$ for substrates manufactured with the pure "Grey PN: F100G" resin, and with a load of GO. Figure 58(a) demonstrates that $E^{\prime}$ has the highest value for the substrates with GO-reinforced at $0.02 \% \mathrm{w} / \mathrm{w}\left(E^{\prime}=2459 \mathrm{MPa}\right)$ and $0.04 \% \mathrm{w} / \mathrm{w} \quad\left(E^{\prime}=2340 \mathrm{MPa}\right)$ and decreases with the addition of $\mathrm{GO}$. Although, for the specimen in pure resin is obtained the lower value of $E^{\prime}$ $\left(E^{\prime}=896 \mathrm{MPa}\right)$, which mean that the GO, to concentrations of $0.02 \% \mathrm{w} / \mathrm{w}$ to $0.12 \% \mathrm{w} / \mathrm{w}$, provided a greater elastic and stiffness to the polymeric-resin matrix, highlighting the glass transition region. Then, the glass transition process is thereby confirmed, suggesting that the behavior of the material in pure resin and with GO can be evaluated through rheological properties.

Figure $58(\mathrm{~b})$ highlights the change of $\tan \delta$ of the specimens in pure resin and specimens GO-reinforced. The maximum value of $\tan \delta$ is mainly influenced by the $T_{\mathrm{g}}$. Accordingly, loading the polymeric-matrix reinforced with GO have higher $\tan \delta$ values regarding the pure resin substrate, where to the increase the GO concentration the $\tan \delta$ value is approximated to the $\tan \delta$ value obtained for the specimen pure resin. The high values of $\tan \delta$ indicate specimens GO-reinforced at different concentrations have behavior viscose (Figure 58(b)). In the maximum peak occurs the polymer's glassy transition regime $[43,90,91]$, and when the peak is sharp the $\tan \delta$ value indicates that a regular structure is formed (Figure 58(b)).

The presence of GO in polymeric-matrix clearly increase the maximum $\tan \delta$ value, from $\sim 0.51$ for specimens in pure resin to $\sim 0.57$ for specimens GO-reinforced at $0.04 \% \mathrm{w} / \mathrm{w}$. The GO highly influenced the molecular dynamics in the polymeric-matrix, giving rise to increasing the $T_{\mathrm{g}}$ and thermal stability of the specimens GO-reinforced as compared to the specimen in pure resin $[43,90]$. The $E^{\prime}$ results showed that specimens GO-reinforced to low concentrations, is higher than the substrates in pure resin in the glass transition regime between $58^{\circ} \mathrm{C}$ and $67^{\circ} \mathrm{C}$; however, when increasing the GO content the $E^{\prime}$ value decrease.

Pure "Grey PN: F100G" resin has a $T_{\mathrm{g}}$ value $\sim 58.6^{\circ} \mathrm{C}$. This value slightly shifted depending on the concentrations $\mathrm{GO}$ loadings (Table 11 ). The polymer-matrix reinforced with $\mathrm{GO}$ might lead to enhancement of $T_{\mathrm{g}}[43,92]$. 
The DMA results of specimens GO-reinforced demonstrated a more viscose behavior for lower GO concentrations as compared with the substrate in pure resin and the specimens GO-reinforced to high concentrations.

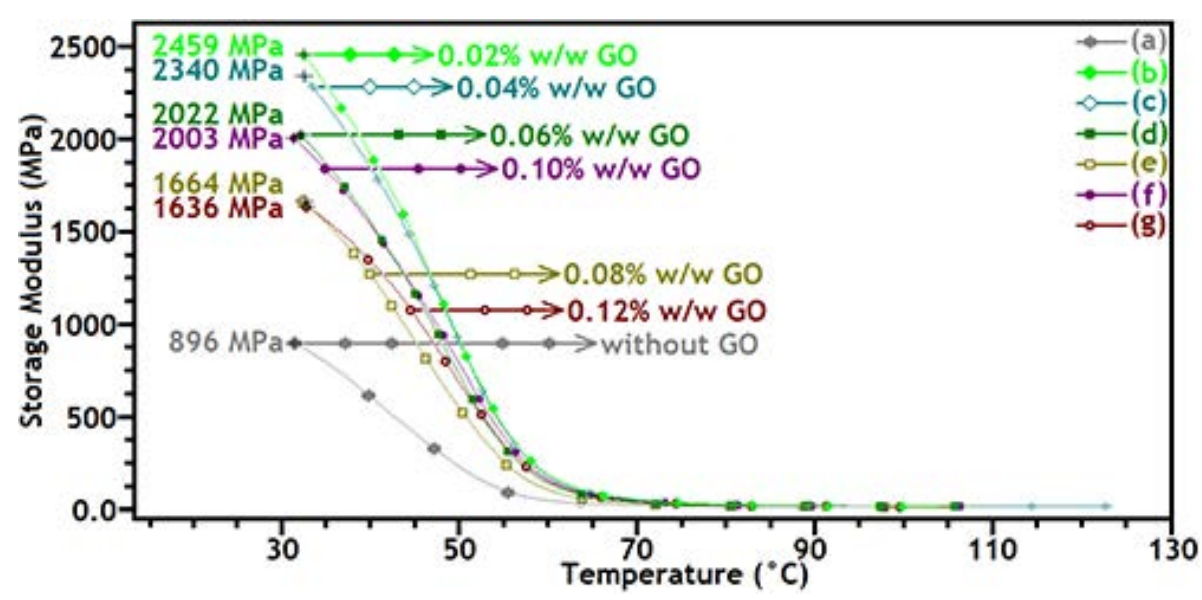

(a)

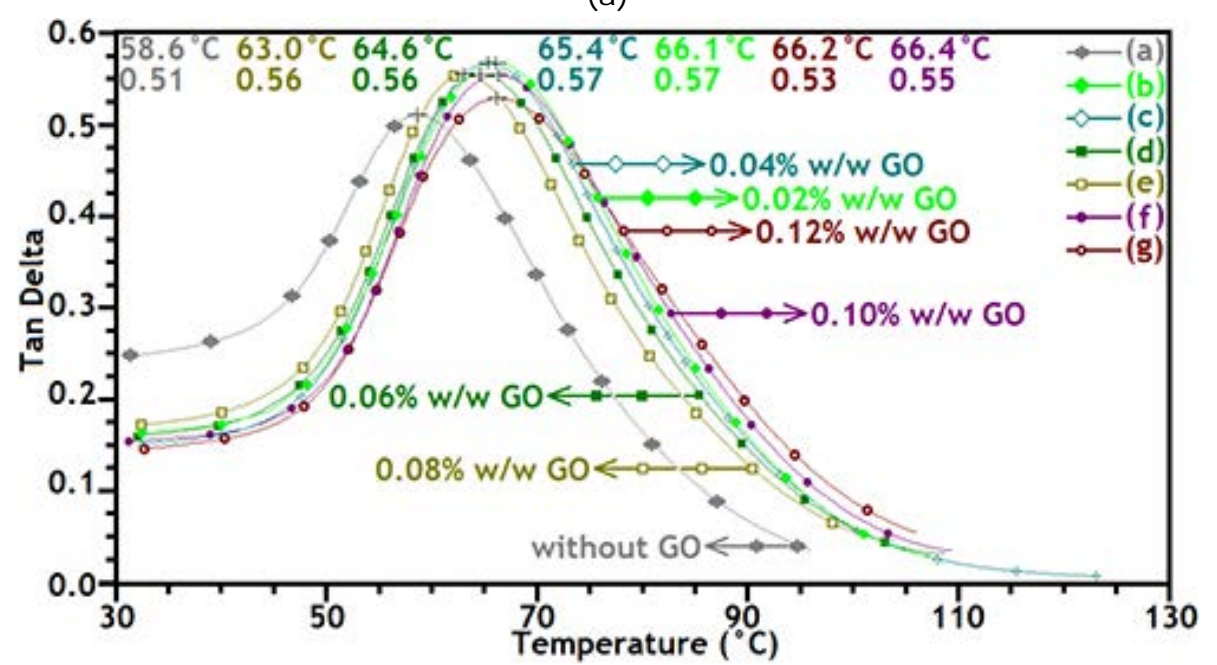

(b)

Figure 58. DMA curves of the substrates manufactured pure resin and with GO. (a) Storage modulus, and (b) loss factor as a function of temperature, pure resin $(*-a)$, with GO-reinforced at $0.02 \% \mathrm{w} / \mathrm{w}(\bullet-b), 0.04 \% \mathrm{w} / \mathrm{w} \quad(\Delta-c)$, $0.06 \% \mathrm{w} / \mathrm{w}(\cdot-\mathrm{d}), 0.08 \% \mathrm{w} / \mathrm{w}(\square-e), 0.10 \% \mathrm{w} / \mathrm{w}(\cdot-\mathrm{f})$, and $0.12 \% \mathrm{w} / \mathrm{w}(\circ-\mathrm{g})$.

Figure 59 and Figure 60, the behavior of experimental data of the storage modulus in the function of GO concentration was demonstrated and is presented. Figure 59 shows the mathematical relation obtained for the GO-reinforced specimens and post-cured during $14 \mathrm{~min}$ and $28 \mathrm{~min}$, with tends second-order polynomic. The storage modulus behavior for substrates manufactured in "Grey PN: F100G" resin and GO-reinforced are presented in Figure 60. In this case, likewise to before case, is highlight a mathematical relation second-order polynomic that it is obtained analyzing two sections (it is because to results dispersion); for concentrations between $0.00 \% \mathrm{w} / \mathrm{w}$ to $0.04 \% \mathrm{w} / \mathrm{w}$, and concentrations between $0.04 \% \mathrm{w} / \mathrm{w}$ to $0.12 \% \mathrm{w} / \mathrm{w}$ (see Figure $60(\mathrm{~b})$ ).

DMA was performed to determine the $E^{\prime}$ in temperatures function. It is observed that $E^{\prime}$ of the specimens GO-reinforced are higher than pure resin in the glass transition regime 
between $50^{\circ} \mathrm{C}$ and $100{ }^{\circ} \mathrm{C}$. Also, the $E^{\prime}$ values decrease with an increasing graphene content although the increase is not in proportion to the amount of GO.

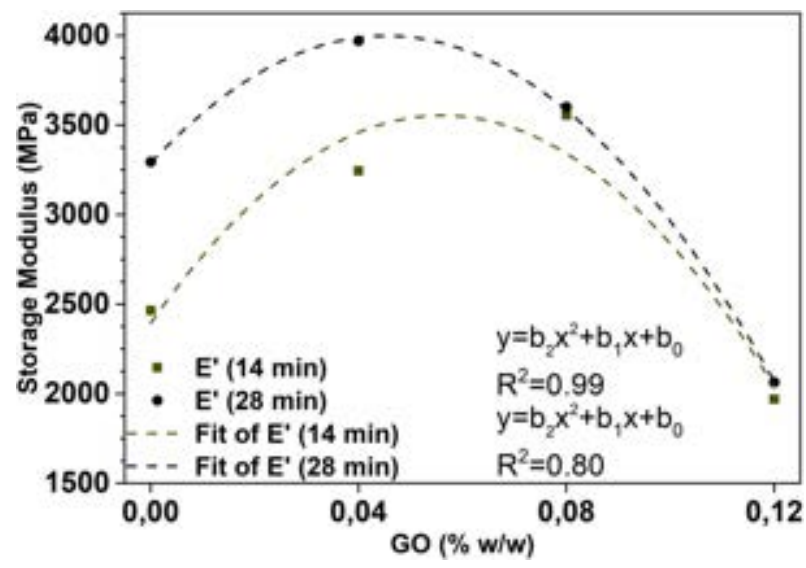

Figure 59. Relation obtained of the experimental data of $E^{\prime}$ as a function of $\mathrm{GO}$ concentration. GO-reinforced specimens with post-cured during $14 \mathrm{~min}$ and $28 \mathrm{~min}$.

The mathematical relation shown in Figure 59 and Figure 60 are very correlated with the mathematical relation presented in Figure 47 and Figure 48 obtained of tensile testing. So, signifies that the properties of polymer-based nanocomposites reply very well to the distribution, concentration, geometry, and properties of the GO in the polymer matrix, where high concentrations of $\mathrm{GO}$ demonstrate a more elastic behavior as compared with the pure resin specimen, suggesting an enhanced stiffness of the material. These specimens GOreinforced were prepared using a solution-based process, which can be easily scaled up to industry level. Accordingly, a whole spectrum of applications and functionalities based on these two leading technologies could be exploited (3D printing and GO materials).

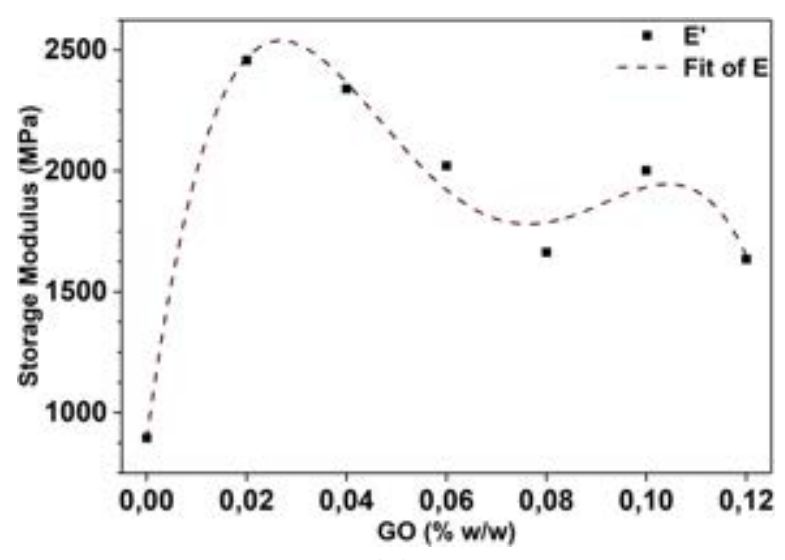

(a)

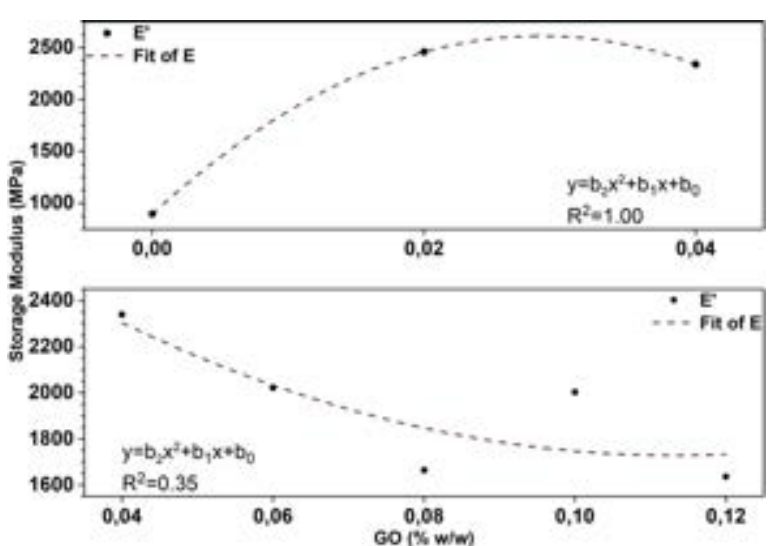

(b)

Figure 60. Relation obtained of the experimental data of $E^{\prime}$ as a function of GO concentration. GOreinforced specimens to concentrations different.

5.4.2. Differential scanning calorimetry. DSC Figure 61 shows the glass transition, melting and degradation peaks of polymer-matrix specimens' pure resin and GO-reinforced in the region of $30^{\circ} \mathrm{C}-480^{\circ} \mathrm{C}$. It is needed to notice that the crystallization of all specimens is very low, which means that the GOs is interacting with polymer bulk. It also means that the GO embedded is well bound with the polymeric matrix, which will be beneficial for the internal and interfacial load transfer $[95,96]$. Then, the generated $T_{\mathrm{c}}$ explains the elastic- 
viscous performance of 3D printed GO-reinforced specimens. However, before any manufacturing by $3 \mathrm{D}$ printing, $T_{\mathrm{g}}$ is the first and most vital parameter to be determined $[43,97]$. Figure 61 shows the DSC curves representative, from which $T_{\mathrm{g}}$ values can be calculated that are reported in Table 11. The substrate manufactured in pure "Clear FLGPCL $02 "$ resin has a $T_{\mathrm{g}}$ value close to $\sim 61.8^{\circ} \mathrm{C}$ and $\sim 61.0^{\circ} \mathrm{C}$ for the post-cured during $14 \mathrm{~min}$ (Figure 61(a)) and $28 \mathrm{~min}$ (Figure 61(b)) respectively. This value slightly shifted to $\sim 71.4^{\circ} \mathrm{C}$ and $\sim 65.4{ }^{\circ} \mathrm{C}$ for the GO-reinforced specimens at $0.04 \% \mathrm{w} / \mathrm{w}$, to $\sim 68.9^{\circ} \mathrm{C}$ and $\sim 70.9{ }^{\circ} \mathrm{C}$ for the GO-reinforced substrates at $0.08 \% \mathrm{w} / \mathrm{w}$, and to $\sim 62.6{ }^{\circ} \mathrm{C}$ and $\sim 68.0{ }^{\circ} \mathrm{C}$ for the GOreinforced specimens at $0.12 \% \mathrm{w} / \mathrm{w}$ with $14 \mathrm{~min}$ and $28 \mathrm{~min}$ post-cured respectively (Figure 61 and Table 11). The GO-reinforcing polymer-matrix might lead to enhancement of $T_{\mathrm{g}}$ $[43,92,96]$. Accordingly, GO additives restrict the segmental mobility of the "Clear FLGPCL 02 " resin chains, which increases the melting temperature of the amorphous materials $[1,43,90,96]$. The same trend was observed in DMA-derived $T_{\mathrm{g}}$ values, with a slight elevation that depends as the oxide graphene content varies (Table 11).

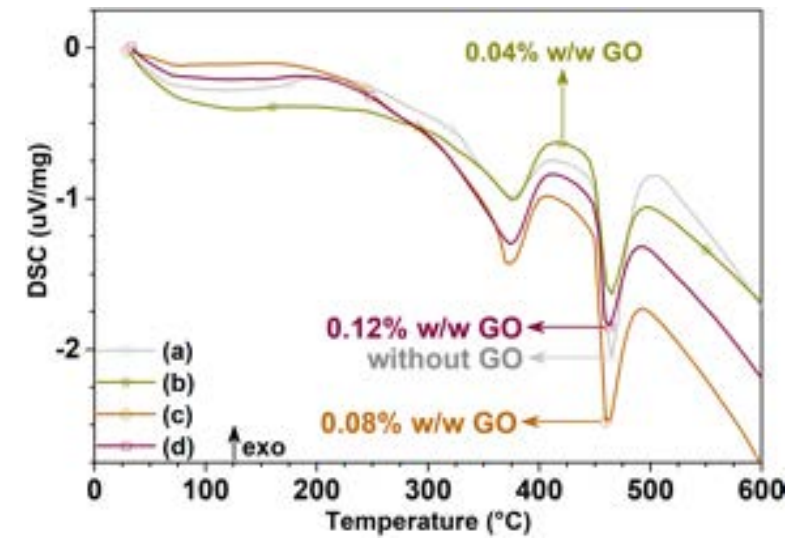

(a)

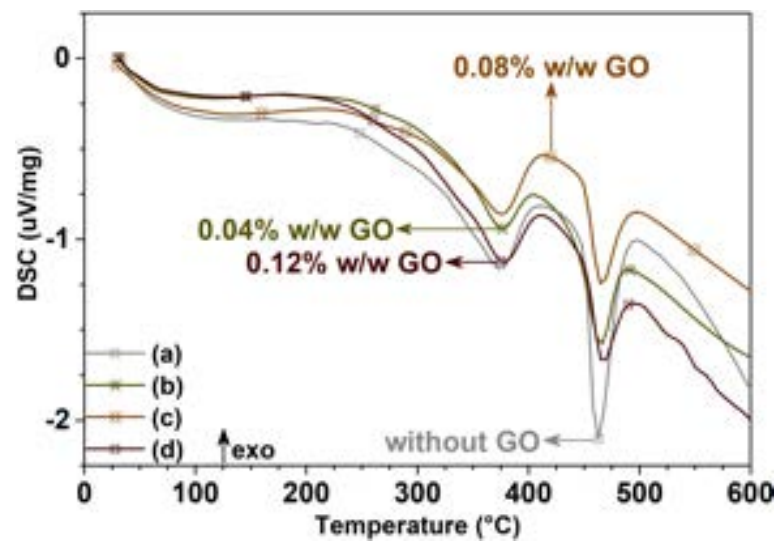

(b)

Figure 61. Representative curves of DSC thermal analysis of the specimens in pure resin (o-a and - -a), and GO-reinforced at $0.04 \% \mathrm{w} / \mathrm{w}$ ( $\mathrm{a}-\mathrm{b}$ and $*-\mathrm{b}), 0.08 \% \mathrm{w} / \mathrm{w}(\diamond-\mathrm{c}$ and $\bullet-c)$, and $0.12 \% \mathrm{w} / \mathrm{w}$ ( $\square-d$ and - -d) with post-cured during (a) $14 \mathrm{~min}$, and (b) $28 \mathrm{~min}$.

DSC curves of specimens manufactured in pure "Grey PN: F100G" resin and with GO embedded in the polymer-matrix are presented in Figure 62. The results of the DSC tests demonstrate a broadly distributed glass transition region and the presence of an exothermal signal. The distributions of the glass transition region cover a region between $50{ }^{\circ} \mathrm{C}$ to $80^{\circ} \mathrm{C}$ for the substrates in pure resin, between $56^{\circ} \mathrm{C}$ and $91^{\circ} \mathrm{C}$ for the GO-reinforced specimens at $0.02 \% \mathrm{w} / \mathrm{w}$, between $54{ }^{\circ} \mathrm{C}$ and $92{ }^{\circ} \mathrm{C}$ for the GO-reinforced substrates at $0.04 \% \mathrm{w} / \mathrm{w}$, between $57{ }^{\circ} \mathrm{C}$ and $71{ }^{\circ} \mathrm{C}$ for the GO-reinforced specimens at $0.06 \% \mathrm{w} / \mathrm{w}$, between $52{ }^{\circ} \mathrm{C}$ and $70{ }^{\circ} \mathrm{C}$ for the GO-reinforced substrates at $0.08 \% \mathrm{w} / \mathrm{w}$, between $55^{\circ} \mathrm{C}$ and $76{ }^{\circ} \mathrm{C}$ for the GOreinforced specimens at $0.10 \% \mathrm{w} / \mathrm{w}$ and between $54{ }^{\circ} \mathrm{C}$ and $97{ }^{\circ} \mathrm{C}$ for the GO-reinforced substrates at $0.12 \% \mathrm{w} / \mathrm{w}$. Thus, the $T_{\mathrm{g}}$ value slightly increased when polymer-matrix is loading with GO. $T_{\mathrm{g}}, T_{\mathrm{c}}, T_{\mathrm{m}}$, and $T_{\mathrm{d}}$, were measured and are reported in Table 11 . These transition temperatures present minimal variations with the content of $\mathrm{GO}$ as indicated in Figure 62 and Table 11; where the GO acting as extra nucleation sites for heterogeneous nucleation, a phenomenon that is quite typical for nanofillers additions [70,93,94]. 
DSC Figure 44 shows the $T_{\mathrm{g}}, T_{\mathrm{m}}$ and $T_{\mathrm{d}}$ peaks of polymer-matrix specimens' pure resin and GO-reinforced in the region of $30^{\circ} \mathrm{C}-480^{\circ} \mathrm{C}$. It is needed to notice that the crystallization of all specimens is very low, which means that the $\mathrm{GO}$ is interacting with polymer bulk. It also means that the $\mathrm{GO}$ embedded is well bound with the polymeric matrix, which will be beneficial for the internal and interfacial load transfer $[95,96]$. Then, the generated $T_{\mathrm{c}}$ explains the elastic-viscous performance of 3D printed GO-reinforced specimens. However, before any manufacturing by 3D printing, $T_{\mathrm{g}}$ is the first and most vital parameter to be determined $[43,97]$. Figure 62 and Table 11 shows $T_{\mathrm{g}}$ values calculated, where pure resin has a $T_{\mathrm{g}}$ value close to $\sim 60.3{ }^{\circ} \mathrm{C}$. This value slightly shifted to $\sim 65.9^{\circ} \mathrm{C}$ for the GO-reinforced specimens at $0.02 \% \mathrm{w} / \mathrm{w}$, to $\sim 64.4{ }^{\circ} \mathrm{C}$ for the GO-reinforced substrates at $0.04 \% \mathrm{w} / \mathrm{w}$, to $\sim 63.3{ }^{\circ} \mathrm{C}$ for the GO-reinforced specimens at $0.06 \% \mathrm{w} / \mathrm{w}$, to $-62.4{ }^{\circ} \mathrm{C}$ for the GO-reinforced specimens at $0.08 \% \mathrm{w} / \mathrm{w}$, to $\sim 64.2{ }^{\circ} \mathrm{C}$ for the GO-reinforced specimens at $0.10 \% \mathrm{w} / \mathrm{w}$, and to $\sim 65.9^{\circ} \mathrm{C}$ for the GO-reinforced specimens at $0.12 \% \mathrm{w} / \mathrm{w}$ (Table 11). The GO-reinforcing polymer-matrix might lead to enhancement of $T_{\mathrm{g}}[43,92,96]$. Consequently, $\mathrm{GO}$ additives restrict the segmental mobility of the "Grey PN: F100G" resin chains, which increases the melting temperature of the amorphous materials $[1,43,90,96]$. The same trend was observed in DMA-derived $T_{\mathrm{g}}$ values, with a slight elevation that depends as the GO-content varies (Table 11).

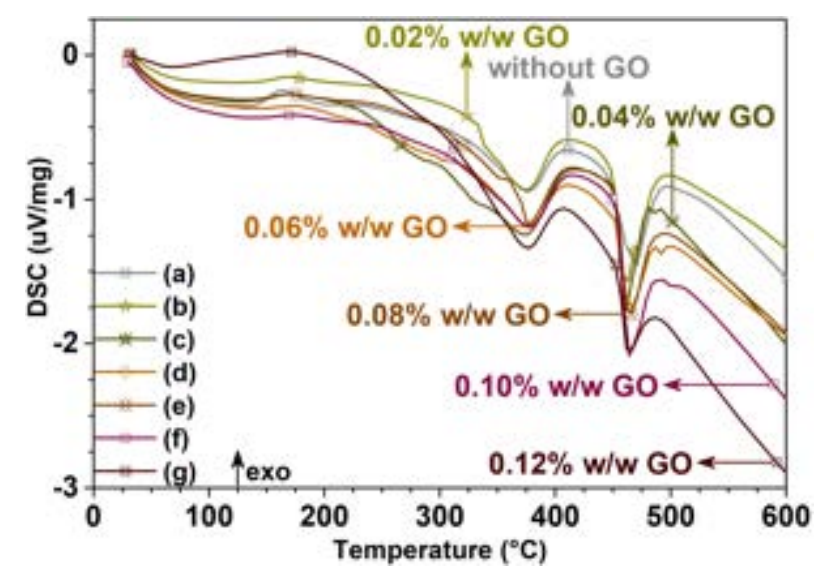

Figure 62. Representative curves of DSC thermal analysis on specimens manufactured in pure "Grey PN: F100G" resin $(\cdot-a)$, and GO-reinforced at $0.02 \% \mathrm{w} / \mathrm{w}$ $(\mathrm{x}-\mathrm{b}), \quad 0.04 \% \mathrm{w} / \mathrm{w}(*-\mathrm{c}), 0.06 \% \mathrm{w} / \mathrm{w}(\diamond-\mathrm{d})$, $0.08 \% \mathrm{w} / \mathrm{w} \quad(-\mathrm{e}), 0.10 \% \mathrm{w} / \mathrm{w} \quad(\square-f)$, and $0.12 \% \mathrm{w} / \mathrm{w}(\cdot-\mathrm{g})$.

5.4.3. Thermogravimetric analysis. TGA results of specimens manufactured in pure "Clear FLGPCL 02" resin and GO-reinforced between room temperature and $600{ }^{\circ} \mathrm{C}$, are provided in Figure 63. The same values within an error margin of $5 \%$ were obtained from the TGA analysis, showing consistency in our experiments. Slight mass loss around $80{ }^{\circ} \mathrm{C}$ was attributed to the loss of absorbed water in resin, moreover of the organics dissolvent as such as the IPA, where most of the IPA was to be evaporated during the UV post-curing, and after $100{ }^{\circ} \mathrm{C}$. Effects of $\mathrm{GO}$ on the melting and thermal degradation behavior can be easily seen within DTGA curves provided in Figure 63. The $T_{\mathrm{m}}$ and $T_{\mathrm{d}}$ are tabulated and provided in Table 11 , where $T_{\mathrm{m}}$ and $T_{\mathrm{d}}$ are almost unchanged with the addition GO. One of the reasons for this behavior is the lack of chemical interaction between "Clear FLGPCL 02" resin and the GO. Before resin starts to melt and degrade, surface interactions between the resin and the GO might get lost. The stability of the GO was attributed to the protective nature of the polymer-matrix at high temperatures $\left(600{ }^{\circ} \mathrm{C}\right.$ in this case) for a limited amount of time. 


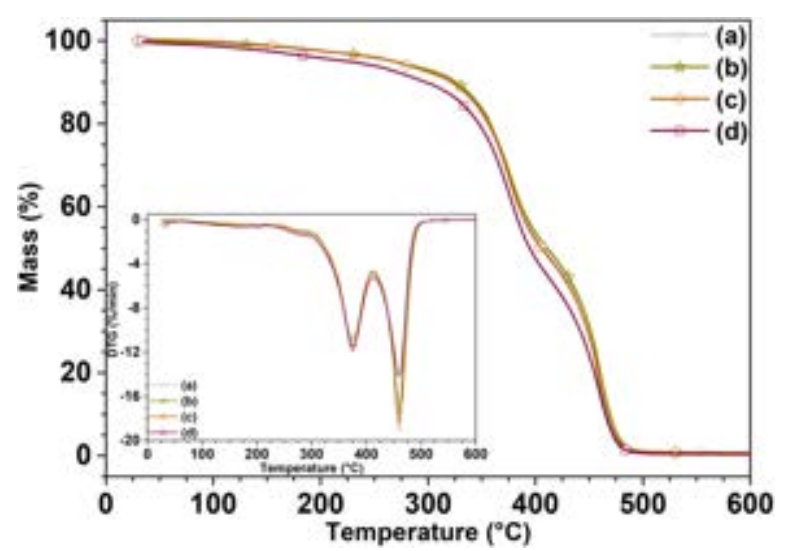

(a)

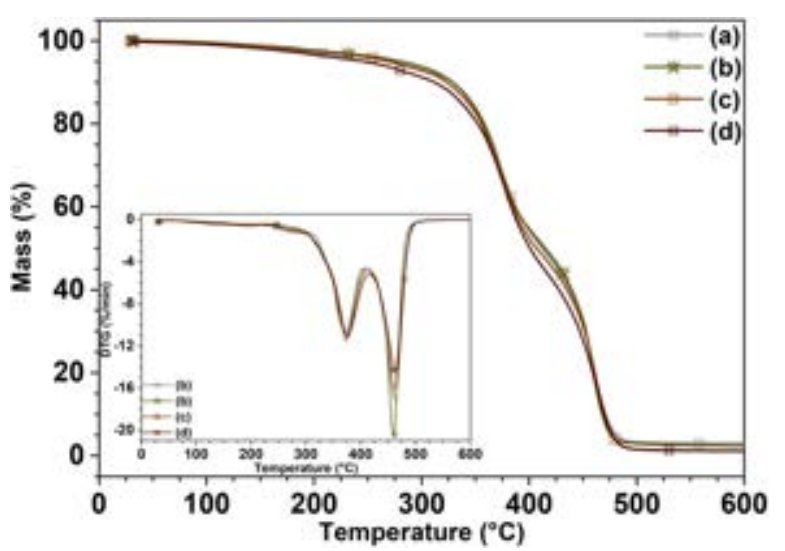

(b)

Figure 63. Representative curves TGA thermal analysis. (a) specimens in pure resin (o-a), and GOreinforced at $0.04 \% \mathrm{w} / \mathrm{w}(\mathrm{a}-\mathrm{b}), 0.08 \% \mathrm{w} / \mathrm{w}(\diamond-\mathrm{c})$, and $0.12 \% \mathrm{w} / \mathrm{w}(\square-\mathrm{d})$ during $14 \mathrm{~min}$ of post-cured. (b) specimens in pure resin $(\bullet-a)$, and GO-reinforced at $0.04 \% \mathrm{w} / \mathrm{w}(*-b), 0.08 \% \mathrm{w} / \mathrm{w}(\bullet-c)$, and $0.12 \% \mathrm{w} / \mathrm{w}(--\mathrm{d})$ during $28 \mathrm{~min}$ of post-cured.

The thermal stability of the samples manufactured in pure "Grey PN: F100G" resin and GO-reinforced was investigated by TGA to ensure the GO into the bulk of the specimens were stable. Under pyrolytic conditions in the $\mathrm{N}_{2}$ atmosphere, the degradation of the samples occurred with a sharp weight loss around $300^{\circ} \mathrm{C}-500^{\circ} \mathrm{C}$, accompanied with possible organic fragments (e.g. methacrylic acid and ester) [70,98]. Thermogravimetric analysis results between $32{ }^{\circ} \mathrm{C}$ and $600{ }^{\circ} \mathrm{C}$, are provided in Figure 64 . Slight mass loss from TGA curves around $80{ }^{\circ} \mathrm{C}$ was attributed to the loss of absorbed water in resin, moreover organics dissolvent as such as the IPA.

The effects of the $T_{\mathrm{m}}$ and $T_{\mathrm{d}}$ behavior of the specimens in pure "Grey PN: F100G" resin and GO-reinforced are apparent within the DTGA curves provided in Figure 64 . The $T_{\mathrm{m}}$ and $T_{\mathrm{d}}$ are tabulated and provided in Table 11. These temperatures are almost unchanged with the addition of $\mathrm{GO}$ at $0.02 \% \mathrm{w} / \mathrm{w}$ to $0.12 \% \mathrm{w} / \mathrm{w}$, (Figure 64 ). One of the reasons for this behavior is the lack of chemical interaction between "Grey PN: F100G" resin with the GO. Before resin starts to melt and degrade, surface interactions between the resin with GO might get lost. The stability of the GO was attributed to the protective nature of the polymer-matrix at high temperatures $\left(600{ }^{\circ} \mathrm{C}\right.$ in this case) for a limited amount of time.

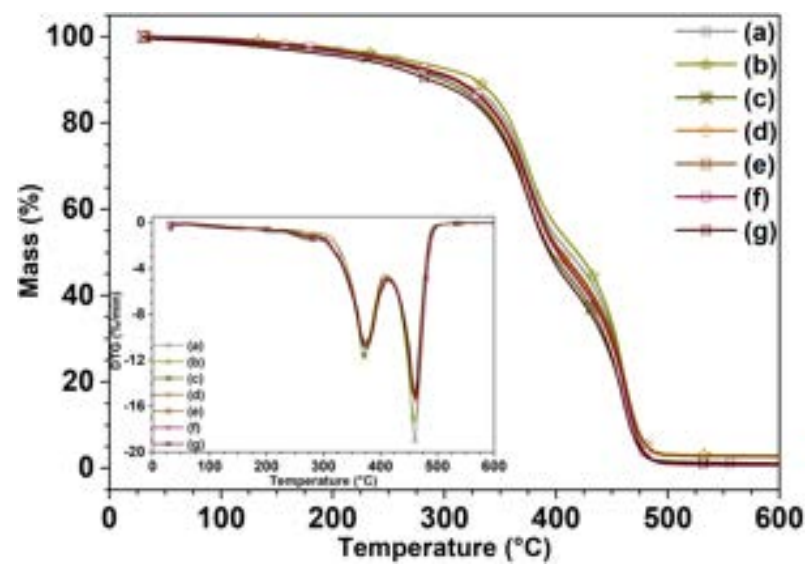

Figure 64. Representative curves of TGA thermal analysis on specimens manufactured in pure "Grey PN: F100G" resin (-a), and GOreinforced at $0.02 \% \mathrm{w} / \mathrm{w}(\mathrm{x}-\mathrm{b}), 0.04 \% \mathrm{w} / \mathrm{w}$ $(*-c), \quad 0.06 \% \mathrm{w} / \mathrm{w} \quad(\diamond-\mathrm{d}), \quad 0.08 \% \mathrm{w} / \mathrm{w} \quad(\bullet-e)$, $0.10 \% \mathrm{w} / \mathrm{w}(\square-\mathrm{f})$, and $0.12 \% \mathrm{w} / \mathrm{w}(-\mathrm{g})$. 
Table 11 shows a discrepancy between the $T_{\mathrm{g}}$ values obtained from DSC measurements and DMA analysis, attributing to the fact that DMA is highly dependent on the frequency of strain oscillation, whereas DSC measures a heat quantity in a temperature change between the target sample and the reference sample, where variations are inevitable. Although, $T_{\mathrm{g}}$ results obtained from these two means are not identical in the specimens in pure resin and the specimens GO-reinforced, both show a tendency that the $T_{\mathrm{g}}$ varies slightly as the GO loading varies in the polymeric matrix. Accordingly, $T_{\mathrm{g}}$ obtained on the substrates with $\mathrm{Cu}$ NWs and CuNi NWs decrease in relation to $T_{\mathrm{g}}$ measured on the pure resin specimen (see Table 8); while for the GO-reinforced substrates, $T_{\mathrm{g}}$ increases (Table 11).

Table 11. Values determined from DMA, DSC, and TGA analysis on specimens manufactured in pure resin and GO-reinforced.

\begin{tabular}{|c|c|c|c|c|c|c|}
\hline \multirow[t]{2}{*}{ Material type used } & \multirow{2}{*}{$\begin{array}{c}\text { Nanofiller } \\
\text { percentage } \\
(\% \mathbf{w} / \mathbf{w})\end{array}$} & \multicolumn{4}{|c|}{$\begin{array}{l}\text { Transition and degradation temperatures } \\
\qquad\left({ }^{\circ} \mathrm{C}\right)\end{array}$} & \multirow{2}{*}{$\begin{array}{c}\text { Residue } \\
(\mathbf{m} \%)\end{array}$} \\
\hline & & $T_{\mathrm{g}}-$ DMA & $T_{\mathrm{g}}-\mathrm{DSC}$ & $T_{\mathrm{m}}$ & $T_{\mathrm{d}}$ & \\
\hline Clear FLGPCL 02 resin & Pure resin & 69.1 & 61.8 & 376.1 & 460.8 & 0.8 \\
\hline \multirow{3}{*}{ GO (14 min post-cured) } & 0.040 & 71.5 & 71.4 & 376.3 & 460.9 & 0.6 \\
\hline & 0.080 & 71.6 & 68.9 & 375.3 & 459.3 & 0.1 \\
\hline & 0.120 & 67.9 & 62.6 & 375.3 & 460.2 & 0.1 \\
\hline Clear FLGPCL 02 resin & Pure resin & 70.1 & 61.0 & 373.6 & 459.8 & 2.7 \\
\hline \multirow{3}{*}{ GO (28 min post-cured) } & 0.040 & 72.7 & 65.4 & 372.8 & 459.9 & 1.3 \\
\hline & 0.080 & 73.0 & 70.9 & 375.2 & 461.2 & 0.8 \\
\hline & 0.120 & 70.7 & 68.0 & 375.6 & 462.1 & 0.8 \\
\hline Grey PN: F100G resin & Pure resin & 58.6 & 60.3 & 375.5 & 461.2 & 0.7 \\
\hline \multirow{6}{*}{ GO } & 0.020 & 66.1 & 65.9 & 374.4 & 460.0 & 2.6 \\
\hline & 0.040 & 65.4 & 64.4 & 372.3 & 458.0 & 1.4 \\
\hline & 0.060 & 64.6 & 63.3 & 374.8 & 461.2 & 1.4 \\
\hline & 0.080 & 63.0 & 62.4 & 374.0 & 462.7 & 2.6 \\
\hline & 0.100 & 66.4 & 64.2 & 376.7 & 462.6 & 0.8 \\
\hline & 0.120 & 66.2 & 65.9 & 376.2 & 461.3 & 0.6 \\
\hline
\end{tabular}

\subsection{Spectroscopic Characterization}

The chemical and structural properties of specimens manufactured in pure "clear FLGPCL 02" and "Grey PN: F100G" resins, and GO-reinforced, were carefully assessed with standard techniques, such as Raman, FTIR, and DRX.

5.5.1. Raman spectroscopy. Raman analysis was used to verify the presence of graphene in the polymeric matrix of "Clear FLGPCL 02" resin [70]. The representative spectra of GOreinforced specimens at $0.04 \% \mathrm{w} / \mathrm{w}, 0.08 \% \mathrm{w} / \mathrm{w}$, and $0.12 \% \mathrm{w} / \mathrm{w}$ during $14 \mathrm{~min}$ and $28 \mathrm{~min}$ of post-cured shows a broad D peak at $\sim 1330 \mathrm{~cm}^{-1}$ and a $\mathrm{G}$ peak at $\sim 1596 \mathrm{~cm}^{-1}$, related to the defects and hybridization type carbon [104]. These two peaks can be captured from the whole Raman spectra of G0-reinforced substrates presented in Figure 65. D peak is related to the breathing modes of $s p^{3}$ atoms in hexagon rings activated by the defects such as vacancies or grain boundaries, while $G$ peak is due to the bond stretching of all $s p^{2}$ pairs in both rings and chains [104]. Moreover, the intensity variations are attributed to GO content embedded into specimen bulk, crystallinity variation or stress structural. 
In Figure 65, the spectrum for the specimen GO-reinforced at $0.04 \% \mathrm{w} / \mathrm{w}$ present a grade relative of structural disorder, while in acquired spectra on specimens GO-reinforced at $0.08 \% \mathrm{w} / \mathrm{w}$ and $0.12 \% \mathrm{w} / \mathrm{w}$ the structural disorders increased considerably. Then, as increase the $D$ band intensity, increase significantly the structural disorders in the polymer matrix. Accordingly, is observed that the increase (or intensity variation) the D-band is due to increase GO content in of the specimens-bulk.

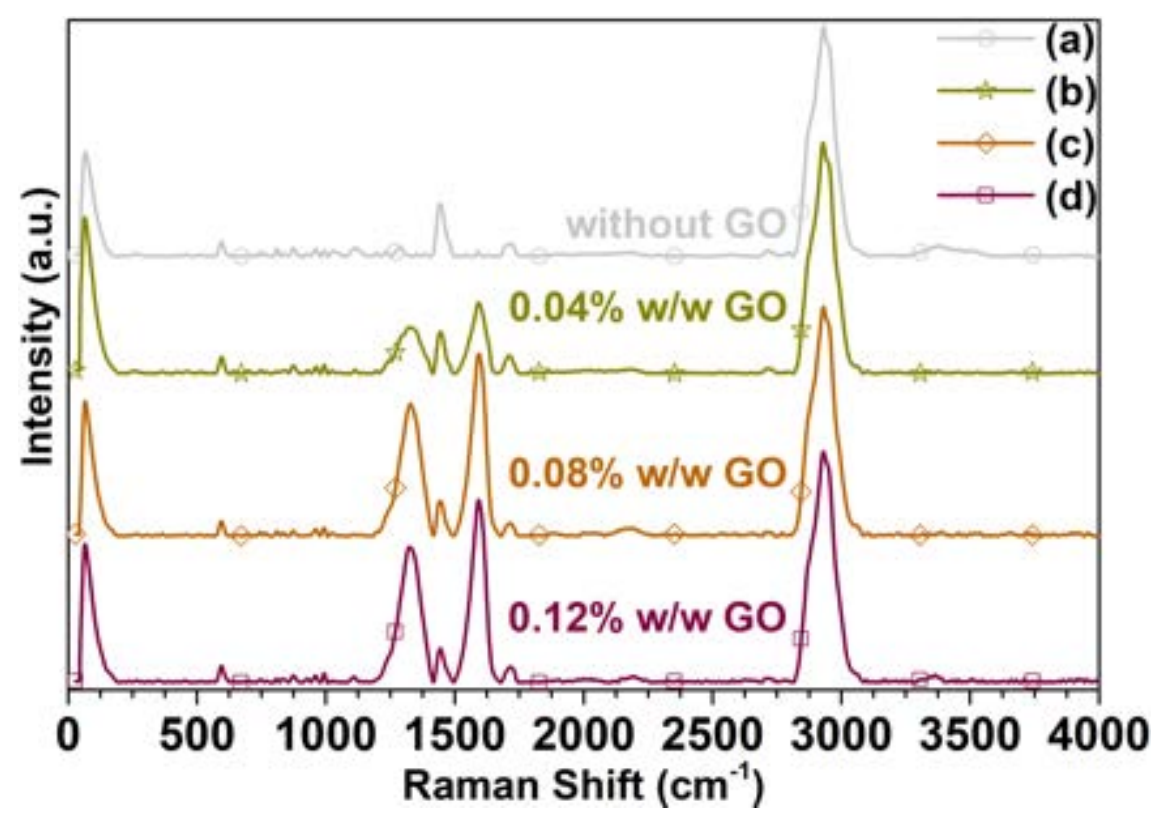

(a)

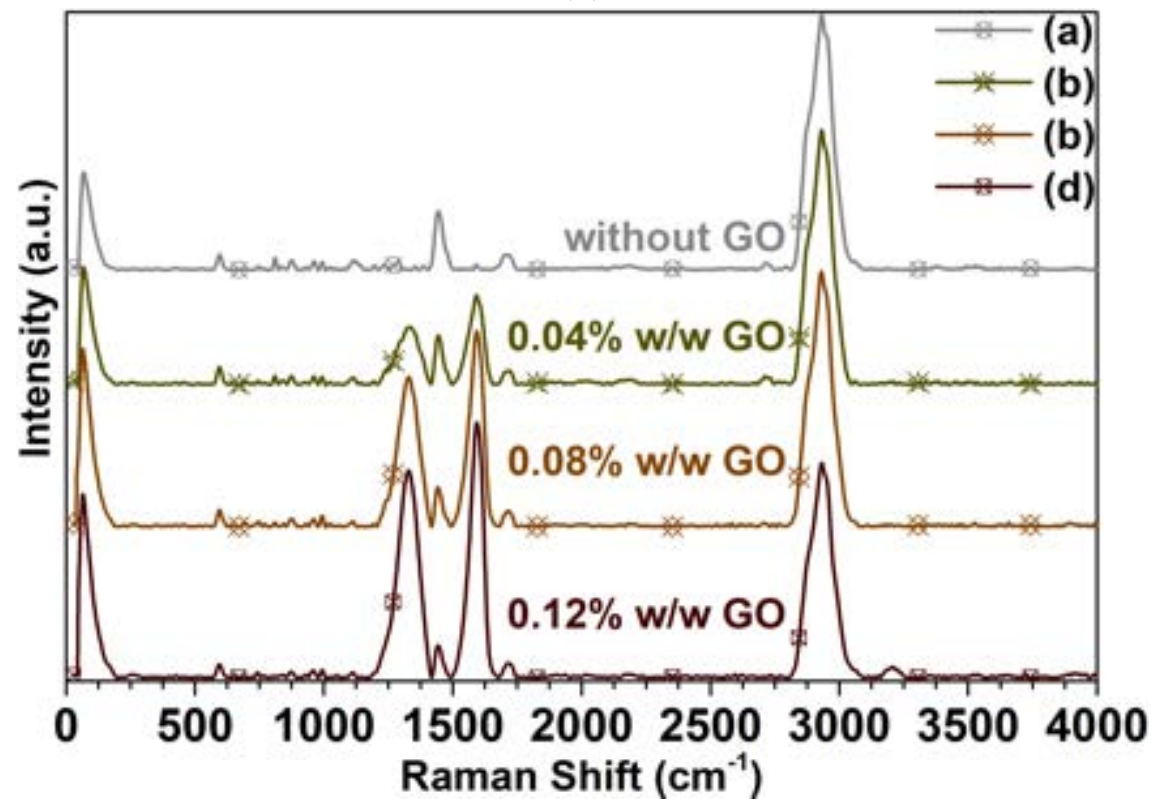

(b)

Figure 65. Raman spectra acquired on substrates manufactured pure resin and with GO. (a) specimens in pure resin (o-a), and GO-reinforced at $0.04 \% \mathrm{w} / \mathrm{w}(\mathrm{x}-\mathrm{b}), 0.08 \% \mathrm{w} / \mathrm{w}(\diamond-\mathrm{c})$, and $0.12 \% \mathrm{w} / \mathrm{w}(\square-\mathrm{d})$ during $14 \mathrm{~min}$ of post-cured. (b) specimens in pure resin $(\cdot-a)$, and GOreinforced at $0.04 \% \mathrm{w} / \mathrm{w}(*-\mathrm{b}), 0.08 \% \mathrm{w} / \mathrm{w}(\bullet-\mathrm{c})$, and $0.12 \% \mathrm{w} / \mathrm{w}(-\mathrm{d})$ during 28 min of post-cured. 
The Raman spectra of the specimens manufactured in pure "Grey PN: F100G" resin and the acquired of GO-reinforced substrates are shown in Figure 66. G0 have two main characteristic bands, denoted as the $D$ and $G$ bands. The D-band, also called the "disorderband", is related with the disorders of carbon network in the $s p^{3}$ hybridization and with defects in the carbon structure caused by the oxygenated groups, which so only become in Raman active upon symmetry loss in the network; this band was identified $\sim 1331 \mathrm{~cm}^{-1}$ (Figure 66). The $\mathrm{G}$-band, which is a band representative of $\mathrm{C}-\mathrm{C}$ bonding, is a characteristic band of the structure of the graphite produced by the $E_{2 \mathrm{~g}}$ mode of the carbon atoms in $s p^{2}$ hybridization, then this band is found in all Raman spectra as the signature of the graphitic network and was located $\sim 1596 \mathrm{~cm}^{-1}$ (Figure 66) $[105,106]$.

In Figure 66 appreciated significantly the $D$ and $G$ bands according to as increase the $G 0$ content. Notwithstanding, the GO increase in polymeric-matrix did not signify that GOreinforced specimens have better behavior on mechanical properties (see Figure 48 and Figure 60).

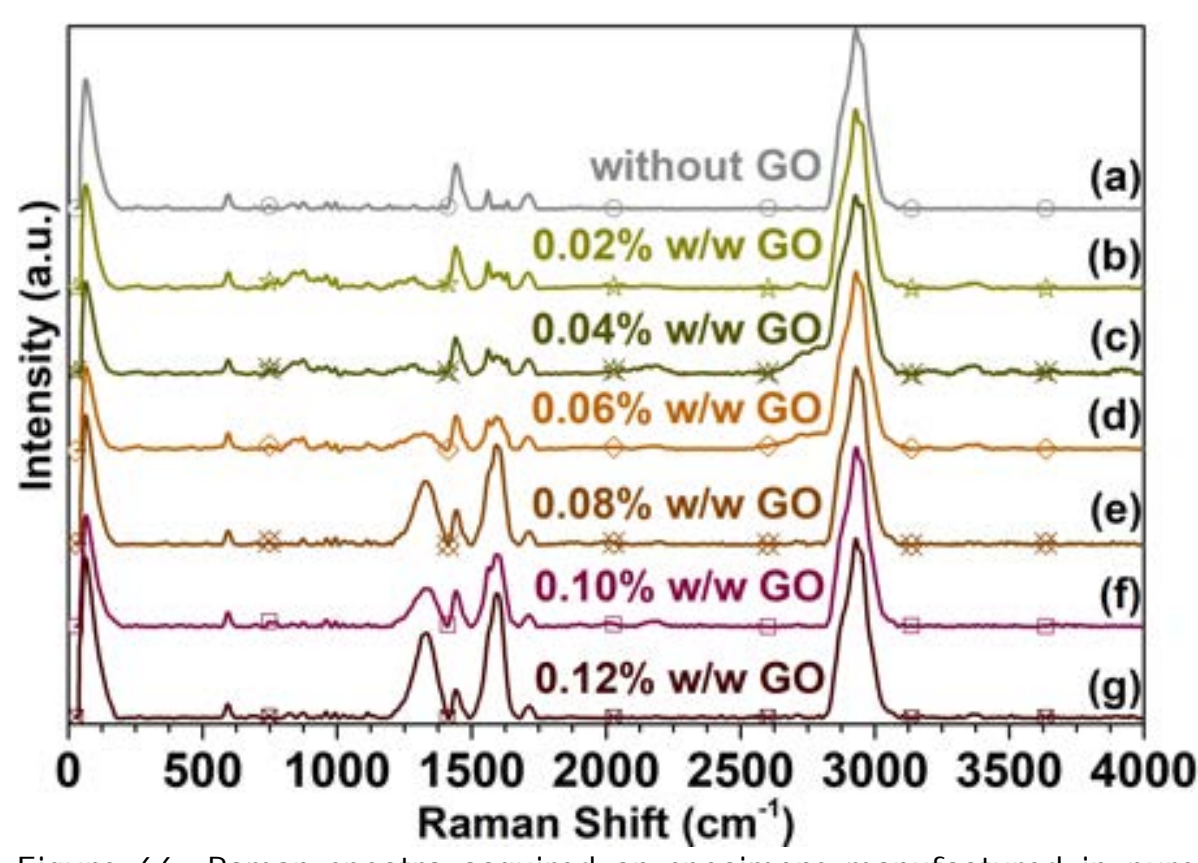

Figure 66. Raman spectra acquired on specimens manufactured in pure "Grey PN: F100G" resin (o-a), and GO-reinforced at $0.02 \% \mathrm{w} / \mathrm{w}(\mathrm{x}-\mathrm{b})$, $0.04 \% \mathrm{w} / \mathrm{w}(*-\mathrm{c}), 0.06 \% \mathrm{w} / \mathrm{w}(\diamond-\mathrm{d}), 0.08 \% \mathrm{w} / \mathrm{w}(\bullet-e), 0.10 \% \mathrm{w} / \mathrm{w}(\square-f)$, and $0.12 \% \mathrm{w} / \mathrm{w}(-\mathrm{g})$.

Similarly, the spectra in Figure 66 occurs the same behavior of the spectra presented in Figure 65 . Then, the specimens GO-reinforced at $0.02 \% \mathrm{w} / \mathrm{w}, 0.04 \% \mathrm{w} / \mathrm{w}$ and $0.06 \% \mathrm{w} / \mathrm{w}$ presents a greater of structural order, in comparison to the acquired spectra on specimens GO-reinforced at $0.08 \% \mathrm{w} / \mathrm{w}, 0.10 \% \mathrm{w} / \mathrm{w}$ and $0.12 \% \mathrm{w} / \mathrm{w}$, where the structural disorders increased considerably. Thus, as the $D$ band intensity increases, the structural disorders in the polymer matrix increase. In addition, the variation of the $D$ band is influenced by the GO content added to the bulk specimens. 
5.5.2. Fourier-transformed infrared. The FT-IR spectra acquired on the specimens manufactured in pure "Clear FLGPCL 02" resin and GO-reinforced substrates, both with postcured during $14 \mathrm{~min}$ and $28 \mathrm{~min}$ are shown in Figure 67. In these spectra is observed the presence of different groups functional and characteristic bands of the GO-interaction with the polymer matrix. Broadband between $\sim 3146 \mathrm{~cm}^{-1}$ and $\sim 3689 \mathrm{~cm}^{-1}$, is attributed to stretching and bending vibrations of the $-\mathrm{OH}$ bonds correspond to the hydroxyl and carboxyl groups. Three bands identified at $\sim 2952 \mathrm{~cm}^{-1}, \sim 2925 \mathrm{~cm}^{-1}$ and $\sim 2868 \mathrm{~cm}^{-1}$, are assigned to the $\mathrm{C}-\mathrm{H}$ bond stretching vibrations. The band at $\sim 1700 \mathrm{~cm}^{-1}$ indicates the presence of the ester group $\mathrm{C}=0$ stretching vibrations. Band in $\sim 1636 \mathrm{~cm}^{-1}$, is attributed to the $\mathrm{C}=\mathrm{C}$ bond stretching vibrations. The band at $\sim 1451 \mathrm{~cm}^{-1}$ can be attributed to the bending vibrations of the $\mathrm{C}-\mathrm{H}$ bonds of the $-\mathrm{CH}_{3}$ groups. Broadband between $\sim 1355 \mathrm{~cm}^{-1}$ and $\sim$ $1395 \mathrm{~cm}^{-1}$, is attributed to stretching vibrations of the $\mathrm{C}-\mathrm{OH}$ bonds. Band in $\sim 1239 \mathrm{~cm}^{-1}$ correspond to stretching $\mathrm{C}-\mathrm{O}$ bonds (acids) and $\mathrm{C}-\mathrm{O}-\mathrm{C}$ (epoxides). The band at $1050 \mathrm{~cm}^{-1}$ correspond to stretching $\mathrm{C}-\mathrm{O}$ bonds (alcohols). Moreover, the bands at $888 \mathrm{~cm}^{-1}$, $1299 \mathrm{~cm}^{-1}$, and $1409 \mathrm{~cm}^{-1}$ can be attributed to the $\mathrm{C}-\mathrm{C}, \mathrm{O}-\mathrm{CH}_{2}$, and $\mathrm{C}-\mathrm{OH}$ stretching vibration, respectively. The two bands at $\sim 1323 \mathrm{~cm}^{-1}$ and $\sim 747 \mathrm{~cm}^{-1}$ are attributed to the $\alpha$-methyl group vibrations. Furthermore, the distinct absorption bands from $\sim 1070 \mathrm{~cm}^{-1}$ to $\sim 1207 \mathrm{~cm}^{-1}$ can be attributed to the $\mathrm{C}-\mathrm{O}-\mathrm{C}$ stretching vibrations [70,94,58-116].

In each a spectrum presented in Figure 67, there are no appreciable differences between the FTIR spectra of the specimens manufactured in pure resin and with GO-reinforced because the resin does not form any covalent bond with this type of nanofiller, and moreover, the spectra have the same bands in the same wave numbers, indicating there is no difference in the structure. Additionally, the GO embedded in the polymer-matrix does not add new functional groups that can be observed in the infrared (see Figures 67).

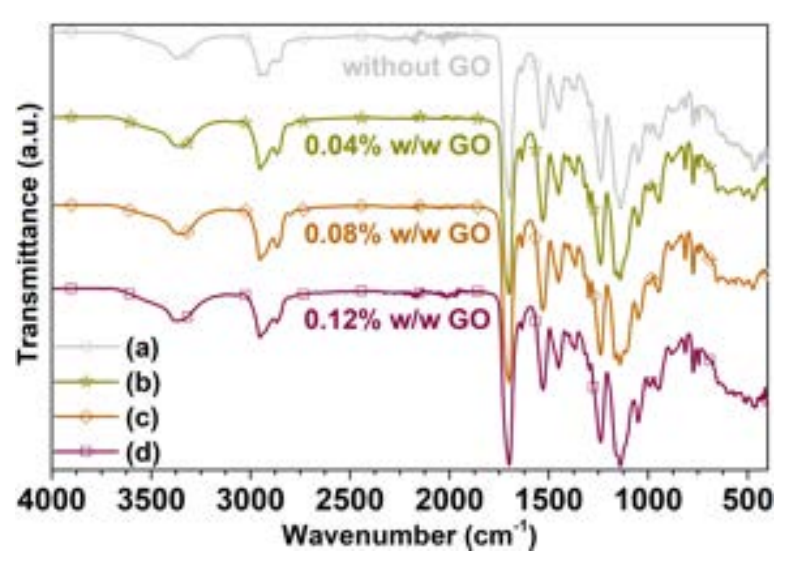

(a)

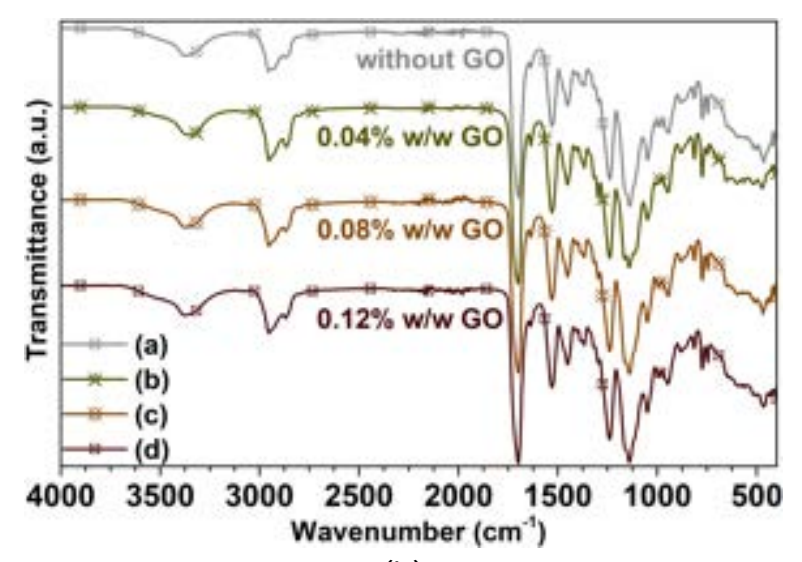

(b)

Figure 67. FTIR spectra acquired on substrates manufactured pure resin and with $\mathrm{GO}$. (a) specimens in pure resin (o-a), and GO-reinforced at $0.04 \% \mathrm{w} / \mathrm{w}(\mathrm{x}-\mathrm{b}), 0.08 \% \mathrm{w} / \mathrm{w}(\diamond-\mathrm{c})$, and $0.12 \% \mathrm{w} / \mathrm{w}$ ( $\square-\mathrm{d}$ ) during 14 min of post-cured. (b) specimens in pure resin $(\bullet-a)$, and GO-reinforced at $0.04 \% \mathrm{w} / \mathrm{w}(*-b)$, $0.08 \% \mathrm{w} / \mathrm{w}(-\mathrm{c})$, and $0.12 \% \mathrm{w} / \mathrm{w}(-\mathrm{d})$ during $28 \mathrm{~min}$ of post-cured.

According to the above discussions, it can be concluded that the used photoreactive polymer resin in the analysis reported in Figure 67 is a resin with a type of macromolecular MAA and MMA mixture. 
Figure 68 presents the FT-IR spectra of the specimens manufactured in pure "Grey PN: F100G" resin and GO-reinforced. In these spectra, to the same then the showed in Figure 67 , is observed the presence of different groups' functional and characteristic bands of the GO-interaction with the polymer matrix. Accordingly, broadband between $\sim 3146 \mathrm{~cm}^{-1}$ to $\sim 3689 \mathrm{~cm}^{-1}$ and $\sim 1760 \mathrm{~cm}^{-1}$ to $\sim 3049 \mathrm{~cm}^{-1}$ are attributed to stretching and bending vibrations of the $-\mathrm{OH}$ bonds correspond to the hydroxyl and carboxyl groups, and to the stretching vibrations of the $\mathrm{C}-\mathrm{H}$ bonds, respectively. The bands at $\sim 1700 \mathrm{~cm}^{-1}$ and $\sim$ $1636 \mathrm{~cm}^{-1}$ correspond of the $\mathrm{C}=0$ bonds stretching vibrations of the ester group and to the $\mathrm{C}=\mathrm{C}$ bond stretching vibrations, respectively. Band in $\sim 1451 \mathrm{~cm}^{-1}$ is attributed to the bending vibrations of the $\mathrm{C}-\mathrm{H}$ bonds of the $-\mathrm{CH}_{3}$ groups. Broadband between $\sim 1350 \mathrm{~cm}^{-1}$ and $\sim 1395 \mathrm{~cm}^{-1}$, is attributed to stretching vibrations of the $\mathrm{C}-\mathrm{OH}$ bonds. The band at $\sim$ $1242 \mathrm{~cm}^{-1}$ correspond to stretching $\mathrm{C}-\mathrm{O}$ bonds (acids) and $\mathrm{C}-\mathrm{O}-\mathrm{C}$ (epoxides) and band at $\sim 1052 \mathrm{~cm}^{-1}$, correspond to stretching $\mathrm{C}-0$ bonds (alcohols). Moreover, the bands at $882 \mathrm{~cm}^{-1}, 1299 \mathrm{~cm}^{-1}$, and $1409 \mathrm{~cm}^{-1}$, are attributed to the $\mathrm{C}-\mathrm{C}, \mathrm{O}-\mathrm{CH}_{2}$, and $\mathrm{C}-\mathrm{OH}$ stretching vibration, respectively. The two bands at $\sim 1326 \mathrm{~cm}^{-1}$ and $\sim 747 \mathrm{~cm}^{-1}$ correspond to the a-methyl group vibrations. Furthermore, the distinct absorption bands from $\sim 1075 \mathrm{~cm}^{-1}$ to $\sim 1206 \mathrm{~cm}^{-1}$, can be attributed to the $\mathrm{C}-\mathrm{O}-\mathrm{C}$ stretching vibrations [70,94, 107-116].

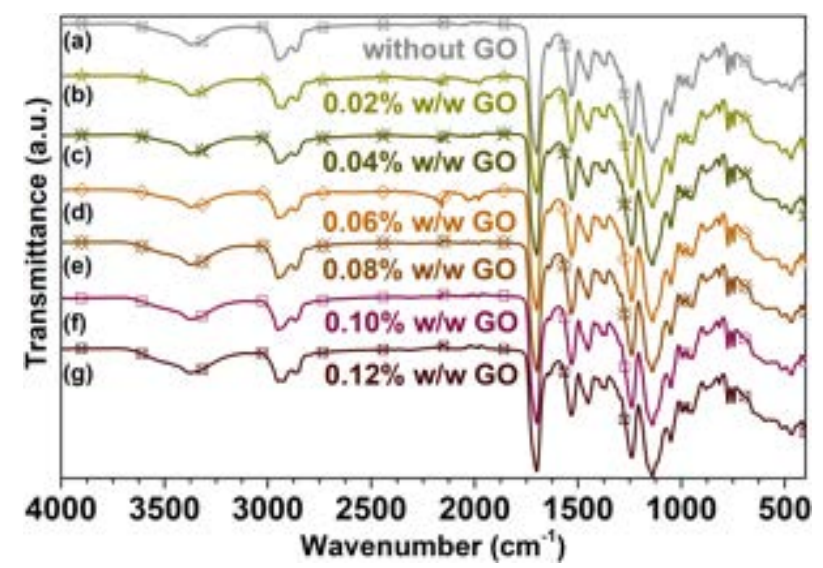

Figure 68. FTIR spectra acquired on specimens manufactured in pure "Grey PN: F100G" resin $(\cdot-a)$, and GO-reinforced at $0.02 \% \mathrm{w} / \mathrm{w}(\mathrm{x}-\mathrm{b})$, $0.04 \% \mathrm{w} / \mathrm{w}(*-\mathrm{c}), 0.06 \% \mathrm{w} / \mathrm{w}(\diamond-\mathrm{d}), 0.08 \% \mathrm{w} / \mathrm{w}$ $(\bullet-e), 0.10 \% w / w(\square-f)$, and $0.12 \% w / w(-g)$.

Similarly, the spectra in Figure 68 occurs the same behavior of the spectra presented in Figure 67. Therefore, there are no appreciable differences between the FTIR spectra acquired on the specimens manufactured in pure resin and the GO-reinforced, meaning the resin not form bonds covalent with the GO, indicating there is no difference in the structure, because the spectra have the same bands in the same wave numbers. In addition, the GO embedded in the polymer-matrix does not add new functional groups that can be observed in the infrared (see Figure 68).

According to the previous discussions, it is concluded that the used photopolymer "Grey PN: F100G" resin, in the analysis reported in Figure 68, is a mixture of macromolecular MAA and MMA mixture. 
5.5.3. X-ray diffraction. In the patterns XRD presented in Figure 69, there are not appreciable differences and no diffraction peaks in the specimens manufactured in pure "Clear FLGPCL 02", "Grey PN: F100G" resin, neither in the GO-reinforced specimens. Meaning, the material providing of the mixture of $\mathrm{GO}$ with the pure resin, is an amorphous material.

According to the previous discussions, it can be concluded that the GO-embedded in the photopolymer resin did not produce relevant structural changes, not form any covalent bond, neither add new functional groups. Therefore, the improvements of thermal-mechanical properties possibly are associates to the grade of structural order produced by the content of the $\mathrm{GO}$ in the polymeric matrix.

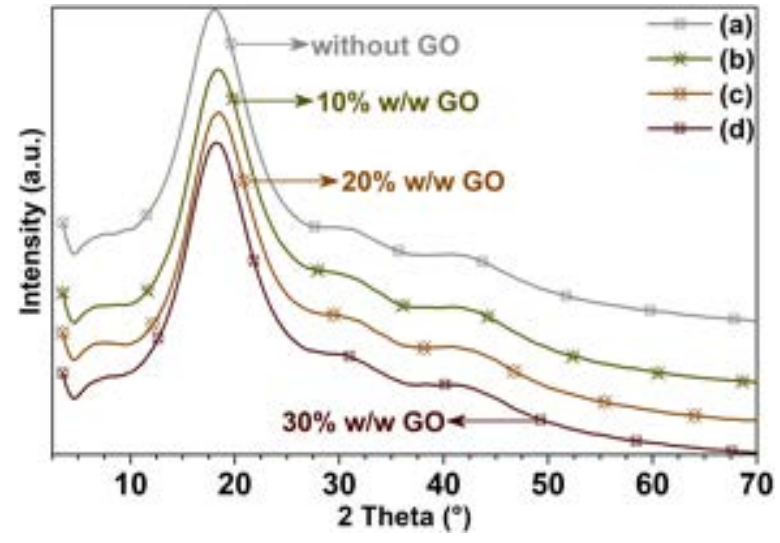

(a)

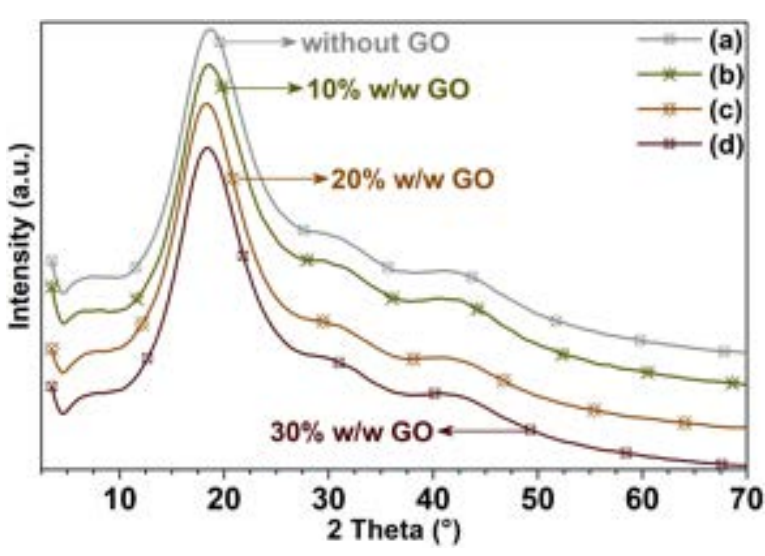

(b)

Figure 69. XRD patterns acquired on specimens manufactured pure resin and with GO. (a) pure "Clear FLGPCL 02" resin $(\bullet-\mathrm{a})$, and GO-reinforced at $0.04 \% \mathrm{w} / \mathrm{w}(*-\mathrm{b}), 0.08 \% \mathrm{w} / \mathrm{w}(\bullet-\mathrm{c})$, and $0.12 \% \mathrm{w} / \mathrm{w}(--d)$ with post-cured during $28 \mathrm{~min}$. (b) pure "Grey PN: F100G" resin $(\cdot-a)$, and GOreinforced at $0.04 \% \mathrm{w} / \mathrm{w}(*-\mathrm{b}), 0.08 \% \mathrm{w} / \mathrm{w}(\bullet-\mathrm{c}), 0.12 \% \mathrm{w} / \mathrm{w}(\cdot-\mathrm{d})(-\mathrm{g})$. 


\section{Surface Functionalization}

An additional goal of our research is linked to the possibility of functionalizing the surfaces of complex textured geometries obtained by additive photopolymerization and to compare the properties of coated and uncoated substrates. To this end, magnetron sputtering of titanium and diamond like carbon is applied, due to its potential tribological, optical and biomedical applications. Partial results have been already presented in [69] and have been submitted for evaluation to Coatings (peer-reviewed open access journal).

\subsection{Experimental Setup}

$3 \mathrm{D}$ geometry of the substrate selected was a circular disk of $21.3 \mathrm{~mm}$ diameter with a surface texture with the curvilinear transversal section of curvature radius $1.0 \mathrm{~mm}$ (see Figure 70 ). The substrate was created in computer assisted design (CAD) software, SketchUp Make 2016 version 16.0.19911 (Trimble Navigation Limited), which facilitates the making, modification, analysis, and optimization of a certain model, validating the features, properties, and feasibility of the design. The substrates were fabricated with commercial resin (photosensitive resin) using the laser stereolithography technique with a layer thickness of $0.1 \mathrm{~mm}$. We chose this shape of the substrates considering that surface coated rapid prototypes have great potential for lab-and organ-on-chip applications in the microfluidic industry, in which channels, grooves, ridges, and textures with hundreds of microns or even few $\mathrm{mm}$ in height or depth are usually present.
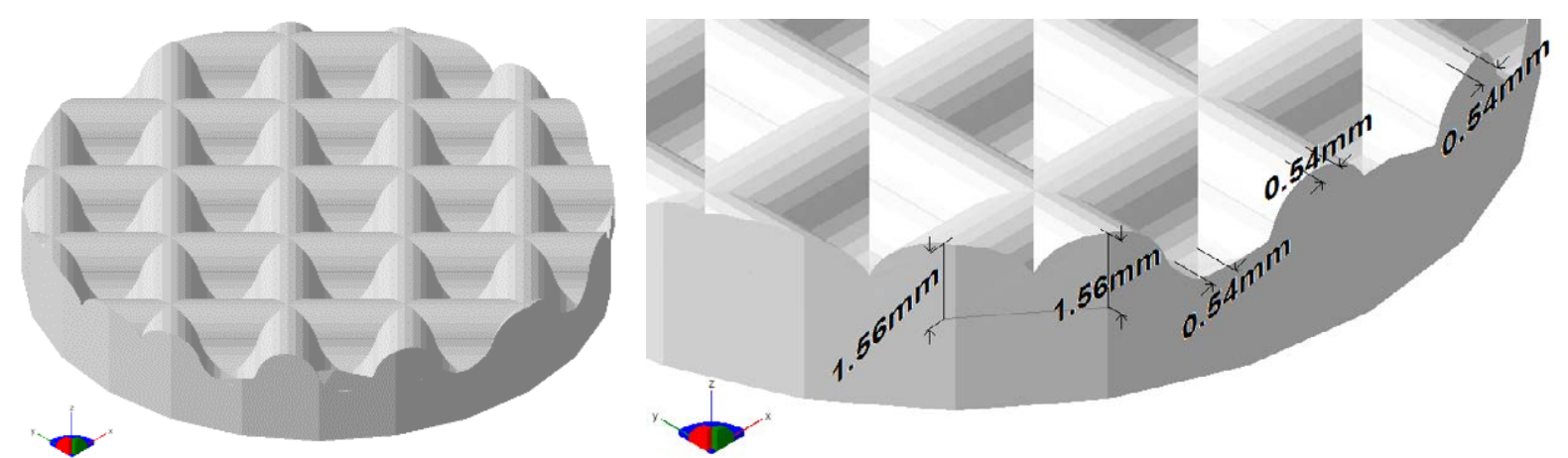

Figure 70. Substrate of curvilinear section modeled in SketchUp.

The magnetron sputtering technique was used for the deposition of both $\mathrm{Ti}$ and DLC layers. In the case of $\mathrm{Ti}$, the deposition was carried out with a pure metal Ti rectangular target $\left(200 \times 75 \mathrm{~mm}^{2}\right)$ with a purity of the $99.9 \%$ in argon atmosphere (Ar). The Ar working pressure and the magnetron DC power was set to $4 \times 10^{-3}$ mbar and $200 \mathrm{~W}$, respectively. The deposition time was 7 minutes, giving rise to a total thickness of the Ti layer of $200 \mathrm{~nm}$. Further, a pure graphite rectangular target $\left(400 \times 100 \mathrm{~mm}^{2}\right)$ a purity of the $99.9 \%$ was used for the deposition of the DLC layer. The magnetron was operated in pulsed-DC mode, $150 \mathrm{kHz}$ frequency, $4 \mu$ s pulsing time. The purity of the sputter targets was $99.0 \%$. The base pressure of the sputter system was of $5 \times 10^{-6} \mathrm{mbar}$, and argon working pressure was set to $7 \times 10^{-3}$ mbar. The substrates were located, on system simple rotation and parallel, to a 
distance of $8 \mathrm{~cm}$ from the target during the deposition. The deposition time was 90 minutes, giving rise to a total thickness of the DLC layer of $40 \mathrm{~nm}$. The measurement of the film thicknesses of $\mathrm{Ti}$ and DLC, masked deposition on a glass slide, was determined with a profilometer.

The validation of the manufacturing and deposition process was performed through optical microscopy and Raman spectroscopy. Consequently, we presented preliminary research, to find possible future applications (functional low-cost devices) of the photopolymer resins used in 3D photopolymerization, coated with different metallic or nonmetallic species. We focused on analyzing two regions of a selected texture (crest and valley), where we used two coatings types ( $\mathrm{Ti}$ and $\mathrm{DLC}$ ) deposited by magnetron sputtering. The optical microscopy allowed us to know the geometric accuracy manufactured by each $3 \mathrm{D}$ printer and the Raman spectroscopy to identify species deposited specifically in the texture holes.

The substrates manufactured with photopolymer resin Clear FLGPCL 02 by the laser stereolithography technique in the Form 1+printers, are presented in Figures 71(a). In Figure 71 (b) the Ti-coated substrate is appreciated, and in Figure 71(c) the DLC-coated substrate is presented. The deposited coating is well defined and can be clearly appreciated compared to the uncoated substrate. In addition, Figures 71 demonstrate surface finishes with irregularities, perhaps by the quality level of the low-cost stereolithography system used. In Table 12, we report the geometric differences of the substrate designed concerning the specimen printed; additionally, it is noted that the substrate manufactured with the Form $1+$ printer has good accuracy, but with a surface finished acceptably.

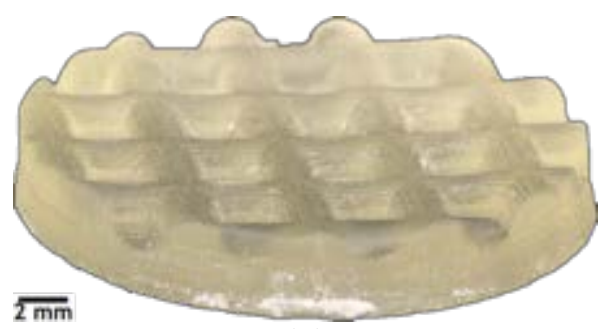

(a)

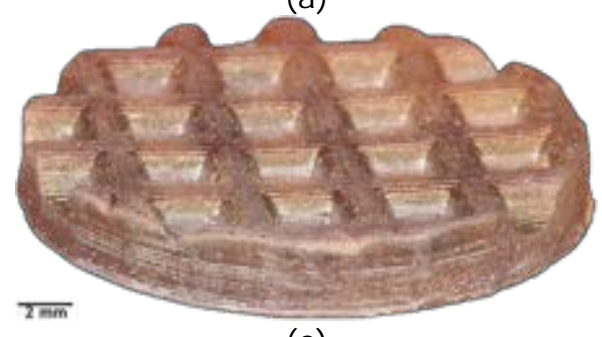

(c)

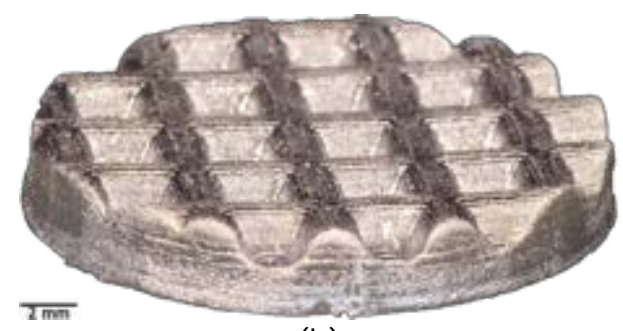

(b)

Figure 71. Specimens with surface textures including a network of $1 \mathrm{~mm}$ diameter crossing ribs. (a) pure resin, (b) Ti-coated and (c) DLC-coated.

Table 12. Values of the length, mass and volume measurements of the cylindrical substrates manufactured in the Form 1+ printer.

\begin{tabular}{|c|c|c|c|c|c|c|c|}
\hline \multicolumn{4}{|c|}{ CAD dimensions } & \multicolumn{4}{|c|}{ Measurements of printed substrates } \\
\hline $\begin{array}{l}\text { Radius } \\
\text { (cm) }\end{array}$ & $\begin{array}{c}\text { Thickness } \\
\text { (cm) }\end{array}$ & $\begin{array}{c}\text { Volume } \\
\left(\mathrm{cm}^{3}\right)\end{array}$ & $\begin{array}{l}\text { Mass* } \\
\text { (g) }\end{array}$ & $\begin{array}{l}\text { Radius } \\
\text { (cm) }\end{array}$ & $\begin{array}{c}\text { Thickness } \\
\text { (cm) }\end{array}$ & $\begin{array}{c}\text { Mass } \\
\text { (g) }\end{array}$ & $\begin{array}{c}\text { Volume } \\
\left(\mathrm{cm}^{3}\right)\end{array}$ \\
\hline 1.022 & 0.356 & 1.150 & 1.265 & 1.019 & 0.335 & 0.976 & 0.887 \\
\hline
\end{tabular}




\subsection{Morphological Properties}

Morphological properties of the substrates manufactured using the laser stereolithography technique of low-cost, were analyzed through optical microscopy technique of dispersive light, which presented to following.

6.2.1. Optical microscopy. Figures 72 to Figure 74 present the detail of surface features obtained by the optical microscopy of the surface of devices printed in the Form 1+ with Clear FLGPCL 02 resin, uncoated and with a Ti layer of about $200 \mathrm{~nm}$ and other with a DLC layer of around $40 \mathrm{~nm}$, where the thickness is observed a uniform throughout the entire perimeter of the section. We observed the layer by layer process and average roughness in the $z$-axis direction of 3D surface texture printed by Form 1+, however, the influence on the final geometry is not dramatic, as the designed details are around two times larger than machine accuracy.

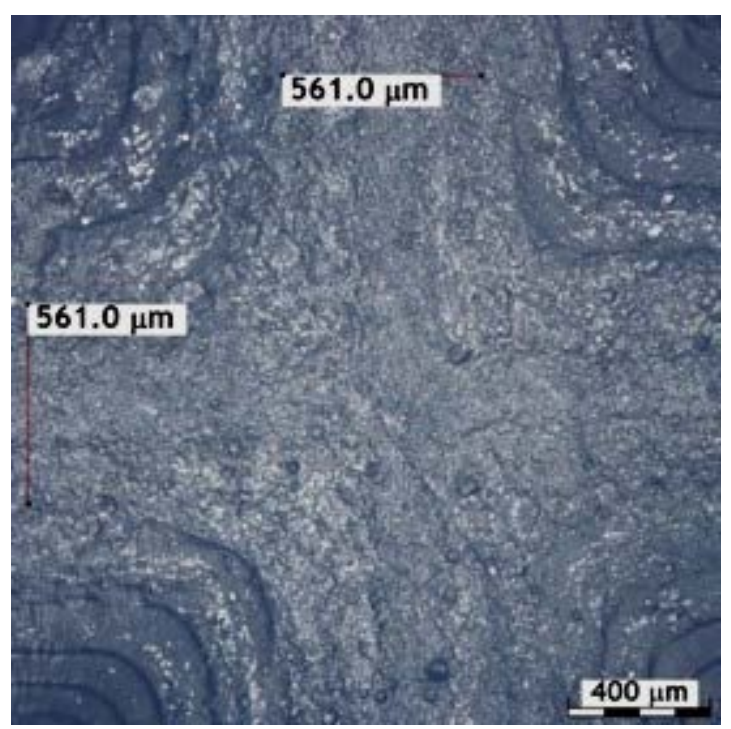

(a)

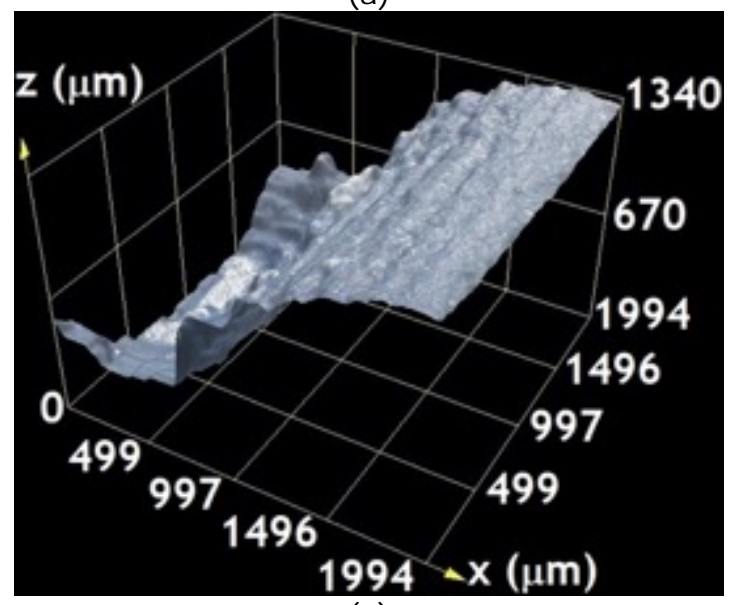

(c)

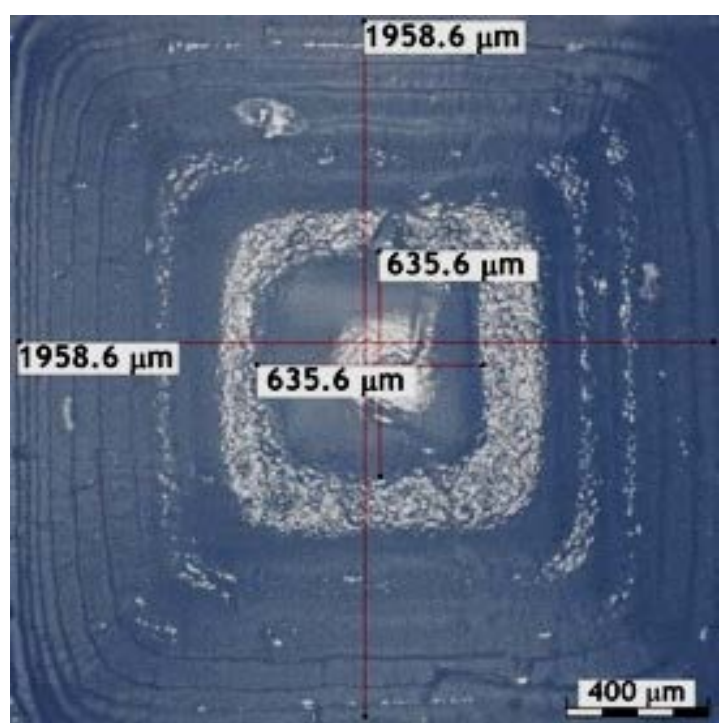

(b)

Figure 72. Acquired images with $10 \mathrm{X}$ objective lenses on the uncoated textured surfaces. (a) crest, (b) valley, and (c) the height between crest and valley.

Figure 72 the value of the thickness of the last layer of the crest manufactured was $561.0 \mu \mathrm{m}$, a value that was somehow complex to obtain by the poor surface finish (Figure 72(a)). Figure 72(b) the internal structure printed has better manufacturing precision for 
curved sections, with a precision in terms of curvature, which is determined by the length of $635.6 \mu \mathrm{m}$ measured between the boundaries of the deepest layer. The surface topography between the crest and the valley of the textures manufactured is presented in Figure $72(\mathrm{c})$. The average crest-valley length measured in the texture manufactured was $1283.3 \mu \mathrm{m}$.

The curvature of valley and crest of the surface texture manifest an approximate increase of $3.9 \%$ in the curvature of the crest and $17.7 \%$ in the curvature of the valley (Figure $72(a)$ ). Accordingly, it is determined that the curvature of the valleys is manufacture with good precision in the Form1+ printer.

Figure 73 presents the Ti-coated substrates using the sputtering magnetron technique, where on the surface a homogeneous color without delamination of the coating is evident. The surface finish and well-defined contours contribute to the accuracy of the measurement process. Figure 73(a) correspond to the crests, Figure 73(b) to the valleys, while Figure 73(c) present the digitally reconstructed surface between crests and valleys. Again, the final geometry after manufacture and Ti deposition maintains the characteristics initially defined in the CAD files. In addition to the possible physical and chemical applications, the titanium coating provides useful aesthetic properties that could have wide decorative applications of industrial interest.

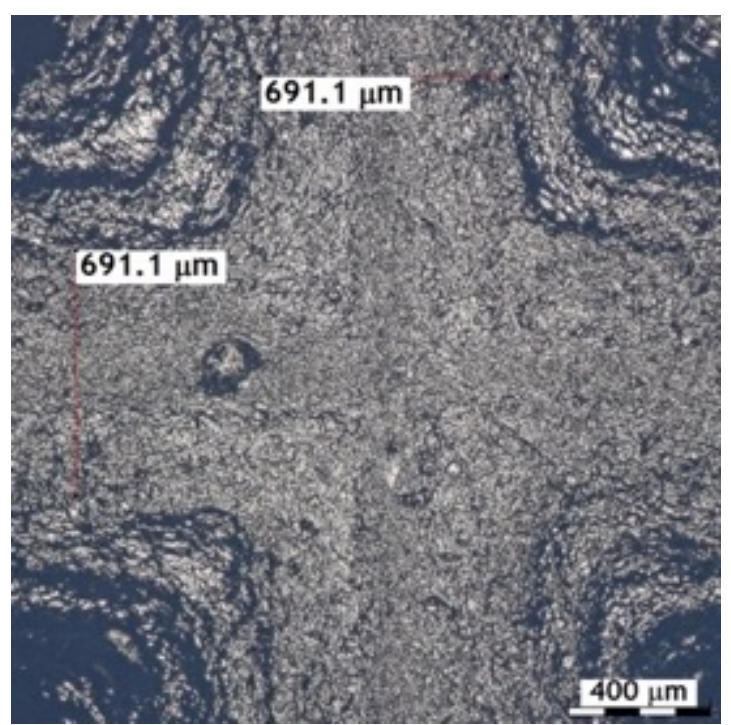

(a)

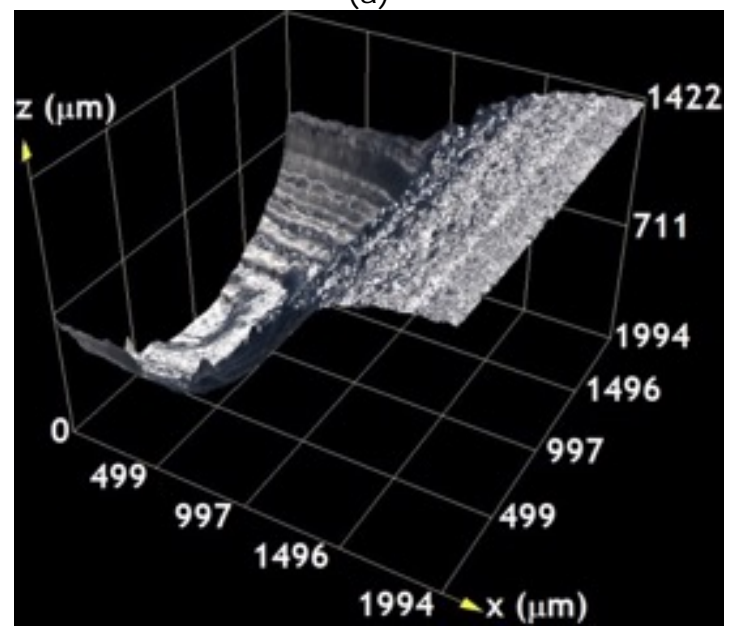

(c)

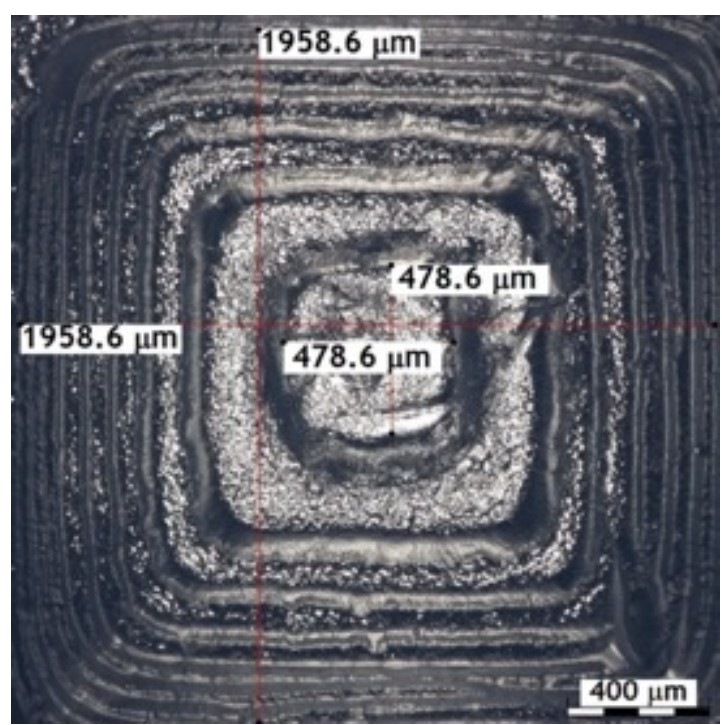

(b)

Figure 73. Acquired images with $10 \mathrm{X}$ objective lenses on the Ti-coated textured surfaces. (a) crest, (b) valley, and (c) the height between crest and valley. 
Surface textures DLC-coated are presented in Figure 74. Like the Ti-coated surfaces, the crests (see Figure 74(a)), valleys (see Figure 74(b))) and the length between crest and valley (see Figure $74(c)$ ) of the surface texture exhibit similar color without delamination of the applied coating (the coatings have an adequate aspect and are not are peel off immediately), providing a better appearance on the surface in relation to the uncoated ones. Further, the final geometry of the device after coating does not experiment relevant macroscopic changes being that the thickness of the deposited films is in the range of the $40 \mathrm{~nm}$ to $200 \mathrm{~nm}$, where only the influence the color shade and brightness that the surfaces acquired exist.

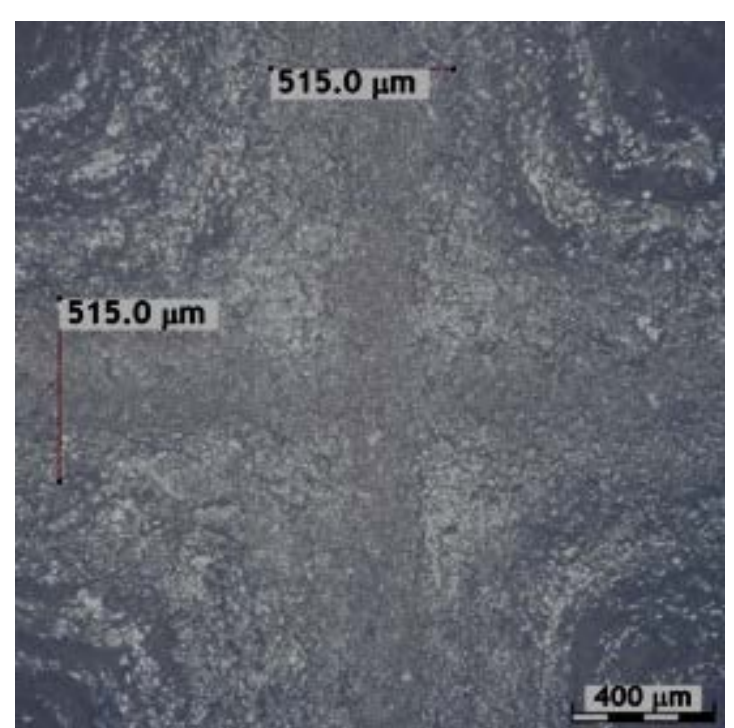

(a)

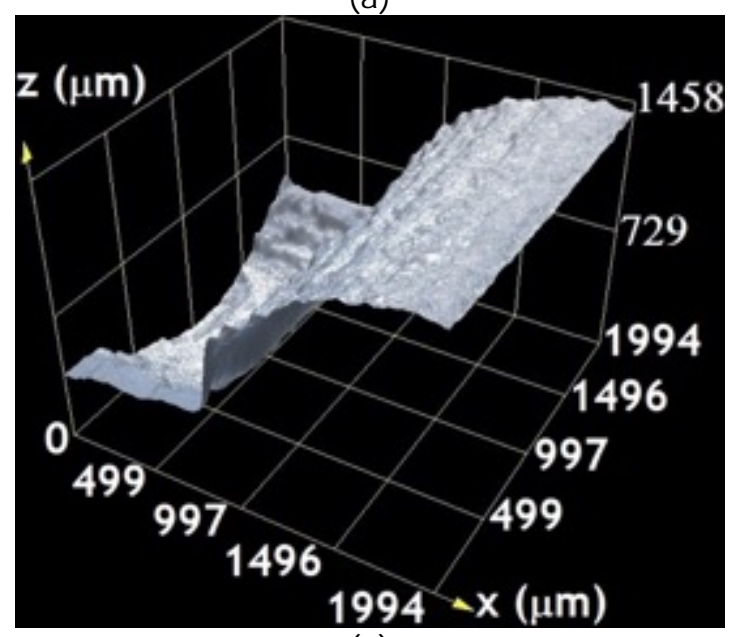

(c)

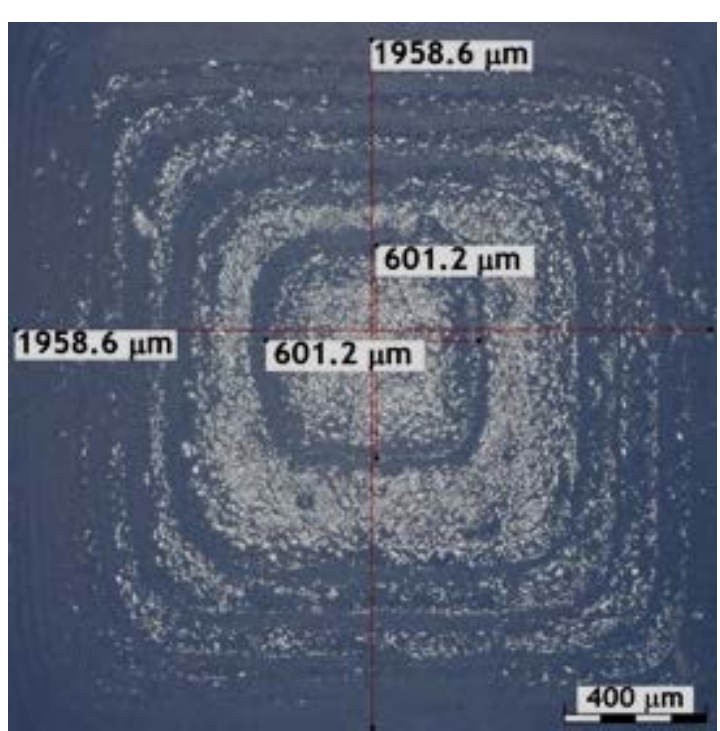

(b)

Figure 74. Acquired images with $10 \mathrm{X}$ objective lenses on the Ti-coated textured surfaces. (a) crest, (b) valley, and (c) the height between crest and valley.

According to the optical microscopy analysis performed and presented in Figure 72 to Figure 74, we can conclude the viability that has the laser stereolithography technique in combination with the magnetron sputtering technique, for the development of micrometric substrates with complex three-dimensional geometries or surface textures functionalized, which include perforations up to a $500 \mu \mathrm{m}$ diameter cross-section. Moreover, the different types of applied coatings ( $\mathrm{Ti}$ and $\mathrm{DLC}$ ) contribute to the verifying the possibility of applying versatile functionalization to micro-systems manufactured from photosensitive resins by laser stereolithography. The measurements taken upon both the crests and valleys help 
check that this type of surface modification technique is suitable and can even be used to internally coat the perforations present in the textures of materials used for a wide set of industrial applications, from tribology to biomedical ones.

\subsection{Spectroscopic Characterization}

The chemical and structural properties of specimens manufactured in pure "clear FLGPCL 02" resin, and Ti- and DLC-coated, were carefully assessed through Raman spectroscopy.

6.3.1. Raman spectroscopy. Micro-Raman analysis was performed on the surface of the substrates manufactured in photosensitive resin by the Form 1+ printer, both upon the uncoated and upon the Ti- and DLC-coated specimens (see Figure 75). The spectra Raman were acquired in mode spectral, that unlike the reflection mode, the mode spectral allows us to obtain an interaction volume from the surface to the material bulk between $1 \mu \mathrm{m}$ and $10 \mu \mathrm{m}$, which depends on the nature of the material and the conditions of equipment operated. Moreover, with this parameter is allow evaluating, among other characteristics, the possible interactions between the film deposited by magnetron sputtering and the substrate material.

The Raman spectrum obtained in the substrates manufactured with the Clear FLGPCL 02 resin uncoated and coated with $\mathrm{Ti}$ and DLC is presented in Figure 75. The spectrum of Figure 75(a) reveals three Raman burly peaks at $1455 \mathrm{~cm}^{-1}$ (strong), $2940 \mathrm{~cm}^{-1}$ and $2960 \mathrm{~cm}^{-1}$ (very strong) that correspond to the $\mathrm{C}-\mathrm{H}$ bond vibrations for uncoated surface and those manufactured with Clear FLGPCL 02. The peak (weak) at $600 \mathrm{~cm}^{-1}$ is attributed to the $\mathrm{C}-\mathrm{C}$ bond vibration. The band between $800 \mathrm{~cm}^{-1}$ and $950 \mathrm{~cm}^{-1}$ corresponds to the $\mathrm{C}-\mathrm{O}-\mathrm{C}$ bond vibrations and between $1000 \mathrm{~cm}^{-1}$ and $1150 \mathrm{~cm}^{-1}$ to the $\mathrm{C}-\mathrm{O}-\mathrm{C}$ bond asymmetric stretching vibrations. In peak at $1408 \mathrm{~cm}^{-1}$ found the $\mathrm{CH}_{3}$ bond asymmetric stretching vibration and in $1710 \mathrm{~cm}^{-1}$ the $\mathrm{C}=0$ bond vibration. Additionally, the weak peaks between $2700 \mathrm{~cm}^{-1}-2850 \mathrm{~cm}^{-1}$, and $3150 \mathrm{~cm}^{-1}-4000 \mathrm{~cm}^{-1}$ are attributed to the $\mathrm{O}-\mathrm{CH}_{3}$ and $-\mathrm{H}$ bond vibrations respectively [70].

Figure 75(b) the spectrum acquired on surface manufactured in photopolymer resin and $\mathrm{Ti}$-coated is presented. The bands at $426 \mathrm{~cm}^{-1}$ and $605 \mathrm{~cm}^{-1}$ can be assigned to rutile [117123]. Further, broadband between at $229 \mathrm{~cm}^{-1}$ and $293 \mathrm{~cm}^{-1}$ may be attributed to the multiphoton vibration mode [117-123]. The other relevant peaks in the spectrum correspond to the vibration modes of elements identified in the pure resin (see Figure 75(a)). Additionally, in these spectra, the vibration modes are identical to the spectra acquired in the valley as on the crest, which means that Ti was deposited well on the entire textured surface.

Raman spectra obtained on the crest and on the valley of the surface texture manufactured with Clear FLGPCL 02 resin and DLC-coated is presented in Figure 75(c). In these spectra, the more representative peaks correspond to the vibration modes that were identified on the uncoated surface. However, the peaks at $1396 \mathrm{~cm}^{-1}$ and $1589 \mathrm{~cm}^{-1}$ reveals variations associated with the vibrational modes typical for graphitic carbon in the bands $D$ $\left(A_{1 \mathrm{~g}}\right)$ and $\mathrm{G}\left(E_{2 \mathrm{~g}}\right)$, compared to the uncoated surface and the surface coated with Ti (see Figure 75(d)) [124-130]. 


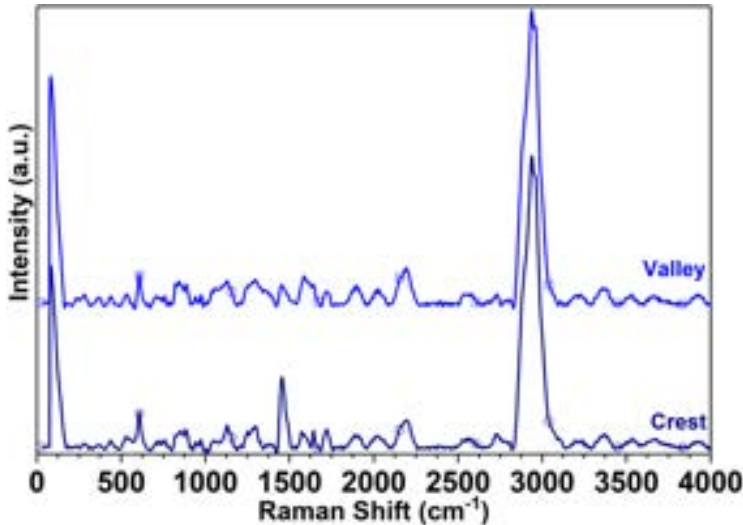

(a)

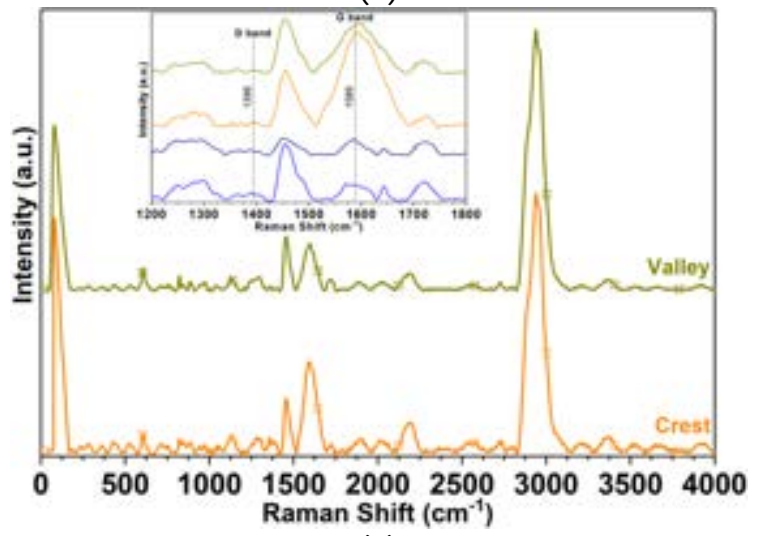

(c)

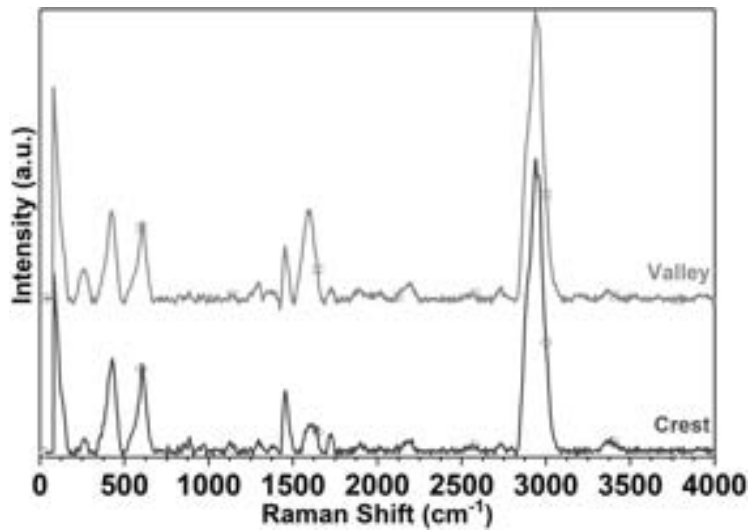

(b)

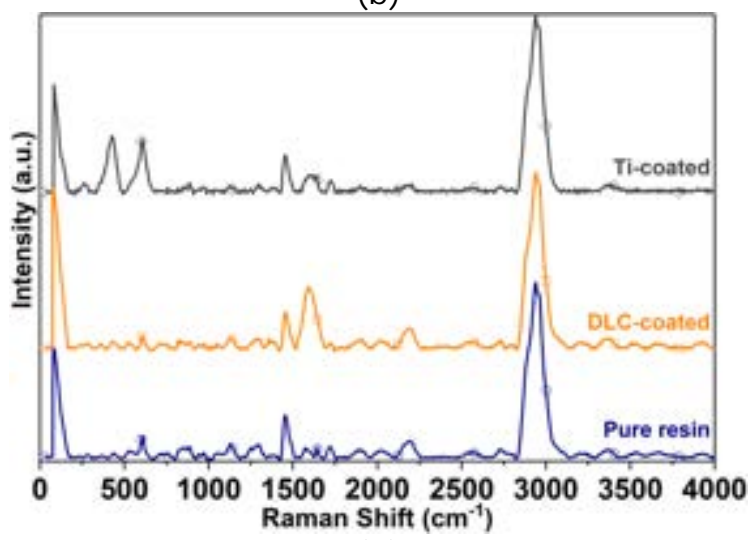

(d)

Figure 75. Raman spectra acquired on the crests and valleys of the substrate printed in the Form 1+ with Clear FLGPCL 02 resin. (a) uncoated surfaces, (b) Ti-coated, (c) DLC-coated, and (d) spectral comparison on the crest.

Therefore, although there are small variations in intensity, there is no difference in the chemical composition of the substrates or those manufactured in resin Clear FLGPCL 02, in relation to the measurements made for each species because there are no significant shifts in the Raman frequency of the peaks corresponding to the $C$ bond vibrations (Figure $75(d)$ ).

Regarding the above, optical microscopy of reflected light was used to measure the morphology and to validate the surface finish of the surface textures of the substrates manufactured in pure resin, as well the quality of the DLC and Ti coatings deposited. Likewise, Raman spectroscopy was used to determine the vibrations and the bands of present species in the substrate/ coating interface, such in the crest as in the valley. Although the functional coatings by magnetron-sputter be a straightforward technique and are very studied, we did not know if the devices manufactured in polymeric photosensitive resins by means of the SLA technique, could be covered maintaining a good aspect; and if the deeper surfaces of the texture they were coated. Hence, these results will allow contributing to the advantages and the feasibility of the additive manufacturing by $3 \mathrm{D}$ printing process for the different final applications. 


\section{Conclusions}

In accordance with the proposed aim and objectives, aspects as morphological, mechanical, thermal and structural behavior of photopolymer pure resin and reinforced with nanofillers, was undertaken and explained. As results and analysis performed to determine the devices functionality manufactured by stereolithography low-cost, to follows the foremost scientific and technological conclusions are summarized, and the additional contributions.

\subsection{Scientific and Technological Conclusions}

In accordance with the proposed objectives and with the basic hypothesis that the functionalization of photopolymers can prove transformative for the future of additive manufacturing, main scientific and technological results of the thesis include:

$\checkmark$ Innovative functional photopolymers for additive photopolymerization, based on the addition and adequate dispersion of copper nanowires, copper nanowires and nanoparticles, copper-nickel nanowires and graphene oxide within commercial resins, have been developed.

$\checkmark$ The additive manufacture of complex geometries using such innovative functional photopolymers has been demonstrated and the presence of the employed massfunctionalization additives (metallic nanowires and nanoparticles and graphene oxide) has been correlated with the modification of mechanical and thermal properties and with the polymerization degree. Besides, the lowering of cross-linking density due to the addition of nanoparticles, nanowires and nanoplatelets is demonstrated and attributed to light scattering during the photopolymerization process.

$\checkmark$ Composite resin with graphene oxide structures manufactured by laser stereolithography technique present interesting thermal-mechanical properties, especially as regards improvements on strength and ductility for low concentrations of the functionalizing agent $0.02 \% \mathrm{w} / \mathrm{w}-0.04 \% \mathrm{w} / \mathrm{w}$. Composite resin with $\mathrm{Cu}$ or CuNi NWs and NPs remain unchanged below $600^{\circ} \mathrm{C}$, in terms of melting and degradation temperatures, due to $\mathrm{Cu}$ and $\mathrm{Ni}$ having higher melting points.

$\checkmark$ The possibility of surface functionalizing complex geometries obtained by additive photopolymerization by using magnetron sputtering of titanium and diamond-like carbon has been also demonstrated and its potential for improving tribological, optical and biological performance has been discussed.

$\checkmark$ Through this research, a significant set of characterization techniques has been used and their synergies for adequately understanding the behavior, depending on the type of filler and processing conditions, have been analyzed. In consequence, a 
methodology for characterizing functional photopolymer resins with optimal use of resources and techniques has been achieved.

$\checkmark$ The actual implications and potential impact of such scientific and technological results has been discussed in the different chapters. Summarizing, it is important to highlight that, in spite of some possible improvements, the manufacturing of complex three-dimensional geometries, by laser stereolithography and using a set of innovative mass-functionalized photopolymers, has been demonstrated. In addition, in cases for which a final surface functionalization is needed, the magnetron sputtering technique has proven successful for the incorporation of $\mathrm{Ti}$ and DLC thin films.

$\checkmark$ Therefore, we consider that this research work may be of interest for the 3D printing manufacturing community, especially for all those using the SLA technique, because it details a possible way of functionalizing polymeric resins with nano-additives and discusses the potentials and limitations of a wide set of characterization techniques for studying and evaluating the properties of photopolymerized composites.

$\checkmark$ Regarding future industrial applications, this research work underscores the possible use of laser stereolithography, in combination with functional nanomaterials, for the fabrication of devices including: advanced tissue engineering scaffolds for in vitro studies, MEMS or microelectromechanical systems or additively manufactured objects in general, in which improved mechanical and thermal performances are needed, or in which surface interactions and overall aesthetics may play a special role. Accordingly, the methods described in this research work are also suitable for decorative or functional applications, which may also benefit from possible improvements to the electrical and magnetically properties of the functionalized resins, which is proposed as a key continuation path.

\subsection{Additional Contributions}

Besides, during the PhD thesis development, different dissemination and formative activities have been performed.

\subsubsection{J ournal article}

$\checkmark$ V-Niño E.D., Endrino-Armenteros J.L., Estupiñan-Duran H.A., Pérez-Gutiérrez B.R., Díaz Lantada A. 2016 Caracterización microscópica de texturas superficiales fabricadas aditivamente mediante estereolitografía laser Respuestas 21 37-47.

$\checkmark$ V-Niño E.D., Díaz Lantada A., Lonne Q., Estupiñán Durán H.A., Mejía-Ospino E., Ramírez-Caballero G., Endrino J.L. 2018 Manufacturing of polymeric substrates with copper nanofillers through laser stereolithography technique Polymers 10(1325) 115.

$\checkmark$ V-Niño E.D., Díaz Lantada A., Fernández Martínez I., Estupiñán Durán H.A., Endrino J.L. 2019 Deposition of titanium and diamond-like carbon coatings on 3D printed textured surfaces submitted for evaluation Coatings (peer-reviewed open access journal). 
$\checkmark$ V-Niño E.D., Díaz Lantada A., Lonne Q., Mejía-Ospino E., Estupiñán Durán H.A., Cabanzo Hernández R., Ramírez-Caballero G., Endrino J.L. 2019 Characterization of physical and chemical properties in substrates manufactured with copper-nickel nanowires by photopolymerization submitted for evaluation Polymers (peerreviewed open access journal).

\subsubsection{International conference}

$\checkmark$ Andrés Díaz Lantada, Ely Dannier Valbuena Niño, Iván Fernández Martínez and J osefa Predistinación García Ruiz 2016 Surface biofunctionalization of rapid prototyped microsystems for cell culture application Materials Science and Engineering Congress, Symposium B 10: Surface Engineering and Functionalisation, Darmstadt, Germany.

$\checkmark$ V. Niño Ely D., Endrino José L., Diaz Andrés 2017 Characterization physical and chemical properties of epoxy resins for additive manufacturing by photopolymerization Industrial Research Meeting, Madrid, Spain.

$\checkmark$ E D V-Niño, J L Endrino Armenteros, and A Díaz Lantada 2017 Manufacturing of substrates with nanofillers of copper 4th International Meeting for Researchers in Materials and Plasma Technology, Santa Marta, Colombia.

$\checkmark$ Ely Dannier V. Niño, José Luis Endrino, Rafael Cabanzo Hernández, Andrés Díaz Lantada 2017 Fabricación aditiva de geometrías complejas empleando resinas fotopolimerizables con nano-aditivos de cobre y grafeno y evaluación sistemática de sus características 13을 Congresso Ibero-americano de Engenharia Mecânica / Ingeniería Mecánica, Lisboa, Portugal.

$\checkmark$ E D V-Niño, J L Endrino, Q Lonne and A Díaz Lantada 2018 Manufacturing of de vices using light cur e resin with nanofillers of copper and copper nick el through stereolithography technique Fifth European Conference in Nanofilms, Cranfield, United Kingdom.

$\checkmark$ E D V-Niño, A Díaz Lantada, R Cabanzo, E Mejía-Ospino, H Estupiñán Durán, A Santos J aimes, G Ramírez, and J L Endrino 2019 Analysis of physicochemical properties of the polymer matrix GO-reinforced 5th International Meeting for Researchers in Materials and Plasma Technology, San J osé de Cúcuta, Colombia.

\subsubsection{Final degree thesis}

$\checkmark$ Mayra Stefani Núñez Badillo 2017 Determinación de los costos de fabricación de dispositivos elaborados por impresión 3D, mediante la técnica de estereolitografía láser directores: Ely Dannier V. Niño, Andrés Díaz Lantada, y Alejandro David Martínez Amariz (Universidad de Santander: Bucaramanga, Colombia).

\subsection{Future Research Proposals}

Our research has mainly focused on the development of innovative functional photopolymers for additive manufacturing by laser stereolithography and on the research of the physical and chemical properties of the materials and devices obtained. Special surface functionalizations have been also achieved for cases, in which mass-functionalization does not provide the desired contact, optical or aesthetic properties. Validation of manufacturability with these innovative resins and systematic characterization using a set 
of techniques that prove very adequate for understanding the effects and limitations of the functionalizations obtained and also for analyzing improvement directions. Among future continuation lines that we aim to study in the following years, we propose:

$\checkmark$ Improve the mixing process and the dispersion of nanofillers to let them provide their full potential for enhancing the properties of the base resins. To this end, the use of processes in which ultra-high shear stresses are applied to the resins with fillers could be an approach with high potential for innovating in the photopolymers used in the additive manufacturing field.

$\checkmark$ Analyze the impact of alternative nanoparticles and nanofibers, both inorganic (i.e. Ag nanoparticles) and organic (i.e. hemp fibers), to promote other interesting properties in additively manufactured materials and devices, especially in terms of biocompatibility for in vitro testing devices and tissue engineering scaffolds, which benefit from the complex geometries attainable using additive manufacturing approaches, but in many cases, lack the adequate biological performance.

$\checkmark$ Study the manufacturability of these innovative functional photopolymers with alternative additive manufacturing techniques, including digital light processing for enhanced productivity and direct laser writing based on two-photon polymerization towards micro-manufactured devices and appliances, in connection with the MEMS field, and verify the effects of functionalizations at the micro-scale by using additional techniques (i.e. atomic force microscope-based, transmission electron microscopy technique, nuclear magnetic resonance and gel permeation chromatography, among others).

$\checkmark$ Expand the range of characterization techniques applied in this research to achieve a better understanding of the electromagnetic properties provided to the base resins by the functional additives and work towards electro-active and magneto-active materials capable of being additively processed for the future development of MEMS and mag-MEMS.

$\checkmark$ Apply similar functionalization processes to other photopolymers, including different acrylate-based and epoxy-based thermosets and biophotoelastomers, to enhance their thermo-mechanical properties and achieve more reliable devices for final applications. In addition, synergize with other additive processes based also on photopolymerization, but capable of processing ceramic slurries and resins with metallic loading (lithography-based ceramic and metal manufacturing), to expand the industrialization potential of presented strategies.

$\checkmark$ We plan to approach these continuation lines in forthcoming years and to keep on working in this fascinating field with the support of all colleagues, teams and research centers that have made this PhD thesis possible. 


\section{References}

[1] Ramanathan T, et al. 2008 Functionalized graphene sheets for polymer nanocomposites Nat. Nanotechnology 3 327-331

[2] Print me a Stradivarius: how a new manufacturing technology will change the world The Economist (17 February 2011) p 7

[3] Ford Simon, Despeisse Melanie 2016 Additive manufacturing and sustainability: An exploratory study of the advantages and challenges J ournal of Cleaner Production 137 1573-1587

[4] J acobs Paul F. 1996 Stereolithography and other RP\&M technologies: From rapid prototyping to rapid tooling (Society of Manufacturing Engineers: Michigan, USA)

[5] Bhushan Bharat, Caspers Matt 2017 An overview of additive manufacturing (3D printing) for microfabrication Microsyst Technol. 23 1117-1124

[6] Lin D, et al. 2014 Three-dimensional printing of complex structures: man made or toward Nature? ACS Nano 8 9710-9715

[7] Zhang H-B, et al. 2010 Electrically conductive polyethylene terephthalate/graphene nanocomposites prepared by melt compounding Polymer 51 1191-1196

[8] Kuilla T, Bhadra S, Yao D, Kim N H, Bose S and Lee J H 2010 Recent advances in graphene based polymer composites Prog. Polym. Sci. 35 1350-1375

[9] Lin D, Richard Liu C and Cheng G J 2014 Laser sintering of separated and uniformly distributed multiwall carbon nanotubes integrated iron nanocomposites J. Appl. Phys. 115113513

[10] Lin D, Richard Liu C and Cheng G J 2014 Single-layer graphene oxide reinforced metal matrix composites by laser sintering: Microstructure and mechanical property enhancement Acta Mater. 80 183-193

[11] Lin D, Ye C, Liao Y, Suslov S, Liu R and Cheng G J 2013 Mechanism of fatigue performance enhancement in a laser sintered superhard nanoparticles reinforced nanocomposite followed by laser shock peening J. Appl. Phys. 113133509

[12] Verdejo R, Bernal M M, Romasanta L J and Lopez-Manchado M A 2011 Graphene filled polymer nanocomposites J. Mater. Chem. 21 3301-3310

[13] Y. Zhao, Y. Zhang, Y. Li, Z. He and Z. Yan 2012 Rapid and large-scale synthesis of Cu nanowires via a continuous flow solvothermal process and its application in dye-sensitized solar cells (DSSCs) RSC Adv. 2(30) 11544-11551

[14] Mi-Sun Lee, Kyongsoo Lee, So-Yun Kim, Heejoo Lee, J ihun Park, Kwang-Hyuk Choi, Han-Ki Kim, Dae-Gon Kim, Dae-Young Lee, SungWoo Nam, and J ang-Ung Park 2013 High-performance, transparent, and stretchable electrodes using graphene-metal nanowire hybrid structures Nano Letters 13(6) 2814-2821

[15] Quentin Lonne, Jose Endrino and Zhaorong Huang 2017 UV treatment of flexible copper nanowire mesh films for transparent conductor applications Nanoscale Research Letters 12(577) 1-8

[16] Syed Hamad, G Krishna Podagatlapalli, Surya P Tewari, and S Venugopal Rao 2013 Influence of picosecond multiple/single line ablation on copper nanoparticles fabricated for surface enhanced Raman spectroscopy and photonics applications J. Phys. D: Appl. Phys. 46(48550) 114

[17] M. Kevin, Gregory Y. R. Lim and G. W. Ho 2015 Facile control of copper nanowire dimensions via the Maillard reaction: using food chemistry for fabricating large-scale transparent flexible conductors Green Chem. 17 1120-1126

[18] Fang M, Wang K, Lu H, Yang Y and Nutt S 2009 Covalent polymer functionalization of graphene nanosheets and mechanical properties of composites J. Mater. Chem. 19 7098-7105

[19] Rafiee M A, et al. 2010 Fracture and fatigue in graphene nanocomposites Small 6 179-183

[20] Gong L, Young R J, Kinloch I A, Riaz I, Jalil R and Novoselov K S 2012 Optimizing the reinforcement of polymer-based nanocomposites by graphene ACS Nano 6 2086-2095 
[21] Young R J, Gong L, Kinloch I A, Riaz I, Jalil R and Novoselov K S 2011 Strain mapping in a graphene monolayer nanocomposite ACS Nano 5 3079-3084

[22] Zhao X, Zhang Q, Chen D and Lu P 2010 Enhanced mechanical properties of graphene-based poly(vinyl alcohol) composites Macromolecules 43 2357-2363

[23] Rafiee M A, Rafiee J, Wang Z, Song H, Yu Z-Z and Koratkar N 2009 Enhanced mechanical properties of nanocomposites at low graphene content ACS Nano 3 3884-3890

[24] Xu Z and Gao C 2010 In situ polymerization approach to graphene-reinforced nylon- 6 composites Macromolecules 43 6716-6723

[25] Lee C, Wei X, Kysar J Wand Hone J 2008 Measurement of the elastic properties and intrinsic strength of monolayer graphene Science 321 385-388

[26] Stankovich S, et al. 2006 Graphene-based composite materials Nature 442 282-286

[27] Hicks J, Behnam A and Ural A 2009 A computational study of tunneling-percolation electrical transport in graphene-based nanocomposites Appl. Phys. Lett. 95213103

[28] Zhang H-B et al 2010 Electrically conductive polyethylene terephthalate/graphene nanocomposites prepared by melt compounding Polymer 51 1191-1196

[29] Chu K, Li W-S, Jia C-C and Tang F-L 2012 Thermal conductivity of composites with hybrid carbon nanotubes and graphene nanoplatelets Appl. Phys. Lett. 101211903

[30] Yang S-Y, et al. 2011 Synergetic effects of graphene platelets and carbon nanotubes on the mechanical and thermal properties of epoxy composites Carbon 49 793-803

[31] An X, Butler T W, Washington M, Nayak S K and Kar S 2011 Optical and sensing properties of 1pyrenecarboxylic acidfunctionalized graphene films laminated on polydimethylsiloxane membranes ACS Nano 5 1003-1011

[32] Xu Y, et al. $2009 \mathrm{~A}$ graphene hybrid material covalently functionalized with porphyrin: synthesis and optical limiting property Adv. Mater. 21 1275-1279

[33] Liang J, et al. 2009 Electromagnetic interference shielding of graphene/ epoxy composites Carbon 47 922-925

[34] Zhang H-B, Yan Q, Zheng W-G, He Z and Yu Z-Z 2011 Tough graphene-polymer microcellular foams for electromagnetic interference shielding ACS Appl. Mater. Interfaces 3 918-924

[35] Bunch J S, et al. 2008 Impermeable atomic membranes from graphene sheets Nano Lett. 8 2458-2462

[36] Compton O C, Kim S, Pierre C, Torkelson J M and Nguyen S T 2010 Crumpled graphene nanosheets as highly effective barrier property enhancers Adv. Mater. 22 4759-4763

[37] Kim H, Miura Y and Macosko C W 2010 Graphene/ polyurethane nanocomposites for improved gas barrier and electrical conductivity Chem. Mater. 22 3441-3450

[38] Yavari F, Rafiee M A, Rafiee J, Yu Z Z and Koratkar N 2010 Dramatic increase in fatigue life in hierarchical graphene composites ACS Appl. Mater. Interfaces 2 2738-2743

[39] Terrones $M$, et al. 2011 Interphases in graphene polymer-based nanocomposites: achievements and challenges Adv. Mater. 23 5302-5310

[40] Gross B. C., Erkal J. L., Lockwood S. Y., Chen C. \& Spence D. M. 2014 Evaluation of 3D printing and its potential impact on biotechnology and the chemical sciences Anal. Chem. 86 3240-3253

[41] Mannoor M. S., et al. 2013 3D printed bionic ears Nano Lett. 13 2634-2639

[42] Dragone V., Sans V., Rosnes M. H., Kitson P. J. \& Cronin L. 2013 3D-printed devices for continuous-flow organic chemistry Beilstein J. Org. Chem. 9 951-959

[43] Xiaojun Wei, Dong Li, Wei J iang, Zheming Gu, Xiaoj uan Wang, Zengxing Zhang \& Zhengzong Sun 2015 3D printable graphene composite Scientific Reports 5(11181) 1-7

[44] Sun K., et al. 2013 3D printing of interdigitated Li-ion microbattery architectures Adv. Mater. 25 4539-4543

[45] Symes M. D., et al. 2012 Integrated 3D-printed reaction ware for chemical synthesis and analysis Nat. Chem. 4 349-354

[46] Vaezi M., Seitz H. \& Yang S. A 2013 Review on 3D micro-additive manufacturing technologies Int. J. Adv. Manuf. Technol. 67 1721-1754 
[47] Kim H., Abdala A. A. \& Macosko C. W. 2010 Graphene/ polymer nanocomposites Macromolecules $436515-6530$

[48] Higginbotham A. L., Lomeda J. R., Morgan A. B. \& Tour, J. M. 2009 Graphene oxide flameretardant polymer nanocomposites ACS Appl. Mater. Interfaces 1 2256-2261

[49] Kosidlo U., et al. 2013 Nanocarbon based ionic actuators-a review Smart Mater. Struct. 22 104022

[50] Huang X., Qi X., Boey F. \& Zhang H. 2012 Graphene-based composites Chem. Soc. Rev. 41 666686

[51] Zhao X., Xu Z., Zheng B. \& Gao C. 2013 Macroscopic assembled, ultrastrong and H2SO4-resistant fibres of polymer-grafted graphene oxide Sci. Rep. 33164

[52] Podsiadlo P., et al. 2007 Ultrastrong and stiff layered polymer nanocomposites Science 318 8083

[53] Muller M. B., Gilje S., Kaner R. B. \& Wallace G. G. 2008 Processable aqueous dispersions of graphene nanosheets Nat. Nanotechnol. 3 101-105

[54] Yang H., et al. 2009 Convenient preparation of tunably loaded chemically converted graphene oxide/ epoxy resin nanocomposites from graphene oxide sheets through two-phase extraction J. Mater. Chem. $198856-8860$

[55] Sun Y. \& Shi G. 2013 Graphene/ polymer composites for energy applications J . Polym. Sci., Part B: Polym. Phys. 51 231-253

[56] J ung I., Dikin D., Piner R. \& Ruoff R. 2008 Tunable electrical conductivity of individual graphene oxide sheets reduced at "low" temperatures Nano Lett. 8 4283-4287

[57] Mattevi C., et al. Evolution of electrical, chemical, and structural properties of transparent and conducting chemically derived graphene thin films Adv. Funct. Mater. 19 2577-2583

[58] Brennan-Craddock J, Brackett D, Wildman R, Hague R 2012 The design of impact absorbing structures for additive manufacture J ournal of Physics: Conference Series 382 1-7

[59] Ho K.S., Bradley R.J ., Billson D.R., Hutchins D.A. 2008 Micro-stereolithography as a transducer design method Ultrasonics 48 1-5

[60] Maruo S., Ikuta K. 2002 Submicron stereolithography for the production of freely movable mechanisms by using single-photon polymerization Sensors and Actuators A: Physical 10070 76

[61] Wang J., Goyanes A., Gaisford S., Basit A.W. 2016 Stereolithographic (SLA) 3D printing of oral modified-release dosage forms Int. J. Pharm. 503 207-212

[62] Zhang X., Jiang X.N., Sun C. 1998 Micro-stereolithography for MEMS Proceedings of the 1998 ASME International Mechanical Engineering Congress and Exposition (IMECE) vol 66, ed R.J. Furness (ASME: Anaheim, USA) pp 3-9

[63] Wicker R.B., Medina F., Ranade A, Palmer J .A. 2005 Embedded micro-channel fabrication using lines can stereolithography Assembly Automation 25 316-329

[64] Díaz Lantada A., Rebollo M. 2013 Towards low-cost effective and homogeneous thermal activation of shape memory polymers Materials 6 5447-5465

[65] Díaz Lantada A., de Blas Romero A., Tanarro E.C. 2016 Micro-vascular shape-memory polymer actuators with complex geometries obtained by laser stereolithography Smart Mater. Struct. 25065018

[66] de Leon Al C., Chen Qiyi, Palaganas Napolabel B., Palaganas J erome O., Manapat J ill, Advincula Rigoberto C. 2016 High performance polymer nanocomposites for additive manufacturing applications Reactive and Functional Polymers 103 141-155

[67] Kumar Sandeep, Hofmann Manfred, Steinmann Bettina, Foster E. J ohan, Weder Christoph 2012 Reinforcement of stereolithographic resins for rapid prototyping with cellulose nanocrystals ACS Applied Materials \& Interfaces 4 5399-5407

[68] Sandoval J. Hector, Wicker Ryan B. 2006 Functionalizing stereolithography resins: Effects of dispersed multi-walled carbon, nanotubes on physical properties Rapid Prototyping J ournal 12 292-303 
[69] V-Niño E.D., Endrino-Armenteros J.L., Estupiñan-Duran, H.A., Pérez-Gutiérrez B.R., Díaz Lantada A. 2016 Caracterización microscópica de texturas superficiales fabricadas aditivamente mediante estereolitografía laser Respuestas 21 37-47

[70] V-Niño E.D., Díaz Lantada A., Lonne Q. Estupiñán Durán H.A., Mejía-Ospino E., RamírezCaballero G., Endrino J.L. 2018 Manufacturing of polymeric substrates with copper nanofillers through laser stereolithography technique Polymers 101325

[71] Kirihara Soshu, Miyamoto Yoshinari, Takenaga Katsuhiro, Wada Takeda Mitsuo, Kaj iyama Kenji 2002 Fabrication of electromagnetic crystals with a complete diamond structure by stereolithography Solid State Communications 121 435-439

[72] American Society for Testing and Materials (ASTM) 2014 Standard Test Method for Tensile Properties of Plastics, ASTM D638-14 (American Society for Testing and Materials: West Conshohocken, USA)

[73] Weilie Zhou, Zhong Lin Wang 2007 Scanning microscopy for nanotechnology (Springer: New York, USA)

[74] Herbert E.G., Oliver W.C., Pharr G.M. 2008 Nanoindentation and the dynamic characterization of viscoelastic solids J. Phys. D Appl. Phys. 41074021

[75] Liu T., Phang I.Y., Shen L., Chow S.Y., Zhang W.-D. 2004 Morphology and mechanical properties of multiwalled carbon nanotubes reinforced nylon- 6 composites Macromolecules 37 7214-7222

[76] Cohen S.R., Kalfon-Cohen E. 2013 Dynamic nano-indentation by instrumented nano-indentation and force microscopy: A comparative review Beilstein J. Nanotechnol. 4 815-833

[77] Crosby A.J., Lee J.-Y.2007 Polymer nanocomposites: The "nano" effect on mechanical properties Polym. Rev. 47 217-229

[78] Bansal A., Yang H., Li C., Benicewicz B.C., Kumar S.K., Schadler L. S. 2006 Controlling the thermomechanical properties of polymer nanocomposites by tailoring the polymer-particle interface J. Polym. Sci. Part B Polym. Phys. 44 2944-2950

[79] Ye S., Rathmell A.R., Chen Z., Stewart I.E., Wiley B.J . 2014 Metal nanowire networks: The next generation of transparent conductors Adv. Mater. 26 6670-6687

[80] Cnudde V., J acobs P.J.S. 2004 Monitoring of weathering and conservation of building materials through non-destructive X-ray computed microtomography Environ. Geol. 46 477-485

[81] Hong G., Choi S. 2017 Rapid self-sealing of cracks in cementitious materials incorporating superabsorbent polymers Constr. Build. Mater. 143 366-375

[82] Garcea S.C., Sinclair I., Spearing S. M., Withers P.J . 2017 Mapping fibre failure in situ in carbon fibre reinforced polymers by fast synchrotron X-ray computed tomography Compos. Sci. Technol. 149 81-89

[83] Altun V., Remigy J.C., Vankelecom I.F.J 2017 UV-cured polysulfone-based membranes: Effect of co-solvent addition and evaporation process on membrane morphology and SRNF performance J. Membr. Sci. 524 729-737

[84] Struzynska-Piron I., Loccufier J., Vanmaele L., Vankelecom I.F.J. 2013 Synthesis of solvent stable polymeric membranes via UV depth-curing Chem. Commun. 49 11494-11496

[85] Sandler J., Shaffer M.S.P., Prasse T., Bauhofer W., Schulte K., Windle A.H. 1999 Development of a dispersion process for carbon nanotubes in an epoxy matrix and the resulting electrical properties Polymer $\mathbf{4 0}$ 5967-5971

[86] Xie X.L., Mai Y.W., Zhou X.P. 2005 Dispersion and alignment of carbon nanotubes in polymer matrix: A review Mater. Sci. Eng. R 49 89-112

[87] Ma P.C., Siddiqui N.A., Marom G., Kim J.K. 2010 Dispersion and functionalization of carbon nanotubes for polymer-based nanocomposites: A review Compos. Part A 41 1345-1367

[88] Chakraborty A.K., Plyhm T., Barbezat M., Necola A., Terrasi G.P. 2011 Carbon nanotube (CNT)epoxy nanocomposites: A systematic investigation of CNT dispersion J . Nanopart. Res. 13 64936506

[89] Gayle A.J ., Cook R. F. 2016 Mapping viscoelastic and plastic properties of polymers and polymernanotube composites using instrumented indentation J. Mater. Res. 31 2347-2360 
[90] Vadukumpully S, Paul J, Mahanta N \& Valiyaveettil S 2011 Flexible Conductive Graphene/ Poly(vinyl chloride) Composite Thin Films with High Mechanical Strength and Thermal Stability Carbon 49 198-205

[91] Xu Q F, Mondal B \& Lyons A M 2011 Fabricating Superhydrophobic Polymer Surfaces with Excellent Abrasion Resistance by a Simple Lamination Templating Method ACS Appl. Mater. Interfaces 3 3508-3514

[92] Ramanathan T, et al. 2007 Graphitic Nanofillers in PMMA Nanocomposites-An Investigation of Particle Size and Dispersion and Their Influence on Nanocomposite Properties J. Polym. Sci. B: Polym. Phys. 45 2097-2112

[93] Boiteux G, Boullanger C, Cassagnau P, Fulchiron R, Seytre G 2006 Influence of morphology on PTC in conducting polypropylene-silver composites Macromol Symp $233246 \mathrm{e} 53$

[94] Doganay D, Coskun S, Kaynak C, Unalan H E 2016 Electrical, mechanical and thermal properties of aligned silver nanowire/ polylactide nanocomposite films Compos. Part B 99 288-296

[95] Dalton A B, et al. 2003 Super-tough carbon-nanotube fibres Nature $\mathbf{4 2 3} 703$

[96] Dong Lin, Shengyu J in, Feng Zhang, Chao Wang, Yiqian Wang, Chi Zhou, and Gary J Cheng 2015 3D stereolithography printing of graphene oxide reinforced complex architectures Nanotechnology 26(434003) 1-9

[97] B. Storti D, Anderson R \& Ganter M A 2008 Review of process development steps for new material systems in three dimensional printing (3DP) J. Manuf. Process. 10 96-104

[98] J yotishkumar $P$, et al. 2011 Studies on stress relaxation and thermomechanical properties of poly(acrylonitrile-butadiene-styrene) modified epoxy-amine systems Ind. Eng. Chem. Res. 50 $4432-4440$

[99] K J Thomas, M Sheeba, V P N Nampoori, C P G Vallabhan and P Radhakrishnan 2008 Raman spectra of polymethyl methacrylate optical fibres excited by a $532 \mathrm{~nm}$ diode pumped solid state laser J ournal of Optics A: Pure and Applied Optics 10(055303) 1-5

[100] Xu Xingsheng, Ming Hai, Zhang Qijing and Zhang Yunsheng 2002 Properties of Raman spectra and laser-induced birefringence in polymethyl methacrylate optical fibres J ournal of Optics A: Pure and Applied Optics 4 237-242

[101] Hua M.Z., Feng S., Wang S., Lu X. 2018 Rapid detection and quantification of 2,4dichlorophenoxyacetic acid in milk using molecularly imprinted polymers-surface-enhanced Raman spectroscopy Food Chem. 258 254-259

[102] Sessa C., Weiss R., Niessner R., Ivleva N.P., Stege H. 2018 Towards a surface enhanced Raman scattering (SERS) spectra database for synthetic organic colourants in cultural heritage. The effect of using different metal substrates on the spectra Microchem. J . 138 209-225

[103] Garcia-Rico E., Alvarez-Puebla R. A., Guerrini L. 2018 Direct surface-enhanced Raman scattering (SERS) spectroscopy of nucleic acids: From fundamental studies to real-life applications Chem. Soc. Rev. 47 4909-4923

[104] Ferrari A. C., et al. 2006 Raman spectrum of graphene and graphene layers Phys. Rev. Lett. 97 187401

[105] Casiraghi C, et al. 2009 Raman spectroscopy of graphene edges Nano Letters 9(4) 1433-1441

[106] Childres Isaac, et al. 2013 Developments in photon and materials research Raman spectroscopy of graphene and related materials ed J oon I. J ang (New York: Nova Science Publishers) Chapter 19 pp 403-411

[107] R. Betancourt-Galindo, P. Y. Reyes-Rodriguez, B. A. Puente-Urbina, C. A. Avila-Orta, O. S. Rodríguez-Fernández, G. Cadenas-Pliego, R. H. Lira-Saldivar, and L. A. García-Cerda 2013 Synthesis of copper nanoparticles by thermal decomposition and their antimicrobial properties J ournal of Nanomaterials 2013(980545) 1-5

[108] Zhao T., Li X., Yu R., Zhang Y., Yang X., Zhao X., Wang L., Huang W. 2018 Silicone-epoxy-based hybrid photopolymers for 3D printing Macromol Chem. Phys. 1700530 1-10

[109] Weng Z., Zhou Y., Lin W., Senthil T., Wu L 2016 Structure-property relationship of nano enhanced stereolithography resin for desktop SLA 3D printer Compos. Part A 88 234-242 
[110] H. Guo, X. Wang, Q. Qian, F. Wang, X. Xia 2009 A green approach to the synthesis of graphene nanosheets ACS Nano 3(9) 2653-2659

[111] D. Marcano, D. Kosynkin, J. Berlin, A. Sinitskii, Z. Sun, A. Slesarev, L. Alemany, W. Lu, J. Tour 2010 Improved synthesis of graphene oxide ACS Nano 4(8) 4806-4814

[112] Y. Geng, S. Wang, J. Kim 2009 Preparation of graphite nanoplatelets and graphene sheets J ournal of Colloid and Interface Science 336 592-598

[113] Y. Si, E. Samulski 2008 Synthesis of water soluble graphene Nano Letters 8(6) 1679-1682.

[114] Giang $\mathrm{H}_{\text {., }}$ et al. 2016 Removal of $\mathrm{Cd} 2+$ and $\mathrm{Cu} 2+$ ions from aqueous solution by using Fe-Fe 3 0 4/ graphene oxide as a novel and efficient adsorbent Materials Research Express 3(10) 105603

[115] Rana Surjyakanta, et al. 2015 Organo functionalized graphene with Pd nanoparticles and its excellent catalytic activity for Suzuki coupling reaction Applied Catalysis A: General 505 539547

[116] Baowei Yu, et al. 2017 Adsorption behaviors of tetracycline on magnetic graphene oxide sponge Materials Chemistry and Physics 198 283-290

[117] Sawsen Nezar, Nadia Saoula, Samira Sali, Mohammed Faiz, Mogtaba Mekki, Nadia Aïcha Laoufi, Nouar Tabet 2017 Properties of TiO2thin films deposited by rf reactive magnetron sputtering on biased substrates Applied Surface Science 395 172-179

[118] M. N. Iliev, V.G. Hadjiev, A.P. Litvinchuk 2013 Raman and infrared spectra of brookite (TiO2): Experiment and theory Vibrational Spectroscopy 64 148-152

[119] Masih Rezaee, Seyyed Mohammad Mousavi Khoie, and Kun Hua Liu 2011 The role of brookite in mechanical activation of anatase-to-rutile transformation of nanocrystalline TiO2: An XRD and Raman spectroscopy investigation CrystEngComm 13 5055-5061

[120] S. Sahoo A. K. Arora and V. Sridharan 2009 Raman Line Shapes of Optical Phonons of Different Symmetries in Anatase TiO2 Nanocrystals J. Phys. Chem. C. 113(39) 16927-16933

[121] A. Golubovic, M. Šćepanović, A. Kremenović, S. Aškrabić, V. Berec, Z. Dohčević-Mitrović, Z. V. Popović 2008 Raman study of the variation in anatase structure of $\mathrm{TiO} 2$ nanopowders due to the changes of sol-gel synthesis conditions J. Sol-Gel Sci. Technol. 49 311-319

[122] Y. Shu, K. Ihara, B. Liu; Y. Wang, R. Li and T. Sato 2007 Preparation of anatase, rutile and brookite type anion doped titania photocatalyst nanoparticles and thin films Phys. Scr. T129 268-273

[123] H.L. Ma, J.Y. Yang, Y. Dai, Y.B. Zhang, B. Lu, G.H. Ma 2007 Raman study of phase transformation of $\mathrm{TiO} 2$ rutile single crystal irradiated by infrared femtosecond laser Applied Surface Science 253(18) 7497-7500

[124] J . A. Santiago, I. Fernández-Martínez, T. Kozák, J. Capek, A. Wennberg, J.M. Molina-Aldareguia, V. Bellido-González, R. González-Arrabal, M.A. Monclús 2019 The influence of positive pulses on HiPIMS deposition of hard DLC coatings Surface \& Coatings Technology $35843-49$

[125] Xuming Zhang, KaifuHuo, Hairong Wang, Biao Gao, J ij iang Fu, Tak-Fu Hung and Paul K Chu 2012 Controlled fabrication of core-shell $\mathrm{TiO} / \mathrm{C}$ and $\mathrm{TiC} / \mathrm{C}$ nanofibers on $\mathrm{Ti}$ foils and their fieldemission properties ACS Applied Materials \& Interfaces 4 1037-1042

[126] A. Nath, S. S. Laha and A. Khare 2010 Synthesis of TiO2 Nanoparticles via laser ablation at titanium-water interface Integrated Ferroelectrics 121 58-64

[127] B. H. Lohse, A. Calka, D. Wexler 2007 Raman spectroscopy sheds new light on TiC formation during the controlled milling of titanium and carbon J ournal of Alloys and Compounds 434-435 405-409

[128] R. Saito, G. Dresselhaus, M. S. Dresselhaus 1998 Physical properties of carbon nanotubes (Imperial College Press: London, United Kingdom) pp. 1-272 ISBN: 978-1-86094-379-9

[129] Andrea Carlo Ferrari and John Robertson 2004 Raman spectroscopy of amorphous, nanostructured, diamond-like carbon, and nanodiamond Phil. Trans. R. Soc. Lond. A. 362 24772512

[130] Gert Irmer and Annett Dorner-Reisel 2005 Micro-Raman studies on DLC coatings Advanced Engineering Materials 7(8) 694-705 


\section{Appendix A: Clear Resin Data Sheet}

SECTION 1: Identification of the substance/mixture and of the company/undertaking

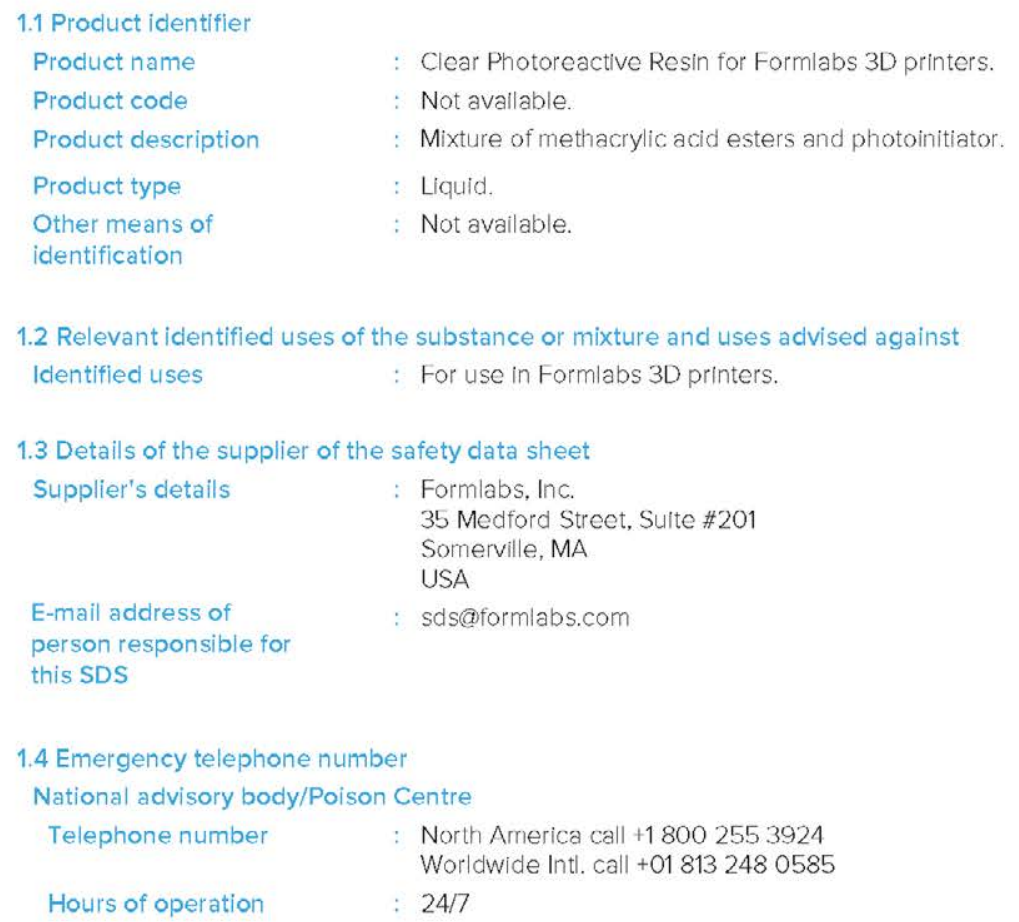

SECTION 2: Hazards identification

2.1 Classification of the substance or mixture

Product definition : Mixture.

Classification according to Regulation (EC) No. 1272/2008 [CLP/GHS]

Eye Irrit. 2, H319

Skin Sens. 1, H317

The product is classified as hazardous according to Regulation (EC) 1272/2008 as amended.

See Section 16 for the full text of the $\mathrm{H}$ statements declared above.

See Section 11 for more detailed information on health effects and symptoms.

\subsection{Label elements}

Hazard pictograms

Signal word

Hazard statements

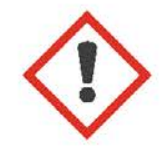

Warning

H319 - Causes serious eye irritation.

H317 - May cause an allergic skin reaction. 


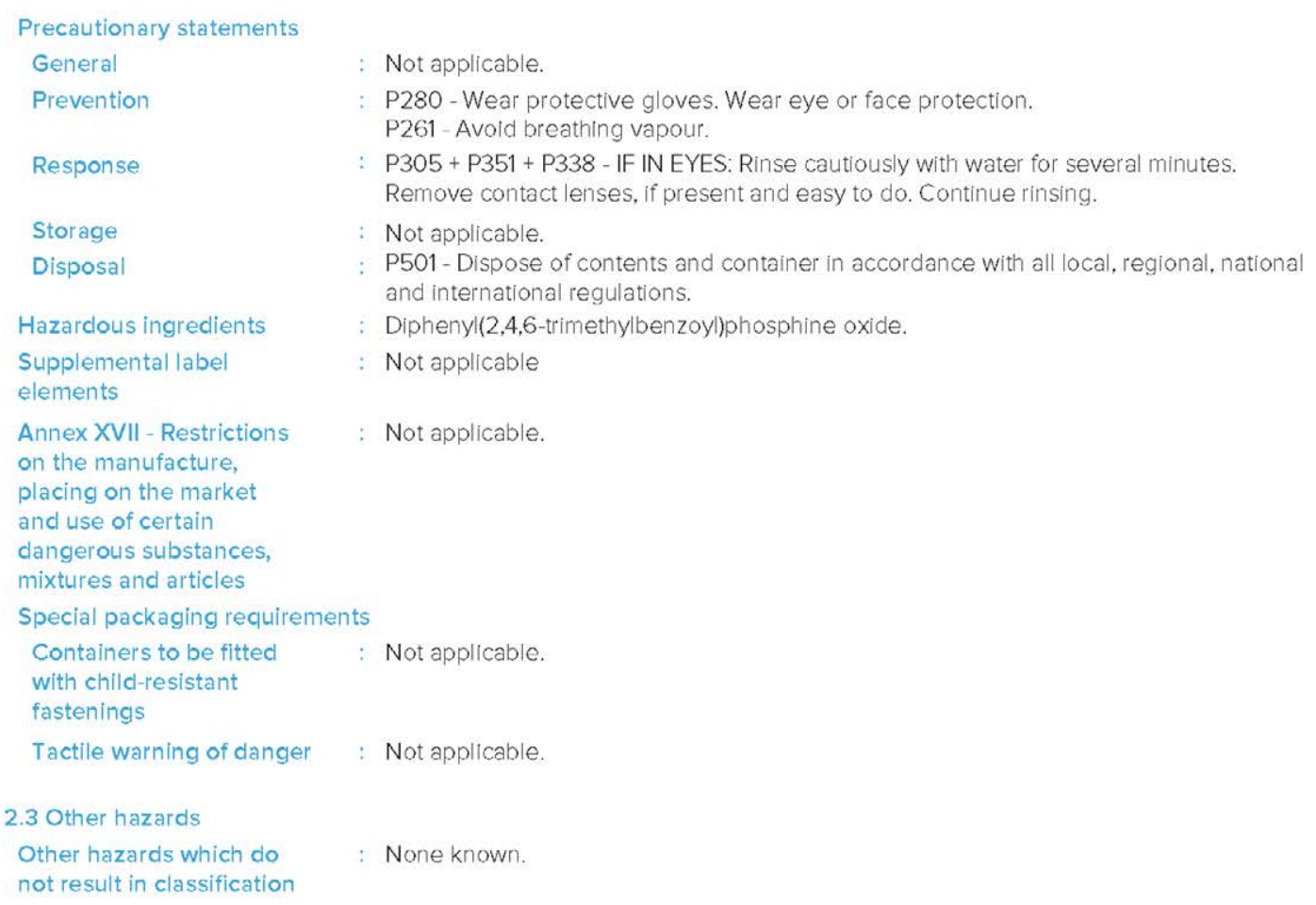

SECTION 3: Composition/information on ingredients

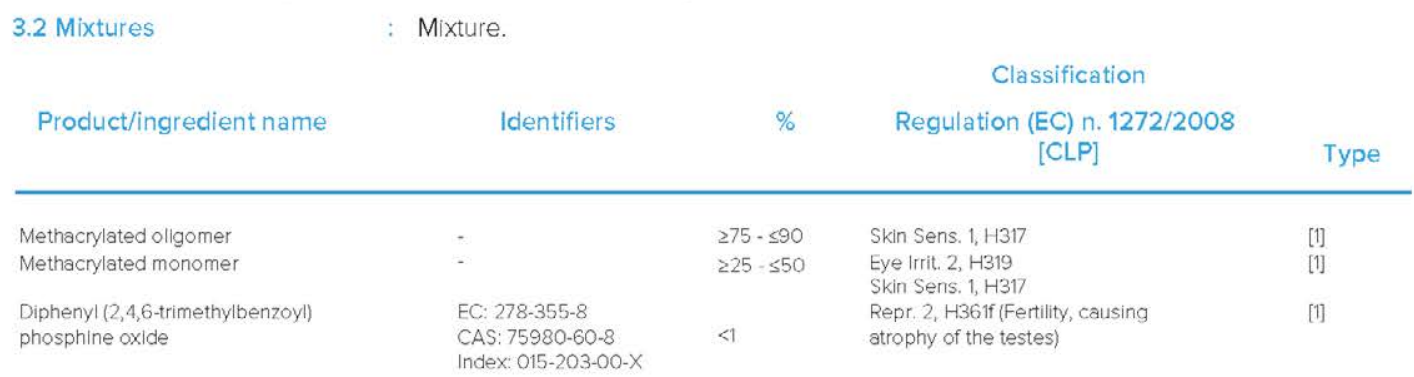

There are no additional ingredients present which, within the current knowledge of the supplier and in the concentrations applicable, are classified as hazardous to health or the environment, are PBTs, vPvBs or Substances of equivalent concern, or have been assigned a workplace exposure limit and hence require reporting in this section.

Type

[1] Substance classified with a health or environmental hazard

[2] Substance with a workplace exposure limit

[3] Substance meets the criteria for PBT according to Regulation (EC) No. 1907/2006, Annex XIII

[4] Substance meets the criteria for vPvB according to Regulation (EC) No. 1907/2006, Annex XIII

[5] Substance of equivalent concern

occupational exposure limits, if available, are listed in Section 8. 


\section{Appendix B: Grey Resin Data Sheet}

SECTION 1: Identification of the substance/mixture and of the company/undertaking

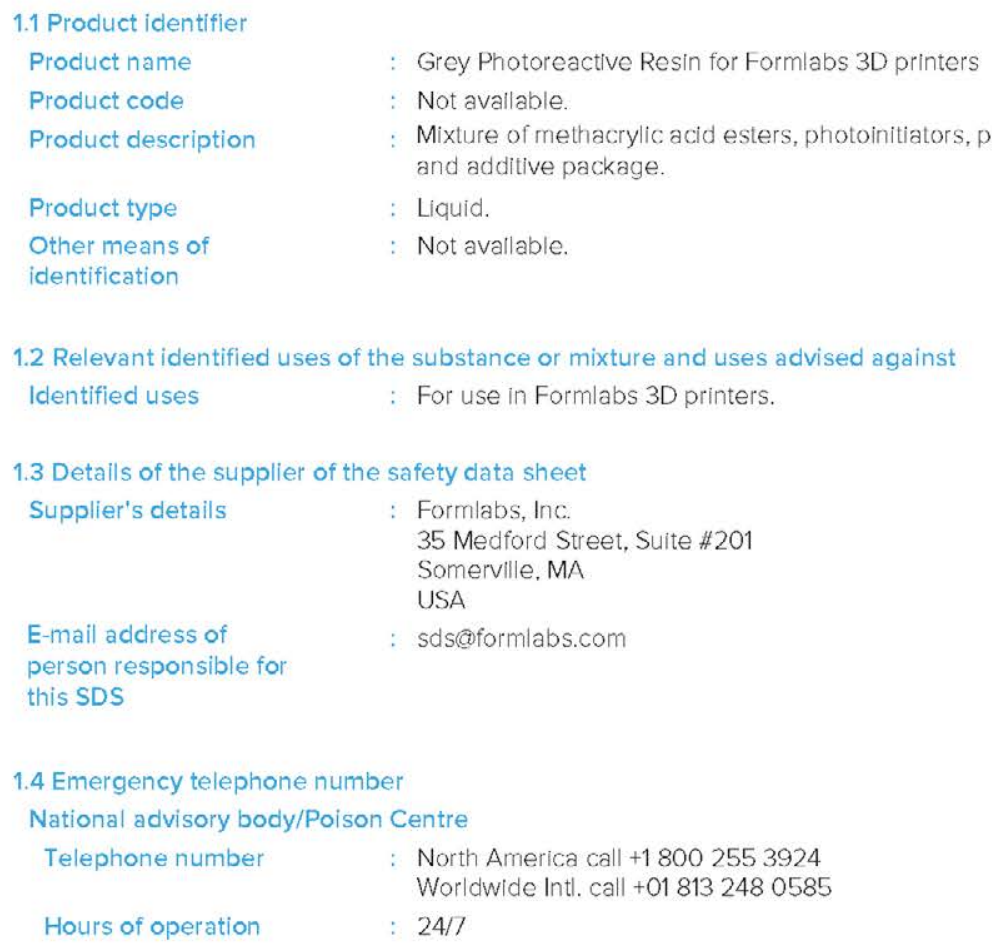

SECTION 2: Hazards identification

2.1 Classification of the substance or mixture
Product definition
Mixture.

Classification according to Regulation (EC) No. 1272/2008 [CLP/GHS]

Eye Irrit. 2, H319

Skin Sens. 1, H317

The product is classifled as hazardous according to Regulation (EC) 1272/2008 as amended.

See Section 16 for the full text of the $\mathrm{H}$ statements declared above.

See Section 11 for more detailed information on health effects and symptoms.

\subsection{Label elements}

Hazard pictograms

Signal word

Hazard statements

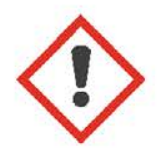

Warning.

H319 - Causes serious eye irritation.

H317 - May cause an allergic skin reaction. 


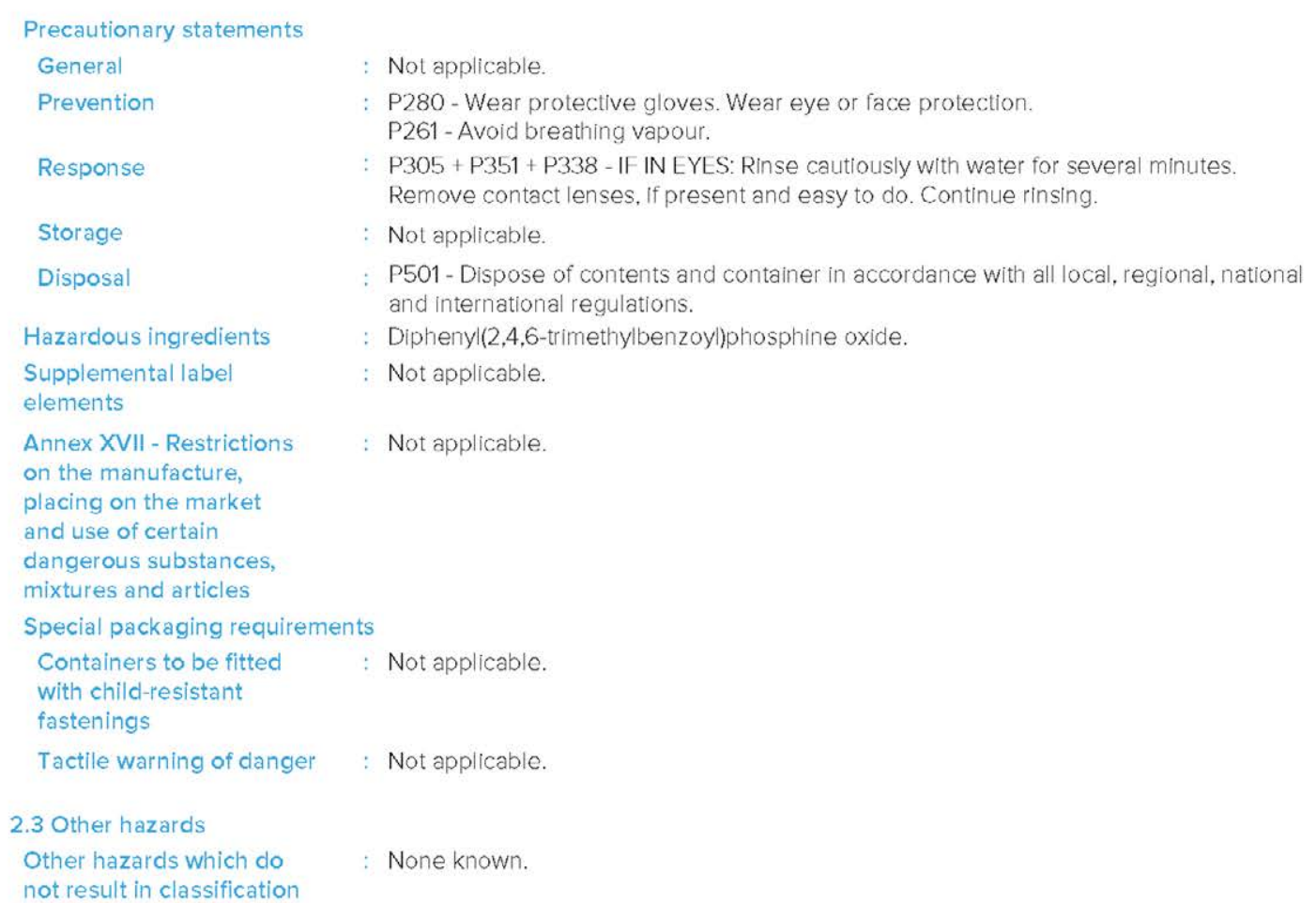

\section{SECTION 3: Composition/information on ingredients}

3.2 Mixtures

Product/ingredient name
Mixture.

Classification

\begin{tabular}{|c|c|c|c|}
\hline \multirow[b]{2}{*}{ Identifiers } & \multicolumn{3}{|c|}{ Classification } \\
\hline & $\%$ & $\begin{array}{c}\text { Regulation (EC) n. } 1272 / 2008 \\
\text { [CLP] }\end{array}$ & Type \\
\hline - & $275-590$ & Skin Sens. 1, H317 & [1] \\
\hline & $225-\leq 50$ & $\begin{array}{l}\text { Eye Irrit. 2, H319 } \\
\text { Skin Sens. 1, H317 }\end{array}$ & [1] \\
\hline $\begin{array}{l}\text { EC: } 278-355-8 \\
\text { CAS: } 75980-60-8 \\
\text { Index: } 015-203-00-x\end{array}$ & $21 \cdot<3$ & $\begin{array}{l}\text { Repr. 2, H36if (Fertllity, causing } \\
\text { atrophy of the testes) }\end{array}$ & [1] \\
\hline
\end{tabular}

There are no additional ingredients present which. within the current knowledge of the supplier and in the concentrations applicable, are classffled as hazardous to health or the environment, are PBTs, vPVBs or Substances of equivalent concern, or have been assigned a workplace exposure limit and hence require reporting in this section.

Type

[1] Substance classified with a health or environmental hazard

[2] Substance with a workplace exposure limit

[3] Substance meets the criteria for PBT according to Regulation (EC) No. 1907/2006, Annex XIII

[4] Substance meets the criteria for VPVB according to Regulation (EC) No. 1907/2006, Annex XIII

[5] Substance of equivalent concern

Occupational exposure limits, If avallable, are listed in Section 8. 